$$
\begin{aligned}
& \text { THE METHODS } \\
& \text { OFTAXATION }
\end{aligned}
$$




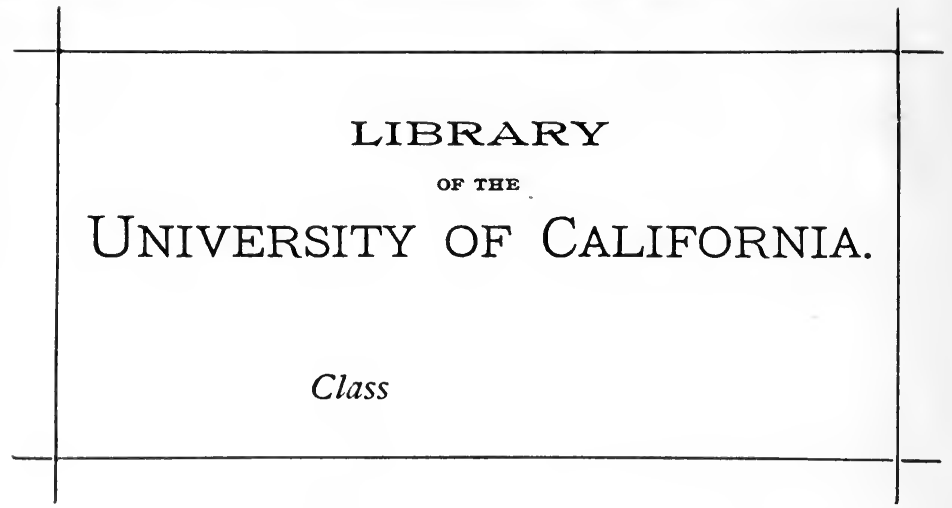


Digitized by the Internet Archive . in 2007 with funding from Microsoft Corporation 


\section{THE METHODS OF TAXATION}





\section{THE}

\section{METHODS OF TAXATION}

COMPARED WITH

\section{THE ESTABLISHED PRINCIPLES \\ OF JUSTICE}

BY

David MacGregor Means

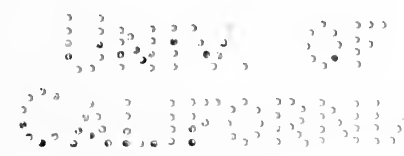

NEW YORK

DODD, MEAD AND COMPANY

1911 


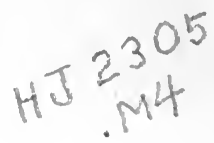

Coptright, 1909, BY

Dodd, Mead and Compant

Published, April, 1909

THE UNIVERSTY PRES, CAMBRIDGE, U. 8. A. 


\section{CONTENTS}

Page

INTRODUCTION . . . . . . . . . . . vii

Chapter

I The Three Methods of Taxation . . . . 1

II Nature and Limitations of Property • • 22

III Unearned Property . • • • • • • • 55

IV Practical Applications of the ProportionATE Method • • • • • • • • . 89

V Income Taxes . . . . . . . . . 138

VI Taxes on Expense . • • • • . • • . 172

VII Taxes on Transfers of Property at Death 211 VIII The Diffusion of Taxes . . • • . . 236

IX The Economic Method . • • • • . . 275

X The Cost of Collecting Taxes . . . . 330

\section{APPENDICES}

A. Extract from "Taxation of Personal PropERTY " • • • • • • • • • • . 363

B. Taxation in Chicago . . . . . . . 370

C. Taxation of LaNd . . . . . . . . . 373 

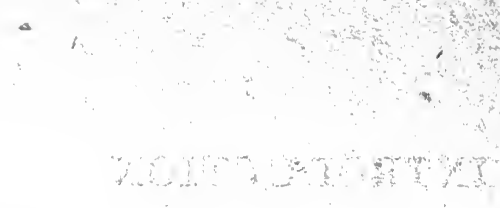

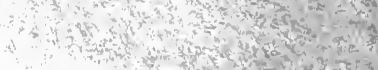

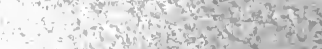

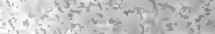

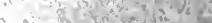

in whos

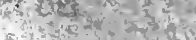

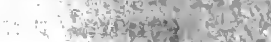

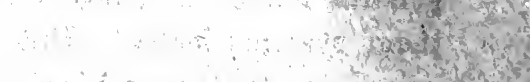
क w

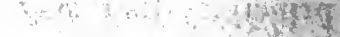

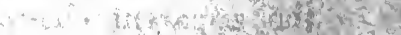

(1)

1 thes

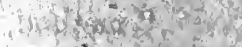

I vistidy pancoly

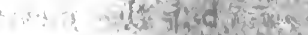

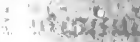

in the है।

का का ?

- की

से की 37 : 2

$x$ y

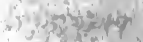

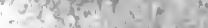

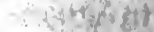

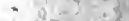

ander

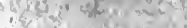
tools 380 an.

\&.. this?

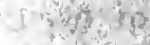

$\therefore \log 3 t$

$x: x^{2}+5$

.

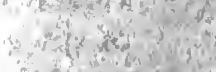

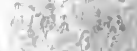

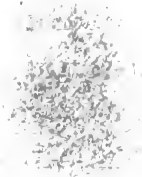

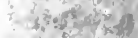
(i) $x^{2}$.

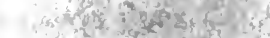

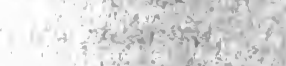

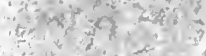

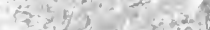
$\because x y=-100$

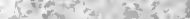

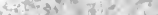
$-23 c^{\circ}=2$ and 


\section{INTRODUCTION}

So many theories and problems are comprised under the general name of taxation as to make it difficult to treat them systematically. But, on examination, we discover principles that may be made to bring some order out of the apparent chaos. These principles may properly be called the methods of taxation; although the term "method," as here employed, is not quite free from ambiguity. It is often used as synonymous with measure; but the measures of taxation devised by legislators are infinite in number. It is obviously necessary to classify these measures, if we treat them at all, and the process of classification according to rational principles exemplifies what is correctly denominated a method. At the same time, the practical applications of these principles are in common speech called methods, and it would be pedantic to ignore this usage, at least where to adopt it will cause no obscurity.

There can be no really adequate criticism of the methods of taxation without some consideration of the right of property. To tax is necessarily to interfere with this right; the revenue of rulers is drawn from the revenue of subjects. Nor can we determine the extent and manner of this interference without referring to the commonly accepted principles of justice. For certain purposes we may speak of the wealth of a people as an aggregate; but we may not in practice disregard the fact that this wealth is owned by a vast multitude of individuals, whose revii 
spective contributions cannot be arbitrarily fixed. If we would examine the methods of taxation, therefore, we must first ascertain what views prevail concerning the institution of property, and what rules or standards of justice are generally recognized in dealing with it.

No writer appears to have devoted himself to this specific inquiry. Works on taxation are numerous; but they are usually either historical and descriptive, or intended to apply particular theories. Most of the manuals of political economy have something to say about taxation, and many valuable monographs deal with problems that have from time to time demanded immediate solution. But we still lack a critical exposition of the relations of existing measures and systems of taxation to the rational bases of its methods; nor, perhaps, is it too much to say that the principles implied in such an exposition have never been clearly formulated. Hence many vigorous and really able commentaries on measures and systems of taxation have been comparatively ineffective. No one can scientifically criticise the laws actually adopted by legislators without having some ideal method in his mind; and he can hardly influence public opinion unless he not only makes this ideal intelligible, but also establishes it on rational grounds.

No doubt there may be permanently inconsistent ideals; and in that event there will probably be permanent inconsistencies in the laws regulating taxation. But, on examination, these inconsistencies may be found to be less than would naturally be inferred from the animated conflicts which have raged over particular problems; less, perhaps, than the participants in these conflicts themselves suppose. The controversy between the intuitional and utilitarian 
schools of ethics has been prolonged and frequently acrimonious; but when the rival methods are put to the test of practice, they are found to be surprisingly similar in their operation. Such may prove to be the case with other conflicting ideals; but whether this be true in the case of taxation, or not, the inquiry can hardly fail to be useful. No one is satisfied with the practical methods employed in assessing and collecting taxes, but there is little agreement concerning the reform of these practices. The first step in such a reform is to ascertain what these practices imply; not merely to catalogue them as formulated in laws, but to explain their results and compare them with the purposes which these results indicate, and with the ideals which are more or less clearly defined in public opinion.

It should be borne in mind throughout the discussion although the examination of the subject must be deferred to a later stage - that altogether the most prolific source of confusion, both in practice and in theory, is the prevalent ignorance concerning the process commonly called the diffusion of taxes. Much reasoning, whether it relates to proportionate, or progressive, taxation, is vitiated when the nature of this process is recognized. Provided the individual who pays the tax can without greater exertion increase his revenue to the extent which the tax decreases it, it is not very material to him whether the tax is proportionate or progressive, or indeed whether it is high or low. To a certain extent, the truth of this principle appears to be recognized, as in the case of customs duties. The importer of dutiable goods pays the government its tax, but he is believed to reimburse himself for his increased expense by selling the goods at an 
enhanced price. The American Sugar Refining Company, for instance, pays a great many millions of dollars in taxes on the sugar which it imports, but in the public belief it recovers these taxes, and perhaps more than recovers them, from its customers, who in turn recover them from the consumers of sugar. On the other hand the same public apparently supposes that an income tax must reduce the incomes of those only who pay it. The conclusions are on their face inconsistent, and there is perhaps no clear understanding of the logical process by which they are both maintained.

It follows that we must distinguish between permanent and temporary measures of taxation, for in most cases a tax, when first imposed, will diminish the revenue of certain persons, but if it continues to be levied will diminish the revenue of others. In fact, temporary taxes hardly admit of scientific treatment, but must be regarded as forced contributions; for we cannot draw logical inferences unless we assume some degree of permanence in our premises. Our reasoning therefore must relate, for the most part, to a stable system of taxation, with some allowance for moderate changes. And this suggests a further caution, that no final judgment can be pronounced or any tax considered by itself, but only as related to the whole system of which it is a part.

While such an inquiry as this is chiefly of scientific interest, there are two practical reasons for undertaking it. In the first place, the present laws and their administration in many cases oblige men to conceal their wealth by deceit, falsehood, and perjury; or else to withdraw from certain occupations because they cannot compete with those who employ these agencies. For the same reason, 
the great class of helpless persons whose property is controlled by trustees is everywhere subjected to exceptionally heavy taxation. In the second place the aggregate of taxation has so enormously increased, and shows so marked a tendency to increase, as to make the future condition of the mass of our people a matter of grave concern. They are eventually the chief, although the ignorant, victims of misgovernment. "The common people of England," exclaimed Adam Smith, "so jealous of their liberty, but like the common people of most other countries, never rightly understanding wherein it consists!" - and we cannot except our people from this description. History warns us that progress can be checked by oppressive taxation, and we may well inquire into the tendencies of our present system. 



\section{THE METHODS OF TAXATION}

\section{CHAPTER I}

\section{THE THREE METHODS OF TAXATION}

THe evident sincerity with which men advocate measures of taxation that are theoretically irreconcilable is a striking proof of the confusion of thought prevailing on the subject. Probably most of this confusion is due to ignorance; we are often unaware of the extent to which the ideals and methods that recommend themselves to us have been tested and condemned in the past. But the confusion does not all arise from this source. It is not uncommon for men to be influenced unconsciously by conflicting ideals, and to favor at different times and under different circumstances practices conforming to one or another of these ideals, without being aware of any inconsistency; or at least without perceiving the cause of it.

Thus, if we define taxation as the process by which some of the wealth of the subjects of a government is transferred to their rulers, to be employed for public ends, perhaps most men would at first assent to the proposition that this process attained ideal perfection when the smallest possible quantity of this wealth was used up in the transfer; for even those who contribute gladly to public ends dislike to have much of their contributions remain in the pockets of the tax gatherers. So, too, the proposition that the best system of taxation is that which least interferes 


\section{THE METHODS OF TAXATION}

with the accumulation of wealth would probably command general assent. But it is conceivable that the expense of collecting the taxes so as to attain this result might be greater than if another end were in view. For, under a different system, there might be features so favorable to large creations of wealth by the "captains of industry" as to make the greater cost of collection of slight consequence. Protective duties, for example, are commonly declared to be advantageous, in spite of their cost, because they increase the prosperity of the whole people. But many would question the proposition altogether, holding the acquisition of wealth not the supreme end, either for individuals or for nations. One country, they would say, may be much richer than another of equal population; but the second country may be the happier. Were there no extremes of wealth and poverty, many of the problems which darken the future of modern societies could not arise, and the greater comfort of the common people might outweigh the diminished luxury of the rich.

Such inconsistencies are by no means peculiar to the views of the ordinary man. They are illustrated to a remarkable extent in Adam Smith's classical chapters on taxation. The enduring merits of his presentation of the subject would in any event make it desirable to consider it; and on account of its very inconsistencies it is the more instructive. As it would be a departure from the usual practice of writers on taxation not to quote the celebrated four maxims, they are given here, in a somewhat condensed form.

I. The subjects of every state ought to contribute toward the support of the government, as nearly as possible in proportion to their respective abilities; that is, 
in proportion to the revenue which they respectively enjoy under the protection of the state.

II. The tax which each individual is bound to pay ought to be certain and not arbitrary. The time of payment, the manner of payment, the quantity to be paid, ought all to be clear and plain to the contributor and to every other person.

III. Every tax ought to be levied at the time, or in the manner, in which it is most likely to be convenient for the contributor to pay it.

IV. Every tax ought to be so contrived as both to take out and to keep out of the pockets of the people as little as possible over and above what it brings into the public treasure of the state.

The second and third of these maxims have been generally accepted as indisputable; but they evidently involve much contentious matter. For, if it be desirable that the time of payment should be certain, and clear and plain to everyone, it might be necessary to fix the time and the manner of payment without reference to the convenience of the contributor. Taxes on real estate, for example, are almost everywhere made payable at a certain time, and the contributor is subjected to a penalty if he does not pay them at that time, whether it suit his convenience or not. Moreover, what are known as indirect taxes have been generally favored because those who indirectly contribute them are not aware of it, and are thus kept in ignorance, not only of the time and manner of payment, but also of the quantity to be paid. So the suggestion that every person should know what others pay seems to imply some politieal end which is not self-evident; and we see that in England much care is taken that the quantity 
of the tax paid by the individual on his income shall not be disclosed to the public.

For similar reasons, the fourth maxi: seems not to be always reconcilable with the second and third, although the inconsistency may not be of great importance. And, practically, it may be urged, the three rules are but more specific statements of the principle that taxes should be so levied as to cause the least possible discouragement to the accumulation of wealth. As Adam Smith observes, although vexation is not, strictly speaking, expense, it is certainly equivalent to the expense at which every man would be willing to redeem himself from it. No doubt indirect taxes seem to take out and to keep out of the pockets of the people a great deal more than direct taxes, over and above what they bring in to the public treasury; yet the manner in which they are levied is so convenient for contributors as greatly to diminish the force of this objection. It would be reasonable to maintain, however, that the convenience of the contributor is to be consulted through the imposition of such taxes as are really least expensive for him, rather than those that cost him more without his perceiving it. In this view the third maxim is subordinate to the fourth, and the three together may be treated as cases under the general principle of economics above stated.

The first maxim, however, introduces a principle of an entirely different character, failure to notice which has occasioned later writers some perplexity. The last three of the maxims, as we have seen, relate to the economy of the process of taxation in the aggregate; but the first lays down a rule of justice with reference to the rights of individual taxpayers. It does not state an economic principle, 
and has no apparent relation to the accumulation of wealth. A tax may be certain, convenient, and economical, without being at all proportioned to the revenue of the taxpayer. In fact, such a tax might be collected entirely from the revenue of a small class in the community. On the other hand, a tax proportioned to the revenue of the tax payer might be both inconvenient and wasteful. If we could discover a tax that was at the same time economical and proportionate to revenue, it would accord with all four maxims; but it is significant that of the twelve classes described by Adam Smith, all, with one possible exception, offend against one or more of his maxims, and nearly all offend against the first.

These maxims, therefore, must be regarded as illustrating rather than as dispelling the confusion which prevails concerning the methods of taxation. They are conflicting, and they contain nothing which enables us to say which should prevail. The fact that Adam Smith's treatise was largely descriptive and historical perhaps caused him to overlook this inconsistency; and, in fact, he introduces in his recommendations for reform a principle repugnant to his first maxim. But as this maxim evidently implies a fundamental principle, it has been scrutinized by later writers, and some of their criticisms will aid us in distinguishing the chief methods of taxation.

The comments of the late Professor Fawcett may be quoted mainly because they illustrate a misconception that still prevails. He observes: "Notwithstanding the deference due to such a high authority, we believe that it will be found that, if the language employed by Adam Smith is closely analyzed, his first maxim of taxation is not only expressed in words which are obscure, but that it is almost 
useless for any purposes of practical application. It will be observed that Adam Smith, in the first place, affirms that the subjects of a state ought to contribute to the support of the government in proportion to their respective abilities: then he professes to make this statement of his principle more clear by enunciating it in different terms; for he explains that 'contributing to a government in proportion to a person's abilities' is the same thing as 'contributing in proportion to the revenue which he enjoys under the protection of the state.' These two statements of the principle, if they have any precise signification, do not mean the same but entirely different things."

It is clear, however, that when Adam Smith said that ability to contribute was to be measured by revenue, he meant precisely what he said. The fact that other writers have used the term "ability" in a different sense is immaterial, so long as Adam Smith defines the sense in which he uses it. Were there any obscurity in his language it would be wholly removed by the illustration of his meaning which he at once gives. He says: "The expense of government to the individuals of a great nation is like the expense of management to the joint tenants of a great estate, who are all obliged to contribute in proportion to their respective interests in the estate." The meaning of this comparison is unmistakable. No matter what the circumstances of the shareholders in a common enterprise may be, or what the inequality of their shares, the principle of contribution stated by Adam Smith is recognized by law and usage.

Mill's criticism is from a different point of view. He does not expressly state what construction he puts on the first maxim, but he evidently disapproves of Smith's use 
of the term "ability." "Equality of taxation," he declares, "as a maxim of politics, means equality of sacrifice. It means apportioning the contribution of each person towards the expense of government, so that he shall feel neither more nor less inconvenience from his share of the payment than every other person experiences from his. This standard, like other standards of perfection, cannot be completely realized, but the first object in every practical discussion should be to know what perfection is. . . . Setting out, then, from the maxim that equal sacrifices ought to be demanded from all, we have next to inquire whether this is in fact done, by making each contribute the same percentage of his pecuniary means. . . . To take a thousand a year from the possessor of ten thousand, would not deprive him of anything really conducive either to the support or to the comfort of existence; and if such would be the effect of taking five pounds from one whose income is fifty, the sacrifice required from the last is not only greater than, but entirely incommensurable with, that imposed upon the first. The mode of adjusting these inequalities of pressure which seems to be the most equitable, is that recommended by Bentham, of leaving a certain minimum of income, sufficient to provide the necessaries of life, untaxed."

We have here a definition of equal taxation essentially different from that formulated by Adam Smith. He maintained that every subject should contribute in proportion to his revenue. Mill maintains that every subject should contribute in inverse proportion to the discomfort which he suffers from making his contribution. Now it is evident that a psychological investigation into the quantity of pain endured by every individual taxpayer in a nation 
is impracticable: it would be necessary to ascertain the amount of the wealth owned by the individual, and then to estimate the pain or discomfort caused by the various rates of deduction through taxation. Some allowance may perhaps be made for certain peculiarities in the circumstances of individual taxpayers; their net wealth, we may say, rather than their gross wealth, should be estimated. But the point is that we must assume a quantitative relation beween feeling and material possessions; the possessor of large wealth must be held to suffer less pain from the decrease of his revenue by a proportionate part than the poor man suffers by a corresponding decrease. Hence the conclusion follows that every subject should contribute not in a simple proportion, but in some geometrical proportion to his wealth or revenue. Mill indeed seems inclined to go somewhat further than this, and to hold that the very poor should pay no taxes at all. As taxation according to this principle has come to be known as "progressive," it will be convenient, in referring to it, to adopt that term.

Here, then, we find illustrated three quite distinct and apparently conflicting methods employed by men in their reasoning about taxation. As we have said, the method suggested by Adam Smith in his first maxim may be designated the proportionate method; that proposed by Mill may be called the progressive method; and that deducible from Smith's other maxims we shall term the economic method. The ideals implied in these methods are presumptively inconsistent. The ideal of the proportionate method is simply proportionality: that taxation should be contrived with the purpose of taking from every subject the same proportionate part of his wealth. This ideal 
might be defined with reference to the subject as quantitative, or mathematical, equality. The ideal of the progressive method may be called socialistic. The existing distribution of wealth is deemed unjust. A part of the possessions of those who have greater wealth should be taken from them, and given to, or applied to the use of, those who have less; and taxes should be contrived with this purpose in view. The ideal here is apparently equality, or equalization, of sacrifice on the part of the subjects. The ideal of the third, or economic, method seems to be predominantly fiscal. The first and second ideals are personal in character; they have reference to the circumstances of the individuals constituting the state. The third is impersonal; it is concerned with the total amount of wealth, not with its ownership or distribution, although it seems to imply that the increase of the wealth of human beings is a desirable end, and that taxation should be contrived with the purpose of interfering as little as possible with its attainment.

Still, we are not compelled to assume that these ideals are necessarily attainable only by their respective methods. Taxes might conceivably be levied in accordance with either the first or the second ideal, and attain the third. We might find that the wealth of the community reached the highest possible figure under a progressive income tax, or under a general property tax, and in either case the fiscal ideal would be realized. But the converse of this seems less easily conceivable. It might be true that taxation according to the economic method would result in quantitative equality, but no one appears to contend that such taxation would bring the socialistic ideal to pass.

But however this may be, these ideals must be respec- 
tively supreme in their different methods. A socialist might hold that, in taxation, the proportionate or the fiscal ideal was most satisfactory; and those who accept the fiscal ideal are by no means committed to the proposition that the present distribution of wealth is ideally just, or even the best practically obtainable. They might even judge a state where there was less wealth, equally distributed, to be happier than one where there was more wealth but less equality. But they would hold either that the present order is so rooted in the nature of things that it cannot be altered by legislation, or that the proper way to reduce excessive accumulations of wealth in the hands of individuals is not to confiscate them after they have been acquired, but to remove the causes that enable men to acquire them; for if those causes cannot be removed, the evil might be aggravated rather than cured by taxation. It is the end to be attained in levying taxes that differentiates the methods. In every method a certain purpose must control. Other purposes must be collateral and subordinate; and it is immaterial to this inquiry that such purposes exist, or even what Utopias men imagine, except in so far as we find them conflicting with the premises necessary to rational procedure.

Yet so many complaints are heard of the tendency of existing measures of taxation to encourage dishonesty, as to make it worth while to inquire whether we should not recognize a fourth method. The ideal of such a method would seem to be the promotion of virtue, and the purpose to be attained in taxation would be predominantly ethical. Taxes should be so levied as to elevate the morals of the taxpayer, or at least not to deprave them. It is certainly paradoxical to deny such a proposition, for we consider 
that the whole system of legislation should promote virtue, and the laws regulating taxation are a part of this system. Hence we seem committed to a political and ethical inquiry of rather wide scope.

Now, to a certain extent, this is what is contemplated in the present investigation; for both the proportionate and the progressive methods make professedly ethical claims, which it is our business to test. These methods, as we have seen, are personal; they propose in adjusting taxation to regard the circumstances of every individual. And as their very aim and purpose is declared to be the attainment of justice, it seems absurd to say that the effect of such adjustment on the morals of the individual is immaterial. For, however we define the concepts of virtue and justice, we certainly do not think that justice can be attained by discouraging virtue. Should it appear, therefore, that the practical application of the first two methods actually hinders virtuous action, the fact that they profess the attainment of justice as their ideal would not save them from condemnation.

It is true that the economic method makes no such claims. It professes to be impersonal; it is apparently concerned with the increase of wealth rather than the increase of virtue. Indeed, as we shall see, it abandons the attempt to ascertain the wealth of the individual as futile; and if we cannot even find out how rich every man is, we certainly cannot estimate the extent of his virtue. Nevertheless, the moralist can say that the promotion of virtue is a criterion to which the economic method, like the others, must submit. For if we should find by experience that this method does deprave men, we should certainly condemn it; and hence it is legitimate to inquire into its ethical results. 
And, as a matter of fact, the advocates of this method claim as one of its chief merits that in practice it removes much temptation to falsehood and dishonesty, and relieves virtuous people from the penalties to which they are subjected by the other methods. These claims, of course, challenge examination, and imply the supremacy of the standard that might at first seem irrelevant. Yet, after all, a standard so purely formal as this seems to be properly described as a test or criterion of methods of taxation, rather than as itself a method.

It is to be added that the fact that taxes, however levied, are always and necessarily paid by persons, is a dominating consideration. The exaction of these payments cannot be successfully carried on in defiance of the convictions of those who make them. Every taxpayer is disposed to scrutinize the amount of his contribution and the manner in which it is collected, and to compare his payments with those of his neighbors. Under such conditions the legislators cannot ignore ethical considerations; their demand for recognition is so imperative as to make the fiscal end appear subordinate. If taxation is to be scientific, it must be a continuous and substantially permanent process, which it cannot be if its practical applications are condemned by public opinion. That opinion would incessantly interrupt and alter the process, thereby destroying the economic gain of permanency. The fiscal method, in short, would be impracticable if men were rationally convinced that it was unjust.

As has been intimated, however, there is in theory nothing incompatible between a fiscal and an ethical end. The two ends may coincide; and in the sequel we shall perhaps find reason to believe that they tend to coincide. 
But this is far from self-evident, and in such a community as ours, with such a confusion of taxes as here exists, it would be idle to examine methods of taxation without some preliminary inquiry concerning prevalent conceptions of justice. Under a despotism, or even under an aristocracy, taxation, when not very oppressive and vexatious, may be regulated without asking whether its methods would meet the approval of the mass of the subjects, if they were consulted. The two hundred and fifty millions of people inhabiting British India, for example, are taxed at the discretion of a very few men, according to principles which the taxpayers no more think of questioning - or of understanding - than they do the causes of the monsoon. Much the same is true of taxation in such a country as Russia; but in a community where public opinion is alert, no system of taxation can be accepted as permanent unless rational grounds are offered for holding it just; or, at least, as resulting in as near an approach to justice as could be attained under any other system.

But when we ask what is meant by justice, we find ourselves at once perplexed. Philosophers, from Plato to Spencer, have labored to define it. The search has been instructive and fruitful, but it has not resulted in a definition that has been universally, or even generally, accepted, or that appears to apply satisfactorily to all the cases arising in practice. In truth, the word has many meanings. The standards of morality are not the same for all races, or for all members of the same race. They vary in different sections of the same country, and among different classes in the same community. In the last analysis every responsible human being must have his own standard of right and wrong, and it is only by yielding and modify- 
ing his own convictions that he can attain a modus vivendi with his neighbors. Hence if any standard of right or justice can be said to prevail in a society, it must be the result of compromises so numerous and so extensive as to make scientific definition very difficult. To compromise is to deviate from a standard; and, where many individuals are concerned, the degrees of variation and the reasons for them become quite incalculable.

Nor may we forget to what extent the judgments which men pronounce are, if not irrational, at least unrational. As Swift said, the proper definition of man is not animal rationale, but at most rationis capax. As men's conduct is largely determined by instinct or impulse, so their conclusions are affected by prejudice and habit. ${ }^{1}$ It follows that large fields of human activity are almost outside of the scope of reason. Precedent commonly controls, and whatever has been held just in the past continues to be called just in the present. Under such conditions, progress unavoidably brings confusion. Precedents become often absurdly inapplicable; "vested rights" are transformed into vested wrongs; and law, administered according to obsolete standards, may illustrate the maxim "Summum jus, summa injuria."

For the present purpose, at any rate, we cannot proceed on the theory that justice is something so absolute and permanent in its nature as to be susceptible of exact definition. To be universally applicable, any definition must

1 "In fact most persons are liable to confound intuitions on the one hand with mere impressions or impulses, which to careful observation do not present themselves as claiming objective validity; and on the other hand, with mere opinions, to which the familiarity that comes from frequent hearing and repetition often gives an illusory air of selfevidence which attentive reflection disperses." SibGwICK, Methods of Ethics, Book III, Chap. XI. 
be so general in its terms as to be practically useless. All would agree that laws that promote the general welfare are just; but if we should examine the numerous acts of Congress that profess to comply with this constitutional mandate, we should find ourselves no nearer a satisfactory definition of justice. We must be content to adopt, as on the whole most rational, the standards proved by experience to be most generally acceptable, to reconcile their differences so far as we can, and to show to what extent men fail to apply consistently the standards which they actually recognize.

Of course it is axiomatic that propositions accepted as self-evident must not conflict with one another; for in such event not all the propositions can be true. In the case of an individual man professing to adopt his conclusions rationally, there is no escape from the necessity of harmonizing his intuitions. But when we consider a multitude, even as members of the same society, we cannot insist on such harmony. Hence we are limited to universal consent as the test of the truth of the fundamental principles of justice. The maxim quod semper, quod ubique, quod ab omnibus, furnishes an empirical standard quite as high as can be here applied. Our course, therefore, must be to proceed per enumerationem simplicem; to collect the current judgments concerning just methods of taxation, and to compare them with such leading principles or practical rules as are universally accepted as politically just, or are at least not rejected on rational grounds by any considerable number of men.

It is true that universal consent does not establish any proposition scientifically; too many absurdities have in the past been implicitly endorsed by public opinion for 
such a contention to maintain itself. Nor may we expect that those who are in the habit of speaking of justice usually in figurative terms and with emotional emphasis - as something absolute and unchangeable, will be content to subject this sublimated conception to the vagaries of popular opinion. But as these persons have not presented a definition of this exalted entity which has either been generally accepted, or conclusively established on rational grounds, their claims do not need to be considered in the present inquiry. To frame on rational principles an ideal system which every one must accept as just, would certainly be desirable, if it could be done; but it is more than is here attempted. Still, we may say, it would open the way for the establishment of such a system if men could be brought to see clearly what principles they do accept as essentially just, and what corollaries are implied in these principles. They may not at present be fully aware of the methods which they actually employ, but they may recognize them when explained, and admit their cogency in cases to which they might not, without reflection, have supposed them to be applicable.

The difficulty of the inquiry is somewhat lessened, because what we are concerned to discover is that quality in the acts of our rulers which men commonly approve as just, rather than such a quality in human acts generally. There must of course be some analogy between the acts of an individual and those of such a corporation as a government. Every government is administered by men, and they, and the citizens who maintain them in office, are in some degree responsible for the morality of governmental conduct. But the rules applicable to such conduct are not only less severe than those of the indi: 
vidual conscience, but are also far simpler. Diplomatists have usually been gentlemen, and, as individuals, have regarded lying as dishonorable. But in former times, if not now, they have felt it not incompatible with honor to lie for their governments; and soldiers do not hesitate at deeds which, as human beings, they execrate. Whenever one person acts as the agent of another, responsibility is lessened and moral standards are lowered. The officer of a government, like the servant of any other corporation, throws the responsibility for his acts on his employers; and rulers and directors divide the burden with one another and with those who have placed them in their positions. It is hardly possible to find an instance in history where the conduct of a government has been such as fully to meet the requirements of the rules of morality accepted by its subjects, and we must therefore apply a comparatively low standard in testing the justice of governmental action.

That the rules applicable to the conduct of government are simpler than those affecting individual morality, is evident when we consider how small a portion, relatively, of human conduct falls under the control of the magistrate. Religion is now almost exempt from governmental interference; most duties arising from the domestic relations and those of friendship, even those of ordinary intercourse, do not very often need to be enforced by law. Moreover we do not need to inquire into the justice of all the acts of government, but only a special class of them. For example, if we were obliged to ask concerning the justice of the purposes for which the government spends its revenue, the field of investigation would be greatly broadened and its nature would be very different. It is 
not always practicable to ignore questions of this kind; but to discuss them adequately would so complicate our undertaking that we are compelled to assume that revenue is to be properly spent, and confine ourselves to the examination of the justice of the methods by which it is raised.

This course has, it is true, an arbitrary look. It seems reasonable to say that the purpose of levying taxes is to confer benefits, and that we cannot properly decide on the justice of the methods of imposing burdens, without considering what is just in the distribution of benefits, or "dispensing justice." But we are not prepared to assume that government is an agency for the equal distribution of benefits; or that, if it is to undertake this task, it must, as would be necessary, take cognizance of the circumstances of every subject, in order to establish a correspondence in the apportionment of benefits and burdens. All that can be conceded is that it would be desirable, if practicable, to consider the chief ends for which taxes are expended, while we are examining the methods of taxation, and that this may be done to some extent. Hardly anyone would assert that there is, for example, any known method of determining the proportionate benefit, to a citizen of an interior state, of the building of a man-of-war, or of a public edifice a thousand miles away, or of the construction of a canal at Panama, or of protective duties generally; and it is impossible to estimate the gain to a childless man of free public schools. Such inquiries, however complicated, are of course legitimate; but to attempt them here would expand this essay into a treatise on government in general, and would render hopeless the attainment of the specific end proposed.

This point is of such importance as to make further 
illustration desirable, and, although it will involve some repetition in the sequel, we shall take it from Mill's criticism of the doctrine that taxation should vary with the amount of protection afforded by government. He asserts that government does not exist solely for the protection of persons and property; and he also denies that to be protected in the ownership of ten times as much property is to be ten times as much protected. He concludes with this proposition: "If there were any justice in the theory of justice now under consideration, those who are least capable of helping or defending themselves, being those to whom the protection of government is the most indispensable, ought to pay the greatest share of the price; the reverse of the true idea of distributive justice, which consists not in imitating but in redressing the inequalities and wrongs of nature."

Many persons, however, would not accept this definition of distributive justice, 'which they regard as limited to redressing the inequalities and wrongs created by human institutions. They consider that the advantages of strength - physical, intellectual, and moral - cannot be, and should not be, conferred on weakness. They regard it as unjust to exempt lazy and vicious men from the consequences of their acts, and doubt if justice requires that the weak should pay nothing for the protection which is provided by the strong. They dread the results of offering a premium to feebleness and incapacity, and thereby hampering the development of superior natural endowments. In fact, they would hold it decidedly advantageous, politically, for every citizen to contribute, and to know that he contributes, to the support of the government. Some persons would even go so far as to maintain 
that if this knowledge were brought home to the members of the inferior classes of society, they might effectively insist on such reforms in government as would come near to reduce the price of protection to an insignificant figure. These opinions are not without plausibility; but we notice them here, not to take part in the controversy, but merely to indicate the complications avoided by excluding from this inquiry such contentious matter as does not positively demand consideration.

When we examine the system of laws under which we live, and in harmony with which the constitutions of our bodies politic have been framed, we find certain principles, or rules of conduct, so thoroughly imbedded in this jurisprudence as to give it its most distinctive features; and we also find these features commanding the approval of the most enlightened observers in all countries. These rules could not have attained their position, or retained it when attained, had they not been recognized as just by those who have only to obey the laws as well as by those who make them. They pervade the morality of common life, and are universally appealed to as axioms of justice. It seems reasonable, therefore, to regard those rules of justice which men practically assume in their daily conduct, as having superior validity to those which are disputed, and as presumptively controlling in the matter of taxation. Hence the claim that any particular measure or any particular method is required by justice must be tested by these rules; and, unless very substantial reasons can be given why this test should not be conclusive, such claims as cannot endure it must be rejected.

In ascertaining these principles two courses of procedure are open to us. We may examine the current 
maxims of morality in the light afforded by the treatises on jurisprudence, the decisions of courts of justice, the bills of rights, and the constitutions of bodies politic; and, selecting such principles as we find common to all these sources, apply them to the methods of taxation. Or we may begin by testing the assumptions of the methods of taxation, by examining and comparing the arguments used in their support, and the criticisms to which they have been subjected. This examination will disclose appeals, implicit or avowed, to the rules of justice of which we are in search, and which may be verified by reference to the sources enumerated above. The former course would be the more scientific, were our aim to develop a system of jurisprudence to which taxation should be made to conform. The latter course seems more appropriate, when the aim is to test methods of taxation by accepted standards of justice; and as it has the further advantage of corresponding with the course naturally adopted by anyone who proposes to inquire into these methods, we may give it the preference. Adopting it, we find ourselves at once confronted with the problems arising from the right of property; for the first two methods appear to involve certain assumptions concerning the distribution of wealth, on which we cannot pass without considering what the ownership of wealth involves. We are thus led to proceed, somewhat informally, to an examination of the nature of property, and the limitations of it, if any, that are justly demanded in our society. 


\section{CHAPTER II}

\section{NATURE AND LIMITATIONS OF PROPERTY}

Ar first thought, perhaps, most men would to-day admit, as has been generally admitted in the past, that Adam Smith's leading maxim embodies the most simple and obvious method of attaining justice in taxation. The analogy of the contribution of the tenants of a great estate is very effectively employed, for such a method of contribution is recognized as just, both in business and in law. It is true that we are not now familiar with great estates parcelled out among tenants; but nothing is more common than co-tenancy as partners and stockholders, and in such affairs no other method of apportioning expense than that of contribution in proportion to interest, or revenue, appears ever to be thought of as just. Even the most radical reformer would reject as visionary a proposal that the shares of the poorer owners of a railroad should be exempted from their proportionate part of the operating expenses, or that the dividends of the holders of many shares should be at a less rate than that paid to the holders of a few.

But, if we examine the analogy more carefully, we find that it is imperfect; and imperfect at the critical point. For the associations in which men engage for business purposes are all formed by deliberate agreement, and these agreements always provide, or at least assume, that the necessary disbursements shall be made from funds contributed by the participants in proportion to their respec- 
tive interests. This method of contribution, therefore, is unquestioned, because by the very act of agreement it is explicitly recognized as just. No one denies the justice of holding men to such promises, and it is immaterial whether this method would be regarded as just or not, had it not been adopted; although, no doubt, the fact that it has been universally adopted indicates that it is not regarded as unjust.

The members of that community or association which we call the state have entered into no such agreement for contribution. Many writers have found it convenient for their theories to assume that states were at some remote period formed by agreements or compacts between all their members; but no one now claims that there is any historical basis for this assumption. Nor can it be maintained without question that our remote ancestors had any authority to enter into agreements binding their posterity, even if they bound themselves. Nor, if this were conceded, would it be possible to show that the method of contribution in proportion to revenue was implied in any of the social compacts which have been attributed to mankind.

Furthermore, it is urged with much force, justice requires that many of the methods and institutions defended by the fiction of an ancestral compact should be changed; and it does not seem possible to deny this, unless we are prepared to maintain that every change is unjust. No one, however, would say that justice forbids living men to modify the customs established by those long dead, and even if we found the method of proportionate contribution imbedded in our law, we need not infer that it is now a just method. We cannot, therefore, regard its justice as proved by the analogy drawn from a joint-stock corpora- 
tion or co-tenancy in a great estate; nor does it command such universal assent as to enable us to adopt it as selfevident. The most that can be said is that if the present institutions cause wealth to be distributed justly, or even with a reasonable approach to justice, the burdens of taxation may with as much justice be correspondingly distributed.

But hardly any one maintains that the present distribution of wealth is ideally just; nor is it easy to imagine a definition of justice that would be satisfied by existing conditions. The expression of discontent with these conditions is common; it is frequently earnest and even violent. The gravamen of the complaint is the great inequality in the possessions of individual owners; from which it appears that justice, in the opinion of the discontented, means a certain equality in the size of estates. Now, however vague the concept, the word "equality" is fundamental in our constitutions. The proposition that all men are created equal, and have equal rights to life, liberty, and the pursuit of happiness, was explicitly enounced when our government was established, and has never been formally repudiated. While this proposition is hardly equivalent to the assertion that every one should justly own the same quantity of wealth, it is declared to mean that every one should have the same opportunity to acquire wealth - which will be found usually to mean opportunity to acquire the same amount of wealth. In fact, it is urged, the right of property, either in itself or by its excessive enlargement, precludes equality of opportunity in the pursuit of happiness, of liberty, even of life itself. Nearly the whole of the surface of the earth is owned by a comparatively small number of individuals, 
while most material things are likewise in their possession. The right to live has little value without the means of living, nor is the right to pursue happiness of practical use to those who cannot secure the material conditions on which happiness depends. The complaint has been formulated a thousand times, but never more clearly than by Louis Blanc, half a century ago, when he declared that the only right of the poor man, the right to work, amounts to little more than a permission to do so if he can find any one to employ him. ${ }^{1}$

This view of property is undoubtedly impressive when it is first presented, and it is only when we reflect on the enormously increased opportunities for work which civilization has brought, that we see that it does not correspond with actual conditions. There is, indeed, nothing modern in such complaints; they appear in the records of the "dawn of history." There is no reason to suppose that they will not be heard till the end of time, for we can neither conceive an equal distribution of goods as actually carried out, nor imagine how it could be main-

1 "All around him he finds the soil preoccupied. Can he cultivate the earth for himself? No; for the right of the first occupant has become a right of property. Can he gather the fruits which the hand of God ripens on the path of man? No; for, like the soil, the fruits have been appropriated. Can he hunt or fish? No; for that is a right which is dependent upon the government. Can he draw water from a spring enclosed in a field? No; for the proprietor of a field is, in virtue of his right to the field, proprietor of the fountain. Can he, dying of hunger and thirst, stretch out his hands for the charity of his fellow-creatures? No; for there are laws against begging. Can he, exhausted by fatigue and without a refuge, lie down to sleep upon a pavement of the streets? No; for there are laws against vagabondage. . . . What, then, can the unhappy man do? He will say, 'I have hands to work with, I have intelligence, I have youth, I have strength; take all this, and in return give me a morsel of bread.' This is what the working men do say. But even here the poor man may be answered, 'I have no work to give you.' What is he to do then?" 
tained were it ever effected. ${ }^{1}$ We must assume that there will always be honest, industrious, and prudent men, as well as those who are vicious, indolent, and improvident; and it is quite certain that the latter class will always complain that their lack of comfort is due to the unjust institutions of society. We cannot give hearing to every one who calls on the name of justice, merely because of that invocation; for the authors of the most flagrantly dishonest schemes insist that they are just.

Nor can it be admitted that complaints of the unequal distribution of wealth are now so reasonable as they have often been in the past. However gross the inequalities, the common people are, on the whole, raised much above the miserable level of their forefathers, and extreme porerty is now usually connected with moral delinquency. The claim that the institution of property is intrinsically unjust and must be abolished, or that justice demands the equal distribution of goods, does not command serious attention. Property is now so generally diffused as to make the number of those who will listen attentively to such arguments comparatively insignificant; and the tendency to such diffusion is apparently growing.

The fact that universal suffrage has prevailed for several generations in the wealthier states of our union is presumptive evidence that the right of property is not commonly regarded as unjust. Macaulay's impressive warning was written half a century ago; but we seem to

1 "Were the landlords all hanged and their estates given to the poor, we should be (economically) much happier perhaps for the space of thirty years. But the population would be doubled then; and again the hunger of the unthrifty would burn the granary of the industrious." T. CarlyLe, Life, II, p. 74. 
be even farther from the predicted catastrophe than we were then. His reasoning, with that of other sagacious observers of our great experiment, was sound enough; but their premises have not been substantiated. It will be worth while to review these premises, in order to ascertain what opinions concerning justice they attribute to mankind, and whether there is reason to expect such opinions to prevail hereafter. Such a review discloses the apprehension, amounting in many instances to an assumption, that if the suffrage were universal the poor would control the government and use it to confiscate the property of the rich. The case was well stated by Webster, in his Plymouth oration, delivered in 1820.

"The freest government," he declared, " if it could exist, would not be long acceptable, if the tendency of the laws were to create a rapid accumulation of property in few hands, and to render the great mass of the population dependent and penniless. . . . Universal suffrage, for example, could not long exist in a community where there was great inequality of property. ... In the nature of things, those who have not property and see their neighkors possessing much more than they think them to need, cannot be favorable to laws made for the protection of property. When this class becomes numerous it grows clamorous. It looks on property as its prey and plunder, anl is naturally ready, at all times, for violence and revolution. ... The true principle of a free and popular government would seem to be, so to construct it as to give to all, or at least to a very great majority, an interest in itspreservation; to found it, as other things are founded, on m?n's interest."

Th: premise or assumption, it seems, of those who were 
alarmed at the prospective consequences of universal suffrage, was the existence of a majority, or a very large minority, of citizens without property. But, in fact, Webster's condition has been complied with. In our large cities, it is true, the great majority own no real property; but through their deposits in savings banks and insurance companies of various kinds, as well as through direct ownership of personalty, they are substantially, and to a large extent consciously, interested in the preservation of property. Even those who are entirely dependent on their wages are not altogether unaware that wages might cease if property were overthrown, and are to that extent intelligently interested in maintaining it; it is, in fact, "founded on men's interest." If the inequalities of wealth cannot be removed without destroying this institution, the rich seem to have no present need to fear. We shall not, as the extreme communists desire, abolish both, but preserve both.

Still, we are evidently not confined to this alternative. Dissatisfaction with extreme inequalities of property is not the same thing as dissatisfaction with property itself The former feeling not only prevails among the ignorant poor, but also permeates the educated classes, and is not unknown even among the rich. Without conceding the claims supported under the names of communism, or collectivism, or socialism, we cannot ignore the existence of a body of doctrine of this tendency, elaborated by men of ability, and by no means without the use of rational methods. The conclusion seems unavoidable that some modifications of the right of property are universall, or at least with some approach to unanimity, admitted to be ideally just, even if not practically attainable. To under- 
stand the present state of public opinion it seems necessary to review the arguments commonly employed in the past to justify this right, and to test their validity according to the standards of justice now recognized. We must know something of the origin and nature of property before we can answer the question how it can be altered without wrong.

Every attempt at such alteration, it might almost be said, has been strenuously and even violently opposed, on the ground that property is something sacred. The connotation of this term is extremely vague; but as commonly used it seems to imply that rights of property are unalterable without the consent of their possessors. We know, however, as a matter of fact that alterations have been incessantly made in the past; and, as we have observed, no one contends that such a continuous process has been throughout unjust. There seem, indeed, to be no rights that are in any strict sense unalienable; nor do we attain any additional sanction by substituting the term "natural." It is true that until a comparatively recent period the doctrine of "natural rights" was much relied on by the philosophers who undertook to explain the institution of property. Modern criticism, however, has made it evident that our knowledge is not really advanced by appealing to this doctrine. In fact the word "natural" is so ambiguous as to aggravate, and even to arouse, controversies over a subject intrinsically contentious and obscure.

In common speech any right seems to be called natural when it is universally recognized and long established, and is therefore regarded as normal in contrast with what is exceptional. But the term is also applied to such rights 
as are supposed to have existed in the primitive state of man, as well as to those which would exist in an ideal state of society. In the former view, the existence of a right proves its justice; hence the " sacredness" of vested rights, and the doctrine crudely expressed in the maxim "Whatever is, is right." But in the latter view the justice of an established or vested right is to be determined not by the fact of its existence, but by its conformity to an ideal, whether that ideal be referred to the past or to the future. The distinction is clearly stated by Sidgwick:

"For, from one point of view, we are disposed to think that the customary distribution of rights, goods, and privileges, as well as burdens and pains, is natural and just, and that this ought to be maintained by law, as it usually is; while from another point of view, we seem to recognize an ideal system of rules of distribution which ought to exist, but perhaps have never yet existed, and we consider laws to be just in proportion as they conform to this ideal." 1

The two views are obviously divergent; and the resulting ambiguity of the term "natural" is so confirmed as to make it desirable to limit its use. When it is necessary to employ it, it seems better, on account of the great indefiniteness of the ideal sense, to call that "natural"

1 "It is characteristic of an unprogressive society that in it these two points of view are indistinguishable; the Jural Ideal absolutely coincides with the Customary, and social perfection is imagined to consist in the perfect observance of a traditional system of rules." SiDGwick, Methods of Ethics, Book III, Chap. V, p. 2. Compare Maine's assertion "that much the greatest part of mankind nas never shown a particle of desire that its civil institutions should be improved, since the moment when external completeness was first given to them by their embodiment in some permanent record." 
which has been so long established as to have become customary and legal. But the fact that we speak of bad customs and unjust laws proves that what we properly call a natural right does not necessarily commend itself to our consciences, although we may not perceive how it can be rightfully altered. For no change in the law of property can be made without affecting unfavorably the condition of some members of the community, and these persons, if they have been guilty of no offense in acquiring their property, may reasonably complain of injustice when they are deprived of it. The fact that the condition of other persons is improved by this change in the law has, strictly speaking, nothing to do with relieving this injustice; for, if those who suffer have done no wrong to those who are benefited, they cannot be justly charged with the cast of this benefit, and to compel them to bear it we call an injury.

Hence it seems that, while our consciences would of course approve an ideally perfect system of distribution, could it be revealed to us, they would revolt at the consequences of any attempt to realize it in practice. And this raises the question whether a system that is unattainable is properly to be regarded as an ideal system; for while a young man may be indirectly benefited by following Emerson's advice, "Hitch your wagon to a star," legislalation on this plan would probably be disastrous. Progress is retarded by wasting energy. One who tries to lift a weight beyond his strength exhausts himself without accomplishing anything toward his purpose. In practical affairs, and especially in political affairs, attainability must ordinarily be characteristic of any ideal. Absolute justice is not satisfied by partial application. To apply an ideal 
standard only in certain cases, or to a limited extent, may aggravate injustice rather than remove it. ${ }^{1}$

While this antinomy must evidently be disclosed in a progressive community, the fact that progress seems normal in modern states shows that in practice the difficulty is overcome or ignored. Solviter ambulando. Legislation exhibits a continuous series of compromises between the forces of conservatism and progress, and in these compromises we shall expect to find some common qualities or principles. The conservative is compelled to recognize some other ideal than the mere maintenance of present conditions; the reformer must accept something short of ideal perfection. No doubt extreme measures are often adopted; but this implies that they are regarded as unjust by a large part of the community, and are therefore not apt to be permanent. They work with so much friction as to defeat their own object, and such equilibrium as they produce is dangerously unstable. No ideal can be realized in a house divided against itself; justice cannot prevail in the midst of discord. It is true that no compromise, even if called successful, can seem to either party to conform perfectly to justice; but it may be accepted by both as the closest possible approximation thereto, because no more will be yielded by one side, no less insisted on by the other.

1 Governments, for example, pay some of their employees higher wages than are paid by private persons, with the avowed purpose of establishing an ideal rate of compensation which other employers will be led to imitate. But as the industrial operations of governments are usually carried on without regard to resulting deficiencies, while private employers must make a profit or be ruined, and as the revenue of government is subtracted from that of private employers or their employees, the policy tends to defeat its ostensible purpose and to intensify the injustice which it professes to remove. 
Now we find this common quality of compromises, or what we may call the regulative principle of progress, explicitly recognized in our jurisprudence, and formally stated in our constitutions. Private property, it is declared, shall not be taken for public use without just compensation, which is generally understood to mean, and sometimes defined as, a pecuniary equivalent. This principle appears on examination to be consistent with the doctrine that men should have equal opportunities to acquire wealth. No doubt the condemnation of property for public use results temporarily in giving advantages to a small number of persons at the expense of the rest. But this gain may be, what it is usually asserted to be, only the removal of obstacles which have hindered these persons from enjoying that equality of opportunity to which they are justly entitled; and it is supposed to result in a permanent gain of this kind to the public at large. When a new highway is opened it must be of especial convenience to a few; but they may have previously contributed to the cost of other highways from which they have derived no advantage, and eventually the new road should facilitate general commerce. No doubt the compensation awarded is frequently imperfect; money may not console a man for the loss of an ancestral home by condemnation proceedings, any more than payment by an insurance company will reconcile him to its destruction by fire. But as men build with the knowledge that fire may destroy the work of their hands, so they acquire property with notice that their title is, as it always has been, subject to the right of eminent domain.

This principle seems to be generally accepted as almost self-evident, and its history shows that it is permanently 
satisfactory to mankind on rational grounds. We might therefore recognize it as fundamentally just, were it not for the objection, often very strenuously urged, that when property has been unjustly acquired, the public may justly take it without compensation. Now this evidently cannot refer to the illegal acquisition of wealth ; for what is illegally acquired does not become the property of the possessor, but belongs to the individual from whom it was taken, not to the public. It follows that the unjust acquisition must be a legal acquisition, and the contention is therefore that laws permitting the acquisition of some forms of property are unjust, and must be overthrown or disregarded without compensating those who are thereby deprived of their possessions. Thus it is maintained that laws recognizing property in human beings were justly abolished in this country without any pretense of compensation to the slaveholders of the Southern States.

The emancipation of the slaves, however, was an act of war; and we find that principles of justice have very slight application when bodies of men are struggling to destroy each other's lives and property. Before war actually broke out, it must be remembered, the slave owners might have received compensation had they been willing to abandon the institution of slavery; and, under the circumstances, their refusal was practically a waiver of their constitutional right. But whether we can construct an cthical code by which the conduct of men engaged in mutual slaughter is regulated, or not, such a code would evidently be useless as a guide to men living together as friends in a peaceful society. Inter arma silent leges; but under normal conditions laws must be altered by law and not by violence. And, as we have seen, a method of altera- 


\section{LIMITATIONS OF PROPERTY}

tion has been devised under which the inevitable injury caused by any alteration is reduced to a minimum.

This conclusion is not affected by our recognizing the right, or even the necessity, of revolution. The conscience of the individual man is for him the supreme authority, and if it forbid him to obey a law, he may rightfully refuse obedience. Thus many conscientious persons declined to obey the constitutional mandate to return fugitive slaves to their owners, and sometimes actively resisted it. They were in effect rebels; they apparently initiated the revolution which finally extinguished slavery, and they may be thought to have acted justly, because, it is commonly said, the event justified them. But even in the case of perhaps the most beneficent revolution that has ever taken place, we can justify violence only on the ground that peaceful methods were unavailable. The end being to abolish property in human beings, the normal course of reform would have been to employ the means provided by the constitution; and, had not the slave-holders resorted to violence, we may infer, from the example of other movements of emancipation, that this course would have eventually been taken. In this view the revolution was not the act of the antislavery party, but of the pro-slavery party, and it is irrelevant to inquire whether the opponents of slavery were justified in their course.

Even in the case of what are called successful revolutions, we must always ask if the beneficent results could not have been better obtained by peaceful methods; and if it clearly appears that they could have been, we do not consider the revolution justified. Unsuccessful revolutions, of course, are even less justifiable; although we must admit that the blood of the martyrs may be the seed of 
the church, and beware of considering temporary results alone. The scope of this inquiry, however, does not require us to decide on the responsibility of individuals, but on the justice of organized and violent resistance to law. But this is civil war; it means that rulers will try to kill their subjects, and subjects their rulers. It is perhaps conceivable that human happiness is promoted by operations of this kind, at least when we think of some cruel despotisms; but arguments in support of this conclusion generally ignore what might have happened had suitable measures been employed to preserve peace. All war necessarily inflicts terrible suffering on many human beings guiltless of moral delinquency; but civil war is so peculiarly cruel and demoralizing as to make it difficult to believe that the existence of any right of property in material things can cause more misery than such a remedy. Rights of property existed in France that were indefensible on rational grounds; but it has been demonstrated that the Revolution was caused; not by this injustice, but by the intolerable burden of a mass of taxes so contrived as to make productive industry impossible.

Still, it may be contended, the provision for compensation may be revoked by constitutional methods. It seems to be supported by common sense, because it has the prestige given by being expressed in the constitution; but if it be clearly seen that it perpetuates gross abuses, common sense may reject it. And if it should prove that much the greater number of the people had taken this view, the standard that we have adopted would require us to admit its justice. But we find no evidence leading us to believe that men would generally say that private property might be taken by government without compen- 
sation. This would be to abolish property as a legal institution, which we have seen reason to think will not take place. No doubt great numbers of men have submitted to tyrants; but this does not prove that they thought it just that they should be deprived of their possessions by their government. Nor does the case seem to be altered if we say that men may be deprived, not of all, but of certain kinds of legally acquired property without compensation. For this is not to say that the law may not declare that after a given time a certain kind of property shall cease to be recognized; this may be unwise, but as it applies to all members of the community we do not call it unjust. It is to say that certain individuals who have acquired wealth on the faith of the assurance given by the law that such wealth shall be protected, and who have violated no law, shall find that assurance withdrawn and that protection withheld. The codes, both of law and of ethics, condemn such proceedings as unjust for reasons which are fundamental in our civilization.

These reasons appear to depend on two leading principles: first, that men may justly own the product of their labor, and second, that they may be justly compelled to keep their promises. The two principles are clearly distinguishable, but in describing their application writers have so often confounded them as to make it difficult to preserve the distinction; and in this way the legal right conferred by prescription has come to be asserted as also a fundamental principle of justice. The true origin of these principles will be disclosed if we continue our examination of the methods employed by philosophers in explaining and justifying the right of property. These 
methods will be found to have changed somewhat as civilization has progressed, but discarding the mutable elements, we may hope to obtain a permanent residuum of truth.

The earlier writers on property, who were prone to appeal to "nature," usually regarded priority of occupation as conferring or constituting, a natural right; and it has certainly played an important part in defining the territorial jurisdictions of several of the more powerful states. The doctrine was apparently first elaborated by the Roman publicists for the purpose of fortifying the defective title by which the nobles held possession of the public lands; but it came to have a very wide application. Grotius lays it down that prior occupation of the soil, "by the tacit consent of mankind," gave a right to its use, and as the use was prolonged, to its substance. The violent disputes among the European powers over discoveries of whole continents lying outside of Christendom show that the consent of mankind was by no means a matter of course; and the application of the principle was palpably absurd. It may confer, as Maine says, enormous advantages merely as the consequence of a piece of good luck, and its connection with the idea of justice is altogether adventitious. ${ }^{1}$

1 "In applying to the discovery of new countries the same principles which the Romans had applied to the finding of a jewel, the Publicists forced into their service a doctrine altogether unequal to the task expected from it. Elevated into extreme importance by the discoveries of the great navigators of the 15 th and 16 th centuries, it raised more disputes than it solved. . . . Moreover, the principle itself, conferring as it did such enormous advantages as the consequence of a piece of good luck, was instinctively mutinied against by some of the most adventurous nations in Europe, the Dutch, the English, and the Portuguese. ... Bentham was so struck with the confusion attending the application of the legal principle that he went out of his way to eulogize the 
Much learning and ingenuity have been expended both in attacking and defending this principle; but it originally amounted only to an expression of a rule of expediency. Occupation gave title not because of any prevalent conception of natural justice, but because men's quarrels had to be terminated. The earliest tribunals were not constituted to apply laws but to preserve order. The easiest, and in that sense the most natural, course for a judge to follow, when several persons appeared before him claiming title to the same thing, was to recognize the one that had possession as the owner; and the maxim Beati Possidentes is the ultimate legal basis of the tenure of the earth by its occupants. Like other animals, men have appetites that must be gratified with the fruits which the earth affords. They would starve without them, and they appropriate them in order, to satisfy their hunger. Having seized them, like other animals they resist with force attempts to deprive them of their possessions; and it was perhaps originally the chief function of civil government to prevent such interference. A law recognizing occupancy as conferring a right of property seems therefore of the nature of a statute of repose; like the rules limiting the time within which actions may be brought, it "quiets title." Strictly speaking, however, it asserts nothing as to the justice of any title which it supports; although it

famous Bull of Pope Alexander the Sixth, dividing the undiscovered countries of the world between the Spaniards and the Portuguese by a line drawn one hundred leagues west of the Azores; and, grotesque as his praises may appear at first sight, it may be doubted whether the arrangement of Pope Alexander is absurder in principle than the rule of Public law, which gave half a continent to the monarch whose servants had fulfilled the conditions required by Roman jurisprudence for the acquisition of property in a valuable object which could be covered by the hand." MaIne, Ancient Law, Chap. VIII. 
may imply that justice is promotted by requiring whoever would question such titles to a vercome the presumption in their favor established by th leir mere existence.

We must admit, therefore, t'nat however indispensable the principle that occupancy gives title may be in the practical administration of $j$ 'sstice, it gives too much im-

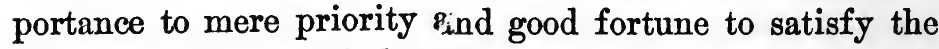
moral sense of mankind. The accident of time cannot be of the essence of justice; and hence philosophers have usually maintained that the expenditure of labor is a fundamental requirite in establishing a right of property. Thus when they speak of occupancy as conferring title, they assume that labor is added. As Locke says, the labor of a man's body and the work of his hands are properly his, and "whatsoever then he removes out of the state that nature hath provided and left it in, he hath mixed his labor with and joined to it something that is his own, and thereby makes it his property." Evidently in these observations Locke had in mind the case of a savage who had plucked fruit from a tree, or taken fish from a stream, or even planted a piece of ground for the purpose of providing himself with food. The thing possessed and the labor expended on it are indispensable to the subsistence of the owner, and the recognition of property in this form seems to have been a fundamental condition of any advance in civilization, as without it perpetual war would prevail. It seems necessary also to extend it to the instruments required in procuring subsistence. No one would be at the pains to provide himself with such implements if he could have no security in the use of them; "if, so soon as he walked out of his tent, or pulled off his garment, the next stranger who came by would have a 
right to inhabit the one and to wear the other." To this extent, at least, property is universally recugnized, and we may adopt as fundamental the principle that he who expends labor on anything unappropriated that is necessary for his existence is thereby justified in its exclusive possession.

To this principle the doctrine that justice demands that all men shall have equal opportunity to acquire wealth is necessarily subordinate. For the material things constituting wealth are limited in quantity, while no limit can be assigned to the possible number of men except the deficiency of food. It has often happened in the past, and sometimes happens to-day, that the quantity of food procurable by a community has not been enough for the subsistence of the whole population; and, while it is hard to reconcile such conditions with Divine justice, we do not regard it as unjust, according to human standards, that those who have provided by their labor so much food as will barely suffice to keep them alive should use it for themselves, even if their neighbors are starving. For, as some must perish, it seems unjust that it should be those who have labored and been provident, rather than those who have not. The parable of the wise and foolish virgins has many practical applications. So when a shipwreck occurs the capacity of the life-boats is often found insufficient. The boats will sink if all the passengers crowd into them; and probably no one would contend that justice requires all to be drowned because all cannot be saved.

These illustrations, however, show that as property is regarded as just because it is necessary to support life, so the justice of the ownership of more than is necessary 
must be otherwise established. We cannot admit that occupancy and the expenditure of labor in providing food to a greater extent than is required to support life give a self-evidently valid title to the surplus; at least while other men equally willing to labor are starving. Failure to notice this qualification has led many writers to state the right of property in the results of labor too absolutely. "1'hus Mill gives the following definition: "The institution of property, when limited to its essential elements, consists in the recognition in each person, of a right to the exclusive disposal of what he or she have produced by their own exertions, or received either by gift or by fair agreement, without force or fraud, from those who produced it. The foundation of the whole is the right of producers to what they themselves have produced." $\mathrm{He}$ adds that bequest is one of the attributes of property; "the ownership of a thing cannot be looked upon as complete without the power of bestowing it, at death or during life, at the owner's pleasure." He distinguishes, however, the capacity of making bequests from that of taking them, holding it no interference with the right of property to limit the latter capacity.

The same doctrine was set forth by the late Henry George in his book, "Progress and Poverty"; a work which deserves notice here because of the large number of persons who seem to have been favorably impressed with the method of taxation recommended by the author. He maintains, after Locke, that " as a man belongs to himself, so his labor when put in concrete form belongs to him. And for this reason that which a man makes or produces is his own, as against all the world - to enjoy, or to destroy, to use, to exchange, or to give." The right of 
unlimited transfer is especially emphasized: "Thus there is to everything produced by human exertion a clear and undisputable title to exclusive possession and enjoyment, which is perfectly consistent with justice, as it descends from the original producer, in whom it vested by natural law."

It is obvious that these statements involve material extensions of the original doctrine. "The law of nature and reason," as Blackstone says, may entitle him who works to the fruits of his labor, so far as the satisfaction of his wants is concerned. But it is not apparent, as we have pointed out, that a man becomes entitled to an unlimited quantity of material things by virtue of labor expended on them, or that a title originally just continues with unimpaired validity for all time. For the quantity of available matter is limited; and, as population increases, many substances become relatively scarce. When gold was first discovered in California, Mr. George informs us, it was obtained by what was called " placer mining," or washing the grains of metal out of the gravel in which they were imbedded. The miners in each district fixed the amount of ground that an individual could take, and the device is said by this writer to have secured substantial justice. "One man might strike an enormously rich deposit, and others might vainly prospect for months and years, but all had an equal chance." A new comer, however, might find all the available ground preoccupied, and that he had no chance at all; while after a time all the accessible gold would have passed into private ownership. Under such circumstances good luck and priority, rather than labor, seem to be the foundation of property. 
Substances of unstable composition, perishable articles, as they are called, may be appropriated without question because otherwise they will be useless, but durable materials are affected with the claims of future generations. Of some of these materials the quantity may be practically unlimited. Population will perhaps never become so dense as to make it difficult to obtain an abundance of ordinary stone or clay. The supply of certain things, however, is proved to be relatively deficient by the value which they attain. That they have any value proves some degree of scarcity; and, as this scarcity becomes more appreciable, the value of that portion of the substance that has passed into private ownership is enhanced. Under the unlimited right of transfer asserted in the passages above quoted this portion may pass into the hands of persons who did not exist when it was produced, and who performed no labor in its acquisition. The fact that labor was expended in the remote past by ancestors or benefactors does not of itself cause men to regard as just the title of the possessor of great wealth, toward the accumulation of which he has not lifted a finger.

It is evident that neither of the writers quoted has sufficiently considered all that is involved in asserting an unlimited right of transfer. As to right of transfer by bequest, indeed, Mill's statements seem irreconcilable. For we cannot say that a man has perfect liberty in giving, when others have not perfect liberty in receiving. Were this true, we might say that to restrict the capacity to buy does not limit the power to sell, - a conclusion too absurd to deserve attention. The difficulty felt by Mill is not confined to transfers by bequest. He had in mind the acquisition of great estates by legatees without any labor on 
their part; but the same result may appear when gifts are made by the living. And even in the case of transfers for a valuable consideration, the consideration may be inadequate; or, as we have seen, the value of the object transferred may in the course of years very greatly increase.

So far as labor justifies property, therefore, the right to an object obtained by exchange seems to be limited to the same extent as the right to an object produced; that is, by the necessities of the proprietor. To this extent we may follow the older writers, and say that the right to hold by exchange whatever has become the subject of property. is derived from that conferred by occupancy and labor, "the first occupant abandoning what he had occupied by allowing such person as he chose to take his place. The second and every later occupant being in occupation, and no one being concerned to question the possession except those who had permitted it, the law confirmed the bargain"; and it is to this day reluctant to allow any, transfer made with due formality to be disturbed. So far as the law is concerned, therefore, we might say that all titles are based on occupancy, original or derivative; and justice, in the legal sense, would mean little more than the observance of the rules governing transfers. Nor when we consider the frightful misery of those peoples whose governments fail to apply such rules, or to respect titles acquired in conformity to them, can we deny that there is some truth in this view. In such matters the experience of all nations shows, as Adam Smith says, that a very considerable degree of inequality is not near so great an evil as a small degree of uncertainty.

The study of this experience brings to light the true 
reason why men have always held it just that the right of property in things obtained by transfer should be recognized. The whole fabric of civilization rests on this right. No progress beyond the life of the brutes could ever have taken place without it. It is indispensable to what Adam Smith calls the division of labor, which is the source of all our wealth. There is, as he expressed it, in human nature a certain "propensity to truck, barter, and exchange one thing for another," which is "common to all men, and to be found in no other race of animals, which seem to know neither this nor any other species of contracts." Without the recognition of this species of contract, society could not have been organized, nor law developed; nor could peace have anywhere prevailed. As the life of the individual depends on his having property in what he has produced, so the life of whole communities of men depends on their having property in things obtained by exchange.

As Adam Smith showed with incomparable power, by means of such property the sum total of wealth, and therefore the average wealth of every one, is enormously increased. Whatever the original source of title, nearly all things now owned have come into their owners' possession by exchange or transfer. The quantity of goods consumed by those who produce them is comparatively so small as to make it hardly an exaggeration to say that everything is produced in order to be exchanged. Most things, indeed, are exchanged many times before they are finally consumed. Services having no tangible embodiment are commonly requited by some "material equivalent," as we say, and "value" has come to mean value in exchange. The advance of civilization may be measured by the removal 
of hindrances to freedom of transfer, and nearly every attempt to restrict it by taxation has been found to diminish the wealth of the community rather than to increase the revenue of the sovereign. Modern industry could not be carried on without legal recognition of this right of free contract; it would be paralyzed were any question to exist as to the validity of the title to things obtained by barter.

No doubt the weakness or necessity of one party to an exchange sometimes gives the other what we call an unfair advantage, even when both parties are competent to contract and no fraud or force has been employed. Indeed, bargains of the largest class, those in which poor men barter their labor, are often stigmatized as unjust, on the ground that laborers are compelled by their poverty to accept such terms as employers choose to offer. It admits of no question, however, that the condition of the poor has been bettered as liberty of contract has been legalized; nor can we imagine a community where this complaint of unfairness would not be heard. For, ex vi termini, the laborer is not a capitalist, and the very fact that one of the parties to the contract of hiring possesses accumulated wealth, while the other does not, constitutes the supposed unfairness.

But it seems clear that if wealth gives an advantage in this bargain, the advantage would be rather increased than diminished by whatever made the bargain more difficult. The prodigious development of the means of physical transfer, and the incessant endeavors to lessen the cost of transportation, imply the common acceptance of freedom of exchange as just; and in spite of numerous legal restrictions, modern society may be said to be constituted on this 
principle. ${ }^{1}$ Hence it is argued that the apparent injustice of great aggregations of wealth in the hands of individual owners is an inevitable adjunct of progress, and that if they cannot be prevented without interfering with the freedom of contract, less injustice will be caused by tolerating them than by attempting to prevent them. In this view, the fact that a few men acquire great wealth is a consequence of the institutions that enable the mass of the people to acquire wealth at all. As a matter of fact, those who regard great estates as an evil have generally proposed to regulate the disposition rather than the acquisition of them; nor are men anywhere forbidden to own more than a prescribed quantity of wealth.

If property in things obtained through transfer is just, it is evident that justice requires the recognition of title by prescription. The reasons for this are succinctly stated by Mill, 2 and need not be enlarged upon. It may be added,

\& "If there is one thing which more than another public policy requires, it is that men of full age and competent understanding shall have the utmost liberty of contracting, and that their contracts when entered into freely and voluntarily shall be held sacred and shall be enforced by courts of justice." Jessen, M. R.

2 The principle of individual property requires "that a title, after a certain period, should be given by prescription. According to the fundamental idea of property, indeed, nothing ought to be treated as such, which has been acquired by force or fraud, or appropriated in ignorance of a prior title vested in some other person; but it is necessary to the security of the rightful possessors, that they should not be molested by charges of wrongful acquisition, when by the lapse of time witnesses must have perished or been lost sight of, and the real character of the transaction can no longer be cleared up. Possession which has not been legally questioned within a moderate number of years, ought to be, as by the laws of all nations it is, a complete title. Even when the acquisition was wrongful, the dispossession, after a generation has elapsed, of the probably bona fide possessors, by the revival of a claim which had been long dormant, would generally be a greater injustice, and almost always a greater private and public mischief, than leaving the original wrong without atonement. It may seem hard that a claim, originally just, should be defeated by mere lapse of time; but there is a time after 
however, that barter would become impossible were every new owner compelled to trace the title of whatever he acquired. While, strictly speaking, no title can be acquired or given by a thief, the law refuses in many cases to allow the title of one who purchases in good faith for value to be questioned; and the nature of large classes of personal property is such as to make this rule necessary. To compel every one who received a coin or a banknote to trace the title by which it has been previously held before he could be assured that he had a right to hold it, would be universally regarded as the height of injustice. In such cases immediate title by prescription is evidently a necessity of human industry; and the case of land, where the law permits a superior title to be asserted against an innocent purchaser for value within a certain number of years, does not constitute an exception to the principle. For the purchase of land is usually a.momentous transaction, implying deliberation, as well as careful scrutiny of official records, and there is so little room for error or deception that some states guarantee against all attacks the title of a purchaser who has observed due formalities. Where the customary periods of limitation prevail, few conveyancers, perhaps, would hesitate to say that more injustice is caused in practice by bringing forward titles that have been overlooked than would be caused by precluding them, and this opinion is confirmed by the very small losses incurred by the companies that insure titles.

which (even looking at the individual case, and without regard to the general effect on the security of possessors), the balance of hardship turns the other way. With the injustices of men, as with the convulsions and disasters of nature, the longer they remain unrepaired, the greater become the obstacles to repairing them, arising from the aftergrowths which would have to be torn up or broken through." Miln, Pol. Ec., Book II, Chap. II, \& 2. 
The conception of barter seems to involve also the principle that men should keep their promises, and that government may justly compel them to do so. For if there were no legal way of holding men to their contracts, many of the most important ones, which require time for their performance, would not be entered into, and the course of industry would be interrupted by incessant quarrels over the most ordinary transactions. As what we call scientific knowledge is based on the principle of the uniformity of natural law, which enables us to predict the future, so in human affairs it seems desirable that men should be so far as possible enabled to rely on having their expectations fulfilled. Progress consists to a great extent in eliminating or overcoming the uncertainties of nature, and in establishing relatively permanent conditions in industry. In spite of our great achievements in this direction, disastrous results from the failure of reasonable expectations are still common, and were no one obliged to do as he agreed the mischief would be incalculable. In order to avoid the state of private war which would otherwise prevail, all governments have established tribunals for the purpose of compelling men to perform their promises, or to pay damages for their failure; and this we call dispensing justice. Indeed, it is obvious that if justice requires equalization of opportunity, the application of this principle is necessary. For while rich men might be able to compel those with whom they dealt to keep faith, poor men would usually be quite helpless if the law did not help them, and we see that the condition of the poorer classes is extremely miserable in communities where the courts fail to discharge this obligation.

While this principle of justice is as well established at 
law as it is in morals, the propensity of rulers to exercise despotically the authority with which they are clothed, manifested through the colonial governments, caused the insertion in the constitution of the United States of the provision already referred to, that no state shall pass any law impairing the obligation of contracts. We need not inquire whether or no the federal government is restrained by this principle, as we wish only to know if there is one standard of justice for rulers and another for subjects. The criticism which this constitutional provision has often received seems to indicate that some such distinction is believed to exist. Legislators have entered into corrupt and improvident contracts, and many contracts, apparently unobjectionable when made, prove oppressive to posterity. Now, when individuals make improvident contracts, their loss may be said to be limited by the duration of their own lives, even if we admit that their children may feel a natural disappointment. But the relation of the legislature to coming generations differs from that of a parent to his offspring not only in duration but also in extent. The contract of the legislature, being of larger scope, may result in a serious impairment of that equality of opportunity which is of the essence of justice, and may tend to create a permanent monopoly " These results may sometimes become so intolerable as to make it seem a less injustice to break the contract than to keep it; they may even threaten revolution. Under these circumstances, as often happens when a contract made by individuals proves to be very onerous to one of them, policy may advise modifications that strict law would not enforce. By the exercise of legal casuistry courts have in some cases sustained laws that did impair the obligation of contracts; and they have 
not always required due compensation to be given for property taken for public use. These cases, however, are on the whole exceptional, and the most strained decisions profess to comply with the principles of justice laid down in the constitution.

As has been observed, in a progressive society conflict between vested rights and the requirements of changed conditions is inevitable, and there must be some principle upon which the conflict can be regulated. In most cases it seems clearly just that the public should compensate those whose rights of property are extinguished, even if the state has made no express contract establishing those rights. For we think it as unjust for rulers to disappoint the reasonable expectations of their subjects, as for other men to practice deceit in their dealings; and when any form of property has been legally recognized, it seems reasonable to assume that this recognition will continue, on the grounds above stated in considering property obtained through exchange. ${ }^{1}$ But these grounds themselves suggest the limits of what it is reasonable to expect. For their chief element is the expediency of allowing men to contract freely, and certain kinds of property may in time be

1 The ideally just man is he that sweareth to his own hurt and changeth not, and the standard of the law is really not much below this ideal. The courts have developed the doctrine of estoppel in pais, or by conduct, as well as by deed and record, to a degree that commands admiration. It is worth while to quote the definition of estoppel by conduct given by Sir James Stephen. "When one person by anything which he does or says, or abstains from doing or saying, intentionally causes or permits another person to believe a thing to be true, and to act upon such belief otherwise than but for that belief he would have acted, neither the person first mentioned nor his representative in interest is allowed, in any suit or proceeding between himself and such person or his representative in interest, to deny the truth of that thing." Digest of the Law of Eridence, Art. 102. 
found to interfere with this right. When this becomes very apparent, it ceases to be reasonable to expect that such kinds of property will be permanent. Thus men were long ago restrained by the statutes against perpetuities from "forging those fetters that seem, by restricting the dominion of posterity, to extend their own," and proprietary rights exercised through incorporations have been repeatedly curtailed. Rulers chosen by the people may enter into contracts binding on the present generation; but when they create burdens for men yet unborn, it is reasonable to expect that their proceedings will be eventually subject to revision.

Such modifications, when made with proper caution, do not seem to constitute a disappointment of reasonable expectations, and need involve no breach of good faith by rulers. Very few persons would be hindered from engaging vigorously in the acquisition of wealth by the apprehension that the period during which they could render it inalienable after their death might be at any time shortened by law. And moreover the practical influence that may be wielded by the managers of great aggregations of wealth in the corporate form has always constituted a warning that property of this kind is more exposed to restriction, if not actual confiscation, than that held by individual right; and the statutes of mortmain were professedly enacted because the free transfer of property was impeded through its accumulation by certain corporations. As to modern industrial corporations, especially those that have been authorized to exercise the right of eminent domain, it has long been obvious that their rights of property are liable to somewhat extensive modification, and it cannot be said that a purchaser of shares in these bodies is dis- 
appointed in reasonable expectations when the burdens laid on them are increased in the same manner in which they have been increased in the past.

In recent years, too, legislators have commonly provided, in granting such franchises, that the rights of property conferred shall be limited, and such property must be held to be acquired by individuals with notice of these prospective limitations. In practice, however, it must be said, the courts appear to have generally annulled laws that would effect the actual confiscation of such property, and to have relieved proprietors from burdens that would deprive men of a reasonable return from their investments. On the whole it seems that the justice of the principle that reasonable expectations shall not be disregarded by governments is generally recognized. It is true that the holders of certain kinds of property have been sometimes heavily amerced; but this has in modern times usually been when some emergency like war compelled the government to obtain revenue as it could, or when the imposition of a new burden has been a long time proposed, or when it is very gradually introduced. The common sense of mankind does not appear to condemn such proceedings as violating the good faith which justice requires governments to observe. The maxim "caveat emptor" is notoriously applicable on the stock exchange. He who purchases a share in a corporate enterprise does so with fair warning that, as he relieves himself of the personal care of his capital, he is liable to pay for this relief by suffering various amercements. 


\section{CHAPTER III}

\section{UNEARNED PROPERTY}

WrTH some such qualifications as have been stated, the justice of most existing rights of property seems to be generally recognized. But there is one species of property - that in land; or, more strictly, the rent of land which is declared to be of a different nature from all other kinds, and to be indefensible by the considerations that support the justice of property in general. This species of property, it is said, necessarily deprives men, both those now living and those yet to be born, of that equality of opportunity which justice demands. While property in things separated by labor from the common mass may be thought less absolute than is asserted by the exponents of these views, property in the surface of the earth - to which the law annexes dominion over the matter of the earth as far as its center, and over the surrounding atmosphere upwards to infinity - should, according to them, be restricted, or abolished altogether. The improver of land, it.is observed by Mill, has just title to it, but not the mere proprietor. The principle that product belongs to the producer does not apply to the raw material of the earth. "It is no hardship to any one to be excluded from what others have produced; they were not bound to produce it for his use, and he loses nothing by not sharing in what otherwise would not have existed at all. But it is some hardship to be born into the world and to find na- 
ture's gifts previously engrossed, and no place left for the new comer."

This hardship, however, is not regarded by Mill as implying that it is wrong to be a landlord, and his proposed remedies do not conflict with the generally accepted standards of justice. They are intended to prevent the acquisition of an absolute right of property in land in the future, not to confiscate such rights as have been lawfully acquired in the past. This is not true of the measures proposed in Henry George's work, "Progress and Poverty." The author expresses strong indignation at that violation of what he calls natural justice which he regards as a necessary consequence of the ownership of land by individuals, - ownership which may conceivably be unlimited in extent and of indefinite duration. He maintains that the requirement of justice that there be equality of opportunity to labor can be met only when every human being is admitted on equal terms at the moment of birth as a tenant in common with all the existing inhabitants of the earth. At present the soil has almost everywhere fallen into the exclusive possession of a small part of the population, the landlords, who permit its use by their fellow creatures only on payment of a tribute, called rent. In so far as land has been made productive by the labor of the owner, or of those from whom he derives title, it is just that compensation should be paid, when practicable, by such as desire to take advantage of this productiveness; but title by occupation, or prescription, having no foundation in justice originally, can gain none by lapse of time. Those having no other title are regarded as mere-trespassers on the common estate, and justice, so far from defending their possession, demands that they be evicted. 
It is only the proprietors of land which commands no rent that need not be disturbed; for no one would be profited by disturbing them. ${ }^{1}$

So far as the existence of an " unearned increment of value" is concerned, i.e. a value not created by the labor of the landlord, there is nothing in these statements that has not been maintained by Mill and Adam Smith; and they both show that there would be no injustice in subjecting this kind of property to special taxation. The term "rent," it is hardly necessary to say, is here used in the Ricardian sense, and means only the differential profit or revenue derived from exceptionally desirable land, so far as its desirableness has not been caused by labor directly spent upon it. The exceptional value of such land is due to the existence of societies of men, the members of which desire to use their productive powers to the greatest advantage, and compete with one another for the most favorable situations and opportunities. The land-

1 "If all existing men were to unite to grant away their equal rights, they could not grant away the right of those who follow them. For what are we but tenants for a day? Have we made the earth, that we should determine the right of those who after us shall tenant it in their turn? The Almighty, who created the earth for man and man for the earth, has entailed it upon all the generations of the children of men by a decree written upon the constitution of all things - a decree which no human action can bar and no prescription determine. Let the parchments be ever so many, or possession ever so long, natural justice can recognize no right in one man to the possession and enjoyment of land that is not equally the right of all his fellows. Though his titles have been acquiesced in by generation after generation, to the landed estates of the Duke of Westminster the poorest child that is born in London to-day has as much right as has his eldest son. Though the sovereign people of the State of New York consent to the landed possessions of the Astors, the puniest infant that comes wailing into the world in the squalidest room of the most miserable tenement house, becomes at that moment seized of an equal right with the millionaires. And it is robbed if the right is denied." 
lords, Adam Smith says, who, like other men, love to reap where they have not sown, take advantage of this competition to exact from their tenants all that the land will produce beyond the ordinary return to labor and capital. The attention and good management of the landlord may in many cases account for some part of the ordinary rent of land, but "ground-rents, so far as they exceed the ordinary rent of land, are altogether owing to the good government of the sovereign, which, by protecting the industry either of the whole people, or of the inhabitants of some particular place, enables them to pay so much more than its real value for the ground which they build their houses upon. . . . Nothing can be more reasonable than that a fund which owes its existence to the good government of the state should be taxed peculiarly, or should contribute something more than the greater part of other funds towards the support of that government."

We need not say that Adam Smith would not have countenanced the view that justice requires the confiscation of existing ground-rents had it been presented to him; and Mill clearly explains the immorality of such a demand. It is based upon an absolute theory of justice, which, even as an ideal, seems to find little support either in reason or experience. If the attempt is made to apply it in practice the way is beset with difficulties. For the ground-rents of a particular city are caused only indirectly and in part by its inhabitants. So far as they are criminally disposed, or even indolent and improvident, their presence positively diminishes the value of the land; and in many cities land values are intimately connected with the prosperity of the country at large, and even with that of the whole earth. The western farmer, when his 
grain is exported from New York, pays tribute to the landlords there, and the same is true of the people of England who consume this grain. Some part of the expense of importing and exporting merchandise, according to this theory, consists of rent; and some part of this charge falls on the producers and consumers of this merchandise, wherever they may live.

Were the title to all the land in the city of New York vested in the municipal government, justice would require that it should distribute its rents not exclusively among its own inhabitants, nor the people of the State of New York, nor even the people of the United States, but among the people of the whole world. For an absolute theory of justice cannot respect persons, nor discriminate against any human being because of race or situation. It cannot regard the accident of birth within the limits of a particular city or country - no more than the accident of priority of time of occupation - as giving any peculiar merit; and when a child is born in Warsaw or in Peking it becomes at that moment seized of an equal right with the millionaires of the city of New York and of all the other cities of the earth. ${ }^{1}$ Such rights would not be enforced by taking the rents of a city from their present owners and giving them to all its inhabitants. This would be in effect to recognize one of the most odious forms of privilege by discriminating not only against aliens, but also against citizens born outside of favored places. From this conclusion there seems no escape; and if we admit that the theory must be modified in practice, it ceases at

1 Although in the passage quoted above it is laid down that natural justice can recognize no right of one man to land that is not equally the right of all men, the author elsewhere contended that Chinamen should be excluded from the United States. 
once to be absolute, and the policy to be followed in its modification becomes a question of expediency.

Indeed, when it comes to the practical redistribution of wealth, there seems to be little disposition to apply the theory that every human being is entitled to an equal share, or even to an equal opportunity to acquire it. The members of the white races have almost invariably denied such equality to their darker colored brethren, and most nations discriminate against aliens, even when they do not exclude them. Nor if the absolute nature of the theory is modified, and it is asserted only of the members of a particular state, do we find any general disposition to accept it, unless among those who may be beneficially interested. For there are everywhere territorial divisions and boundaries of communities, and the residents of every community appear to consider it just that they should enjoy their own peculiar advantages of situation, and not be compelled to make them over to the dwellers in less favored places. In other words, the theory in question would consistently require that cities should be treated like individual men, and distribute the rents that they exact among all those from whom they are exacted; while in fact even those who advance the theory seem not to regard this as just. On the other hand, were the rents of such a city as New York to be employed in giving freely to its inhabitants many things which they now obtain only by labor, there would probably result a great addition to the population, through immigration as well as through an increased birth rate. Were this increment of population laborious, it might tend to increase rent, and thus exact for the city an additional tribute from the outside world, thereby still more encouraging immigration, and 
so on. But were the people demoralized by this redistribution of wealth, as appears to have happened when the people of Rome received largesses from the rulers, there might result a decrease in rent, and a diminution of the benefits freely distributed, followed by such social disorders as are related in Roman history. The fundamental weakness of the theory evidently lies in its ignoring desert, and assuming mere existence in a certain place to constitute a just claim to a share in whatever advantages the place enjoys, without regard to their cause.

Were the claim that justice requires the expropriation of landlords supported by even stronger arguments, it would seem impossible for it to command that general assent which we regard as indispensable. Such assent is rendered less possible in this country, not only because of the great number of land owners, but also because of the even greater number of persons who through loans secured by mortgages to individuals and fiduciary institutions, and through ownership of shares in corporate enterprises, belong practically to the same class. To overcome the support generally accorded to the constitutional provision for compensation when property is taken for public use, it would be necessary to convince the members of this class, which probably comprises much more than half the population, that the confiscation of rent would promote the general welfare, if not their own interests. No doubt it is urged with much force that such confiscation would greatly stimulate industry by relieving it of the incubus of an idle class; but this result is highly problematical. Those without capital could not lease land; those with capital are able now to obtain land of which they can make profitable use, and their exemption from 
other taxes would tend to give them for a short time an inordinate profit.

On the other hand, it is altogether uncertain to what extent enterprising men would lease land which they know could not, so far as they are concerned, increase in value, and from which they might be dispossessed by any one who would pay them the cost of producing, or reproducing, their improvements. ${ }^{1}$ Experience seems to show that men are not willing to make very costly improvements on leased land unless they hold it for a long time; but the advances in the value of land are often very rapid, and the "unearned increment" during the term might be very great. Yet should there be a decrease in the value of land, it might not seem altogether just for the government to compel its tenants to pay rent that they could not earn; and while such problems can be dealt with by the English rulers when they arise in India, and might be if they should arise in Ireland, they could not be so easily handled by the governments of our own country. Had the owners of tillable land in some parts of England been dispossessed a generation ago, and had the government relet this land, it might find itself now obliged to forego its rent and face conditions similar to those which have made Trish landlords so unpopular. ${ }^{2}$

1 It is evident that if unoccupied land is taxed at a high rate in order to induce the owners to improve it, the buildings erected will, probably, be of a character inferior to what would have been erected had the land remained unoccupied until its value had increased. While the community might gain an increased present revenue, posterity might suffer through the expense of destroying and replacing unsuitable structures. To a certain extent, however, this loss is inevitable in a progressive society; and were buildings not taxed the process would be modified.

${ }_{2}^{2}$ Sir A. Milner and Sir R. Giffen, testifying before the commission on agriculture in 1896, estimated that the value of farming land in the 
It should be added that even if we admit it to be practicable to distinguish the value of improvements from that of the land, this latter value may have been partly created by the sagacity of the owner, or by the acts of individuals or bodies of men, more than by the labors of the citizens at large. Thus the extension of the elevated railways in the city of New York increased the value of much land three or four fold, and those who ventured their capital in an enterprise which was at first of very uncertain outcome, might seem to have a just claim to some part of this increment, at least as against the landlords, and perhaps against the community. For if the enterprise, while enhancing the value of land, had not proved remunerative to those who carried it on, it would probably not have been thought just to repay them their losses; but if this would not be just, it would seem reasonable to allow them something more than the ordinary rate of gain, since the community was greatly benefited through the happy outcome of the venture. The construction of railroads through the prairies of the west was followed by an increase in the value of land often ten or twenty fold; and it seems unjust that settlers who acquired this land for a nominal price should appropriate the whole of an increment that was created certainly in part by the capital invested in railroad building.

The value of land may be said to be everywhere created by its accessibility as much as by any other cause, and the dominant landlords seem therefore to be the owners of railroads and canals. But no one would

United Kingdom had been reduced, because of American competition, from about $£ 2,000,000,000$ in 1874 , to less than $£ 1,000,000,000$ in 1894. 
venture to assign a definite increase or decrease of the value of a particular piece of land as the effect of the construction of the Suez or the Panama canal; and while we may be satisfied that the value of farming land in England has been greatly diminished, and that of farming land in the United States greatly increased, by the construction of railways and canals, and by the improvement of steam engines and vessels, it seems hopeless to attempt to apportion the benefits in accordance with any theory of justice, or to offset the gains against the losses. The difficulty of adjusting the charges for transportation is notorious, communities seeming to be as jealous of one another as individuals; and were the government to confiscate the railways, it would be altogether beyond its powers to apportion the expected advantages in such a way as to satisfy the demands put forth as just by different states and cities. For it is easy to see that such rates as would satisfy one would be ruinous to others, and the only practical solution would be by compromises dictated by necessity and expediency, and not in accord with any absolute theory of justice. The fact that common ownership of land has everywhere prevailed in the past, and been almost everywhere abandoned, must be taken to prove that individual ownership is not generally regarded by mankind as unjust.

Apart from considerations of expediency and convenience, it seems probable that men recognize the existence of an "unearned increment" in the values of other things as well as land, and that this increment is, abstractly, no more defensible than ground-rent. The theory of those who would confiscate ground-rents is too broad to be applicable in practice, while as regards personal property 
it is too narrow and arbitrary. As we have seen, the assertion that a man has a right to what he has produced by his own exertions is ambiguous. Evidently he cannot produce matter, but can at most move certain parts of it, and separate and combine them for useful purposes. This matter, as well as the mere surface of the earth, may be subjected to monopoly, being also limited in quantity; and justice demands equality in the distribution of the former as well as the latter. Indeed we seem to regard justice as outraged not so much by the nature as by the disproportionate size of possessions; the ownership of great accumulations of personalty may be as offensive as that of great tracts of land. We cannot well contend that no one may rightfully own a diamond mine, while we maintain an absolute right to own diamonds which some fortunate miner took from it before other persons knew that it existed, - perhaps before such persons came into existence. Nor does it seem easier, practically, to establish a clear title to movable things in general than to real estate. As labor has in most cases, at least in long settled countries, become inextricably mixed with land, and cannot in fact be applied to matter without the possession of land, so movables are but detached portions of land. Some degree of possession, in short, is indispensable to every form of industry. The title to movable things must be vested in the landlords or have been derived through them; and if they had no title they could give none.

Moreover, in spite of the justice of prescriptive right, it must be admitted that whatever claim to any form of property is attained by labor is in common estimation lessened by lapse of time. Hardly any one disputes the justice of securing to the laborer the immediate results 
of his toil; but, as years pass on, his claim gradually ceases to impress us so strongly, and a presumption appears insensibly to arise that the due reward of his exertions has been paid. The most striking illustration of this tendency occurs in the case of authors. It is only in modern times that they have obtained legal protection of the results of their labors, in spite of the fact that the immaterial nature of their products excludes the possibility of monopoly. The author's property consists merely in the exclusive right to repeat, or copy, a particular arrangement of words which he has devised, and which no one else could have produced, either by accident or design. This right can frequently have little value unless it can be sold and preserved indefinitely; but the law limits its duration, so that it may expire even in the author's lifetime. ${ }^{1}$

In general it seems to be true that the title to very desirable things that have come into the possession of such as did not produce them is justified on other grounds than the original expenditure of labor thereon. Labor being conceived as performed in order to satisfy the wants of the laborer, the title that it gives must somehow and in some degree be commensurate with those needs. As the titles to a great number of things may in the course of years become vested in a single person, we find ourselves

1 Probably there is some confusion in the mind of the public between conyright and patent right, which has operated to the disadvantage of suthors. There is, however, no analogy between the cases, the letters patent granting a monopoly of the use of matter in a specified way, although the idea of making such use may have occurred to many before the letters were granted, and would probably have occurred to others long before the term expired. The statute of 1710 accidentally curtailed the author's right, which was unlimited at Common Law. The ideas expressed by an author become public property; those of the patentee can be made use of by others only with his consent. 
less disposed to regard the labors of the original creators of these things, than to inquire how their present owner is justified in possessing far more wealth than is sufficient for ordinary requirements. The right of a man to the product of his own exertions may be unquestionable; but the right of one man to what has been produced, not by his own labor but by that of a hundred others, is different, and cannot be justified, as was attempted by Henry George, by asserting that what the laborer produces is his for all time. On the contrary, it is now coming to be understood, as we have seen, that rent is a phenomenon not peculiar to land, but a generic feature of all property, the acquisition of which is not subject to free competition. The vogue of the term "unearned" signifies that desert is now regarded as an essential element in establishing the justice of ownership; and desert is not an inherent quality of wealth, whether real or personal, and cannot be transferred or inherited. There may be good reasons for maintaining existing rights of property in general; but, so far as abstract justice is concerned, property in land seems no less defensible than such personal property, at least, as consists of portions of matter.

While moralists have always maintained the justice of compensating desert, or service rendered to society, this view has. now become so prevalent that we might say that desert is regarded as limiting, at the same time that it supports, the right of property. As Mill remarked, no man works by himself in our modern world. In every act of his life he is aided by the present or past coöperation of others, and as nothing is the product exclusively of his own exertions, he can maintain no absolutely exclusive right in what he is said to produce. The creation 
of wealth to any considerable extent is possible only through the organization of industry. In this organization, and in its defense and protection, nearly all the members of society may be said to participate, and they justly share in the wealth that could not have been produced without their participation. When Adam Smith observed that ground-rents were altogether owing to the good government of the sovereign, or, as we should say, to the existence of an orderly society, he stated a law, as we have seen, that is not applicable to land alone. The wages of labor and the profits of capitalists are beyond question increased by the security afforded by a good government, and this increase may be an "unearned increment" as much as the rent of land. Hence we find it maintained that whoever possesses wealth of any kind, acquired without rendering any service to society, may with justice, according to the principle stated by Adam Smith, be taxed peculiarly, or contribute something more than others to the support of the government.

In opposition to this claim it is plausibly argued that the actual difference between the deserts of different men, measured by the values of their services, is far greater than is commonly understood. An incompetent or dishonest servant frequently does his master more harm than good. He injures or makes away with what is committed to his charge, so that the value of his services is actually negative. A faithful and capable servant, on the other hand, may greatly improve his master's property. Were the results of his management compared with those of the bad servant's, his desert might be measured by the whole value of the property affected, for he has both preserved and increased it, while the other would have destroyed it. 
So in manufacturing or mercantile business, a bad manager may cause the loss of the whole capital invested, while it may be doubled by a good manager. In the same way a bad lawyer will lose a case which a good one would have gained, and a capable physician will save the life of a patient who would have died under the treatment of an incompetent practitioner. So whoever invents a method of attaining any useful result with less labor than has been before required, or discovers some new property of matter, may render a valuable service to all mankind, and deserve a corresponding recompense. In all such cases the size of the reward, it is claimed, is often less than would be justified by the value of the service rendered. The community is really richer, after paying this reward to its servants, than it would have been had their service not been rendered, and their compensation, so far from being greater than they deserve, is less than justice would award them. Certainly, we can hardly estimate in millions, or perhaps billions, of dollars the value to the world of the services of the inventors of the steam engine and the sewing machine; and money cannot measure our debt to the discoverers of anæsthetics and to those who have developed antiseptic surgery.

There is much force in this argument, and its validity is to a certain extent generally admitted. It is possible, of course, to say that nature is itself unjust in its distribution of natural endowments, and that those who have been favored by birth or ancestry with exceptional strength and ability are not on that account meritorious or deserving. But this is carrying the analysis further than is demanded by common sense, and congenital superiority is generally regarded as justly entitling its possessors to cor- 
responding rewards; otherwise the survival of the inferior would be encouraged. Conceding this, however, it may be replied that the argument amounts to little more than an explanation of the methods according to which rewards are now distributed, and begs the question of their justice. This appears more clearly if we press the argument, and inquire whether it would be just for a physician of exceptional skill to refuse to save the life of a rich man unless the patient would requite him with the whole of his fortune, or whether lawyers might justly charge their clients fees equal to the sums which but for their labor the clients would have lost. The exaction of such payments would be universally condemned as unjust; yet, strictly speaking, it would be no more than equivalent in value to the service rendered. In common speech conduct of this kind is described as taking an unfair advantage of the necessities of the person served, and this implies some other standard of justice than that employed when we measure value of services by, the loss which would be suffered if they were not rendered. But, when we ask what this standard is, we are usually referred to what is customary; and in practice the justice of a charge or compensation in any particular case is apt to be determined by what others would charge for the service under like circumstances. We still lack some element enabling us to say whether customary payments are just or not.

Yet some light is thrown on the problem by this examination, for the appeal to what is customary suggests the existence of competition among those who have services to sell. We may assume that whenever anything or any service is found to be of great value to the community, 
many persons will endeavor to furnish the necessary supply, and that after a time the compensation obtained by such persons will, in many departments of industry, tend to become no greater than what they would obtain by employing their time and money in other occupations. Hence in a community where perfectly free and speedy competition prevailed, the customary rewards would tend to be the same as those required by ideal justice. For if any one attempted to charge more for his services than their equivalent, measured by their " cost of production," others would soon underbid him. Thus no one could obtain exceptionally large compensation unless his service were of such exceptional value as was due to his individual excellence, - a kind of desert which we must for practical purposes agree to accept as a part of the natural order of things. In this way the issue becomes really one of fact and may therefore be decided by evidence furnished by experience. Accordingly we find those who assert the justice of the existing distribution of wealth maintaining that free competition exists, and appealing to the many instances where poor men have acquired great wealth, as proof that rewards are fairly proportioned to deserts.

There are undoubtedly so many cases of this kind as to constitute some approximation to justice, and to make the mass of mankind tolerably submissive to existing institutions. Yet, when we consider the facts, it appears that many great fortunes are acquired by those who have avoided, or been relieved from, competition. Inventors seem to be a peculiarly deserving class of citizens, but the effect of the patent laws is to favor those who are prior in their application, to the total exclusion of others whose desert is substantially equal. It frequently happens that 
a number of persons are in search of some improvement, and discover it simultaneously; but while one becomes very rich from the monopoly granted him by law, the others are prohibited from making any use of the product of their labors. It is equally notorious that inventors have been sometimes unable through poverty to make profitable use of their discoveries, and that those who have furnished them money have obtained the greater share of the gains arising from their patent rights. Much the same is true of the discoveries of mines; the fortunes made by those who have purchased the claims of these discoverers being especially conspicuous illustrations of wealth acquired through exemption from competition. The public has been abundantly informed also that many large fortunes have been created by the rapid advance in the value of land, which is attributed to the relative scarcity caused by the growth of population and the attendant monopoly obtained by the land owners. In some notable instances great wealth is thought to have been accumulated by men engaged in manufacturing, by means of rebates, or unfairly low rates of transportation, which have enabled them to undersell their competitors.

It is notorious also that temporary monopolies arise in every branch of trade, through control of the supply of any staple commodity. Bagehot, in speaking of the power of the Bank of England to fix the rate of interest, observes " A single large holder, - especially if he be by far the greatest holder, - may fix his price, and other dealers may say whether or not they will ask more than he does. A very considerable holder of an article may for a time vitally affect its value if he lay down the minimum price which he will take, and obstinately adhere to it. 
This is the way in which the value of money in Lombard Street is settled." 1

This description applies to numberless "corners," or temporary monopolies; and perhaps most of the great fortunes made in commerce have been due to sagacious speculation concerning the fluctuations of demand and supply. The methods employed are too familiar to require mention; but they are frequently such as forbid the speculator to assert that his gain is justified by any service to the community. For such operations in modern trade very great capital is necessary; only the possessors of large fortunes can engage in them. Such fortunes have thus come to be denounced by many writers as equally unjust in their acquisition and in their employment; they are said to be created at the expense of the public and used to its detriment. The ability of their possessors, it is maintained, is misdirected. Their labor is pernicious; and those to whom their wealth passes hold it by a title resting in law and not in justice.

In recent times many fortunes have been made in "reorganizing" and in combining enterprises, by persons standing in such relations to these enterprises as to make it impossible for others to compete with them. In these affairs the possession of exclusive information concerning important plans or "developments," has enabled those favored to enrich themselves. Through family influence,

1 "The reason is obvious. At all ordinary moments there is not money enough in Lombard Street to discount all the bills in Lombard Street without taking some money from the Bank of England. As soon as the Bank rate is fixed, a great many persons who have bills to discount try how much cheaper than the Bank they can get these bills discounted. But they seldom can get them discounted very much cheaper, for if they did every one would leave the Bank and the outer market would have more bills than it could bear." 
or friendship, and by political favor, many lawyers obtain lucrative positions or profitable business; and the methods of obtaining public office are notorious. Physicians, as a rule, must depend more on their own abilities to meet competition; but they are often aided by personal influence, and only popular authors and artists have clear titles to the comparatively modest fortunes which they acquire. In all the other cases, it may be contended, the services for which such great rewards have been received are either of little value to society, or would have been rendered for very much less had competition been allowed. Much wealth, it must be admitted, is acquired by fraudulent use of their position by trustees, and much by positive cheating. Much, too, is acquired by gambling, including under this term a large part of the transactions on the exchanges; and in such cases it is obvious that the gains of one speculator are made up of the losses of others.

Making every allowance for popular exaggeration, there seems to be sufficient truth in the foregoing statements to render it impossible to regard the title to many fortunes as justified by the deserts of their proprietors. The facts in many cases are too well known in the business world to be disputed, and some of them have been judicially established. Without going to the length of asserting that every poor man is by virtue of his poverty incapable of competing on fair terms with the wealthier persons to whom he must sell his labor, we cannot deny that competition is so imperfect in certain departments of human activity as to enable many persons to obtain wealth without rendering corresponding services; and this seems to imply that such equality of opportunity as justice would require does not prevail. 
Yet, so far as existing wealth is concerned, there is some ground for regarding this conclusion as mistaken. The fact that the title to great possessions is vested in a single individual by no means proves that the opportunities of others to acquire wealth are thereby limited, or that competition is thereby prevented. For the wealth of the rich man must usually be, as we say, "invested "; i. e., it must be employed as capital in producing more wealth; which is indeed a most effective way of increasing opportunities. This process necessarily furnishes opportunities for activity, both to those who know how to use capital effectively, and to laborers, and perhaps under the most advantageous conditions. If the same amount of wealth were divided among a hundred owners, it might either be invested by them, as it was by the sole owner, or used directly; in which case they would take the place of the former users. So far as production on a large scale is advantageous, the tendency would be to investment; and, so far as income is concerned, the rich man is perhaps more likely to reinvest it than the man in moderate circumstances. The division of wealth might thus operate to reduce the rate of its production, and in that way to restrict rather than to enlarge opportunity; for it cannot be too strongly emphasized that to invest capital and to furnish employment to laborers are the same thing. Furthermore, experience seems to prove that the capacity to manage capital is rare; for, of those who undertake mercantile business, which is perhaps the simplest form of business, it is said that ten fail where one succeeds, and such persons are not apt to be wiser when they invest in the enterprises of others than when they attempt management for themselves. And many would agree with Adam Smith that the management 
of industrial affairs by government is almost always wasteful, and that to appropriate a large part of the wealth of the rich for public uses would tend to impoverish the people, by creating a privileged class of placeholders who consume wealth that would otherwise be employed productively.

It is urged, also, that the injustice complained of - the denial of opportunity to acquire wealth - would not be removed by confiscating the large estates that now exist; for this would not remove the causes of such accumulation, but might rather intensify them. History furnishes abundant evidence that whenever rulers undertake to deprive wealthy subjects of their possessions, such uncertainty as to the security of property takes place, as to furnish, not equality of opportunity to the common people, but exceptional opportunity to the boldest and most unprincipled speculators. And if we review the methods by which fortunes have been acquired, it does not appear that men would be deterred from such acquisitions by the threat of future confiscation; on the contrary, the withdrawal of the more scrupulous might enable the less scrupulous to make even greater gains. In this view, justice would be more nearly attained by repealing the laws that prevent free competition in acquiring property, than by confiscating property acquired through the operation of such laws.

These arguments, however, rest to a great extent on an assumption that is disputed. The rich man may invest judiciously some part of his income; but he also makes unwise investments, and he certainly uses some part of his wealth in unproductive expenditure. He is tempted to display his aflluence; he may build palaces, and keep many carriages, and a large retinue of servants. Still it cannot be assumed that, if his wealth were distributed, those who 
received it would not also use it in building more costly houses and in keeping more carriages and servants; for we know that so soon as men find themselves able, they are apt to indulge in these very forms of expenditure. The same is true of dress and of furniture; their expense almost always increases with income. On the other side of the account, we find it urged that rich men give away vast sums of money for numberless public purposes, as well as in their private charities; and some of the most liberal of them have lived very simply. Were they deprived of their wealth, it is conceivable that institutions which now furnish opportunities to many poor people to better their condition would perish, and many needy and helpless persons would become destitute. But there is much evidence that liberality is not less, in proportion to income, among men of moderate wealth than among the very rich; and, if wealth were more diffused, there would be less need to extend aid through eleemosynary channels, either public or private. While society owes much in a thousand ways to the refined and enlightened benevolence of the "leisure class," we cannot say how much it might owe to members of other classes were their leisure increased.

On the whole, we seem to be obliged to fall back on the general principles of ethics; and if we do so, there is no way of escape from Bentham's conclusions. We must admit that wealth is, taking all things into consideration, a source of happiness (or of welfare, if that term be preferred); and that such happiness, in the case of an individual man, does not increase in proportion to the amount of wealth that he possesses. It may be maintained that this proposition is not true when the quantity of wealth is small. A man who cannot procure what is necessary 
to support life must be unhappy, and to increase his income might therefore increase his happiness out of all proportion to the quantity of the increment. But this does not appear to hold true after the ordinary desires and tastes have been satisfied. Even if the attempt to arrange pleasures in a quantitative scale were to succeed, common sense would never admit that the feelings of one man should in practical affairs outweigh those of a thousand others. Men in general unquestionably believe that, if the expenditure of wealth is pleasurable, the quantity of pleasurable feeling - even allowing for quality - is greater when a large number of persons are able to indulge luxurious tastes than when the ability is confined to a few. Hence if the total amount of wealth spent unproductively by a hundred persons would be no greater than that spent by one, if he owned most of it, the capital of the community would not be impaired, while its happiness would be increased by a more equal distribution. Conceding that great fortunes do not limit opportunities for the acquisition of wealth, at least to the extent often asserted, and that they may even tend to increase the aggregate wealth of the community, it seems impossible to deny that their existence is commonly believed to diminish the quantity of happiness potentially enjoyable by its members, if not the quantity actually enjoyed. This opinion, as we have before observed, is held by many who do not think such potential happiness to be practically attainable by means of taxation; or indeed by any compulsory system.

In this discussion we have hitherto ignored the existence of family relations, and considered the right of property to belong exclusively to individuals, as some writers on the subject, even in modern times, and in spite of such a con- 
spicuous fact as the feudal tenure of land, have frequently done. But it is now commonly maintained that this right was originally vested in communities. The Civil Law is thought to have based the right, in part at least, on the institution of the family. The father and the son were regarded as in a sense one person, so that, on the death of the one, the property rather continued than descended. It is certainly true, at the present day, that men everywhere regard it as the duty of parents to provide sustenance for their children until they are able to support themselves, and this is commonly a legal obligation. Hence the title conferred by labor requires to be somewhat enlarged. Justice must authorize men to acquire by their exertions wealth sufficient for the maintenance, not only of themselves, but also of their families. This obligation, too, is not thought to terminate with life; for, while men are not required by law to accumulate wealth on which their families may live after they die, they are praised for doing so. Indeed, the advance of civilization may be measured by the extent to which accumulation for this purpose prevails, and the encouragement which is given in many ways by law to such accumulation indicates that it is commonly regarded as just.

The principle that the labor of the possessor of wealth constitutes the sole justification of his title plainly does not apply in this case. In spite of the emphatic endorsement given by Mill to the right of free acquisition by contract, he appears to admit that those who acquire without exertion the fruits of others' labor have but a limited title. ${ }^{1}$ Very young children often possess wealth " trans-

1 "Private property, in every defense made of it, is supposed to mean the guarantee to individuals of the fruits of their own labor and absti- 
mitted to them without any labor or exertion of their own," and this is true also of those who receive wealth by gift, as in many cases no valuable consideration is returned by them to the giver. Yet we do not think that justice forbids us to accept gifts, for we hesitate to call giving unjust, and are perhaps rather inclined to commend it as often a means of lessening the inequalities of fortune. In the case of children, it is obvious that if their parents do not provide for their support, others must do so; while by means of this parental support they become capable of rendering services of value to society. And giving may be defended by similar reasons; for the recipients of gifts are often as needy as children, and equally helpless, and the gifts may enable them to become self-supporting. Indeed, it is on this ground that our system of free schools is defended.

But while the right to acquire and to transfer the products of labor is thus enlarged, so as to include more than

nence. The guarantee to them of the fruits of the labor and abstinence of others, transmitted to them without any merit or exertion of their own, is not of the essence of the institution, but a mere accidental consequence, which when it reaches a certain height, does not promote, but conflicts with the ends which render private property legitimate." Pol. Ec., Book II, Chap. I, \& 3. Compare this with the following: "The right of property includes, then, the freedom of acquiring by contract. The right of each to what he has produced implies a right to what has been produced by others, if obtained by their free consent; since the producers must either have given it from good-will, or exchanged it for what they esteemed an equivalent, and to prevent them from doing so would be to infringe their right of property in the product of their own industry." Book II, Chap. II, \& 1. Compare also this proposition: "Unlike inheritance $a b$ intestato, bequest is one of the attributes of property; the ownership of a thing cannot be looked upon as complete without the power of bestowing it, at death or during life, at the owner's pleasure; and all the reasons which recommend that private property should exist, recommend pro tanto this extension of it." Ibid., § 1. Mill distinguished limiting the capacity to take bequests from restricting the power to make them. 
suffices for the needs of the individual producer, it is subject to the same limitations. Society coöperates in the production of this additional wealth, and the rights of children and other beneficiaries are qualified by the claims of the community. Whatever is necessary for the support of those who cannot support themselves must somehow be provided, as a matter of justice; for in this country, and in some others, it may be demanded of the state as a legal right. We may perhaps go somewhat further in this direction, as most men probably do not consider it just that the children of the rich, who have been used to a generous mode of life, should be reduced at once, on the death of their parents, to the condition of the poor. But we cannot go beyond this point without encountering a widespread opinion that the right of property is extended too far, when a very great quantity is transferred at the death of its owner to persons who have had no part in producing it. This is indicated by the favor with which the taxes known as death duties, or transfer, or succession, or inheritance taxes, are coming to be regarded. These taxes are intended to fall heaviest on large estates, and on those who are presumed to have had least claim to be supported by the decedent. Whether these taxes actually fall where they are intended or not, we cannot doubt that their purpose is called just by a large portion of the community. As no satisfactory method of diminishing great fortunes during the lives of their possessors has been discovered, the inequality, it seems to be thought, is somehow corrected by preventing them from transmitting these fortunes to those whom they wish to enjoy them after their death.

In a society which may be said to be founded on barter, where the energies of the citizens are intensely devoted to 
bargaining, and where nearly all public servants demand pecuniary compensation for their services, it is inevitable that the view of justice proper to a contractual regime should prevail. Where nothing is done except for a consideration, the value of the consideration will be closely scrutinized; and whoever possesses much of value for which he appears to have given no consideration, will find many to question the validity of his title. Some exception is made in favor of children and a few other beneficiaries; "natural love and affection" is admitted by the law as a consideration for a grant. But these exceptions seem to be made only when small estates are concerned. The great inequalities of wealth cannot be satisfactorily explained as due to corresponding differences of desert; and not infrequently wealth and desert seem to vary inversely. As to how much wealth any individual may justly own, no reasoned convictions appear to prevail. Millionaires would perhaps agree that no one could justly possess a hundred millions, while poorer people may question the justice of the millionaire's title. Perhaps the line would be drawn a little above the amount of wealth sufficient to maintain a family of average size in comfort, measured by the standard of the lower middle class. No doubt greater possessions would often be recognized as due to greater desert; but this would be less and less true as estates increased in magnitude.

Indeed, when we consider all that is implied in the theory of political equality on which our government is founded, it seems unreasonable to expect the "average man" to be sincerely convinced that the possession of great wealth implies corresponding desert, or excellence. Some superiority in capacity, and even in virtue, may 
be conceded; but the good opinion which every man naturally has of his own deserts and abilities forbids him to admit that his neighbor is a thousand, or a million, times more meritorious than himself. Humility and self-depreciation are not so common as to make it conceivable that extreme inequalities of wealth can ever be harmonized with the theories of justice that predominate in a democracy. As Aristotle bluntly says, those who have the political power will have their own views of what is just; and, however erroneous these views may seem to disbelievers in political equality, they must be accepted as necessarily influencing the institutions of a society founded on this theory. It is true that the lack of desert on the part of the rich does not logically imply its existence among the poor; the desert of many of them is a negative quantity. When we come to the problem of distribution, it is not easy to maintain that all the poor, without regard to merit, are to share in the wealth which the government is to take from the rich. Indeed, on the theory that wealth must be earned by service, men in general have no valid title to the vast accumulations left by past generations; we are obliged to regard their inheritance of all the ages as the gift of nature. Nor if unearned wealth is believed to corrupt the morals of the rich, as is sometimes asserted, is it apparent why it should not have the same effect on the morals of other classes. Notwithstanding these considerations, it does not seem to admit of question that most men think that a more equal distribution than now prevails would better accord with justice, even if certain members of the community obtain, in the process, more than they deserve.

Before the application of these principles is considered, it may be well to restate briefly the conclusions reached 
in the last two chapters. We have found that the analogy drawn by Adam Smith between the members of a body politic and the tenants of a great estate is fallacious, because these members have entered into no such agreement as that made by tenants with their landlord. Even if such an agreement were implied, it could bind only one generation; and no one contends that human institutions are not properly subject to alteration. At present the distribution of wealth is admitted to be very unequal; and this is thought to deprive some men of a reasonable opportunity to acquire wealth. For the theory of political equality seems to imply that men ought to be able to acquire equal quantities of wealth. The claim is made that such equality is unattainable if property is recognized; but the evidence fails to support this claim, and the preservation of property under the regime of universal suffrage indicates that it is a permanent institution. But this does not signify that property may not be modified, and if we examine the arguments advanced in its support we find that many limitations have been recognized. Nothing is gained by calling it a natural right; but it may be called sacred in the sense that men's possessions cannot justly be taken for public use without compensation. Even in the case of property in human beings this principle has been recognized, nor is it really affected if we admit the right of revolution. It seems to rest on two principles: that men may justly own the product of their labor, and that it is just to compel them to keep their contracts. In a sense, occupation may be regarded as labor; but strictly it seems to give title only to what is needed for subsistence. To so much wealth it gives an indisputable right; to more than this it gives no such title, at least while there are 
men who cannot support themselves because others have appropriated more than they need. But as man is a bartering animal, civilization being impossible without freedom of transfer, title by exchange and by prescription must be recognized; and as the condition of the poor is always miserable where any uncertainty exists, justice is better attained by such recognition. For similar reasons, men must be held to their promises by force of law; and, on the other hand, rulers are restrained from making laws that impair promises. Yet the promises of rulers, as they may affect posterity, are less binding than those of private individuals; and, especially when made to corporations, are accepted as subject to rather extensive modification and revision, although not to actual repudiation.

No little ingenuity has been expended in the endeavor to show that property in land, or its rent, is of a different nature from other property. This claim is based on the view that land has a value due to scarcity, and that landlords may deprive the rest of the people of the earth even of standing room. Hence it has been proposed that whatever value land may have because of its scarcity should be confiscated, the rents being applied to public uses. But no practical scheme for distributing this value among all the inhabitants of the earth has been suggested, and justice would not be satisfied by making such distribution among the dwellers in places where land has exceptional value. In fact it would be altogether impossible to ascertain the persons to whom particular lands may owe their increased value, as appears when we consider the effect of the construction of highways, etc. But the fundamental objection to the claim is that in so far as value is due to scarcity, there may be an "unearned increment" of value 
in nearly every thing that is the subject of property. It is matter, rather than land, that may be scarce, and advances in the value of personal property are perhaps more extreme than those in the value of real estate. On the other hand, there seems to be little support for the claim that the expenditure of labor on matter creates an absolute and indefinitely transmissible title, for eventually this title may be vested in persons who have done nothing whatever to earn it.

Justice, however, appears to demand that some consideration of benefit to society should support property; and the concept of desert is in modern times of increasing importance. Yet it seems vain to try to measure desert, or to lay down any rule of proportion between desert and wealth. Were competition free, it might be supposed that men's wealth would measure the value of their services; but the hindrances to free competition are innumerable, and perhaps in the nature of things insuperable. Nor is it clear that the existence of great wealth in the possession of one man decreases the wealth, actual or potential, in the possession of others; and in some cases it is clear that it does not. But, if wealth is a source of happiness, it cannot be denied that the aggregate of happiness would be greater when many persons were wealthy than it would be if ownership were more concentrated. These conclusions are subject to some modification when we consider that the possessor of wealth is presumptively a father of a family and responsible for its support. But these modifications relate chiefly to estates of limited size, and do not materially alter the prevailing opinion concerning very great fortunes. Hence there is a manifest disposition to question the right to obtain much more than is 
sufficient for comfortable existence by gift or bequest; for such property seems to be peculiarly "unearned." And this tendency is likely to be marked in a society where nearly every one may be said to be engaged in trade, and where a consideration is looked for in every transaction. When the government of such a society is based on universal suffrage, it is not to be expected that the mass of mankind, even if not controlled by envy, will consider that great wealth implies corresponding desert, or will not think it just to attempt to diminish the inequalities of fortune.

Admitting the prevalent assumption that a few men possess much more wealth than they have earned, and that the great majority possess much less than they have earned, it follows that, in such a society as ours, at least, the principle of the proportionate method of taxation does not commend itself as fundamentally just. Were our government to succeed in compelling its subjects to contribute to its expense in proportion to the revenues that they respectively enjoy under its protection, the chief ground of complaint would still remain. If the revenues of individuals are to be considered in levying taxes, it seems clear that the progressive, rather than the proportionate method is ideally just. The ratio of contribution should increase geometrically, not arithmetically; every increment of wealth beyond a certain quantity being regarded as earned, in part at least, by the members of the society collectively, and not wholly by the individual in whom the legal title to it is vested. No doubt, as we have seen, the qualification of desert is to some extent ignored in the process of distribution; all the poor, irrespective of merit, are to be relieved of a part of their burden. But the rain falls on the just and on the unjust, and in prac- 
tice the injustice of benefiting the worthless is disregarded, if it is unavoidable when we would reward the deserving.

It is obvious, however, that we beg the question if we assume that an ideal distribution of wealth can be produced by means of taxes. We cannot even assume that greater equality of fortunes can be so produced. Such attempts may but aggravate the evil which they are meant to cure, and create more inequality than they remove. Before we adopt any conclusion on such a subject, we must inquire what is to be learned from experience. Now it is evident that, for the strict application of either of the first two methods, it is indispensable that the government should ascertain the amount of the wealth, or of the revenue, of every subject. Without this information it is plainly impossible to graduate taxation either proportionally or progressively. If it cannot be obtained for the one purpose, it cannot for the other; and unless it is obtained, we cannot say that justice is promoted by either method. Of the progressive method we have had, in this country, but little experience, while the proportionate method has been employed, nominally at least, in all our states. We may therefore proceed to inquire how far its application has in practice resulted in the attainment of its ideal; and, in so far as it has failed, how far, from the same causes, the progressive method must also fail. 


\section{CHAPTER IV}

\section{PRACTICAL APPLICATIONS OF THE PROPORTIONATE METHOD}

WERE it generally admitted that wealth consists only in material things, and were ownership limited to things within the jurisdiction of the government to which the owners are subject, it might be practicable to apply the proportionate method without inquiry into the circumstances of individuals. For all wealth being taxed at a certain ratio, every individual owner would presumptively contribute his proportionate share. The immense number of rights of property which, although invisible and intangible, are commonly regarded as wealth, and the extension of these rights into remote jurisdictions, make this simple solution unavailable. In the alternative, the amount of the possessions of every individual must be ascertained. Whether he is to be taxed according to a simple or a progressive ratio, the total quantity of his property must be known to the tax-gatherer before the ratio can be applied in practice. Without this knowledge the ratio would be altogether indeterminate, and its application could be just only by chance.

Various methods of obtaining this necessary information have been resorted to by rulers, but they can all be arranged in two classes. Inspection or examination by others than the owners of the property to be assessed is one method; disclosure, or confession, by the owners is the other. The methods may be combined, and both are in 
common use. A modification of the method of inspection appears in the practice of inferring that the possessor of certain property is the possessor of other kinds, and especially that he who indulges in what are deemed luxuries must have an income corresponding with this expenditure. Such inferences may conceivably be valid and useful; but we shall find that as ordinarily drawn they are too conjectural to be regarded as meeting the requirements of justice.

In a community where agriculture is the chief industry, where the habits of life are simple, the quantity of wealth small, and commerce insignificant, it is conceivable that the assessors of taxes may form by inspection approximately correct judgments of the value of the property of every citizen. Such wealth as exists is nearly all visible, it is situated within the geographical limits of the community, and it is not subject to frequent changes of ownership. These having been in earlier times the conditions prevailing in the states of this Union, the measure known as the general property tax was universally adopted. By this measure every person is assessed annually at the place of his residence for all real estate owned by him in that place, and usually for all, or almost all, personal property owned by him, wherever it may be. Real estate owned by nonresidents is taxed where it is situated. Under this system it is obvious that, so far as regards real estate, while the several assessors may be ignorant of the amount owned by any person, he would yet be taxed on the whole of his possessions. So far as real estate is concerned, therefore, the general property tax would conform to the proportionate method of taxation; but unless the knowledge obtained by the assessors of the several communities 
were communicated to the whole body, the progressive method could not be applied.

For reasons which will presently be explained, it has in many states been thought necessary to supplement the method of inspection by the method of disclosure, or selfassessment. In these states, owners of property are directed by statute to report to the assessors all their possessions, with their value, and to swear that their reports are true. In some states such reports are required only when the taxpayer objects to the valuation put on his property by the assessor, but in other states every one is commanded to make them, under penalties of varying degrees of severity. As this requirement of a sworn return was very early introduced, it is probable that the method of inspection was even then found insufficient.

But whether the method was satisfactory or not in a primitive state of society, it long since ceased to be available, as to personal property, in most parts of this country. The population of the cities has enormously increased, manufactures have everywhere sprung up, commerce has advanced with prodigious strides, and all industrial transactions have been wonderfully quickened. Property has taken on many new forms, and is little affected by spatial limitations. The fact that a rich man resides in a particular town and a particular state establishes but a slight presumption that much of the property from which he derives an income is situated in that town or in that state. He may own land in every state in the union, and he may be a creditor of the British Government, or the empire of Japan. Under such conditions the method of inspection does not produce an equal distribution of the burden of taxation. Such persons as have property only at the 
place of their residence are practically, as a rule, assessed at a higher rate than those whose property is situated elsewhere. The assessors may be able to discover the existence of the property belonging to the former class, but to discover that of the latter is in most cases quite beyond their power.

The essential differences between real and personal property, and between visible personalty and choses in action, or invisible and intangible rights, have become much more conspicuous as the modern economic system has developed; but some of them have been always observable. In the first place, land is visible and immovable. The tax-gatherer and every other person can see it, and the owner cannot remove it, or hide it. Certain kinds of personal property are visible; but they can be removed and concealed. Title to such property passes by delivery, and nowadays with great frequency. The same things may be owned by several persons on the same day, and by a hundred persons in the same year. Into the daily consumption of an inhabitant of any city there enter materials drawn from every part of this country and from every quarter of the earth. The bread that he buys of the baker is made from flour that the baker bought from the jobber, and the jobber from the wholesale dealer or the miller. The miller ground it from wheat that may have been bought and sold many times after it was harvested, or even before it was taken from the field. Within a few months the same particles of matter have been owned for a brief period by many different persons residing in many different jurisdictions, some of whom may have never seen, or been within a thousand miles of, their property. Bread, however, is very simple in its composition compared with 
clothing and many other things in common consumption, the materials of which may have been within a twelvemonth the property of an incalculable number of persons.

As it is evidently impossible for the assessors to discover all these titles by inspection, personal property of this kind is taxed under the general law, like real estate, only once a year. Real estate, however, is comparatively seldom transferred, and when a sale takes place the rents and taxes can be apportioned. The value of the building in which a merchant carries on his trade, and that of the land on which it stands, can be ascertained by the assessor, and by every one else, without very great difficulty. That value is nearly the same on every day of the year, and varies slowly, as a rule, from year to year. But the value of the stock of goods which the merchant has on hand cannot be easily ascertained. He can seldom determine it precisely himself, although no one else can determine it near so well. It is not the same on any two days, nor in any two months; and it may be very different on the day when the assessor makes his inspection from what it is on any other day of the year. Nevertheless the merchant is usually taxable for its value on that day, while the thousand persons who have owned it within a year are exempt. It may be presumed that these persons are taxed as owners of some equivalent for the property which they have sold, but the presumption is very slight. Such equivalent, even if at the time open to inspection, may have since altogether disappeared.

For much personal property, although tangible, is evanescent. It comes into being, undergoes many transformations, and is consumed within a year. The wheat grown from the seed sown in the spring may be eaten before 
winter, and if the date of assessment falls in the winter, it will not be taxed either as wheat or flour or bread. The same is true in various degrees of the other cereals, of fruits and flowers, of fuel, and of everything which is used up in satisfying human wants and purposes. The milk of a cow during a year may amount to 3,000 quarts, and be worth $\$ 200$; but neither the dairyman, the milkdealer, nor the consumer, all of whom have owned the milk, may be taxed for his ownership therein. As the general property tax is commonly assessed, only the most bulky and durable objects are actually subjected to inspection; and objects of the greatest value, such as jewels, although durable and intended especially for display, do not fall within the assessor's range of vision.

The difficulty of the assessors' task is very greatly increased by the division of our country into states that are, so far as taxation is concerned, mutually independent. The dates fixed for the valuation of property vary in the different jurisdictions, so that a carload of wheat might be moved through four or five states and escape taxation in every one of them; or, if its movements were properly timed, it might be taxed in all of them. The farmer who produced the wheat may have exchanged it for a carload of fertilizer, which might experience the same vicissitudes. According to the judgment displayed in managing such transfers - and the case supposed is by no means merely hypothetical - the value of the goods may be very considerably reduced or enhanced. We accordingly observe great activity in the movement of merchandise out of a state as the date of assessment approaches, while imports appear to be stimulated so soon as this date is passed. It is obvious that the owners of this merchandise do not 
intend to be taxed on what they have received, or are to receive, from its sale. Were they to be so taxed, the motive for hurrying the export would not exist, and the presumption is that neither the goods exported, nor those for which they are exchanged, are subjected to taxation. Similar activity in the transfer of money and deposits in banks takes place as the date of assessment approaches; capital being actually removed from the state, or employed in the purchase of securities exempt from taxation. Riches often have wings, and at the stroke of a pen may be made to fly to the uttermost parts of the earth.

But if the assessment of tangible personal property is difficult and incomplete, that of intangible property is frequently altogether impossible. Such property cannot be perceived by the senses, and the knowledge of its existence may be confined to very few persons. In certain cases its existence is made apparent by public records, but most claims and credits are known only to the parties concerned. A minute and inquisitorial examination may sometimes enable the assessor to assign a correct value to the goods of a merchant; but no inspection within his power will inform him of the extent of the claims which the merchant has on the property of others, or of those which others have on his property. Some paper evidences of obligations may be discovered, to which there are no offsets, but such discoveries are not likely to be very extensive unless the owner of the claims lends his aid; and the number of small claims evidenced by no written obligation is in the aggregate enormous.

The modern practice of carrying on business with borrowed capital, commonly spoken of as the credit system, has made personal property rights far more intricate than 
they were originally, and has correspondingly increased the difficulty of assessing them for taxation. The function of credit is, to the eyes of the ordinary observer, completely disguised by the employment of money; but it is demonstrable that in most of the operations of production and exchange, what is borrowed is, in the last analysis, something material. This tangible capital, however, is the basis of a number of credits. The person who owns it lends it to another; or, what is the same thing, gives him an order that will insure him its possession. But this order may be transferred by the first borrower, or he may pledge it as security for another loan from a different lender, and the process may be indefinitely extended. The tangible capital, meanwhile, may never leave the possession of the original owner, and he may be repaid eventually by the confirmation of his possession. But so long as his order is outstanding, his property in this capital is only nominal; the right to it is elsewhere, perhaps in many unknown hands and evidenced by many instruments of credit. On the other hand, the lender may deliver the capital when the loan is originally made, and never demand its return. He may be satisfied with the promise of the borrower, and this promise he may lend, or on its security he may borrow.

The nature of this complicated process may be illustrated by an example. A merchant may borrow a thousand dollars from a bank, pledging the bond of some corporation for the same amount as security. The bank thus acquires a right of property either in the other possessions of the borrower, or in the bond, or in both. The borrower acquires a right of property in the possessions of the bank, as he does not remove the thousand dollars from its cus- 


\section{THE PROPORTIONATE METHOD}

tody, but accepts an order for them in the shape of a credit in his account. There has been no addition to the tangible wealth of the community; but, in the eye of the law, personal property has increased by the sum of a thousand, or two thousand dollars, and in many states such property is taxable. Nor does the transaction, so far, increase the wealth either of the bank or the customer, since it amounts merely to balancing one claim against another, the interest on the bond being assumed to equal the interest on the loan. But the bond is evidence of a property right, and is taxable, and so are the thousand dollars in the possession of the bank. This thousand dollars may itself be nothing but the paper promise of the government to pay that sum, secured by the wealth of the whole people, on which they are taxed; and the bond may be secured by the pledge of the stock of another corporation. This also is in many cases taxable personal property, while the tangible possessions of the corporation are also taxed. Thus, on the basis of material wealth having a value of a thousand dollars, there have been created personal property rights having ten times that value in the view of the law, which accordingly subjects them to taxation.

The fact that such rights are extensively created no doubt proves that some economic gain results from their creation. But it also proves that the law is not enforced, for no conceivable gain from such transactions would come near to make up for the loss from taxation, were the tax actually paid. In the ordinary course of business, no one borrows who does not expect to make a profit by doing so, after paying interest on the loan; but the current rate of profit is far from sufficient to pay the rate of taxation 
nominally current on personal property. Since the tangible property which is the basis of numberless credits is taxed at this rate, it seems impossible to tax all the credits at the same rate; and whether possible or not in theory, it is evident that in practice most of these credits must escape the observation of the assessor.

That these conclusions are correct seems to be demonstrated by the records of the financial markets. A very large part of personal property of the intangible kind consists of claims evidenced by bonds for the payment of money, and many of these bonds are openly bought and sold on the exchanges, their prices being regularly quoted. Some of these bonds, as those of the United States, are, by the terms of the law authorizing their issue, exempt from taxation everywhere in this country; many others are exempt within more or less limited jurisdictions. Owing to certain provisions in the currency laws, government bonds have for banks a quite exceptional value, the extent of which, however, is so difficult to determine precisely as to make it unsafe to use the price of these bonds in drawing our inferences. Other non-taxable bonds, however, sell at prices not much higher than those of taxable bonds of approximately equal security. The income derived from a first rate bond, if the ordinary tax on it were paid by its owner, would often be no more than half that derived from an untaxed bond; but the market values of such bonds may not differ more than a fraction of one per cent. No doubt many bonds are held by institutions, such as savings banks, not liable to taxation upon them; but the quantity in the possession of individuals is enormous. The quantity, however, found by the assessors to be in such possession is very trifling. Men who hold 
such securities in trust are aften subjected to taxation. Men who hold them as their own property evidently, as a rule, have no intention of paying taxes on them. They are sometimes compelled to do so, in spite of their intentions; but the prices which these securities steadily command show that such payments are exceptional.

While it is evident that inspection fails to discover the ownership of much personal property of this description, it is impossible to ascertain the extent of the failure. Even if it were practicable to learn the rate of taxation in every taxing district, it would be of little service, because the assessed value of property has no determinable relation to its market value. By comparing a number of places, we may perhaps obtain an average rate, but we can only conjecture it to be generally prevalent. In some places the rate of taxation is much less than one per cent; in others it is three or four times as much. It is probable that where the rate of taxation is very low, a greater proportion of bonds is taxed than where it is high; but we know that rich men generally reside in cities where a low rate of taxation seldom prevails. Bonds issued by well-known corporations are frequently scattered through all the states, and large numbers of them are owned in foreign countries. The value of bonds so owned would not be much affected by the fact that they were free from taxation in the state where they were issued.

In many communities assessors make no attempt to discover the owners of this kind of property, and if a bond is practically untaxed, its value would be little increased were it exempt by law. It might seem that some definite conclusion on this point could be reached by ascertaining the amount of bonds actually extant, and com- 
paring it with the amount of personal property of this kind returned by the assessors throughout the country. Were it possible to obtain trustworthy figures, which it is not, such an investigation would be inconceivably laborious, and it would be vitiated by our inability to discover the extent of foreign ownership. It would be futile, also, because of the great quantity of bonds held by numberless institutions exempt from taxation, for whom non-taxable bonds have, of course, no peculiar value.

We have so far referred chiefly to bonds made payable to bearer and transferable by delivery. These bonds are issued almost exclusively by corporations, they usually have many years to run, and they are practically the only bonds dealt in on the exchanges. But the value of bonds made chiefly by individuals, for relatively short periods, and payable to specified persons, is collectively enormous. As these bonds are almost invariably secured by mortgages of real estate, they are, under our system of making title to land depend on record, necessarily registered. It follows that when a mortgage is made to any one residing within the registration district, the assessors may be able to discover the owner of the bond by a mere inspection of the record. But when the mortgage is made to a nonresident, and especially when the mortgagee resides in another state, it seldom happens that the assessors where he resides discover this record, nor are they often able to carry on investigations outside of their jurisdiction on the chance of occasionally making such a discovery. The method of inspection leads to great inequalities in the assessment of all kinds of intangible property, but in the case of mortgage bonds of this description the injustice is peculiarly aggravated. It is probable that persons residing 
where real estate is situated will be better able than nonresidents to judge of its value, and will therefore be more willing to lend on its security. But this method of taxation discriminates against such loans, and thus compels borrowers to seek accommodation in other places. On the other hand, residents are under a strong inducement to invest their capital elsewhere; an inducement to which they yield to a notorious extent, although with frequently disastrous results, as many residents of the Eastern states can testify.

This inequality is still further aggravated by the fact that property held in trust for helpless and incompetent persons is usually required by law to be invested within particular jurisdictions, and is thus more open to the inspection of the assessors. The accounts of executors and trustees are to a considerable extent matters of record, and as the property which they administer is frequently directed by testators, and practically also by the laws regulating trusts, to be invested in bonds made by individuals, all their transactions may be examined. When estates are settled, it is often necessary for executors to take bonds secured by real estate situated where they reside, and such bonds can seldom escape taxation. As they are assessed at their face value, while real estate is generally assessed at much less than its market value, the rate of taxation frequently amounts to one half of the rate of interest which the bond bears, and sometimes to the whole of it. Cases of extreme hardship to lunatics, infants, and widows can hardly fail to arise under such circumstances, and they are in fact of frequent occurrence. It must be admitted, therefore, that the general property tax, so far as it depends on the inspection of assessors, is assessed with the 
greatest inequality, and falls with exceptional severity on those who are least able to bear it.

Such inequality has naturally attracted much attention, and its effects have been repeatedly investigated. The amount of evidence thus accumulated is enormous, and it would be quite impracticable even to enumerate the reports that have been made. As the conditions disclosed are very much the same in the different states, we may take for illustration the results presented by a special commission appointed by the General Assembly of Connecticut. Although this report was made in 1887, later inquiries in Connecticut and elsewhere have shown that the same conditions still exist. So long ago as in 1844 a legislative committee reported that more than one third of the personal property owned in the state paid no taxes. This opinion was based in part on comparisons made between the inventories of the estates of decedents returned to the Probate Courts, and the tax-lists of the same persons for the year preceding their decease. Adopting the same method, the later commission selected six Probate Districts, each in a different county, and subjected some five hundred estates to careful scrutiny. In one of these districts the amount of taxable property inventoried was about $\$ 7,000,000$, while the amount appearing on the tax-lists of the same persons was $\$ 1,581,000$. It would seem that in this district 77 per cent of the taxable property was untaxed; in other districts the percentage ranged from 45 to 80 . A part of the discrepancy, however, is explained as due to the fact that real estate is generally inventoried at a higher valuation than that of the assessors. Making allowance for this, it would seem that at least one half of the personal property passing through the Probate Courts 
had not been taxed while the owner was living. In some other states tax commissioners have estimated that three fourths of all personal property is not taxed.

Further inquiry in Connecticut proved that such personal property as paid taxes at all was chiefly of a tangible nature. Deducting such property, as well as the capital stock of moneyed corporations, all the intangible property in the state was found to be but four per cent of the grand list. There are 167 towns in the state, and in 81 of them not a single bond was assessed for taxation. Meriden is a considerable town; but no bonds were listed there. Waterbury is thought to be a rich city; but its citizens appeared to possess bonds only to the amount of $\$ 750$. Some of the financial officers of the general government are fond of computing the amount of money in circulation in the country. In 1885 this was declared to be about $\$ 23$ per caput, and the share of Connecticut (which, however, must have been far greater than the average) would have been perhaps $\$ 16,000,000$. But, according to the assessors' returns, the money in possession of the people of that state was but $\$ 1,100,000$, and in forty-three towns, some of them not unimportant, there was no money at all. Taking the items of bonds, notes, money at interest, and cash, it appears that while in 1855 they had amounted to $\$ 19,186,000$, and in 1865 to $\$ 20$,521,000 , they had fallen in 1885 to $\$ 13,208,000$. In view of the enormous investments during this period in railroad and other bonds, and in Western mortgage loans, this record is peculiarly impressive.

For it is to be observed that these results took place while the method of disclosure as well as that of inspection was in use. Taxpayers seem to have been always required 
to make out lists of all their property, and since 1850 have been obliged to swear to the truth of these lists. In addition to the penalty of perjury, forfeiture of goods has been resorted to $;^{1}$ but conviction for perjury of this kind is unheard of, and the forfeitures have been extremely insignificant in amount. The amount of intangible property returned for taxation does not appear to be affected, whether the law makes a false return punishable as perjury or not, nor does the dread of confiscation appear to have any strength as a motive. Making due allowance for intangible property disclosed by the accounts of trustees, it seems hardly too much to say that very few owners of such property in Connecticut are not guilty of false swearing in making out their lists. Such matters are too delicate to be discussed in public, but in private conversation the resort to such practices, while it may be deplored, is regarded as a necessary mitigation of the inequality created by the law.

1 Early in the eighteenth century the law declared that the rateable value of unlisted property should be confiscated, half of it going to the inspectors, half to the colony. This method was soon abandoned, and a fourfold rate of taxation imposed on omitted property, half of which valuation went to the assessors. This was the law for over a century, but the additions made were so inconsiderable as to average less than $\$ 30,000$ in the whole state. In 1821 this valuation was made threefold instead of fourfold, the assessors getting no part of it; but this penalty proved entirely ineffectual, and was abolished in 1851 . In 1865 a penalty of ten per cent for not returning a list was imposed, and in 1882 this was made progressive, ten per cent being added every year; but in 1885 the progressive feature was repealed.

In 1890, a law was passed for a special purpose, and without any idea of reforming the practice of taxing personalty. But the terms of the law were general, and authorized any person to report to the State Treasurer any bonds, notes, or other choses in action in his possession, and to pay a tax on them at the rate of one-fifth of one per cent a year in place of other taxes. To the surprise of the legislature, many millions of concealed securities were presently disclosed, the owners presumptively calculating that it was not worth while to commit perjury to save two 


\section{THE PROPORTIONATE METHOD}

Another conclusion, of much practical importance, is to be derived from these facts. It is that while men will, as a rule, in the sworn returns which they make to the assessor, declare the value of their own property to be less than it is, they seldom make such false statements concerning the property which they hold in trust for others. This is partly because they have not the same inducement of personal gain; for they have little direct profit in relieving the property of their wards from taxation. But it is chiefly due to the fact that trustees are compelled for their own protection, as well as formally required by law, to keep accurate accounts of their proceedings. These accounts are not only subject to the inspection of the persons interested, but must also, in many cases, be recorded in local offices, or returned to state departments. As private trustees are seldom allowed to employ the funds committed to their charge in active business, their accounts are comparatively simple, and state the value of the funds clearly, or so that it can be easily ascertained. For most trustees, therefore, the objections to making false returns are very serious, and, as appears from the records in Connecticut above referred to, they cause executors to disclose the existence of much concealed property. The method of disclosure is thus available in the case of those whose property is not in their own name, chiefly because it can be supplemented by the method of inspection.

mills of interest. The value of securities so registered has ranged from $\$ 20,000,000$ to $\$ 40,000,000$ a year. In 1897 the legislature, reasoning that twice the revenue might thus be obtained, doubled the tax; but, as this calculation proved incorrect, it is probable that many persons thought it better to conceal their property than to pay a tax of two-fifths of one per cent upon it. A similar law in Maryland has had equally remarkable results in causing concealed property to be added to the lists. 
Attempts have been made in some states, as in Massachusetts, to enable the assessors in certain taxing districts to obtain the information available to assessors elsewhere. Thus when a taxpayer removes from one community to another, a list of his possessions may be transmitted to his new residence. State assessors may also compare the reports of the local assessors and other records for the purpose of enforcing correct returns. Lists of stockholders in various corporations may also be examined by state assessors, so that the owners of stock may be reported to local assessors for taxation. But as there is no way of inspecting claims and rights to property without the limits of the state, these attempts cannot bring about any equality of taxation. Owners of claims enforceable within the state may be more frequently taxed, but this would tend rather to aggravate than to remove the inequality. The inducement would be all the stronger for those who have money to lend, to lend it without the state, and borrowers would find it all the more difficult to obtain accommodation at home, where it would normally be provided. It may sometimes happen that nonresident lenders send their money into a state to be loaned, for the same reason that resident lenders send their money out of it, and that the two movements are of equal volume. In such event the loss to individual borrowers might be comparatively trifling, although the aggregate expense of this circuitous method of extending credit would be considerable. But there are differences between neighboring states, both in their tax laws and in the ways in which they are applied, which renders it impossible to do more than conjecture as to the extent of such movements. It admits of no question, however, that all attempts to apply the general tax to intangible 
property by the method of inspection necessarily result in such a distribution of burdens as is unequal in the extreme.

The fact that much intangible property escapes the observation of the assessors has induced the legislators in some states to resort to the odious practice of employing spies and informers, who are rewarded from the taxes on the property which they add to the assessment lists. This practice was in former ages generally adopted by despotic rulers, who empowered such persons as contracted to collect the revenues to use whatever methods they found most efficacious. These persons agreed to pay specified sums to the rulers, and compensated themselves with the additional amounts which they extracted from the subjects. Under this system extortion flourished, and the distress which it caused to the common people was one of the chief causes of the French Revolution. We read that Voltaire, being in a company where it was proposed that every one should tell the most horrible story of human oppression that he knew, when his turn came, merely said: "There was once a farmer general of the revenue." The government of the United States, not many years ago, authorized the payment to informers of a moiety of the customs duties recovered through their labors, but the practice was attended with such scandalous corruption that it had to be modified to some extent. Spies are still employed by that government to aid in the collection of these duties, but they are attached to the revenue service, and are partly, at least, compensated with regular wages.

It might seem that such practices had been sufficiently condemned by experience, but they have been revived in recent years by several of our legislatures. It has long been the law, in the State of Ohio, that taxpayers should 
make out lists of their personal property and verify them by oath, their assessments being increased one half in case of their failure to comply with the statute. The assessments of personal property under this statute being as unsatisfactory as the experience of other states indicated that they would be, about 1880 the practice of employing in. formers began to be authorized by the legislature, and in 1888 the officers of every county were empowered to contract with such persons, their compensation not to exceed one fifth, or in some cases one fourth, of the sums recovered through their activities. The county auditor was also to receive a commission of five per cent on these collections. These statutes are said to have been enacted through the influence of certain persons who at once made contracts with the authorities in many counties, and proceeded to organize a bureau of detectives for the purpose of systematic investigation within and without the state.

The results of this enterprise, while no doubt highly satisfactory to the "tax inquisitors," as they are called, seem not to have been especially advantageous to the state. The assessed valuation of personal property in Ohio was over $\$ 535,000,000$ in 1875 . In 1879 it had fallen to $\$ 443$,000,000 , and in 1882 it rose again to $\$ 542,000,000$. In 1888 , when the system of farming the taxes was authorized, the valuation was $\$ 532,000,000$, and it continued to rise until 1893 , when it was $\$ 568,000,000$, falling in 1897 to $\$ 511,000,000$. There can be no question, however, that personal property had increased during this period at a very much greater rate than these figures indicate. It is not certain that the activity of the inquisitors did not cause as much property to be removed from the state as it added to the lists, but it is certain that the expense of collecting 
the taxes increased far more than in proportion to the increased assessment. It might be expected that the assessment of intangible property would show a marked increase, such property being least apt to be listed. In fact such assessments have decreased. The assessed value of credits fell between 1888 and 1896 from $\$ 111,900,000$ to $\$ 102$, 800,000 ; that of bonds and stocks from $\$ 7,400,000$ to $\$ 7,300,000$; while money and deposits alone showed an increase, the figures being $\$ 33,800,000$ in 1888 , and $\$ 34$,700,000 in 1896. In Cincinnati, where the inquisitorial system was first adopted, the valuation of personal property fell between 1888 and 1897 from $\$ 51,500,000$ to $\$ 44,900,000$. In Cleveland, a rapidly growing city, this valuation increased materially, but at a less rate than in the years preceding the employment of the inquisitors.

Moreover, the assessed value of bonds and stocks more than thirty years before 1898 had been over $\$ 12,000,000$. In 1851 the value of money and credits in Hamilton County, (Cincinnati), was about $\$ 3,293,000$; in 1903 it was $\$ 3,153,350$. In 1866 the value of intangible property in this county was about $\$ 17,460,000$; in 1896 it was $\$ 5,389,350$. During that period the amount of money fell from $\$ 6,778,883$ to $\$ 1,097,283$, the population meanwhile having more than doubled. In 1903 the deposits in banks and trust companies appear to have amounted to about $\$ 400,000,000$, of which about $\$ 55,000,000$ was returned for taxation. Of the $\$ 70,000,000$ on deposit in 1896 with the banks of Cleveland, $\$ 1,741,129$ was returned for taxation. The claim that the terror of the law has caused many persons to make returns that they would otherwise have omitted seems to be without support. Whatever gain may be derived from this source is probably 
much more than offset by the removal from the state of residents owning large amounts of intangible property; nor may we disregard the possibility that immunity may be purchased of men who are willing to exercise the office of inquisitor; although in ten years they deducted, from some $\$ 1,600,000$ which they collected in two counties, over $\$ 460,000$ as their legal compensation. As the auditors of these counties deducted also four per cent, the government received about $\$ 1,135,000$ of the $\$ 1,600,000$ exacted from the taxpayers.

Neither the statute of 1885 , nor that of 1888 , provides any safeguard against corrupt dealing by the tax-gatherers; indeed the statute of 1885 did not limit the compensation of the inquisitors. It is not necessary to advertise for bids, nor to award the contract to the lowest bidder. There is no limit to the time for which these contracts may be made. The County Auditor, who awards them, and who sits as a judge to hear and determine the issues, is directly and largely interested in the amount that he finds due from the taxpayer. In some cases the amount claimed has been $\$ 200,000$ and over; and if the claim was sustained the auditor would receive $\$ 8,000$ or $\$ 10,000$, and the inquisitor $\$ 50,000$. The opportunities for collusion between the auditor, the inquisitor, and the taxpayer are. very great. Many suits have been brought for large amounts, and quietly settled for very small ones. It is asserted that large sums have been collected from taxpayers, no part of which has reached the treasury. While we cannot test the truth of these assertions, it is obvious that there is nothing in the law to prevent such practices, and everything to encourage them.

It is safe to say that no recognized principles of justice 
authorize the employment by government of spies and informers who are rewarded out of the taxes which they aid in collecting. How far it may be justifiable to offer rewards to informers who secure the conviction of those guilty of felonies it is not necessary here to inquire; but the failure to pay a tax is not commonly regarded as an offense of such turpitude as needs to be repressed by the drastic means employed against murderers and highwaymen. The testimony of men who use deceit and treachery in procuring evidence is always open to suspicion, and is especially so when it is for the pecuniary interest of such men to have their testimony received. They may profess to lie for a good end; but experience has justified mankind in placing little credit in such professions. It is intrinsically probable that men who do not scruple to prostitute their honor for gain will not be very particular as to the quarter from which the gain is received, and this presumption has been abundantly justified by experience. Informers are frequently bribed by those who dread their attacks, even when such attacks would fail if resisted; for few men in business can afford to have their integrity put in question by a criminal proceeding. As we have remarked, such shocking scandals arose under the "Moiety Act," which was passed during the excitement of the civil war, as compelled congress to repeal it; and the modified system which now prevails is severely condemned by those familiar with its operation, because of the corrupt dealings which it encourages. So far as any enlightened public opinion exists on the subject, it seems, in civil cases at least, to disapprove judgments obtained through the testimony of witnesses who are paid if their evidence secures verdict. 
It may excite astonishment that methods resulting in such extreme inequality should ever have been resorted to by legislatures, and it is certainly remarkable that they continue to be commonly employed. Yet the proposition that all forms of property should be taxed alike is a plausible one, and when we consider that most of our lawmakers are not very familiar with the operation of economic laws, or perhaps with fiscal science, it may seem less surprising that they endeavor to apply this principle. In order to apply it, as we have seen, it is indispensable to ascertain the total quantity of property owned by every individual, and as this information is generally in the possession of the individual owner, and of no one else, the most obvious course to attain it is to put the question to the owner directly. We accordingly find that this course has been followed from the earliest times and in every part of the earth. From the point of view of the ruler, no citizen ought to refuse to furnish such information; and attempts to evade this duty are properly treated as crimes. In many countries, and even under the Roman Empire, torture has been used to compel the delinquent taxpayers to disclose their hidden property. King John of England, if we may believe Roger de Wendover, induced Jews to reveal the amount of their wealth by pulling out their teeth, and perhaps in some Oriental countries the bastinado is still used for similar purposes. Where such views concerning the administration of justice prevail, the fact that a law is commonly violated is not an argument for its repeal. Such violation constitutes an argument for increasing the severity of punishment, not for yielding to law breakers. It is true that the burdens of those who comply with the law are increased by the failure of others to disclose their 
wealth; but this result is regarded as a consequence not of the law but of the perversity of those who disobey it. ${ }^{1}$

This theory of jurisprudence has been largely discredited by experience. It evidently disregards all distinctions between laws. We commonly speak of good laws and bad laws, and when a law is believed to work injustice it is difficult to persuade men that it ought to be enforced. It may sometimes be advantageously enforced for the very purpose of creating so much indignation as will cause its repeal; but when its repeal is not proposed by the government, or is positively resisted, the subjects may regard it as their duty to disobey. No truth is better established by experience than that most men, when in position to exercise control over others, are irresistibly tempted to use their power arbitrarily. The progress of civilization is due in great measure to the refusal of subjects to obey the unreasonable commands of their rulers. It is the especial pride of the English-speaking peoples that the sturdy spirit of their progenitors established the rights of subjects on a permanent basis, and made clear certain principles of justice which no statutes were to contravene. The mere fact that a ruler commands is not, to an Englishman, a sufficient reason why he should obey. The command must seem to him to accord with constitutional principles of justice, or he may decline to comply with it. No sacrifice may seem to him too great if made in defense of the funda-

1 At a time when distilled spirits were selling in open market for less than the amount for which they were taxable, and the returns from this excise had very greatly fallen, the Commissioner of Internal Revenue, the late David A. Wells, proposed a tax low enough to insure the collection of an abundant return. But a representative of New York, Roscoe Conkling, declared that he was not ready to admit that the nation which had put down a great rebellion at a cost of so much blood and treasure, could not collect a tax of two dollars a gallon on whiskey. 
mental liberties of his people. If he is commanded to abjure his religion, he may choose rather to go into exile or to be burned at the stake. If he is ordered to persecute others, he may prefer to go to prison. If ship-money is levied unjustly, he may, like John Hampden, refuse to pay, at the risk of forfeiting his estate and losing his head. If a law directs him to return a fugitive slave to his master, he may decide to aid the fugitive to escape and defy his rulers to prevent him. Laws are not obeyed because they are ordained by rulers, but because they are thought just by subjects. The law cannot make that a crime in common estimation which nature, as Adam Smith says, never meant to be such; it cannot effectively punish conduct which is not condemned by the moral sense of the community. Our government is supposed to represent its citizens; its laws are supposed to express the will of the whole people. If they conflict with established principles of justice, they should not be enforced, but repealed. The true sanction is not the legislative fiat, but public opinion.

Probably most men do not refuse to disclose the extent of their ownership of invisible property from any deepseated conviction that resistance to laws subversive of morality is a righteous obligation. They may regard the enforcement of such laws as of the nature of persecution; but persecution, as Leslie Stephen observes, has an ambiguous influence. "If it sometimes generates in its victims a heroic hatred of oppression, it sometimes predisposes them to the use of the weapons of intrigue and falsehood, by which the weak evade the tyranny of the strong." No doubt this result commonly follows; we cannot be blind to the fact that great numbers of men, otherwise lawabiding, and in other affairs of unimpeachable integrity, 


\section{THE PROPORTIONATE METHOD}

notoriously evade the law by concealment, deceit, and even false swearing. While parsimony and meanness may explain this in part, we know that many of those persons are liberal in their voluntary contributions to public ends. Inquiry among them shows that they rebel at what they regard as the outrageous inequality of the burdens imposed by the law. They are thoroughly convinced that to tax a debt, when the property on which the debt is a lien is also taxed, is "double taxation." The debt would have no value if the debtor had no property; and if the debtor has property, his ownership is really limited by the rights of his creditors. This conviction is certainly well founded; and, whether well founded or not, it evidently is sincere and ineradicable. Nor is this all. The conviction is equally strong that a very large proportion of those taxable under such laws do, as a matter of fact, evade them, and, in spite of the most severe penalties, will continue to evade them. Whoever pays, therefore, pays not only his own share but that of the delinquents. Obedience to the law is punished, and disobedience rewarded. As a very competent expert in taxation, Sir A. West, puts it, one man's exemption is another man's taxation; and when the grievance of double taxation is added, it seems impossible to deny that the indignation expressed at so great injustice is righteous, even if the method of resisting the injustice is not.

The resort to the method of disclosure, or confession, implies that the assessor is unable otherwise to ascertain the amount of the wealth of the subject. It implies, therefore, that the subject is to act as judge in his own cause, and to assess himself. It implies that if the subject does not choose to communicate his knowledge to the assessor, 
the latter will remain in ignorance. If the subject can conceal his possessions, they are not likely to be discovered; if they were discoverable, the assessor needed not to call on the owner. The latter knows that concealment is commonly practiced, and that if he does not practice it he will pay the taxes of those who do. The requirement of the law appears to most taxpayers as so palpably unjust as to amount to legalizing robbery; and many of them no more hesitate to deceive the assessor than they would hesitate to deceive a highwayman.

It has been the practice in the city of New York to take the names of a large number of persons at random, and assess them arbitrarily. Nearly half of these assessments are erroneous, and are eventually cancelled, the persons assessed appearing before the tax-commissioners, and "swearing off" their taxes. The loss of time thus caused is in the aggregate enormous, and the vexation and annoyance caused by demands for money which is not due are themselves an onerous tax. Many men cannot afford to wait for hours in a cue, in order to prove that an unjust demand has been made upon them; it is cheaper for them to submit to be robbed when the amount involved is not large. Many persons do not understand how to proceed in order to have their assessments corrected; many are ignorant of the details of the laws, and suppose themselves to be taxable for property which is exempt. The government of the City of New York in this manner succeeds in obtaining a considerable sum in taxes to which it has no right whatever. It occupies the position of a petty pilferer, who knows that those whom he plunders will consider that it is cheaper to submit to small depredations than to invoke the law to prevent them. Nevertheless, the ex- 
actions of the government of New York under the general property tax are less severe and less unjust than those of nearly all the states of the union. ${ }^{1}$

When laws professing to tax all property equally result in such extreme inequality, they would seem to be suffciently condemned. In fact, the method of disclosure is repugnant not only to public opinion but also to the spirit of our jurisprudence. Its principle, especially when it requires taxpayers to make returns of their property under oath, conflicts with a fundamental rule of evidence. This rule, proved necessary by very long and painful experience, is expressed in the maxim, Nemo tenetur seipsum prodere, which is embodied in the fifth amendment to the Constitution of the United States. In primitive times, when a person accused or suspected of any offense was brought before a court, he might be compelled to testify. The early jurists apparently reasoned that the accused person must know whether he was guilty or not better than any one else, and it is certainly natural to make the inquiry. Whoever fails to comply with a demand apparently so reasonable, inevitably creates a certain presumption of his guilt. Such refusal naturally arouses indignation, and disposes men to employ strong measures. The most expeditious mode of getting at the truth in such cases seems to be to extort confession. Hence various forms of torture have been used, not only to overcome the reluctance of accused persons to testify, but even to induce witnesses to speak the truth. Practices of this kind still prevail among savages, and they have not quite disap-

1 The evidence on this subject is so voluminous that it is impossible in a work of this character even to summarize it. Many particulars, however, will be found in Appendix A. 
peared from the jurisprudence of the most enlightened nations. The celebrated Dreyfus case called the attention of the world to the powers of French judges in extracting admissions from the accused; and the inferior officers of justice in English-speaking communities frequently yield to the temptation to employ measures which, although illegal, may frighten the guilty into confession. Such practices are constantly resorted to in that crude form of administering justice which we know as Lynch law, and it has been found necessary to prohibit legislatures from applying their principle by constitutional restraints.

The irrationality of such methods in criminal procedure has often been exposed. According to Blackstone, the Civil Law assigned as a reason for using the rack to extort confession from persons accused of crime, that "the law cannot endure that any man should die upon the evidence of a false, or even of a single witness, and therefore contrived this method that innocence should manifest itself by a stout denial, or guilt by a plain confession." The theory of the procedure is more effectively laid bare by Beccaria, who offers the problem: "The force of the muscles and the sensibility of the nerves of an innocent person being given, it is required to find the amount of pain necessary to make him confess himself guilty of a given crime." Most enlightened jurists have concurred in the view that truth is not likely to be attained by compelling witnesses to testify through torture, and Cicero's condemnation of the practice is as emphatic and complete as that of any modern writer. ${ }^{1}$ But while the correctness

1 Tamen illa tormenta gubernat dolor, moderatur natura cujusque tum animi tum corporis, regit quaesitor, flectat libido, corrumpit spes, infirmat metus, ut in tot rerum angustiis nihil veritati loci relinquatur. Cicero, Pro. Sulla, 28. 
of this view is admitted in the case of persons charged with crime, this is not true, at least to the same extent, in other judicial proceedings. No objection, perhaps, exists to compelling disinterested witnesses to testify, but when they are interested pecuniarily in the result, the problem becomes far from simple. On the one hand, justice cannot well be administered if those who have information concerning a matter in dispute refuse to communicate their knowledge. On the other hand, if all persons believed to have such information are threatened with punishment if they refuse to testify, there is danger that the motives which lead them to refuse, will, if overpowered by the dread of punishment, lead them to testify falsely.

The practice of administering oaths in judicial proceedings seems to have been devised to overcome this difficulty. This practice has existed from the earliest times, and was intended to supplement the terrors of human punishment with the dread of the vengeance of the gods. It is probable that in a primitive age the fear of such vengeance may have frequently operated to deter men from false swearing, although historians have preserved for us many picturesque details of the perennial elasticity of the human conscience. But the maxims of the Civil Law prove that present advantage was sometimes found to be a more powerful motive than fear of retribution in a future life. Nullus idoneus testis in re sua intelligitur is the statement in the Digest, and the same rule is laid down in the Code. It is within the memory of living men when the principle of our Common Law, forbidding parties to the record in a civil action to testify, was abrogated; not so much, perhaps, because the theory that parties would testify falsely in their own behalf was thought 
to be erroneous, as because it seemed on the whole easier to get at the truth after hearing the parties give their respective versions of the facts. Certainly, in the opinion of the older judges and writers on the law, witnesses whose interests were affected were not generally restrained from falsehood by their oaths. It has been laid down that willingness to testify in such a case is of itself a ground for distrusting a witness, and that "it can be no injury to truth to remove those from the jury whose testimony may hurt themselves, and can never induce any rational belief." "It is not to be presumed," said Chief Justice Tindal, "that a man who complains without cause, or defends without justice, should have honesty enough to confess it." Interested witnesses, therefore, "the law removes from testimony, to prevent their sliding into perjury."

A distinction obviously exists, however, between the rule which disqualifies a man from being a judge in his own cause, and that which forbids him to be a witness therein. The latter rule was modified because of the extreme inconvenience which it was found to occasion, and not from any conviction on the part of judges that the veracity of mankind had been underestimated. The ability of jurymen to weigh testimony has undoubtedly increased, and it seems on the whole advantageous to allow litigants to give their respective versions of the matter in dispute, and to let the jury accept the account which appears the more probable. The fact that the parties make oath to the truth of their statements has nowadays, in many jurisdictions, no great weight with the court. The employment of compurgators in the wager of law, where each party brought his friends into court to swear that he was telling the truth, may be referred to as proving the importance 
of the oath in securing veracity. But however this may have been in a superstitious age, it will not be contended now by those familiar with litigation, that either parties or witnesses are kept from falsehood by fear of punishment in a future life. Very many persons will not bear false witness; but it is not because they apprehend eternal damnation, or, in many cases, because they stand in awe of the penalty for perjury. On the other hand, it is unquestionably true that many persons will testify falsely when they are satisfied that they cannot be, or will not be, convicted of perjury; and they will often do this to obtain a comparatively insignificant advantage.

The wisdom of compelling parties to testify under oath is more doubtful than that of permitting them to do so. This practice came into vogue under the Civil Law, but the Common Law did not usually, as Blackstone says, reduce the defendant, if in the wrong, to the dilemma of either confession or perjury. ${ }^{1}$ On some accounts it is unfortunate that the practice in Chancery, derived from the Civil Law, has now become general in our courts, parties being compelled to verify their pleadings under oath. As there would ordinarily be no occasion for pleadings unless the parties contradicted each other, one of them must be guilty of swearing to what is untrue. Nothing is so rare, however, as for a person to be prosecuted for perjury of this kind, or indeed of any kind. It is difficult to believe that pleadings would be less veracious

1 It is true, however, that the sentence of peine forte et dure was inflicted on those who refused to plead to certain charges, as we know from the fate of some heroic men who suffered this horrible punishment in order to save their estates for their children; their course preventing the jury from finding a verdict, which was, in some cases, a necessary condition of forfeiture. 
if unverified, and the practice of requiring oaths in all manner of proceedings, and on most trivial occasions, has become an almost meaningless formality. Many of the statutory requirements, indeed, cannot be complied with strictly, and their existence tends, by promoting contempt for judicial oaths, to impair the regard for veracity in other transactions. Beyond question, men do not, in many cases, regard that as seriously wrong which the law regards invariably as a felony. To bear false witness against a neighbor is universally odious, and is perhaps not a very common offense. To testify falsely in behalf of a friend is less severely condemned, and is of comparatively frequent occurrence. To swear to what is untrue in disputes concerning property is evidently regarded as a venial sin, and one to which men are so prone that in some cases the law refuses to listen to witnesses. Thus no one is allowed to establish a claim against the estate of a dead man by swearing to communications had with the decedent, and the Statute of Frauds and Perjuries excludes oral testimony concerning a large class of transactions; although doubt has been felt whether the statute does not cause more perjury than it prevents.

Thus, in spite of the modifications which the Common Law has undergone, it is still reluctant to admit the testimony of interested witnesses, and to compel that of witnesses who are liable to suffer for testifying. One may call his adversary as a witness; but, if he does, he may not contradict him, and the privilege is thus not likely to be abused. And while witnesses, and even parties, are required to give evidence in civil actions, although they may thereby prejudice their pecuniary interests, the law has everywhere adopted the rule in Equity that no one 
shall be compelled to make a disclosure which may expose him to a penalty, or anything in the nature of a forfeiture. This rule has been so often approved by the courts as to make it impracticable even to enumerate authorities. It will be sufficient to refer to one case, decided in the Supreme Court of the United States, where the justice of requiring a person to furnish evidence against himself was directly at issue. ${ }^{1}$ The case arose under a statute requiring a person, charged with failing to pay certain taxes, to produce such of his books and papers as were demanded by the government, or else to have the charges of the prosecution taken as confessed. It was contended, in the defendant's behalf, that this was not only tantamount to compelling him to testify against himself, but was also equivalent to a search and seizure, because it would effect the sole object and purpose of search and seizure; and that it would be an unreasonable search and seizure, within the meaning of the Fourth Amendment of the Constitution.

There is no English precedent for such a law, for even the act under which the obnoxious writs of assistance were issued, in the reign of Charles II, only authorized the search for and seizure of goods on which the government had a lien for taxes. The practice of issuing these writs of assistance to revenue officers was pronounced by James Otis, in 1761, to be "the worst instrument of arbitrary power, the most destructive of English liberty, and the fundamental principles of law, that ever was found in an English law-book." In Lord Camden's celebrated discussion of the right of search, he stated principles which have ever since been recognized in England, and which were built into the foundations of American Government.

2 Boyd vs. United States, 116 U. S. Rep. 621. 
He declared that there was no law justifying an entry on private property for the purpose of inspecting or seizing the owner's papers. He pointed out the difference between such a trespass and the search for stolen goodswhere the owner of the goods is allowed, on his oath of a theft and that his goods are at a certain place, to have a search warrant for that place, on condition that he be present at the execution of the warrant in order to identify his property. As to the "argument of utility," that such a search is a means of detecting offenders by discovering evidence, Lord Camden observed, "It is very certain that the law obligeth no man to accuse himself; because the necessary means of compelling self-accusation, falling upon the innocent as well as the guilty, would be both cruel and unjust; and it would seem that search for evidence is disallowed upon the same principle."

The principles of this judgment, Justice Bradley, pronouncing the opinion of the Supreme Court of the United States, declared to be of the essence of constitutional liberty and security; and he observed that the men who framed and adopted the Fourth and Fifth Amendments relied on the language of Lord Camden as expressing the true nature of the rights of freemen. By the judiciary act of 1789 , the production of papers by parties to an action at law was authorized only in cases where it might have been required by the rules of Chancery. But Chancery never required a party to make any disclosure under oath, or to produce any paper, if the effect would be, or even might be, to tend to prove him guilty of a crime, or to subject him to anything of the nature of a forfeiture of his property. The revenue act of 1874, under which the prosecution took place, while it expressly ex- 
cluded criminal proceedings from its operation, embraced civil suits for penalties and forfeitures. It was not within the literal terms of either the Fourth or the Fifth Amendment, but the Supreme Court held that it violated the spirit of both of them. The fact that the result of the proceeding might be to subject the defendant to fine or imprisonment or forfeiture of goods, made the proceeding criminal in its nature, although it was civil in form. The compulsory production of papers was held to be an unreasonable search and seizure, within the meaning of the Fourth Amendment, and it was also held equivalent to compelling the defendant to be a witness against himself, within the meaning of the Fifth Amendment. The opinion in this case showed also that the purpose of these amendments could not be evaded by making the proceeding for forfeiture in rem instead of in personam. Goods cannot be forfeited without some breach of the law by their owner. As was said by Chief Justice Vaughn: "Goods, as goods, cannot offend, forfeit, unlade, pay duties, or the like, but men whose goods they are." For the same reason, the suggestion that the owner might be cited as a witness in a proceeding to condemn his property was rejected.

Although statutes commanding the owners of property to disclose all that they own to the assessors may not be held unconstitutional, those which provide forfeitures or penalties when property taxable, but previously untaxed, is thus discovered, seem to be clearly so. Even in the former case there is practically a forfeiture, owing to the fact that the burden of those who comply with the statute is increased by the delinquency of those who do not, to say nothing of double taxation. Moreover the considerations which have led to the incorporation of the 
rule in our fundamental law are peculiarly forcible when taxation is involved. In a dispute concerning property, the issue is commonly between two individual claimants. Where it is a question of taxation, the interest of an individual is opposed to that of all the members of the community, represented by the tax-gatherer. A false statement in the former case may cause direct and disastrous loss and suffering to a fellow creature; in the latter case it may be impossible to prove that a false statement will perceptibly lessen the comfort or happiness of any human being. It is obvious that the degree of moral turpitude is much greater in the former case than in the latter. A man who is tempted to testify falsely may be deterred by the reflection that he will rob another of what justly belongs to him; but when the loss is distributed in infinitesimal portions among thousands or millions, this consideration has little weight. It is only necessary, in proof of the existence of this distinction in the ordinary morality, to refer to the attitude of travellers when subjected to the inquisition of the custom house. The number of those who conscientiously endeavor to pay in full the taxes prescribed by law is notoriously small, and the traveller who professes any such intention is apt to be looked upon as a hypocrite. The same insensibility prevails in the relations of the public to property invested in corporations. To obtain transportation on a railroad without paying for it is obviously a wrong to the stockholders; but as they are unconscious of the wrong, any, one who declines to "ride on a pass" on moral grounds is thought quixotic, and many persons do not hesitate to evade paying their fares if they find that they can do so without detection. 
The attitude of our government, in compelling travellers entering the country to make oath to the quantity and value of all their belongings, has been peculiarly unreasonable. If it complied with the ordinary rules of evidence, it would be bound by the testimony of the witness that it called, and would be obliged to accept the valuation that he put on his property. Such a course, however, would undoubtedly illustrate the wisdom of allowing no one to be a judge in his own cause. Few persons who have landed at the port of New York will maintain that their fellow passengers would generally declare to the customs officer the nature and value of their goods, if they were assured that no inspection was to take place; the revenue derived by the government from this source, always insignificant, would perhaps disappear altogether. Instead of observing this rule of evidence, therefore, the government has exercised the prerogative of calling witnesses whose testimony it will accept as conclusive when in its favor, and will repudiate when not; a procedure not much more reasonable than that formerly employed in trials for witchcraft. ${ }^{1}$ If the witness confesses, his testimony is conclusive against himself; if he denies, his testimony is rejected, and other evidence is sought to convict him. If this evidence is sufficient to prove the case of the government, it does not need to compel the witness to testify. If it is insufficient, the witness is in position to decide the case in his own favor, and the presumption is thoroughly established by experience that he will generally so decide.

A remarkable illustration of the light esteem in which

1 In 1907 the government ceased to compel travellers from abroad to make oath to the truth of their declarations. 
oaths have come to be held in these proceedings is afforded by the conduct of many of the assessors of taxes. They are sworn to assess all property at its fair value, but in some states few of them pretend even to attempt to do so. Their disregard of the law is justified, in their opinion and in that of their several districts and communities, by the gross inequalities which prevail under the present system. ${ }^{1}$ In their relations to the state government these districts are like individuals. For purposes of taxation they are obliged to report to the authorities of the state the amount of property owned within their limits, and they are thus interested to have this amount appear as small as possible. The assessors, therefore, are under a strong inducement to undervalue property. To assess it at its full value in one district, while in others it is assessed at much less than that value, is to subject the first district to an unfair burden. The assessors are sensible of this injustice, and they are aware that, if they assist in perpetrating it, they will become odious and not improbably lose their positions. That these considerations are generally more potent than the obligation of an oath appears from the confessions of the assessors, and from much other evidence. As a rule, bonds and notes are assessed at their full value, and so are bank stocks; but

1 The attitude of these assessors resembles that of the English juries, at a time when the law made it a capital crime to steal in a dwellinghouse to the value of forty shillings. Rather than take the life of a fellow creature, guilty only of a petty theft, the jury would declare the value of the goods taken to be less than forty shillings, although it might be obviously much greater. In 1808 a jury found on their oaths that a $£ 10$ Bank of England note was worth only $39 s$. Sir S. Romilly cited in Parliament a case in 1732, where a woman had stolen two guineas and two half-guineas, but the jury pronounced the total value of the four coins to be "'under 40 s." 
real estate, especially where the agricultural interest is strong, is often greatly undervalued. In this way those persons who are too scrupulous or too helpless to conceal their ownership of certain forms of property already taxed doubly, are, through the exemption of others, still further amerced.

Complaints, both official and private, of these abuses have been repeatedly uttered in all parts of the country. We may select, as an example of prevalent conditions, possibly at their worst, the practices found to exist in the city of Chicago, in 1897, by the Taxpayers' Defense League. The inequalities in the assessment of the general property tax, as well as the corruption of the assessors, disclosed by the investigations of this league, are so extreme as to make it seem almost incredible that any scrupulous person could carry on business, or even own property, in that city. For the purpose of decreasing the taxes payable to the state and other public corporations, the assessors of the several taxing districts in Chicago were in the habit of finding the "fair cash value" of real estate to be on the average about one-tenth of its fair market value; although the assessment of some lands was at tenfold the rate applied to others. In order to raise a tax amounting to one per cent of the market value of property, it thus became necessary to have a tax rate of ten per cent. The assessors, however, in some cases from confessedly corrupt motives, often assessed certain owners of personalty for its full value, while they assessed others notoriously possessed of large wealth of this kind for trifling amounts, or exempted them altogether. The rate at which banks and trust companies were assessed varied from 16 per cent of their total capital and surplus down 
to nothing. There has been perhaps, on the whole, a tendency to assess personal property, like real estate, at about one-tenth of its value; but the assessments are altogether arbitrary. Immunity has frequently been offered in behalf of the assessors; and where taxpayers have refused to pay blackmail, their assessments have been made almost confiscatory. ${ }^{1}$

When we review the evidence that has been accumulated on the operation of laws enacted for the taxation of intangible property, and even of personal property in general, the conclusion seems unavoidable that such laws necessarily work injustice. In order to carry them into effect, assessors must be armed with power to compel disclosure; and this power can be exercised only through demoralizing methods, and with demoralizing results. The fact that such measures as are perhaps necessarily employed for the detection of crime and the recovery of stolen property, are resorted to for the collection of a tax, establishes a presumption that the tax is inequitable. Such measures would never be employed unless the tax were actually collected from only a part of the persons commanded to pay it. A tax of this description, as we have seen, increases the burden of those who pay it to the extent that the burden of those who escape it is diminished, and the great expense of employing the methods of criminal procedure increases this burden still further. Treachery and deceit are the necessary weapons of spies and informers, and these arts are so infamous in the estimation of mankind as to make it improbable that honorable men will be induced by pecuniary rewards to engage in an occupation where they must be employed.

1 For details, see Appendix B. 
It is not surprising therefore that men so indifferent to the hatred and contempt of their fellows as to follow this base occupation, should be susceptible to bribes, or disposed to levy blackmail when bribes are not offered. The extent to which corruption of this kind prevails is far greater than is supposed by those who have not had occasion to investigate the subject, and it is obviously likely to be increased by laws which enable informers to compound taxes at their discretion. No one sincerely desirous of attaining justice in the distribution of the burdens of taxation can approve of the employment of corrupt men, or of corrupting and demoralizing methods in the administration of the law. ${ }^{1}$ When the information necessary to assess the property for taxation can be had only by inducing the trusted agents of the owner to betray him, it seems much wiser to change the law than to have the state encourage falsehood and deception. The conduct of the numerous class of persons whose intangible

1 Some of the objections to the preliminary examination of one not yet charged with an offense are stated by Prof. Wigmore as follows. "It is the innocent that need protection. Under any system which permits John Doe to be forced to answer on the mere suspicion of an officer of the law, or on public rumor, or on secret betrayal, two abuses have always prevailed, and inevitably will prevail: first, the petty judicial officer becomes a local tyrant and misuses his discretion for political or mercenary or malicious ends; secondly, a blackmail is practiced by those unscrupulous members of the community who through threats of inspiring a prosecution are able to prey upon the fears of the weak or the timid." So in the case of one duly charged by indictment, and placed on trial. Assuming him to be innocent, why should he not be examined? "The real objection is that any system of administration which permits the prosecution to trust habitually to compulsory self-disclosure as a source of proof must itself suffer morally thereby." The employment of torture is only an extreme application of the theory. The Holy Inquisition endeavored by every kind of compulsion to extort confession, because then evidence was not needed to establish guilt. Wigmore, Evidence, \$2251. 
property is not assessed may be very reprehensible; but it is less subversive of justice than the conduct of rulers who endeavor to enforce taxes considered unjust by those on whom they are levied, through methods which undermine the very foundations of confidence. When the law puts a premium on vice, obedience to law ceases to be regarded as a virtue.

The policy of compelling taxpayers to return lists of all their property and its value, verified by oath, has been condemned by both reason and experience. In practice, these methods of disclosure violate the rules that courts have found indispensable to the attainment of justice. They encourage perjury, they lead to the employment of informers and to the corruption of assessors, they lighten the burdens of the strong and the unscrupulous, and they correspondingly aggravate those of the weak and the conscientious. These results are so notorious, and even so scandalous, as to make the law a by-word. The inequality of its operation causes men to despise and detest their government, and leads them to think it not only justifiable but even praiseworthy to elude its inquisitorial proceedings. Hardly any one denies the existence of all these evils. Wherever we inquire, the testimony is overwhelming that compulsory disclosure is so imperfectly enforced as to produce great injustice; and we cannot avoid the conclusion that this method cannot be consistently supported by those who hold the attainment of justice to be an end in taxation. ${ }^{1}$

1 "The obvious method of requiring an oath as to the accuracy of the return, coupled with the severe penalties attached to all perjury, have been found by experience to be of very doubtful expediency. The history of taxation in the United States has long since established the fact, on documentary evidence, that in that country this requirement has 
For similar reasons, the proportionate method cannot be regarded as conforming to present standards of justice. The theory of justice which it expresses is not accepted by most men, even if they acquiesce in its practical applications; and it is so repugnant to the convictions of a considerable number as to make every attempt to apply it practically more and more difficult. Under these circumstances it would be vain to hope that any system of taxation embodying this method could be permanent. It would be subjected to incessant attack, and even if it applied the method perfectly, the uncertainty of its duration would cause so much injustice among many classes as to outweigh the advantages of theoretical perfection. Moreover, this method has not only never been applied with any approach to perfection, but is also, as we shall see, apparently incapable of being so applied; and the difficulties in the way of its application are of a nature to increase in the future. A partial application of such a theory, however, utterly negatives its claims to justice. Unless every one is taxed in proportion to his property, some must be taxed too much and others too little; a result in direct contradiction of the theory. Whatever the theoretical merits of the method may be, it is evident that the general property tax would carry it out only if all property were assessed at its true value and to its true owner; a result which is nowhere even approximately attained.

made perjury habitual in tax assessments. The danger of using the oath in connection with self-assessment of taxes lies in this fact, that, besides its evil effect on morals, it still further increases the inequality of assessments; one part of the taxpayers will have their consciences aroused by the oath, while others do not, so that the inequality to be expected under any system of self-assessment will simply be augmented." CоHN, Science of Finance, p. 618. 


\section{4}

\section{THE METHODS OF TAXATION}

Moved partly by the desire to remedy the conspicuous injustice of " double taxation," and partly by the disposition to make taxation progressive, or degressive, legislatures have specifically exempted certain forms of property, with the result of making the operation of the general property tax even more unequal. Sufficient furniture for an ordinary household, sufficient food, clothing and fuel for ordinary requirements, together with the implements and stock necessary for a livelihood, are everywhere relieved from taxation. For similar reasons, as well as for several others, deposits in savings banks and the investments of many insurance companies, are in some states, not taxed; and, as we have observed, the bonds of various governing bodies are by their terms untaxable. The value of the securities thus withdrawn from assessment is collectively enormous; and, however wise the policy of such exemption may be, it must necessarily result in increasing the taxes on non-exempt property. Vast quantities of merchandise are exempt under the provisions of the Constitution of the United States relating to commerce; great sums of money are exempt either for the same reason, or because the attempt to tax them would demoralize all industry. It should be added that while it is the rule not to tax directly the owners of the stocks of corporations, when the corporation is taxed on what it owns, this is not the rule concerning bonds; while some states tax their citizens on their holdings of stock in foreign corporations. The popular outcry that personal property evades taxation is usually an ignorant one. By far the greater part of such property is in some states exempt by law; but the burden thrown upon the holders of the remainder may thus be correspondingly aggravated. 


\section{THE PROPORTIONATE METHOD}

As the exemption of many forms of property defeats the purpose of the general property tax, so the imposition of additional taxes effects a similar result. Assuming that the aim of the proportionate method would be attained under such a general tax, the equality of burdens is obviously disturbed by any increase in the burdens of particular individuals or classes. During recent years, the number of new taxes imposed has been considerable, and their amount has materially increased. Most of them are of the nature of licences, or taxes imposed on certain forms of industry. The government may permit individuals to do certain things which they could not lawfully do without that consent, and exact a payment for its permission or licence. Or it may forbid individuals to continue to do things which they might lawfully have done, unless they pay for the privilege. According to the common law, men cannot associate themselves in a business of which they share the profits without entering into partnership. But every partner is liable for the debts of the partnership to the extent not only of what he has contributed thereto, but also of his whole private estate. Under these conditions, no one possessing money and common sense will enter into partnership except with men whom he knows to be trustworthy. Many persons, however, have money which they wish to invest, and many have talents and experience which they wish to employ. To permit such men to combine is so evidently advantageous to industry that the law of unlimited liability has been modified. Men may now form partnerships, called corporations, with the assurance that they can at worst lose only the amount actually invested in the enterprise. The enormous extent to which this device is employed 
shows its necessity in our modern industrial system; and it at the same time suggests to our legislatures the possibility of utilizing this necessity as a source of revenue.

We accordingly find that the legislation of recent years has been fruitful of all kinds of taxes on corporations. The nature and extent of these taxes need not here be considered, but it is undeniable that they constitute a burden of appreciable weight, and must materially alter the proportion which the burden of taxation has borne to the property of the citizens at large. The taxes levied on railroad companies in the State of New York amount to nearly two-thirds of their dividends, and those on insurance companies are frequently equal to their premium receipts. It is clear that these taxes must fall, in the first instance, either on the owners of the stock of these companies, through the reduction of their dividends, or on passengers and freight; or on those who insure their possessions, through the increase of their premiums; or be distributed among these classes. In the same way, the fees derived from licences to carry on particular trades, and especially the traffic in alcoholic drinks, must disturb, and often very greatly disturb, the equality of burdens contemplated by the general property tax.

And, finally, all possible claim that proportionate taxation is secured through the general property tax is disposed of by the establishment of a system of taxation, based upon a different principle, by the action of the general government. The taxes levied under this system have no relation to the amount of property owned by those who pay them, or to the revenue of such persons. They are taxes assessed on certain kinds of goods, and are presumptively paid by the consumers of such goods, not in proportion to 


\section{THE PROPORTIONATE METHOD}

their revenue, but in proportion to their consumption or expense. Such expense may sometimes be in proportion to the revenue of the consumer, but it is frequently altogether disproportionate thereto. The most notable example is afforded by the tax on imported sugar. The effect of this tax is to make the price of sugar to the consumer much greater than what the producer receives, and as the quantity consumed is very large, the burden is both individually and collectively very heavy. The amount expended by a rich man for sugar, however, must be insignificant in proportion to his other expense, while in the case of a poor man this proportion is very considerable. This tax, therefore, which amounts to some fifty million dollars in duties, and as much more in "protection" to the producers of beet sugar and to the planters of Hawaii, Porto Rico, and Cuba/seems to be altogether inconsistent with the proportionate method, falling lightly on the rich, and heavily, on the poor. 


\section{CHAPTER V}

\section{INCOME TAXES}

SrNCE the difficulties in the way of an equal assessment of all property appear to be insuperable, and since the proportionate method can be carried out only through such an assessment, it might seem that we were justified in concluding at once that proportionate taxation is impracticable. We might go further than this, and conclude that progressive taxation is likewise impracticable, for it does not appear how it can be justly applied unless the assessors are able to learn the amount of the property of every citizen - knowledge, as we have seen, the acquisition of which is quite beyond the power of government. It is conceivable, however, that revenue may be more ascertainable than property; that the amount of the income of every one may somehow be known, although the amount of his possessions eludes discovery. Various measures of taxation based on this theory have been devised, and are now in general use, the most important of which are those comprised under the name of the income tax.

Although such taxation is not now employed by our government, it is an established feature of the English system, and it will be instructive to examine its operation in that country. The conditions prevailing there are on the whole much more similar to our own than those of other lands. Our political institutions, and the great body of our law, are of English origin. What is most important, the general attitude of both peoples toward govern- 
ment is the same. Both are disposed to maintain what they call their liberties; those prerogatives of the individual subject which rulers are compelled, by tradition as well as by constitutional restraints, to regard. The peoples of Europe have had no such defense against despotism, and as they have not been trained to take pride in the successful resistance of their ancestors to the encroachments of arbitrary power, they have little of what we are fond of calling the independent spirit of freemen. Hence they endure governmental regulation and interference with a submissiveness which Englishmen can scarcely comprehend, and which they would certainly not imitate. We cannot, therefore, reason safely from the analogy of these countries. Measures that operate successfully, where neither law nor tradition encourage the subject to maintain an independent attitude toward his rulers, may fail where a sturdier spirit prevails. For our purposes, the most useful lessons are to be drawn from English experience; and this is peculiarly true of measures that have been adopted after careful and intelligent deliberation.

Although the injustice resulting from the general property tax, as commonly and perhaps necessarily administered, has caused many writers to look with favor upon the income tax, yet, as a tax on property is presumptively paid out of income from that property, and as the value of property is generally regulated by its capacity to produce income, it might seem that a tax upon income was the same as a property tax. It differs, however, in the respect that many persons who own little property have incomes arising from the services which they render to the community. The collective income of common laborers is enormous, but their property holdings are comparatively small. Many 
professional men have large incomes, but comparatively little realized property. Many merchants and manufacturers borrow much of their capital, and their incomes may be out of all proportion to the property which they own. The number of persons in receipt of regular salaries has in modern times become very great, and many of them have no other means of subsistence. It is reasoned, therefore, that the proportionate method of taxation requires that this large and increasing class of persons should contribute to the support of the government. For it is to be observed that Adam Smith's first maxim declares that subjects should contribute, not in proportion to their property, but in proportion to the revenue that they enjoy under the protection of their government.

But when we consider the sources of this revenue, we are confronted at the outset with a serious perplexity. For, as we shall see, incomes as well as property may be classified as earned or unearned, and to tax all classes alike would seem to offend against the prevailing conceptions of justice. On the other hand, to exempt from taxation those who possess incomes but not property appears to many persons clearly inequitable. The perplexity is illustrated by some observations made by Professor F. W. Taussig. Speaking of the property tax, he remarks:

"One man has little property, but earns a handsome income from a lucrative profession; another man, or perhaps a frail woman, also has a little property and is dependent on this alone for a slender livelihood. Are both to be taxed alike? The same disproportion appears when one man uses property in business operations as a means of earning an income from combined labor and capital, while another has a simple investment or domicile of his own." 
To arrive at a satisfactory solution of such problems, however, it is important to compare parallel cases, and the instances given above are plainly not parallel. Let us suppose rather that there are two frail women, one of whom supports herself by sewing, or washing, while the other depends entirely on the income from a small property. It seemis probable that most men would think it more just to tax the woman who presumptively renders no service to society, rather than the one who earns her income by severe toil. Or we may compare the man who earns a handsome income as a physician, with one who has an equal income from investments. Here, too, most men would probably think it more just to tax the man who does not work, rather than him who does; especially when the receipt of the professional income implies years of preliminary study, during which there has been much outlay and no income at all. To a considerable extent the same judgment might obtain concerning two men, one in active business, and the other not; one deriving his income from skillful management and assiduous industry, the other from wealth which he may have had no part in producing.

In such cases the property tax is presumptively levied on the land and goods of the man in business, and his profits are what is left after paying this and other expenses. They may be regarded as measuring the value of the services which he renders to his customers, and it is quite conceivable that the attempt to reduce his remuneration, even if it seemed just, might not be successful. For, assuming the total burden of taxation to remain the same, income taxes would tend to diminish that part of the burden borne by those who derive their income from property, and to 
increase that borne by those who are paid for services. It is at least possible that the latter class might increase the charges for their services until the former equilibrium was restored. Defining laborers, loosely, as those who use no capital, but obtain their income by selling their services, it is evident that, in the opinion of the public, justice does not demand the taxation of such income. Those other members of the community who render services for pay must employ capital, either owned or borrowed, upon which they already pay taxes, the reduction of which would only in part compensate them for their payment of an income tax. It seems probable, therefore, that a tax of this kind would result either in such an increase of income from services as would tend to reëstablish the present equilibrium, in which case it would depend on fiscal reasons for its justification; or else that it would increase the incomes of those who depend on accumulated property, at the expense of those who render services to the community, a result which conflicts with prevalent theories of justice.

Moreover the equal taxation of incomes, like the equal taxation of property, cannot result in any equality of sacrifice. The necessary expenses of two men receiving the same income, like those of two men of equal property, may be very different in amount, and a tax which would be scarcely felt by one may be a grievous burden to the other. The income tax, furthermore, unless assessed in a very scientific and complicated manner, causes an additional inequality of sacrifice. The incomes of a very large number of persons certainly cease at their death, and as their abilities generally decline before they die, their incomes also diminish, if they do not altogether disappear. A tax 
on incomes derived from terminable annuities, or from personal earnings of every description, is thus a heavier burden than an equal tax on incomes arising from realized property. In the former case it is necessary, in order to provide for subsistence during a period of incapacity, and for the support of the family, to save a part of the income, while in the latter case the whole of it may be spent without improvidence or injustice to those who are dependent. Many plans have been suggested for the correction of this inequality, such as the exemption of income devoted to life insurance, and other forms of saving, but the difficulty of applying such plans, except in a general way, makes it impossible to prevent injustice in particular cases.

For more than two generations parliament has struggled with the problem of distinguishing between earned and unearned incomes. It is easy to make the distinction in particular cases. To formulate a general principle has hitherto seemed impossible. Nevertheless the attempt has at last been made, and since 1907 what are called earned incomes under $£ 2000$ (or those parts of incomes of that amount which are earned) are taxed at nine-pence instead of one shilling. The distinction, however, must be of a very arbitrary character. The income of a lawyer or of a physician, so far as it consists of fees, may be properly enough said to be earned. But professional men having families must provide for their future. Some of the earned income must be saved and invested, and it seems unjust to treat the income arising from such investments as unearned. To tax it is to discriminate in favor of extravagant living, and to discourage men from laying by a part of their earnings, that when they become feeble 
they may not suffer want, and that when they die their families may not be left destitute.

A man engaged in trade may be said to earn his income. But he may cease to be active, while his capital remains in his business. He may thus continue to receive an income which would be classed as earned, but which is not earned by his labor, as it was before. Or he may turn his business into a stock company, while continuing to carry it on himself, and thus earn his income as much as ever he did. Apparently, however, he is now living on the proceeds of an investment, and his income might be classed as unearned. Strictly speaking, only such income is unearned as comes to its owner because of no effort, past or present, on his part. Such may often be the income of the recipient of a large legacy; but even here the legatee may have rendered some service to his deceased benefactor. The mere fact that the estate of the decedent is large cannot of itself establish any presumption that the legatees, especially if their portions are small, have done nothing to earn what they receive. In so far as insurance is effected against the death duties, they really constitute an income tax. They may therefore be equivalent to a tax on the savings of industrious and prudent men; that is, on their earned income, capitalized.

Fortunately for our purpose, the conformity of the income tax to recognized principles of justice has been considered by some of the most enlightened English statesmen. Mill, Fawcett, and Gladstone have all treated the subject, and their reasoning has not been affected by the lapse of time. We have hitherto assumed it to be comparatively immaterial whether a tax was imposed on property, or on revenue, and have treated Adam Smith's first maxim as if 
it was illustrated by the general property tax. While it is true that a tax on property is practically a tax on the revenue which the property produces, true even, in one sense, that all revenue is ultimately derived from property, it is obvious that much revenue is received as direct compensation for labor or service, and that those who receive it may own little or nothing subject to a property tax. The income tax, therefore, as it affects all forms of revenue alike, seems more equitable than the property tax, and apparently conforms precisely to the principle stated by Adam Smith. Yet when we consider the sources of revenue, we have already observed that the situation of a man whose income is derived from accumulated wealth is very different from that of one who depends on his daily labor. The latter is under the strongest inducement to save a portion of his earnings in order to provide for the support of his family in case of his death, or for his own support after he becomes incapacitated. The former is under no such compulsion, and his income is substantially to that extent greater. But if we try to determine how much greater, we find the problem extremely complex. For the property of one man may be of very uncertain value, regarded as a permanent investment, as in the case of a mine, or a ship, or even a house; while that of another may be almost absolutely secure. The revenue derived from property of the former class may be very much greater than that from the latter; or, to state the case more precisely, equal incomes may be derived from principal funds of very unequal values. The larger income implies a greater risk of losing the principal, a risk which should be covered by insurance, as in the case of income derived from daily service. 
At the present time a loan or investment which is, in human estimation, entirely safe, will perhaps produce a return of three or four per cent, while some fairly secure stocks pay eight or even ten per cent on their market price. So money invested in trade, although in this case there is an element of service to be considered, often yields a profit of fifteen or twenty per cent. No wise man acts on the presumption that these precarious revenues will always continue; he prepares for possible and even probable loss, by saving, and his available income is only what is left after he has subtracted a proper allowance for the risk that he is taking. A great part, if not the greater part, of the capital employed in trade is borrowed, and a great part of the revenue which it produces, while commonly regarded as the income of the borrower, is properly that of the lender. Some men invest in terminable annuities; they secure an income for life by sacrificing the whole of their principal. Such income is evidently not the same as that which leaves the principal intact; it consists in great part of payments made out of principal, and he who receives it has no means of meeting an unforeseen increase in his expenses. The gross income from property received by any one thus appears to be a very imperfect measure, either of the value of his property, or of his ability to contribute to the support of the government. And Mill contends that to tax that part of incomes which is saved and reinvested involves double taxation.

Much the same is true of income derived from labor or services. In the case of young men, such income may be earned for many years, and may reasonably be expected to increase for a part of that period. Yet the vicissitudes of life are so numerous that we commonly praise young 
men who do not spend all that they earn, but save enough to provide insurance against the more common forms of disaster. With advancing years and declining strength, it is clear that such income tends to decrease, and it may be regarded, like a life annuity, as drawn in part at least from principal. In certain occupations, such as those of writers and actors, income depends very much on the favor of the public, and unless very large deductions are made to provide against the vagaries of popular taste, affluence may suddenly give place to positive want. In manufactures and in trade in general, similar precautions should be indispensable, as we may infer from the great number of commercial failures. The profits of one year are frequently swept away by the losses of another, and a great part of such profits should be set aside as a reserve, and not treated as income available for expenditure. Other illustrations might be added, but these are sufficient to show that a tax on income in general is so extremely unequal in its operation as to be hardly reconcilable with ordinary standards of justice. It may put a premium on improvidence, and increase the inherent inequalities of natural conditions.

This conclusion is confirmed when we observe the differences in the demands on the incomes of different men. One may be charged with the support of his parents and of his wife and children, while another may have no one to maintain but himself. In the former case the income which is regarded by the law as belonging to the head of the family, belongs really to all its members; and in this case also the importance of the life of the "bread-winner" requires that some of his income be devoted to its insurance. The greatest differences also exist in the health, in 
the ability, and in the industry of men whose income is the same; and in their needs there are corresponding differences. Some men earn money easily, but live with great frugality. Others are prone to wear themselves out with hard work, which they can endure only if they live in a generous way. These differences cannot be offset, one against another; they are often combined in such a manner as to make the conditions of life either extremely easy, or almost intolerably burdensome. There is no semblance of justice in taxing at the same rate two equal incomes, one of which is drawn as interest from sound investments by a vigorous man having few needs and no family, while the other is earned with the most painful toil by a person in frail health, who must out of it provide not only for the present sustenance of half a dozen dependents, but also for their future support in the event of his death.

The equal taxation of incomes, therefore, may result in greater inequality of sacrifice than the equal taxation of property. The property tax falls lightly on the largest class of all, the laborers; but an income tax must be deducted from their wages. The property tax affects what has been called "spontaneous" income; it reduces income for which the recipient may have in many cases expended no labor, while it does not seem to touch the "industrial" income, which is the recompense paid by society for present services. The income tax falls indiscriminately on both species of revenue. The property tax, so far as it is levied on real estate, does not differ materially from a tax on income derived from rent, and is no more unjust than such a tax. In so far as the property tax is levied on tangible personalty, it is similar to a tax on the income from such property, and one tax seems as just as the other. The 
results of attempting to tax intangible property we have examined at length, and there is no obvious reason why the results of attempting to tax the income of such property should be different, or why the same injustice should not be caused in either case. Rents, wages, and salaries, it is true, can to some extent be determined by the inspection of the assessor. Their amount is frequently a matter of record, and always a matter of agreement between two or more parties, both, or all, of whom must concur in order to conceal the true character of the transaction. Taxes on these sources of revenue, therefore, might be assessed with some approach to completeness. Provided the assessors were faithful, they could generally ascertain what rents and salaries were paid, without insisting on disclosure by the recipients; and in the case of wages the accounts of corporations would furnish satisfactory evidence. But the profits of a business or profession cannot always be accurately estimated. Many assets are of uncertain value, many debts are doubtful, many enterprises require years for successful - or unsuccessful - completion, and many persons in business, in small ways as well as large, do not themselves really know how they stand. But if the profits of a business are often scarcely known to its owner and manager, they are not likely to be known to any one else, and are certainly not ascertainable by the inspection of the assessor. On this point Mill's observations are as correct now as when they were first made. $\mathrm{He}$ says:

"Notwithstanding, too, what is called the inquisitorial nature of the tax, no amount of inquisitorial power which would be tolerated by a people the most disposed to submit to it, could enable the revenue officers to assess the tax from actual knowledge of the circumstances of contributors. Rents, salaries, 
annuities, and all fixed incomes, can be exactly ascertained. But the variable gains of professions, and still more the profits of business, which the person interested cannot always himself exactly ascertain, can still less be estimated with any approach to fairness by a tax collector. The main reliance must be placed, and always has been placed, on the returns made by the person himself. No production of accounts is of much avail, except against the more flagrant cases of falsehood; and even against these the check is very imperfect, for if fraud is intended, false accounts can generally be framed which it will baffle any means of inquiry possessed by the revenue officers to detect; the easy resource of omitting entries on the credit side being often sufficient without the aid of fictitious debts or disbursements. The tax, therefore, on whatever principles of equality it may be imposed, is in practice unequal in one of the worst ways, falling heaviest on the most conscientious. The unscrupulous succeed in evading a great proportion of what they should pay; even persons of integrity in their ordinary transactions are tempted to palter with their consciences, at least to the extent of deciding in their own favor all points on which the smallest doubt or discussion could arise; while the strictly veracious may be made to pay more than the state intended, by the powers of arbitrary assessment necessarily intrusted to the commissioners as the last defense against the taxpayer's power of concealment. It is to be feared, therefore, that the fairness which belongs to the principle of an income tax cannot be made to attach to it in practice; and that this tax, while apparently the most just of all modes of raising a revenue, is in effect more unjust than many others which are prima facie more objectionable." Pol. Ec., Book V, Chap. II, $\S 5 .^{1}$

$1 \mathrm{Mr}$. Gladstone condemned this tax even more emphatically. In his budget speech, in 1853, he expressed himself as follows: "Even if you could remove the inequalities, there would still remain, in my mind at least, objections to it of the gravest character. The machinery of the income tax, involving, as it necessarily does, to so large an extent, the objectionable principle of self-assessment, can never be satisfactory to the country. First, because self-assessment leads to grievous frauds upon the revenue, and renders the real inequality of the tax far greater 
The propriety of this criticism has been established by experience. On several occasions facts have been incidentally brought to light which prove that the injustice described by Mill is very extensive, and enable us to estimate its degree with some approach to accuracy. In order to comprehend these facts, however, it is necessary to understand that system of taxes in England which is incorrectly spoken of as "the income tax." In a certain sense, of course, every tax is an income tax. It diminishes the income of the person who pays it, or of some other person. A tax on beer, for instance, must diminish the income of brewers, or of inn-keepers, or of beer drinkers, or of all

than any of those among its inequalities which immediately strike the public eye and feelings; and, secondly, because of the tendency to immorality, which is, I fear, essentially inherent in the nature of the operation. The public feeling of its inequality is a fact most important in itself. The inquisition it entails is a most serious disadvantage. And the frauds to which it leads are an evil which it is not possible to characterize in terms too strong. I believe it does more than any other tax to demoralize and corrupt the people." Disraeli declared "The odious features of this tax cannot by any means be removed or modified." Prof. Thorold Rogers wrote in 1884, "Nobody defends the income tax. It was first imposed on the tyrant's plea that the administration cannot do without it, and it has been continued for the same reason. Every Chancellor of the Exchequer has condemned it in principle, and has continued it in practice. It is not wonderful, therefore, that, fortified by these avowals, people who can evade the tax do so." D. A. Wells, in his Theory and Practice of Taxation, p. 529, remarks: "Those only who were officially and intimately connected at this time with the Internal Revenue Department of the United States Treasury can form any adequate idea of the amount of perjury and fraud that characterized and pervaded the country during the years 1867 to 1872 , as the outcome of the then existing system of internal revenue. And American ingenuity was never more strikingly illustrated - not even by the exhibits of the patent office - than it was at that time in devising and successfully carrying out methods for evading the taxes on incomes and distilled spirits." In 1869, the population being thirty-seven millions, the number of persons returning income for taxation was about 260,000 . In 1872, with a population of thirty-nine millions, the exemption having been raised from $\$ 1,000$ to $\$ 2,000$, the number of returns was only 73,000 , and the receipts were comparatively insignificant. 
three classes. A tax on imported sugar must diminish the income of the importer, or of the refiner, or of the consumer. But it would cause great confusion to describe such taxes as income taxes, and the term is generally applied to taxes assessed directly on the revenue of the individual taxpayer, whether that revenue be in the form of wages, or salaries, or rents, or interest, or profits.

The English system, however, assesses directly only income in the shape of profits, and, in some cases, in the shape of salaries and interest. There is a tax on salaries paid by certain corporations, but it is assessed on the employer, who may or may not fix accordingly the amount which he pays in salaries. There is a tax on payments of interest on loans by governments and other corporations, which is assessed on them, and which may or may not be considered in fixing the rate of interest paid on their loans. There is a tax on rents, assessed to the tenant, who may or may not pay a rent reduced by the amount of the tax. Nominally, in all cases, the landlord, or the bondholder, or the clerk may be charged with the tax, but we cannot assume that the tenant, or the debtor, or the employer, suffers no diminution of income on account of the tax. During the war with the Transvaal Republic, the British Government taxed its consols by increasing the income tax. But when it borrowed it was compelled to pay a much higher rate of interest than before, the price of consols falling from 112 to 92 , so that the net income received by those who lent it their money was probably rather more than it would have been had the tax not been increased. ${ }^{1}$

We find, in fact, that many large borrowers covenant

1 The interest on consols had been reduced from 3 per cent to $2 \frac{3}{4}$, in 1888. It was reduced to $2 \frac{1}{2}$ per cent in 1903 , and consols have since sold below 84 . 
with their creditors that the interest payable on their loans shall not be reduced by taxation. The government of the United States has issued its bonds on these terms, and many states and municipalities exempt their own bonds from taxation. It is evident that the authorities who contract these loans suppose that if they were taxed the rate of interest would be increased, and they would regard it as a foolish proceeding to issue a loan at four per cent, with the proviso that one per cent should be deducted as an income tax. This, however, is practically what is done by the British Government; and it also makes the value of its obligations more speculative by leaving the lender in uncertainty as to the rate at which it will tax them. This uncertainty tends to impair the value of these stocks, while the revenue of the government is of course lessened by the expense of much needless bookkeeping.

This digression has been introduced not to call attention to the diffusion of taxes, a subject which will require much more exhaustive treatment, but to show that the restriction of the meaning of "income," in common usage, is not arbitrary. In fact it would be well to limit the term, " income tax," to a tax on revenue that has actually passed into the possession of the ultimate owner. Revenue in the hands of persons who have to deliver it to others must generally be subject to some deductions, and it is not always easy to determine its true amount. Thus a tax is imposed in England on the profits of railway corporations, and they are authorized to assess this tax on the fund out of which dividends are paid to stockholders. In a sense the stockholders are taxed on their income, for it would be presumptively larger if there were no tax, just as it would be larger if their other taxes were removed; but the tax 
is evidently on the business of transportation, and we cannot assume that it will be paid out of the income of railway stockholders, and not out of that of those who buy transportation of the railways.

No doubt it will be observed that a tax on the profits of an individual may be transferred to others, and the conclusion may be drawn that the distinctions pointed out above are immaterial. But this conclusion is incorrect; for the profits of an individual are what he receives from every source of revenue. To tax his profits is therefore to tax his whole net income; but to tax his rents in the hands of one person, his interest in the hands of another, his salary in the hands of a third, may be to lay a tax on him that has no relation to his net income. He may have incurred losses which leave him with no net income; but these taxes continue. They should not be called income taxes, because the income has disappeared. The income of a banker is not. measured by the quantity of money that comes in to his till. That will run into the millions, while his true income may be but a few hundreds, or even less than nothing. Like all common words, the word "income" is loosely used; but in estimating the financial position of any one it is his net income that is considered. He may have large revenues from some sources; but he may be losing money in other enterprises, and it is only after striking a balance that we can be said to know what his income really is. If an Englishman has no revenue except from land, and is engaged in no business, the tax on rents is a tax on his income. The same would be true in the case of interest and salaries; but it ceases to be true whenever the fluctuating element of profit and loss is introduced. 
These distinctions are substantially recognized in the English law. In view of the inequality of sacrifice caused by taxing incomes without regard to their permanency, or to the differences in the amounts of the necessary expenses of the recipients, that law provides that incomes less than $£ 160$ shall not be taxed, and that incomes less than $£ 700$ shall be allowed a partial exemption. There are five divisions or schedules under which income is assessed. Schedule A applies to income drawn from the ownership of dwelling houses and agricultural land, the tax being deducted from the rent by the tenant, if any, and paid by him to the tax gatherer. The landlord, therefore, has no control over this payment. Schedule C covers income from government securities payable in England. The tax is to be deducted, in most cases at least, from the income before it is paid to the owner of the securities. Schedule E relates to salaries and pensions paid by government or other corporations, the tax on which is deducted before payment. Schedule B applies to the profits of farmers, their profits being arbitrarily assumed to be a certain proportion of their rent. In this case the farmer pays his own tax, but it is not properly an income tax, since he may not even make the rent out of the farm.

It is only under Schedule D that an income tax, strictly defined, is levied; and much of the taxation even under this schedule is not of this description. The railways and other corporations are taxed under this schedule on their earnings, and they therefore deduct the tax from the dividends payable to their stockholders, without consultation with the latter. It is only the income derived from trades, from professions, and from loans and miscellaneous investments, that is, strictly speaking, subject to income tax in 
England. All other revenue, practically, is taxed before it reaches the owner, and is generally discoverable by the method of inspection. ${ }^{1}$ The true profits, or actual net income, of any one engaged in business for himself, or managing his own property, can be known only to himself, and the assessor must in the main accept his figures. To put the matter in few words, other people may report to the assessor whatever sums they pay over to any person, and withhold a tax on such payments under the name of a tax on his income; but it is only that person himself who knows what all these payments amount to, or how far they are offset by losses, and it is, therefore, only he that can determine the true amount of his taxable income. Hence the English law requires from every person having an income of $£ 160$ a disclosure, or declaration, of the state of his affairs. It very wisely does not require this statement to be sworn to; nor is the penalty for making a false one, or for not making one at all, very severe. On the other hand, the revenue officers are sworn not to disclose the information contained in these statements.

The recognition of the distinctions above referred to appears in the provisions for determining exemptions and abatements. The government, as we have seen, imposes a tax on revenue from certain sources before it reaches the owner, and without reference to the amount of his income. But it also provides that incomes below specified figures

1 It is computed that from three-fourths to four-fifths of the tax is collected before the income reaches the owner. The Commissioners estimate that of the gross income in 1901-02, under Schedule D, Public Companies, Local Authorities, and Banks paid on $£ 270,000,000$, leaving for self-assessment by persons and firms $£ 218,000,000$. As some of this can be verified, the amount self-assessed and therefore subject to evasion is about $£ 150,000,000$. As to this, "grossly insufficient returns, or no returns at all, are made over long periods of years with impunity." 
shall not be taxed, or be taxed at a lower rate than that imposed on larger incomes. Hence, in order to obtain the exemption to which he is entitled by law, but of which the law has deprived him, the owner must resort to proceedings against the government. He may have made a return of his income, under Schedule $D$, but he must make another return in order to recover income intercepted before it reached him, and this return must state the amount of tax deducted from every item of revenue. These proceedings are so complicated as to be beyond the comprehension of many persons, and the aid of lawyers, or those familiar with the practice, must be secured. ${ }^{1}$ In numerous cases the expense of obtaining redress more than balances the amount of the possible recovery, and the government thus derives a considerable revenue from those whom it

1 The forms sent out by the Inland Revenue Commissioners are admitted to be perplexing. In criticising them, one of the Committee on the income tax made use of the following expressions: "I confess for my part that the ordinary form which an income taxpayer has to fill up is most confusing; it puzzles me often. . . . Number 3 seems to be expressed in very legal phraseology which may be quite incomprehensible to an ordinary man. ... So smothered in verbiage that it is difficult for an ordinary taxpayer to understand. . . . Many persons have been paying income tax without being really liable."

Persons in trade were, before 1907, assessed on their average income for three preceding years. The labor involved in ascertaining this average is necessarily very great, and small tradesmen are often not capable of the necessary bookkeeping. It is the opinion of many of the experts in the Commissioners' office that the "average" is seldom brought into play to swell the profits of the years preceding the assessment, though it is brought into play to cut those profits down. The Commissioners' solicitor pronounces this an understatement. It may be added that in order to obtain a reduction, the taxpayer must send to the revenue officers all his receipts showing the payment of dividends, rents, etc., which have to be examined at the London office or verified by the surveyor. The amount of clerical labor involved in such proceedings is only imperfectly suggested by the circumstance that the number of claims for repayment is about 450,000 every year, while the number of abatements is nearly 700,000 . 
professes to exempt, but whose income it has, contrary to its professions, subjected to taxation. It thus inflicts an injustice of the same nature as that arising under the assessment of personal property in the City of New York.

It is of course impracticable to determine the pecuniary loss to taxpayers through overpayments, and because of the expense of the proceedings to correct their assessments and to obtain the restitution of money of which the taxgatherers have deprived them. Some evidence, however, may be gathered from the existence of concerns formed for the purpose of procuring such redress. Nearly one hundred such agencies are registered at the Inland Revenue department, and their usual charge is one-third, or one-half, the amount recovered. The business of these agencies, however, is almost entirely derived from claimants residing abroad. There were formerly very few such claimants. In 1887 the number had risen to one thousand, and in 1903 to twenty thousand. The enormous increase of the tax no doubt had drawn the attention of the taxpayers to the importance of asserting their rights, and the advertisements of the agencies had doubtless had an effect. Probably the expense to residents, who generally employ their own solicitors, may have been less in proportion than that incurred by nonresidents, but it must be in the aggregate very large. Persons of intelligence and leisure, and concerns having competent bookkeepers, may dispense with legal aid; but large concerns frequently employ actuaries - a class of persons not much less expensive than lawyers - to attend to their assessments and maintain their rights.

There are manuals published, professedly intended to aid taxpayers in obtaining justice; but the mental ap- 
plication required to comprehend these manuals is for most persons too severe. Without putting a pecuniary value on the enormous aggregate of vexation and wasted time involved in the proceedings, it is perhaps a not unreasonable guess - for we can only guess - that the total cost to taxpayers of obtaining, or of failing to obtain, the repayments to which they are legally entitled, is not less than half the amount recovered. This amount has in recent years risen to some $£ 2,700,000$, the number of repayments being nearly four hundred and seventy-five thousand.

It is supposed that the great majority of taxpayers are entitled to exemption, but many of them are ignorant of their rights, and would be unable to enforce them, even if they knew what they were. Small tradesmen often do not attempt to make returns, probably because their accounts are so imperfect as to render it hard for them to tell what their income really is. In such cases the assessors usually "doom" the taxpayer, who submits to the assessment unless it is too oppressive. It seems that about one-fifth of those assessed under Schedule D are "doomed." While poor men may submit to this because they cannot help themselves, it is obvious that many rich men, as in this country, may prefer the chance of having the assessor underestimate their resources to the certainty of having to pay taxes on all the wealth that they disclose; and the English commissioners complain of the extent of this practice. $^{1}$

1 Sir W. Harcourt said, in his budget speech, in 1894: "Many people are in a happy ignorance of the Income Tax which they pay. I wish there were more of them. Even in the case of trades and professions where you require a declaration of a man's profits you do not attempt an investigation of the income the individual derives from other sources. 
What might be called the reductio ad absurdum of the principle of exemption occurs in the case of the coöperative trading societies. These societies, like other concerns engaged in selling goods, make profits on the capital employed; but these profits are distributed among their members as "bonuses," or by means of reduced prices. They are exempt from income tax, to the extreme displeasure of all the tradesmen who carry on their business in the usual manner. It seems clear that whether capital is employed in the one way or in the other, a profit is made; it is the same thing when a man gets his groceries at a discount as when he receives a dividend in eash. Furthermore, many of these societies sell goods at current prices to non-members, whereby the profits of members are enlarged. Even when this practice does not prevail, it is hard to see why the members of these societies are not really partners in a joint stock enterprise carried on for profit, and therefore as properly liable to income tax as persons receiving an income from other investments. Their exemption is defended on the ground that they are with few exceptions men of very small means, whose incomes would be below the taxable limit. If any part of such income were intercepted it would have to be returned; a proceeding which on account of the large number of the members of these societies - probably more than two millions - would cause an immense deal of trouble and expense. This is true; but it is not true of

I have made a careful investigation of this matter in consultation with the authorities of the Inland Revenue, and they are strongly of opinion that the measures of penal discovery and irritating inquisition which would be involved in any plan which required the determination of every man's income from all sources would render the collection of the Income Tax so odious as to imperil its existence, and in all probability make it impossible to maintain the tax." 
the coöperative societies alone. The difficulty admitted here to exist is not peculiar to this case; it necessarily arises if the principle of intercepting income and then repaying it is adopted at all.

What is known as the income tax in England thus appears to consist in part of an income tax proper, but chiefly of taxes on rents, on the earnings of corporations, on most forms of credit involving the payment of dividends or interest, and on disbursements for salaries and pensions. It is obvious that these taxes are assessed with very unequal degrees of certainty. The tax on consols, or the funded debt of England, is determinable with as much accuracy as the interest payable thereon. The tax on pensions is equally certain, and so is the tax on the salaries of public officers, and on those of officers of public companies. The tax on the earnings of such companies, owing to the necessary publicity of their accounts, is probably assessed with a high degree of certainty. The tax on rents, the contract of leasing being generally written and in the possession of both parties, is also assessed with much certainty; and occupying owners may be assessed by analogy. The tax on colonial and foreign loans, payable through agents in England, is precisely determinable. The tax on foreign investments and on miscellaneous credits is very uncertain in its assessment, as it depends largely on disclosures by interested parties. The tax on profits is of course even more unequal. ${ }^{1}$

1 The official returns of the Commissioners of Inland Revenue give some idea of the degree of inequality which prevails. The inequality due to allowances for abatements and deductions may be first examined. The annual value of lands in the year 1895 was 55.4 millions of pounds, as compared with 67 millions twenty years before. The annual value of houses was 154.5 millions in 1895 , and about 97 millions in 1875. The sum of these values in 1876 was 174.2 , with deduc- 
The inequality arising from the failure to assess all income from foreign investments has been specifically recognized by a statute passed in 1885 , which declares that previous laws had been found "inadequate to secure the charging and payment of income tax upon dividends payable out of the revenues of foreign and colonial states and dividends of foreign and colonial companies." As the law now stands all persons entrusted with the payment of returns from any foreign investments are commanded, under penalty of a fine of $£ 100$ for any failure, to deliver to the Board of Inland Revenue a complete account of such payments. Any one acting as a banker who shall sell or otherwise realize coupons, or warrants, or bills of exchange for dividends, and pay over the proceeds to any person, or credit him therewith, is within the statute. So is any person who by like means obtains payment of dividends for another without the Kingdom. A dealer in coupons who buys from any person not a banker or a dealer is also covered by the statute. A pecuniary re-

tions amounting to 13.1 , leaving a net assessment of 161.1 million pounds. In 1895 the gross assessment was 210.6 millions, the number of separate properties assessed being $9,248,000$, but the deductions were 50.9 millions, leaving a net assessment of 159.7 millions; which signifies that taxable income from this source has decreased in the course of twenty years, and that decrease has since continued. The profits of farmers should have decreased in the same proportion as the annual value of lands; but owing to increased deductions and lower prices for their products, the decline is greater.

In 1870 salaries and pensions amounted to 29.9 millions, with deductions of 2.2 millions. In 1895 they amounted to 51 millions, but the deductions were 16.7. The salaries doubled, but the taxable income from this source increased only one-half. In 1905 the number of salaries assessed under Schedule $\mathrm{E}$ was about 370,000 , the amount being about 86 millions. To this must be added about 100,000 salaries assessed under Schedule D, amounting to about 23 millions, the deductions being over 36 millions. 
muneration is allowed to bankers and others complying with the statute, the allowance not being less than threepence in the pound of the amount of tax collected. Before this statute was passed there seems to have been no tax collected from income in the shape of coupons, but in 1886 income from this source amounting to 5.8 millions of pounds was disclosed, and it has since risen to over 10.7 millions. It would seem, therefore, that before this statute was passed, some of the recipients of income of this description may have failed to disclose its existence; although doubtless much of it was returned as profit. ${ }^{1}$

$\mathrm{Had}$ it not been for the increased assessment under the statute of 1885, the income from English investments in foreign countries assessed under Schedule $\mathrm{D}$ would have risen only from 13.7 to 22.5 millions, between 1884 and 1895 ; and it amounted in the latter year to less than 30 million pounds. To this may be added income from loans to foreign and colonial governments and from Indian railways, assessed at about 24 million pounds, making a total of 54 millions. But in 1882 a very high authority, Mr. Robert Giffen, computed the income from foreign investments at 75 millions. The assessment was then 30 millions. Mr. Giffen made another computation in 1885, according to which the foreign revenue was then 85 millions. In 1895 it is highly probable that it was much more

1 Judging from the aversion of the English taxpayers to the income tax, it seems probable that much evasion would take place under this head if it were practicable. That it is practicable is admitted by the Secretary of the Board of Inland Revenue. He testifies: "If a person receives an open cheque or draft payable through a banker upon which there is no visible evidence that it is in payment of a dividend, we cannot put the banker into the position to determine and decide whether it is income or not. In such cases we are dependent entirely on the return made by the recipient." 
than 100 millions, and perhaps twice as much as its assessed value.

If we compare the returns under Schedule $\mathrm{D}$, we observe that the increase in the income from trades and professions, which is ascertained by the method of disclosure, is very small, while the increase of income from public companies, whose accounts are open to inspection, is very large. In 1870 the income from trades and professions was assessed at 131.8 millions, subject to deductions amounting to 12.9 millions, or a net assessment of $\mathbf{1 1 8 . 9}$ millions. In 1895, the gross assessment was 170.3 , the deductions 49.3, and the net assessment 121 million pounds, a gain of about two millions in twenty-five years. But some uncertainty affects the item of deductions, owing to changes in the law, and other causes. The gross assessment of public companies, etc., however, rose from 97.2 millions in 1885 to 151 millions in 1895 , a gain of nearly 54 millions in ten years. This was from domestic sources only; including foreign sourees the amounts would be 111 millions, and 177 millions. In 1900 the increase in the income of trades and professions during the previous decade was found to be about one-tenth of the increase in the income of public companies. In 1903-04, this income, taking the gross figures, had come to exceed that of trades and professions by one-sixth. But the deductions had become so large as to make it probable that the net income from trades and professions had actually decreased. Doubtless the incorporation of many firms accounts to a considerable extent for this phenomenon; but it tends to confirm the charge that evasion is extensively practiced where it is practicable. Although such evasion is complained of by the Board of 
Inland Revenue, the commissioners charged with the assessment of this tax belong to the propertied class, and the active officers are superior to the ordinary functionary of this kind elsewhere, so that collusive under-assessment is not believed to prevail.

While the evidence points strongly to the conclusion that, under the English system as well as in this country, gross injustice is caused by imposing taxes on property at valuations ascertained by the method of disclosure, it may seem not altogether convincing. It happens, however, that revelations have been made which put the matter beyond question, the evidence having been furnished by the highest authority. In his budget speech in 1853 Mr. Gladstone said:

"I will state what happened in a great town where a new street was to be built. The persons who lived and carried on business in the old street, which was pulled down to make way for the new one, had been charged at a certain amount to the income tax. They had also, of course, made returns at a certain amount under the income tax. When the new street came to be built, they claimed compensation for the loss of their business. Twenty-eight persons in all claimed the sum of $£ 48,159$ as compensation for their profits for a single year. But what was the amount at which they had returned their profits for assessment to the income tax? They claimed $£ 48,000$; they got from the jury nearly $£ 27,000$; but the return of profits for assessment to the income tax which they separately made had amounted only to $£ 9,000$. Frauds of this kind, and in many other cases, do exist; they are inseparable from the character of the impost, human nature remaining as it is."

In their valuable report rendered in 1870 , the Commissioners state that they have often called attention to the 
large evasions practiced under Schedule D by means of fraudulent returns, and continue: "It was not, however, until recently that we were enabled to form a reliable estimate of the loss which the revenue sustains in this way. An extensive demolition of houses by the Metropolitan Board of Works gave rise to a great number of claims to compensation. Two hundred of these were examined by our officers, and in eighty cases surcharges were made and sustained on appeal - that is to say, in 40 per cent of the cases inquired into, the revenue had been defrauded of its dues. The aggregate of the taxable incomes returned by the parties themselves was $£ 73,642$, and the amount ultimately found to be correct was $£ 171,370$, being in excess of the returns by $£ 97,728$, or about 130 per cent."

The commissioners further explained that this was not an exceptional case. "As an invariable consequence of claims for compensation, where the actual profits of trades or professions are divulged, we find the income tax returns largely deficient. And, moreover, this is not confined to any particular class, trade, or profession; we find the same practice prevailing among legal practitioners, when on the abolition of their exclusive privileges in some particular Court they have to make good their claims to your Lordships; we find it on all occasions of large demolition of shops and warehouses for public purposes, in every variety of trade, and we find it in great public companies and in firms whose business is almost a national concern, from its magnitude and world-wide reputation; we therefore think that we may venture to generalize upon the facts which the most recent occasion of compensation cases has furnished." The conclusion reached was that 
130 per cent was rather an understatement of the extent to which the returns ought to be increased.

This statement indicates that about 40 per cent of those who paid income tax returned their income at little more than one-third of its amount. Supposing the income of the other 60 per cent of the taxpayers to have been returned at its full value, they would have paid at nearly three times the rate paid by the others. In view of the moderate rate of the tax at the period in questionamounting only to about one-fiftieth of the income - the aversion to the tax on the part of the English tradesmen appears to Americans of the present generation rather extreme. The property tax here frequently amounts to more than a fiftieth of the gross value, and is perhaps generally equivalent to an income tax of one-tenth to one-fifth. With an income tax in 1902 of fifteen pence in the pound, or more than three times what it was in 1870 , it has seemed probable that the discrepancy then existing was materially, if not correspondingly, increased. In fact the complaints became so serious as to lead in 1904 to investigation by a Parliamentary committee. The proceedings of this committee were not all public, but the testimony taken seems to sustain the complaints. It was perhaps thought unwise to explain to the taxpayers, as was done in 1870 , the methods by which evasion is practiced, or to dwell upon the injustice of a tax which discriminates in favor of the less scrupulous trader. The report of the committee, however, shows great reluctance to resort to more inquisitorial methods than are now employed, and the changes that they have to suggest are not of a nature to remove the fundamental objections to the method of self-assessment, or disclosure. What the report 
especially illustrates is the enormous loss by friction caused by the practice of collecting taxes from those who are not taxable, and then undoing this complicated proceeding. The cost of collecting taxes will be considered later; but a few words on the situation in England may be here introduced. ${ }^{1}$

1 Sir Charles Dilke, the chairman, speaks of "the formidable evidence enforcing the necessity for universal declarations which came before this committee, and was not allowed to be published." The evidence was suppressed because it seemed "to involve the possible use of names which it might be undesirable to give in public, or of systems of evasion which it might be wise not to call too much attention to." It appeared that "enormous evasions of the income tax" took place, that "an enormous amount of property escaped," etc. In consequence of this report, the law was altered in 1907 , so that every one who receives a notice from the Inland Revenue Board $-600,000$ are sent out - must make a return of his income, even if it is nil, under penalty of a fine. This will subject perhaps 200,000 people to vexation, because some of their number have been negligent or dishonest. The penalties for making incorrect returns have been increased, and the period during which the government can recover extended. All employers must give the names and salaries of their employees. The abatement allowed at the end of a year when the profits fell below the average of the three years preceding is to be done away with. The abatement of $3 d$. on earned incomes is to be granted only to those who make out a full statement of all their income; it being thought that many persons who do not now make returns would be led to do so for the sake of the abatement. The evidence taken by the committee proves that the high tax of recent years has not only produced a very large number of claims for repayment from nonresidents, but has also caused an enormous increase in all sorts of claims. "People who considered it hardly worth their while to trouble about making claims when the tax was at $8 d$. did think it worth while when the tax was 1 s." It is to be observed that when a marriage takes place, the incomes of the husband and wife (with some allowance for the separate earnings of the wife) are added for purposes of taxation. Both may have enjoyed exemptions or abatements before their union, which they now lose. It is obvious that this constitutes a discouragement to legitimate sexual connections which may have evil effects on the institution of the family. The changes in the income tax have been as follows: From 1842 , when the tax was reimposed, to 1852 , all incomes over $£ 150$ were charged at $7 d$. in the pound without any abatement. From 1853 to 1862 , incomes over $£ 100$ were charged, but at a less rate than those 
Reckoning as naught the aggregate of vexation and waste of time, it seems doubtful if the various abatements and exemptions allowed constitute a material gain to the community. The expenses of the Board of Inland Revenue, although the commissioners for assessing the tax serve without pay, are perhaps not far from eight per cent of the amount of income tax collected. The number of abatements of $£ 150$ allowed because the income is between $£ 160$ and $£ 400$ is now over 600,000 , and their amount nearly $£ 100,000,000$. The number of incomes in this class is more than four-fifths of the whole number, and their amount is seven-twelfths of the whole assessment to persons. Taking everything into account, it is far from improbable that the total burden imposed by this complicated system, by which the government takes more than its due from its subjects, and returns a part of it to them, after long delay, when compelled to do so by the employment of a cumbersome and perplexing procedure, more than counterbalances the relief afforded by the partial exemption of small incomes. Public companies, etc., having incomes of more than $£ 5,000$ number 5,500 and are onefourth of the whole number. They have incomes amounting to some $£ 231,000,000$, or more than nine-tenths of the income of this class. The number of firms having in-

over $£ 150$. From 1863 to 1871 an abatement of $£ 60$ was allowed on all incomes between $£ 100$ and $£ 200$. From 1872 to 1875 the abatement was $£ 80$, allowed on incomes up to $£ 300$. From 1876 to 1893 incomes below $£ 150$ were exempted, and the abatement was $£ 120$ on incomes below $£ 400$. From 1894 to 1897 incomes below $£ 160$ were exempt, incomes below $£ 400$ were allowed an abatement of $£ 160$, and incomes below $£ 500$ an abatement of $£ 100$. Some abatement was also allowed for the separate earnings of wives. In 1898 incomes between $£ 400$ and $£ 500$ had an abatement of $£ 150$, between $£ 500$ and $£ 600$ an abatement of $£ 120$, and between $£ 600$ and $£ 700$ an abatement of $£ 70$. In 1907 an abatement of $3 d$. was allowed to "earned" incomes under $£ 2,000$. 
comes over $£ 1,000$ is about 15,500 , or more than onethird of the whole number, with income amounting to five times that of the small firms. Were the whole machinery employed in the assessment and collection of the income tax swept away, excepting what was needed for collecting the tax from large firms and corporations, the saving would very soon, it seems possible, make up for the temporary, and largely nominal, increase in the burdens of those interested in these firms and corporations.

The evidence offered by the Board of Inland Revenue, and abundantly corroborated by private persons, together with our experience of the evils of the method of disclosure in this country, seems to make it unnecessary to present anything further in order to sustain Mill's conclusion that the income tax, on whatever principles of equality it may be imposed, is in practice unequal in one of the worst ways. In this conclusion Mr. Gladstone concurred, and he came near to extinguishing the tax; but the Crimean War, in the first place, and his failure to carry the country, at the election in 1874 , prevented him from effecting his purpose. As the tax is apparently paid by a small number of rich people, it would perhaps be idle to expect that the mass of the citizens should concern themselves much as to its justice, and it will probably remain a feature of the English fiscal system for an indefinite period. But unless human nature should change, such a tax must enable dishonest, unscrupulous, and astute men to remove burdens from themselves and place them upon the helpless and the conscientious. Those who are unwilling to make false statements are thus in many cases driven out of business; and while at the perjuries of taxpayers, like those of lovers, Jove may laugh, the prac- 
tices inseparable from the application of the method of disclosure tend to lower the tone of the business world, and to force the direction of industrial affairs into the hands of men who have' little scruple at defrauding or corrupting those with whom they deal, whether they be private citizens or revenue officers. The extent to which collusion with these officers prevails cannot be determined, but we know that it exists in our country, and that it must always be possible where the method of discovery is employed. This method seems to be as incompatible with justice when income is taxed as when personal property is assessed, and as it is impossible to assess incomes without resorting to it, it follows that the income tax cannot be favored by those who regard justice as an end in taxation. 


\section{CHAPTER VI}

\section{TAXES ON EXPENSE}

Since the application of the proportionate method, either by means of disclosure or through inspection, seems necessarily to violate the recognized principles of justice, we might conclude that the method could not be applied at all. There is, however, a conceivable escape from this conclusion. Even if we cannot ascertain the amount of wealth owned by the individual subject, nor the extent of his income, it may be possible to discover these quantities through some process of inference. Income is received in order to be spent, for the most part; and it is conceivable that this expenditure may be measured by the sovereign, and that taxation levied upon it may constitute in effect a proportionate, or even a progressive, income tax. In other words, while we cannot learn the amount of a man's income, we may learn the amount of his outgo, and, by taxing the objects for which he disburses his money, may succeed in compelling him to contribute to the support of the government in proportion to the revenue that he enjoys under its protection.

If we examine the English revenue system, we observe that it has been deliberately framed in conformity with some such theory, and that it is intended to equalize the sacrifices of the subjects. Several causes have operated to produce this result. The insular position of the British Isles has made the collection of duties on imported goods much simpler and more effective than elsewhere. The 
general government has had far more authority than that of the United States, compared with the local governments, while the territory covered is so small as to enable it to act with much greater efficiency. What is of a great deal more importance, the government has frequently been directed by men acquainted with the lessons of political science, and disposed to regard them in the laws which they made and in the administration of those laws. There are clear traces in the English system of the influence of Adam Smith and J. S. Mill; both men of great learning and unusual powers of reasoning, who were sincerely concerned in bettering the lot of the weaker and humbler members of human society by relieving them from those burdens with which that society had aggravated the inequalities of nature. ${ }^{1}$ They were aware, withal, that as it was impos-

1 Even in the eighteenth century, some features in the system of taxation in England seemed to discriminate in favor of the poor. Arthur Young, addressing a French audience at the beginning of the Revolution, said: "We have many taxes in England which you know nothing of in France, but the Tiers État - the poor - do not pay them. They are laid on the rich. Every window in a man's house pays, but if he has no more than six windows he pays nothing. A seigneur with a great estate pays the vingtièmes and tailles, but the little proprietor of a garden pays nothing. The rich pay for their horses, their carriages, their servants, and even for liberty to kill their own partridges; but the poor farmer pays nothing of this; and, what is more, we have in England a tax paid by the rich for the relief of the poor." Pinkerton's Voyages, IV, 200. Tocqueville declared that "for centuries the only inequalities of taxation in England were those which had been successively introduced in favor of the necessitous classes. . . . In the eighteenth century it was the poor who enjoyed exemption from taxation in England, in France it was the rich. In the one case, the aristocracy had taken upon its own shoulders the heaviest public charges in order to be allowed to govern. In the other case, it retained to the end an immunity from taxation in order to console itself for the loss of government." L'Ancien Régime, 146. These statements give but a partial view of the situation, and it would be easy to show that the lot of the English poor was not ideal. But compare Lecky, Democracy and Liberty, I, 337, seq. 
sible for the officers of government to know the pecuniary circumstances of every subject, no system of taxation based on the supposed possession of such knowledge could possibly, unless by chance, be just.

These writers, and we may say economists in general before the present generation, were much influenced by the theory of the division of revenue into rent, profit, and wages. This seemed to point to a tripartite division of mankind into landlords, capitalists, and laborers; the implication being that the classes were mutually exclusive, although the incorrectness of this assumption was generally understood. Now the very act of classification eliminates individual differences, and if there are really three economic classes, the problem of taxation becomes enormously simplified. Instead of having to find out the condition of every individual human being, the legislator needs only to determine the circumstances of a large class, every member of the class being by hypothesis in like condition with every other. With this hypothesis it became possible to bring Political Economy to a high degree of perfection, and much of Ricardo's reasoning is essentially mathematical. It is true that any change in the condition of one class reacts on the others, and the analysis of these reactions was also carried to great completeness; but the main assumption was unaffected.

Although Adam Smith had explained that wages depended partly on the demand for laborers, and partly on the cost of provisions, the researches of Malthus had the effect of attracting attention to the latter cause, and led some economists to dwell on it with rather exaggerated emphasis. A popular impression was thus created that laborers as a class multiplied at such a rate as to keep their 
standard of living so low that they would suffer severe privation if their supply of provisions was reduced. According to this view, when the cost of food declined, laborers took advantage of the plenty, and increased in number till their increased consumption brought them back to their former level. The increased consumption of bread would require a greater acreage of wheat, which could be obtained only by bringing less productive land under cultivation. Since this land should yield the ordinary profit to capital, the better land would yield a higher profit, which would tend to be appropriated by the landlords in the form of higher rents. In so far as these tendencies prevailed, the condition of laborers was fixed, and their standard of living might be not much above that of cattle.

It is lamentably true that in some parts of Europe, and perhaps in the British Isles, the food of many laborers was formerly little better than that of the beasts which they tended, their shelter was hardly superior, and their clothing was a poor substitute for the integuments provided by nature for the horse and the sheep. It was at that time obvious that human beings in such poverty could pay little in the shape of taxes; and this inference continued to be drawn after the facts on which it was based had been altered. Any tax levied on wages already at the minimum needed for subsistence must either compel an increase in these wages - at the expense, according to Adam Smith, of landlords and consumers of manufactures, but really, as Ricardo showed, of profits - or cause the number of laborers to decrease through starvation. The wealthier classes were therefore appealed to by the economists not to injure their own interests by laying taxes on the necessaries of life, and this argument had much influence in the 
struggle for the repeal of those taxes on imported food known as the Corn Laws. It was much easier to convince the capitalists than the landlords, as their interest in having cheap food for their workmen was direct, while the landlords could not understand why the repeal of the corn laws would not lower their rents; but eventually there was a substantial acquiescence in the view that taxes on food were objectionable in their effects on all classes.

It should be remembered, however, that Adam Smith had demonstrated; with his usual thoroughness, that the condition of laborers when he wrote had been raised much above the deplorable standard above described; and in spite of the frightful cost of the wars with Napoleon, that condition probably continued to improve. Many things beside food, Smith pointed out, are required by common laborers. It is worth while to repeat his words: "By necessaries I understand, not only the commodities which are indispensably necessary for the support of life, but whatever the custom of the country renders it indecent for creditable people, even of the lowest order, to be without. A linen shirt, for example, is strictly speaking not a necessary of life. The Greeks and Romans lived, I suppose, very comfortably, though they had no linen. But in the present times, through the greater part of Europe, a creditable day-laborer would be ashamed to appear in public without a linen shirt, the want of which would be supposed to denote that disgraceful degree of poverty, which, it is presumed, nobody can well fall into without extreme bad conduct. Custom, in the same manner, has rendered leather shoes a necessary of life in England. The poorest creditable person of either sex would be ashamed to appear in public without them. In Scotland, custom has rendered 
them a necessary of life to the lowest order of men; but not to the same order of women, who may, without any discredit, walk about barefooted. In France they are necessaries neither to men nor to women; the lowest rank of both sexes appearing there publicly, without any discredit, sometimes in wooden shoes and sometimes barefooted. Under necessaries therefore, I comprehend, not only those things which nature, but those things which the established rules of decency, have rendered necessary to the lowest rank of people. All other things I call luxuries; without meaning by this appellation to throw the smallest degree of reproach upon the temperate use of them. Beer and ale, for example, in Great Britain, and wine, even in the wine countries, I call luxuries. A man of any rank may, without any reproach, abstain totally from tasting any such liquors. Nature does not render them necessary for the support of life, and custom nowhere renders it indecent for people to live without them."

It follows, Adam Smith concluded, that as a tax on the necessary articles of subsistence raised their price, it must correspondingly raise wages. The laborer must still be able to purchase those things which it would be indecent for him to go without. But it is otherwise with taxes on luxuries; the rise in their price will not necessarily occasion any rise in the wages of labor. A tax on tobacco, for example, though a luxury of the poor as well as of the rich, will not raise wages. A tax of three times its original price in England, and fifteen times in France, seemed not to affect wages. So of the taxes on tea and sugar, which had become luxuries of the lowest order of people in England and Holland; and so of the taxes on alcoholic liquors. "The rise in the price of porter, occasioned by an additional tax of 
three shillings upon the barrel of strong beer, has not raised the wages of common labor in London. They were about eighteen-pence and twenty-pence a day before a tax, and they are not more now."

To these conclusions Adam Smith added certain others of very great importance. The sober and industrious poor, he declared, are disposed by sumptuary taxes to limit their expense for superfluities which they can no longer easily afford. But it is the sober and industrious poor who generally bring up the most numerous families, and who principally supply the demand for useful labor. "All the poor, indeed, are not sober and industrious, and the dissolute and disorderly might continue to indulge themselves in the use of such commodities after this rise of price in the same manner as before, without regarding the distress which this indulgence might bring upon their families. Such disorderly persons, however, seldom rear up numerous families; their children generally perishing from neglect, mismanagement, and scantiness or unwholesomeness of their food. If by the strength of their constitution they survive the hardships to which the bad conduct of their parents exposes them, yet the example of that bad conduct commonly corrupts their morals; so that, instead of being useful to society by their industry, they become public nuisances by their vices and disorders. Though the advanced price of the luxuries of the poor, therefore, might increase somewhat the distress of such disorderly families, and thereby diminish somewhat their ability to bring up children, it would not probably diminish much the useful population of the country."

The foundation for a consistent, if not a scientific, system of taxation thus laid by Adam Smith was completed by 
his showing that it was indispensable, for purposes of revenue, to tax laborers. As he observed, "the whole consumption of the inferior ranks of people, or of those below the middling rank, . . . is in every country much greater, not only in quantity, but in value, than that of the middling and of those above the middling rank. The whole expense of the inferior is much greater than that of the superior ranks. . . . The taxes upon expense, therefore, which fall chiefly upon that of the superior ranks of people, upon the smaller portion of the annual produce, are likely to be much less productive than either those which fall indifferently upon the expense of all ranks, or even those which fall chiefly upon that of the inferior ranks; than either those which fall indifferently upon the whole annual produce, or those which fall chiefly upon the larger portion of it. The excise upon the materials and manufacture of home-made fermented and spirituous liquors is accordingly, of all the different taxes upon expense, by far the most productive; and this branch of the excise falls very much, perhaps principally, upon the expense of the common people."

It should be added that liquors fermented or distilled, not for sale but for private use - as is now substantially the case in France - were not then subject to excise, the exemption being more to the advantage of the rich, who brewed their own beer, than of the poor, who bought theirs at the brewery or alehouse. This exemption from very heavy taxes which are paid by the poor laborer and artificer, Smith declared, was very unjust and unequal, and the substitution of a duty on malt, which he demonstrated was fiscally preferable to the existing excise, was desirable as a social reform. 
It is hardly too much to say that the reconstruction of the whole fabric of English taxation according to the principles established by the great Scottish economist, is the most splendid instance in the history of the world of the application of reason in the affairs of government. Nor is it too much to say that the resulting system has been on the whole intended to conform to the demands of humanity commonly recognized by the English people. It approaches, theoretically, nearer to perfection than any other system of taxation that has ever prevailed. It is true that the motives to which Smith appealed were not all of the most exalted character. The things necessary to the comfortable subsistence of the poor were not to be taxed, because the rich would have to pay the tax in the shape of increased wages; but while to act according to selfish advantage does not command our enthusiastic admiration, to follow the dictates of an enlightened self-interest is not easily to be distinguished from virtue. When Smith wrote, not only was the bread of the laborer taxed, but four of the chief necessaries of his life; salt, leather, soap, and candles, as well as coals, wool, and other materials in common use. All have been freed from taxation; and even sugar, which was called a luxury, was exempted in 1874 , although this exemption has now ceased. On the other hand the taxes intended to fall on the rich have been retained; the house tax, the tax on armorial bearings, on carriages, on man-servants, on wines, on sporting. Even the railway passenger tax has been levied on travelers by first and second, but not by third-class carriages. On the whole, the theory of taxing classes of men is consistently applied. Landlords and capitalists pay taxes on rents and on income in general, and their estates are subjected to progressive 
death-duties. Laborers pay chiefly on what are called their luxuries - alcoholic drinks, tobacco, and tea; and the rich are also taxed on their expense for such luxuries.

Yet this inquiry is not primarily concerned either with the theoretical perfection, or the practical efficiency of any system of taxation. We have to determine how far taxation can be shown on rational grounds to conform to recognized standards of justice, and we have already seen that the income tax is on such grounds indefensible. Furthermore, the assumption on which the doctrine of economic classes is based must be submitted to the test of reason. Justice, it seems plain enough, has regard to individual persons; when a man is compelled to submit to an exaction which causes him peculiar suffering, it is no answer to his complaint to tell him that he belongs to a class which does not suffer. Class is a general name; it denotes concrete individuals; but the group in which they are conceived is a metaphysical entity, which is not to be confounded with the actual human being, or treated as if it were of the same order of existences. The doctrine of averages is of immense convenience in statistics; we may ascertain with some degree of accuracy the average height of the inhabitants of a country, or their average weight, or the average duration of their lives. We may perhaps even learn their average intellectual capacity or moral purity. But we should obviously be guilty of the most cruel injustice if we were to estimate the virtue of an individual woman by any principle of averages; her chastity is not to be impugned because of the frailty of many of her sex. There may be an average percentage of dishonesty among servants; but this means only that some individuals are honest and some are not, and no one would accuse a faithful 
domestic of stealing because of the doctrine of chances or general probabilities. ${ }^{1}$

These considerations cannot be ignored in taxation. If justice is to be attained it must be through equality of sacrifices by individuals, and the fact that the aggregate sacrifices of a great many persons divided by their number would give a certain average sacrifice on the part of each, is, so far as justice is concerned, immaterial. To maintain the contrary would be nearly as absurd as to insist that a man aged fifty must really be forty years old, because he belongs to a class of which that is the average age, or to treat a permanent invalid as shamming, because in the

${ }^{1}$ Mr. Gladstone's criticism of this doctrine deserves to be quoted. He said: "It is commonly stated that, though we cannot do justice to each individual, we may do justice as between classes; and that for this purpose we must take an average of each class within itself. Now, I question the doctrine of those who propose to do justice between the various kinds of income by establishing averages for each class within itself. . . . In the name of reason and common sense, I ask how those who demand either equality, or an approach to it, can obtain it by averaging classes of income? Look at annuities. The tables give the value of female life at fifteen years of age at twenty-five years' purchase; but go upwards to seventy or seventy-five years of age, and the value of the life is only five years' purchase: yet you propose to average, forsooth, these dissimilar cases - to bring up the value of the five years' purchase and bring down the value of the twenty-five years' purchase to a common standard. What possible average can these interests admit of? A life of twenty-five years' purchase is five times the value of one of five years' purchase. Will it be any consolation to the life of five years' purchase, when called on to pay three times as much as he ought, on the principles of the reformers of the tax, to pay, that the life of twenty-five years' purchase pays only half as much as he should do? Still more absurd would be the attempt to average trades. Many trades are worth twenty-five years' purchase. . . . Let us, however, state the case moderately, and say that some trades are worth twenty-five years' purchase; there are others not worth more than five, four, or three years' purchase, and how are you to average the interest of a trade worth three and another worth twenty-five years' purchase? I must enter my protest against this averaging of classes as a mode of what is called doing justice in the matter of the income tax." 
class to which he is assigned he is entitled to be sick only three days in a year. The only ground for including a number of objects in a class, is their common possession of certain attributes or qualities, and we can reason concerning a class only in so far as we reason concerning those qualities. Furthermore, the larger the class, the smaller is the number of qualities that it includes; denotation and connotation vary inversely. Man is a very general name; the great number of individuals that it denotes severely limits its connotation, and the fact that a Chinaman and a Spaniard are both men enables us to draw comparatively few inferences concerning them. Laborer is also a very general name; it is applied to an enormous number of human beings who may have very little resemblance to one another, and in fact very few assertions concerning the laboring class have any pretence to accuracy.

For what is the differentia of this class? Is it the performance of manual labor? And does manual labor mean muscular exertion; and, if so, is it with or without intellectual activity? Is it manual labor to telegraph, but not to telephone, to operate a type-writer, but not to use a pen? Is it manual labor to give lessons in gymnastics, but not in writing; to play on the piano, but not to sing? Is it manual labor to care for babes, but not to nurse bed-ridden adults? Enter a modern machine shop, and you behold a number of men apparently doing nothing; really the machines are doing the work, and the men are watching to see that it is done properly. When hand brakes were in general use a great deal of muscular exertion was required to operate them; have the brakemen ceased to be laborers because the air-brakes are operated by steam? Are sempstresses laborers, but saleswomen not? The occupation 
of a bank clerk is properly called extremely laborious; is he properly called a laborer?

It may be said that it is not the exertion of the muscles that constitutes the differentia, but the receipt of compensation for services. Vast numbers of men exercise vigorously, but their exertion is not regarded as labor because it is not paid for by any one; if they exerted themselves for pay they would be laborers. But soldiers might according to this definition be classed as laborers, which is certainly paradoxical. And if every one who does another a service for pay is a laborer, lawyers and doctors must be called laborers, and this too is contrary to usage. Nor does it seem to be material that payment is sometimes made daily or weekly, and sometimes by the month, or even by the year. It is still common for laborers on the land to hire themselves by the year; and teachers may be paid by the hour. Many clerks are employed by the week or month, and many miners and workmen in mills by the year. Possibly it might be maintained that whoever received a compensation that was commonly called wages was a laborer, but not if his compensation was called by another name. But this appears to be a mere verbal distinction, for men doing similar work are said sometimes to receive salaries, and sometimes wages. Moreover, vast numbers of men work for themselves, and for others at the same time; they are their own employers, and they in fact receive both wages and profits. They certainly perform labor, and the products of their labor are of service to the community; but they are not said to receive wages, and are not called laborers.

The existence of this latter class proves that we cannot now, whatever may have been true in the past, make an 
economic class of laborers. Probably the nearest approach to a differentia would be comparative poverty; we might say that men who did work for others for a very small compensation were laborers. The value of this distinction, however, is due to the fact that it is a real distinction between two economic classes, the rich and the poor. It is no doubt true that unless they worked for others some persons would starve and that some would not. Yet a great many people who do work for others could still live comfortably, although more simply, if they did no work. They are rich, but they prefer to have a larger income than suffices to maintain life. And this is true of vast numbers of those who perform manual labor, whether light or heavy; they could subsist on much less than they earn, perhaps on what they have saved from their earnings, and they often give up work when they find their strength declining. In this country, at least, it might almost be said that there is in fact no "irreducible minimum"; there is no considerable number of persons who could not live on smaller incomes than they receive. They could also marry and rear families ; for, under the modern system of industry, wives may earn a good deal by working away from their homes, and the support of children, from birth to maturity, can be largely thrown on the public. There are free lying-in hospitals, free crèches or day nurseries, free schools, with free transportation thereto, free medical attendance and prospectively free lunches, together with numberless "homes," and unbounded private alms.

Even if we limit our reasoning to such persons as receive a compensation for manual labor called wages, we cannot assume that they are comparatively poor. Skilled mechanics often earn more in a year than many lawyers 
or doctors or clergymen. They commonly earn more than clerks and perhaps twice as much as teachers. A skilled laborer in the City of New York receives usually, perhaps, a larger compensation than many a professor in our colleges, than not a few judges, and in some cases three times as much as most country ministers. Some of those employed in iron works are said to earn ten and even fifteen dollars a day; which is ten or fifteen times what many common laborers receive. Even in the same kind of industry, wages differ greatly in different parts of the country. In the City of New York the workmen employed in the building trades obtain as much for an hour's work as men similarly employed in some parts of the country get for working a half, or even a whole day. Now if the purpose of assuming the existence of a laboring class is to assess the average income of its members, it seems clear that very great inequality of sacrifice on the part of individuals must result. Modern economists, we may add, are inclined to class many persons as laborers who would not have been formerly so described. ${ }^{1}$

As a matter of fact, no one has illustrated the inequalities in laborer's wages more strikingly than Adam Smith

'Sidgwick, for example, extends the meaning of "production" so as to include in it the labor of carriers and traders, no less than that of farmers and manufacturers. Pol. Ec., p. 98. And he also includes "in the notion of labor that earns wages all remunerated employment of time and energies; and therefore the exertions, intellectual and muscular, of the employer no less than those of the employed." Ibid., p. 320. He adds also that "there is hardly any branch of industry in which a laborer stronger, more industrious, more skilful, or more careful than his fellows is not likely in one way or another to obtain more than the average rate of remuneration." Such a laborer is only indirectly concerned in the average rate of wages in his own industry. He is even less concerned in the variations in an average found by dividing the aggregate of workers' remuneration among the aggregate of workers. Ibid., p. 328. 
himself. He enumerates five circumstances in the nature of employments which vary the wages of labor, a number to which later economists have made some additions, and he explains how the "policy of Europe" has occasioned other inequalities of much greater importance. It is unnecessary to do more than refer to so classical an analysis; but it shows how vague the meaning of "the laboring class" has always been. As we have seen, when Smith deals with taxation, he divides workmen into the sober and industrious, and the dissolute and disorderly; and much of his reasoning applies to the "lowest rank" or "lowest order" of the people. These classifications are certainly important; but they have no essential relation to the classes of wage-receivers, or of laborers. The full significance of this point will appear if we examine what is involved in his view of the taxation of luxuries.

The classification as a luxury of any object of desire not indispensable to existence depends solely, according to his statement, on the relation which the consumption of that object bears to decency, or the state of public opinion concerning its use. Whatever a man may dispense with without incurring discredit, is a luxury, no matter how universal its use, or how wholesome it may be. Yet, even when he wrote, his reference to leather shoes showed that the standard of decency varied in different parts of the same country, and his illustration taken from the use of linen shows that such standards vary not only from place to place but also from time to time; for linen shirts are now worn only by some of the richer members of society. As he explained, potatoes are a cheaper food than oats, and oats than wheat; the common people of Ireland subsisted largely on potatoes, those of Scotland on oatmeal, and 
those of England on wheaten bread. Now potatoes are "peculiarly suitable to the health of the human constitution"; as much so as wheat, and more so than oats. "The chairmen, porters, and coal-heavers in London, and those unfortunate women who live by prostitution, the strongest men and the most beautiful women perhaps in the British dominions, are said to be, the greater part of them, from the lowest rank of people in Ireland, who are generally fed with this root. No food can afford a more decisive proof of its nourishing quality."

It is certainly not true now, and it was perhaps not true when Smith wrote, that the use of potatoes by an English family would be regarded as indecent. And it is unquestionably true now, and was on his own showing true then, that the ordinary laborer consumed many things beyond what decency required. There exist very great differences in the quality of things comprehended under one name. We speak of meat, meaning usually the flesh of graminiverous animals, including swine. The number of varieties of meat, however, is much greater than that of the species of these animals. Every one that has any acquaintance with agriculture knows that wide differences in value exist between different individuals of the same species, and every one that carries on a household knows that the prices of different parts of the same individual are very divergent. All these differences vary in different parts of the same country, and are even wider in different countries. When we speak of the consumption of meat by laborers, therefore, we are using a very ambiguous expression. We may have in mind the cheaper parts of the cheaper grades of swine or oxen, while our hearers may understand the more expensive parts of the corn-fed steers of the west, or perhaps 
the choicest poultry. The cost of what we have in mind may not be a quarter, or even a tenth, of what we are understood to mean; and corresponding differences in consumption actually take place. There are, however, no corresponding differences in nutritive power, and it can scarcely be contended that decency forbids any one to use in his own house the cheaper kinds of food. Decency, in Adam Smith's sense, means what is required by public opinion; and whatever may be true of private gossip, the contents of the ordinary larder do not fall within the cognizance of the public.

Adam Smith's illustrations also show that he had in mind the clothing in which men appear in public. But the differences in the quality and the cost of clothing are much greater than in the case of food. Even in his day, there was a great difference between coarse and fine linen; and in modern times the qualities of cotton and woolen fabrics, and of their manufacture into clothing, are numberless. Decency does not forbid the use of many of the cheaper grades by "creditable day-laborers"; women, indeed, of the poorer class are often thought more creditable when their attire is not expensive, than when it is noticeably so. Whatever may have been true in the past, it seems impossible to deny that in modern times a very large part of the expense of the mass of the people is for things that they are not required to use by decency; things of higher quality, for which cheaper things of the same kind, or cheaper substitutes, could without injury to health be employed. If this conclusion is valid, we cannot accept Adam Smith's definition of a luxury as satisfactory. It is not the definition that we should now give to the word; and there is reason to maintain that he did not always adhere to it. 
In the first place, as we have already noticed, he called attention to the fact that the whole consumption of the inferior ranks of people is much greater, not only in quantity but also in value, than that of the middling and superior ranks. Almost the whole capital of every country, he declared, is annually distributed as wages of productive labor. Much of rent and profit is distributed in the maintenance of the lower rank, as wages of unproductive labor. The taxes upon expense, therefore, which fall chiefly upon that of the superior ranks of people; are likely to be much less productive than either those which fall indifferently on the expense of all ranks, or those which fall chiefly upon that of the inferior ranks. This conclusion he regarded as proved by the results of the excise.

Accepting this conclusion, which indeed seems indisputable, we see that the excise must fall on all, or nearly all, of the inferior rank of people; for if it were paid by but a few of them it would be unproductive, instead of being the most productive of all taxes. It is true that Adam Smith makes some attempt to show that this tax may be paid only by the immoral members of this rank. He divides this class into two classes for that purpose; the sober and industrious poor, and the dissolute and disorderly. It is implied that only the latter class may submit to this tax; but unless the latter class is a very large one, this implication cannot be correct. Now neither Smith, nor perhaps any one else, would contend that laborers are, as a rule, dissolute and disorderly. Persons of that description constitute but a small part of the whole number. Hence their payments to the excise would amount to comparatively little; and the sober and industrious must pay by far the greater part of this tax. Whether the objects subjected to this tax be 
properly called luxuries or not, they are objects the enjoyment of which the common people will not deny themselves, even if they are taxed on that indulgence.

It is to be noted, too, that Adam Smith expressly declared that he did not mean to throw the smallest degree of reproach upon the temperate use of them. "The trade with the alehouse is not necessarily a losing trade. In its own nature it is just as advantageous as any other, though perhaps somewhat more liable to be abused." The workman may no doubt buy too much of the retailer of fermented liquors, or of the brewer, "as he may of any other dealers in his neighborhood, of the butcher, if he is a glutton, or of the draper, if he affects to be a beau among his companions. It is advantageous to the great body of workmen, notwithstanding, that all these trades should be free, though this freedom may be abused in all of them, and is more likely to be so, perhaps, in some than in others. Though individuals, besides, may sometimes ruin their fortunes by an excessive consumption of fermented liquors, there seems to be no risk that a nation should do so. Though in every country there are many people who spend upon such liquors more than they can afford, there are always many more who spend less." 1

1 "It deserves to be remarked, too, that if we consult experience, the cheapness of wine seems to be a cause, not of drunkenness, but of sobriety. The inhabitants of the wine countries are in general the soberest people in Europe; witness the Spaniards, the Italians, and the inhabitants of the southern provinces of France. People are seldom guilty of excess in what is their daily fare. Nobody affects the character of liberality and good fellowship by being profuse of a liquor which is as cheap as small beer. On the contrary, in the countries which, either from excessive heat or cold, produce no grapes, and where wine consequently is dear and a rarity, drunkenness is a common vice, as among the northern nations, and all those who live between the tropics, the negroes, for example, on the coast of Guinea. When a 
Since the number of things entering into the consumption of the common people is now much greater than formerly, and since the number of species of every one of these things is also considerable, while there are many grades of quality among these species, we seem obliged to abandon Adam Smith's definition of a luxury as inadequate. We may, perhaps, define it as something the consumption of which is not indispensable to healthy existence, but by doing so we unavoidably include many things commonly spoken of as necessaries. We are driven therefore to attempt to classify luxuries, an illustration of which appears in the common parlance by which some things are called harmless luxuries and some hurtful. A further distinction is made between things which men often consume to excess; that is, with injurious results to themselves and to those dependent on or connected with them. Now, as has been explained, a tax on anything not consumed in great quantities is of small consequence; the revenue so arising would be insignificant. Hence the thing taxed must be consumed by all, or nearly all the common people. But it seems no more just to tax the harmless luxuries of the poor than to tax their neces-

French regiment comes from some of the northern provinces of France, where wine is somewhat dear, to be quartered in the southern, where it is very cheap, the soldiers, I have frequently heard it observed, are at first debauched by the cheapness and novelty of good wine; but after a few months' residence the greater part of them become as sober as the rest of the inhabitants. Were the duties upon foreign wines, and the excises upon malt, beer, and ale, to be taken away all at once, it might in the same manner, occasion in Great Britain a pretty general and temporary drunkenness among the middling and inferior ranks of people, which would probably be soon followed by a permanent and almost universal sobriety. At present drunkenness is by no means the vice of people of fashion, or of those who can easily afford the most expensive liquors." Wealth of Nations, Book IV, Chap. III, Part II. 
saries; even if it were practicable to distinguish such things by statute, the attempt, if understood by the public, would be condemned. Hence the tax must be applied to harmful luxuries; to things universally used but which are harmful if used at all, or to things in which immoderate indulgence is very general, whether they be intrinsically harmful or not. The justice of taxing A for consuming a thing which is not harmful to him, because B consumes that thing intemperately, may be considered hereafter.

Now there is undoubtedly a general belief in this country that the drinking of beverages containing alcohol is not essential to healthy existence, although the practice is very extensive among the common people; and there is a widespread conviction that the practice is positively hurtful. Whether the moderate use of such drinks is injurious or not, it is notorious that many persons are immoderate in their use, and that such excess is seriously detrimental, not only to the drunkard, but also to his family and to the community. Similar beliefs prevail to a less extent concerning the use of tobacco. So powerful are these convictions that many persons who habitually consume alcoholic drinks are influenced by them, and regard their own practices as falling somewhat short of the highest requirements of morality.

No doubt many persons are not conscious of any inclination to indulge excessively in things of this kind, and either regard them as harmless luxuries, or as they regard the ordinary necessaries of life. They are so regarded in most European countries, and have always been so. Machiavelli describes a campaign undertaken by the Florentines, which they were obliged to abandon because the region occupied could not furnish wine for the soldiers; 
to subsist without wine was evidently then thought impossible, and in many places it would be thought so to-day. The rulers of France do not venture to tax to any great extent the wine which is universally drunk in the greater part of that country, nor perhaps would a heavy tax on beer be submitted to with patience in Germany. Sir Robert Walpole proposed some very desirable reforms in the English excise, but he was compelled to abandon them for fear of a rebellion. The ignorant apprehension of the common people that their drink might be more heavily taxed, stirred up by certain parties interested against the reforms, proved an insuperable obstacle. ${ }^{1}$ The tax on distilleries has always been peculiarly odious in Ireland, and has been steadily resisted in some parts of our own country. The mass of our common people, however, never having known a time when tobacco and alcoholic liquors were untaxed, and being wholly incapable of estimating how much their expenses are increased by such taxation, cannot be said to have any convictions on the subject; and public opinion, whether rationally or not, appears to be overwhelmingly in favor of taxes on strong drink, if not on tobacco.

Although we are not directly concerned with the question how far the taxation of things, the excessive consumption of which is regarded as pernicious, tends to reduce that excess, it may be observed that no satisfactory

1 The reform proposed by Walpole in 1733 was really the establishment of bonded warehouses. But mobs attacked members, petitions were sent in from the City, and there were signs of general rebellion. Parliament declared that it would not be influenced by mob rule, but Walpole said that in the temper of the country the measure could not be carried without armed force, and that there would be an end to the liberties of England if supplies were to be carried by the sword. The system was not established till 1803. 
proof has been offered that there is less drunkenness in communities where alcoholic drink is heavily taxed than elsewhere. In England, where the excise is heaviest, there is much drunkenness, and the consumption of strong liquors is perhaps greater than in any other country. We have already referred to Adam Smith's observation on the habits of soldiers transferred to the wine-growing provinces of France; and it is well to remember that the early settlers of New England were accustomed to drink ale before they emigrated, and regarded water as an unwholesome beverage. To be compelled to drink it here was one of their greatest hardships, and innkeepers were required by law to furnish ale to their guests. But they soon learned to produce cider in prodigious quantities, and at a later time distilled a great deal of rum. Many aged persons, however, whose recollection goes back to the days when there were no taxes on drink, declare that, making allowance for the general improvement of morals, drunkenness was no greater evil then than now. In those states where drinking is prohibited by law, so far as prohibiting the production, selling, or giving away of drink can achieve that end, there appears to be even more drunkenness than elsewhere. Paradoxically enough, more drunkards are found among the very poor than in the wealthier classes. It might be supposed that the wealthy would not give up their accustomed drinks because they were heavily taxed, and that the poor would do so. But while there is much testimony to the effect that the well-to-do are more temperate than formerly, we find little evidence that this is true of the poorest class.

It seems probable that the very poor, being often very 
miserable, have an intense desire for whatever gives them relief from their sufferings, even if it be but temporary, and if they cannot otherwise obtain it, will deny themselves, to a considerable extent, food, clothing, and other things which appear to those more comfortably situated indispensable to existence. They seek "some short cut to happiness, some moments of emancipating excitement." Strong drink gives them warmth and exhilaration. It brings them brief oblivion of their present misery and of their hopeless future. Similar effects seem to be produced by other stimulants, such as opium and perhaps tea. The almost universal consumption of tobacco, even by those who can obtain it only by stinting themselves in the use of what are called necessaries, indicates that it serves an important purpose, the precise nature of which appears to be imperfectly understood by physiologists. It is certainly paradoxical to describe as luxuries such things as tobacco, which are generally, in the estimation of those who use them, more indispensable than most articles of food; which men, it is true, can forego, as they can forego meat and fish and fruit and sugar, but which they will forego only after they have reduced their consumption of these commodities.

There is some ground for believing that when the cost of these luxuries of the poor, if they are to be so termed, is greatly increased, their quality becomes much impaired. The quality of the distilled liquors consumed in states where their sale is prohibited, is notoriously inferior. The common people in those states often drink alcohol, and other imperfectly refined spirits, the physiological effects of which are very injurious. The prohibition of the traffic amounts to a high tax on liquor; for those who engage 
in so dangerous an occupation must be compensated with a high rate of profit. Hence fermented liquors, having little alcoholic strength in proportion to their bulk, and being correspondingly difficult to conceal, are replaced by spirits of the most concentrated form. The very high excise of the national government causes much illicit distillation, the product of which must be at once disposed of, although the poisonous elements naturally require several years for their elimination. The effects of these inferior liquors are certainly more pernicious than those of properly distilled spirits, or of sound wines and beers, and they are believed to cause drunkenness of a peculiarly violent character. Complaint is also heard that those who are prevented from obtaining alcoholic beverages frequently resort to patent medicines, which contain much alcohol, and to opium and other drugs.

It may be added here that the Internal Revenue returns furnish strong evidence that neither high taxation nor depressed industry has much effect in reducing the consumption of these luxuries; indeed, fermented drinks are now consumed to an enormously greater extent than they were before they were taxed at all. In the year 1907 the revenue from distilled spirits was over $\$ 156,000,000$, and that from fermented liquors was nearly $\$ 60,000,000$. The decline in revenue during the years succeding the panic of 1893, when revenue from other sources fell off materially, was comparatively moderate, in spite of increased taxation. The claim, therefore, that these beverages are proper subjects of special taxation because those who use them can abstain if they choose, does not appear to deserve serious consideration. We are not concerned with what men can do if they choose, but with what they in actual 
life choose to do. Theologians have elaborately explained that men have the power to be sinless; they can, it is maintained, always choose right. In practice, however, they also explain that men do choose wrong; and certainly, in legislation, we must deal with men according to their conduct as exhibited in experience, and not as it might be if they were governed by other motives than those which are actually potent. No one had more thorough information concerning these subjects than the late David A. Wells; and his conclusion was that "if moral influences have ever materialy affected the general consumption of distilled spirits or fermented liquors in the United States, the tabulated tax experiences of its Government, which constitute the only reliable basis for forming an opinion, do not afford any indication of it." 1

On these grounds we must regard it as doubtful whether the high taxation of things, the excessive use of which is commonly called immoral, has much effect in preventing such excess, even if it is not positively demoralizing. Should this conclusion be established, the problems arising from the taxation of articles of consumption would be simplified. We need engage in no controversy concerning what is a necessary and what is a luxury, or whether it is just to compel those who consume certain things in moderation to pay a tax on them because it is thought

1 The president of the Distilling Company of America, a concern which produces a large portion of the spirits consumed in this country, reports that when a state legislature enacts a prohibitory law the sales of his company's products in that state usually increase. During the year 1897 the tax paid on distilled spirits showed a consumption of some $64,000,000$ gallons, or nine-tenths of a gallon per head of population. For fermented liquors the corresponding figures were $1,101,500,000$, and 15.4. In 1907 the number of gallons of distilled spirits paying tax was $134,000,000$, or 1.58 gallons per head; of fermented liquors, $1,873,475,000$, or 22 gallons per head. 
desirable to tax those who use them to excess. So long as such controversies engage the attention of the legislature, it seems hopeless to attempt to treat taxation as a science, or to attain any approximation to the ideal of equality of burdens. As has been pointed out, public opinion is overwhelmingly in favor of taxing certain things called, whether properly or improperly, luxuries, and we must assume that such taxes will long be retained. They should be treated, however, on the same principles as taxes on other things commonly consumed; and our experience shows that they tend to be governed by these principles even when others are involved. The important points are that the revenue of the common people is somewhat more than sufficient for their support, that a tax on anything generally consumed by them may transfer a part of this revenue to the use of the government, and that the more extensive the use, the more productive will the tax generally be. Salt is perhaps more universally consumed than any other commodity, and the English government derives from a tax upon it a large part of the revenue which it requires to maintain its Indian Empire; although the inhabitants of that Empire are perhaps even less able to endure taxation than the common people of England were when Adam Smith wrote.

There is reason to suppose that the effects of the tax imposed by the United States government on distilled liquors are not fully comprehended by the public. Tobacco and tea, wine and beer, are used almost exclusively like food or as drink; they are introduced directly into the alimentary system. Distilled spirits, however, are extremely useful for innumerable purposes. They are indispensable in compounding medicines, which must cer- 
tainly be classed as necessaries rather than luxuries, since without them life would often be lost; but they are also indispensable in many of the arts. In fact there are few substances having so many and such important uses in manufactures as alcohol. It is used as a fuel for motors, and for heating and cooking, as well as to give light. It is necessary in making smokeless powder, in making dyes, celluloid, lacquer, varnishes, and numberless other articles. By its aid cotton can be so treated as to be a cheap and acceptable substitute for silk; and it is indispensable in the processes of photography. It would seem to be dictated by common sense, if not by the most elementary political wisdom, that the government should not deliberately repress all these industries, even if it did nothing to foster them. For more than forty years, however, our government has levied a tax at various rates on the production of this substance, which has during part of this time amounted to nine or ten hundred per cent sometimes even fourteen or fifteen hundred per centon its cost. It can ordinarily be produced and sold for perhaps twenty-five or thirty cents, while the tax has of late years amounted to over two dollars a gallon. In the year 1907, apparently without any intelligent purpose of relieving industry, but with a confused notion that it might thus decrease the profits of the shareholders in the Standard Oil Company, Congress adopted the policy of other countries, and remitted the tax on the distillation of alcohol, provided it was rendered non-potable by adulteration with some poisonous substance. ${ }^{1}$

Although there are, according to men competent to form

1 Nearly 6,000,000 gallons of methylated spirits are consumed yearly in England. 
an opinion on such matters, good fiscal reasons for taxing the production of spirits rather than the sale, our governments have taxed both. The general government compels the payment of license fees by all dealers in alcoholic liquors, and the states and municipalities have commonly adopted a similar policy, the result being that three or four taxes are levied on the same thing. The charge for these latter licenses is often very high; it is a thousand dollars a year in some cities, and more than this in others. They are also very productive of revenue, and the requirements of the law, at least so far as the general government is concerned, are enforced with some strictness. It is evident, therefore, that no fiscal reasons prevent the government from obtaining a large revenue by taxing potable alcoholic liquors where they are sold, and leaving the production of alcohol free. No doubt much untaxed liquor would then be drunk, as much is drunk now. But as it is now entirely possible for any one to obtain liquor elsewhere than at the licensed drinking places, and thus avoid the payment of the tax on drink sold there, and as immense numbers of people do not choose to avoid taxation in this manner, it is clear that the fiscal advantages of taxing the production of alcohol have been exaggerated. There is certainly no pretence to justice in taxing every man who paints his house or varnishes his wagon, because other men are prone to indulge in drink; especially since the feasibility of taxing the latter class and exempting the former is demonstrable.

Although the analysis of the effects of taxing the use of alcohol should properly take place when the diffusion of taxes is examined, it may be here remarked that the excise on distilleries in this country has always been 
fruitful of fraud and corruption. At times whiskey has actually been sold in the market for less than the tax on it, and while the revenue from this source is better collected than formerly, there is notoriously much illicit distillation. Hundreds of lives have been sacrificed in the attempt to collect this tax in the mountainous parts of the sounthern states, and the Commissioner of Internal Revenue has recently declared that in Virginia many of the distillers have been making two or three gallons of whiskey for every gallon on which they pay the tax, and that the same practice goes on to some extent in all the states where whiskey is made. Under the law, the gauger employed by the government is required to watch every drop of liquor as it falls from the still, to barrel it, and place the barrels in a storehouse to which he alone has access. But the law allows a margin of twenty per cent to the distiller; that is, the grain that he uses being weighed, the spirits gauged must be eighty per cent of the maximum quantity that can be distilled from grain of that kind. It is the custom, the commissioner declares, for the gauger to withdraw so soon as he has gauged the required eighty per cent, while the distiller extracts as much more as he can for his own account. Frauds of this kind are inseparable from the practice of manufacturing under the supervision of government employees, and there are many other devices by which unscrupulous manufacturers can undersell such competitors as attempt to comply strictly with the law. It is impossible to estimate the number of illicit stills in existence, but hundreds of them are detected every year, and it is supposed by some of the revenue officers that there may be thousands of them in operation even in the city of New York. Many reputable 
persons are driven out of a business where the policy of the government exposes them to competition of this character, a violation of recognized principles of justice that has been already characterized. ${ }^{1}$

Tested by the principle that justice in taxation implies some equality of sacrifice on the part of individuals, the English system of taxing the expense of the lower order of people, whatever its theoretical perfection, must be condemned. No doubt the poorest of the poor, under this system, contribute to the support of the government; but they contribute far more than in proportion to their revenue. The tax is obviously much lighter for a workman with no family than for one having a wife and children to support, and it becomes progressively lighter as the remuneration of the workman increases. The constituents of the nutrition of the poor are substantially identical with those of the food of the rich. Their blood is physiologically similar to that of their fellow creatures, and they require the same elements in the substances from which it is made. There is, however, an infinite variety in the qualities of these substances, reflected in differences in price; while the difficulties in the way of imposing lower duties on the inferior qualities have been found to be insuperable.

Professor Fawcett long ago observed that the duty paid

1 The extent to which illicit distillation prevails under the very high duties imposed in the United Kingdom has always been considerable, and in Ireland it was formerly so great as to compel the lowering of the tax. The rate prior to 1842 was about $2 s .8 d$. a gallon, and the production taxed about $11,000,000$ or $12,000,000$ gallons. Peel added a shilling to the tax and the production fell to 5,000,000 gallons. After this tax was taken off the quantity gradually rose to $8,200.000$ in 1853 . It was many years before an increased tax was imposed with better results; but there were 1,174 seizures of illicit stills, etc., in 1904-05. 
on the tea consumed by the poor was three times as great, in proportion to the value of the tea, as the duty paid on that of superior quality, but that no method of applying an ad valorem duty had been found practicable. Nor has any such method been found very practicable in the case of strong drink; ${ }^{1}$ the motives to supply the demands of the very poor at the lowest possible price, as we have observed, cause all manner of adulteration to be employed, and force the products of distillation and fermentation into use before the time necessary for the elimination of the most injurious elements has elapsed. It is perhaps natural for one with no craving for such stimulants as these drinks and tea and tobacco, or with the means to procure the finer qualities of them, to stigmatize them as luxuries which the poor, or at least the sober and industrious poor, can deny themselves. But as a matter of fact it admits of no dispute that the very poor do not consider that they can deny themselves these indulgences, and that the very heavy taxes laid on them not only enormously increase their cost, but also materially impair their quality.

It may appear somewhat more practicable to lay taxes on the luxurious consumption of the rich. To keep a footman is hardly to be regarded as essential to healthy existence, and the same is true of the display of coats-of-

${ }^{1}$ On this subject, Gladstone, speaking in 1853, remarked: "Another plan would be to fix a duty of several rates on wine of different values, somewhat resembling the duty on different qualities of sugar. But if that is attended with difficulty in the case of sugar, with how much greater difficulty would it not be attended in that of wine? . . . The Revenue Department would have the greatest difficulty in carrying out such a system." Sir W. Harcourt said in 1894: "A gallon represents six reputed quart bottles of proof spirit, but, in point of fact, at the strength below proof at which spirits are usually sold, it would represent eight bottles." 
arms. So much cannot be said of maintaining a carriage. A physician might be unable to practice without one, and they may be indispensable for the comfort and even for the existence of many feeble persons. Public carriages, indeed, can hardly be classed as luxuries, either of the rich or of the poor. The English government taxes all three forms of expense by means of licenses. The number of licenses to keep male servants taken out is about 220,000 , producing $£ 163,000$; those for armorial bearings number about 57,000, and produce nearly $£ 75,000$. For carriages the number is about 480,000 , producing some $£ 470,000$, and for hacks 133,000 , bringing in nearly $£ 100,000$. Licenses to use guns and to kill game may be regarded as taxes on the luxuries of the rich; they are notoriously disregarded, but they bring in nearly $£ 300,000$. The tax on hair powder survived a long time, but finally became too absurd and too insignificant to be retained. More than half a century ago John Bright said that this tax and that on armorial bearings - which applies even to emblems stamped on letter paper - made the system ridiculous and ought to be abolished. Such taxes cause a vast amount of vexation and loss of time, and are very troublesome to collect. The progressive death-duties, with the high income tax, constitute so heavy a charge on the expense of the rich as should entitle them to relief from petty exactions.

In our own country, taxes on such things as are supposed to be consumed exclusively by the rich have been found to produce comparatively little revenue. The various manufactures of silk, and such articles as kid gloves, seem to be luxuries of the rich, but in fact the great bulk of their consumption is by the middling class of people. 
The same is true of a great deal of jewelry. The common people of many countries are accustomed to preserve their savings in the form of gold and silver ornaments, and many persons in moderate circumstances have quite large investments in precious stones. Gold and silver watches may be regarded as luxuries, but they are by no means purchased by the rich alone. They are very generally taxable, as is jewelry, but the revenue from this source is insignificant. The value of all the diamonds in human possession is very great, and it might seem that they are owned exclusively by the rich. But although they are taxable, like other personal property, very little revenue is derived from them. Things of great value, but of small bulk, it has been found, cannot be reached by the assessor. They can so easily be concealed and removed, and their discovery requires such vexatious inquisition, that no attempt to tax them seems to have been attended with much success. Taxes of this kind may be paid if they are light; but in that case the revenue derived from them is comparatively small. Some exception may be made in the case of Champagne wine; it is occasionally prescribed for invalids, but its chief use is unquestionably as an ostentatious luxury, and it would be impossible to name a substance of which the enhanced price caused by taxation involves less sacrifice on the part of those who pay it. Yet even in this case, as there are many grades of champagne, the tax is heavier on those that are cheaper owing to the difficulty of assessing ad valorem duties; and the same is true of fine wines in general.

The system by which the government of the United States procures its revenue, however, is constructed without the slightest reference to either the proportionate or 
progressive method of taxation, or indeed to any principle of justice whatever. The whole revenue of the government is collected without requiring a single one of the eighty millions of its subjects to disclose the amount of his income, and without any pretence of graduating taxation according to expense. Hence it is altogether a matter of chance whether the national system lessens or aggravates the inequalities caused by the systems of the states; nor do the numerous specific taxes of the states appear to be much more certain in their incidence. The authors of these systems have seldom claimed to have had the equalization of the burdens of individual citizens in view, nor to have even conceived it to be a desirable end; and the discussions of these problems, which have exercised the talents of the most enlightened English statesmen and illuminated the debates in Parliament with the generous utterances of philanthropic wisdom, have found little place in the records of our legislatures.

In explanation of this apparent indifference, it may be said that our rulers have wisely refrained from attempting what they knew they were incapable of achieving; but the principal reason is obviously to be found in the prevalence of the protective theory of taxation. It is the aim of this theory to give the producers of certain goods an advantage in selling them, by taxing like goods produced by foreigners when imported into this country. When this is the aim of legislation, it is inevitable that numberless clashing interests must be somehow harmonized before any measure can be adopted, a process which takes place without any occasion to appeal to any controlling or unifying principle of economical or ethical science. It is of course impossible to adopt the practice of the Eng- 
lish government in imposing taxes, so far as may be, only on things fitted for final and immediate consumption; the theory on which the practice is framed being that a tax paid on what are called raw materials requires the use of a part of a manufacturer's capital, and is regarded by him as an element in the cost of production. On this part of his capital he expects to obtain the same profit as on the rest, and the price is correspondingly increased to every subsequent purchaser. But where the policy of protection is adopted, the producers of raw materials naturally decline to tolerate such measures. The woolgrowers must be protected by a tax on unscoured wool or they will overthrow the whole tariff; there must then be a higher tax on scoured wool to protect the wool cleaner, a still higher tax on yarns to protect the spinner, another on cloth for the weaver, and a final one for the benefit of the maker of clothing. Under such conditions no attempt to adjust taxation with reference to the burden imposed on the poor can possibly be successful.

It may be added that in one of the few cases where our government has imposed a customs duty for the purposes of revenue only, as when a tax on tea was levied by the act of 1898 , the duty was intentionally so graduated as to fall with the greatest severity on the kinds of tea consumed by the very poor. The sacrifices of these persons were deliberately made greater than those of the wellto-do. The tax on imported sugar, as has been observed, also falls heavier on the poor than on the rich. The consumption of this substance does not increase very greatly when the income of the consumer increases, and certainly not in proportion to that increase. Very rich men will employ many servants, and in their households 
there will be much extravagance in the use of sugar, as in the use of other things; but the cost of sugar, and therefore that part of the cost which is due to the tax on it, will constitute a much smaller part of their expenditure, or of their income, than in case of the poor. Whether we attach any importance to the doctrine of economic classes or not, it is at least true that the taxes imposed by our national government appear to fall on the expense of the common people to a much greater degree than on that of the rich.

Taxes on expense fall into the class called indirect; and indirect taxes have always been regarded with high favor by governments. The reason for this is frankly avowed; it is because under this system subjects are not aware how heavily they are taxed. The distinction made in the Constitution of the United States between direct and indirect taxes has given rise to much legal casuistry, and writers on economics have not all agreed in their definitions of these terms. For the purpose of this inquiry, however, it is only necessary to observe that every tax, whether assessed on persons or property, is paid by some person to the tax-gatherer. If it actually reduces the revenue of that person and no other, it is properly called a direct tax. If it reduces the revenue of persons who do not pay it to the tax-gatherer, it is an indirect tax. This reduction is invariably effected through the payment of an enhanced price for things bought, which enhanced price reimburses the person who paid the tax in the first place. If the purchaser resells the thing, he may in turn reimburse himself; but there must always be a final purchaser, who does not resell the thing, but consumes it. As the extent to which the price of the thing has been enhanced in this process must always be a 
matter of conjecture, and as the great mass of the people are ignorant that it has been advanced at all, the temptation to rulers to resort to indirect taxation is of course very great.

We shall return to this subject when the diffusion of taxes is taken up, and it is considered here only because that feature in indirect taxation which recommends it to rulers is totally repugnant to accepted principles of justice. To deceive subjects concerning the extent of their burdens may perhaps be just from the point of view of a despot or an oligarchy; but there can be no pretence whatever that it is just for rulers chosen by the people to deceive their constituents. Indirect taxes, therefore, can be defended in a republic only on the ground of necessity. They may be believed to be indispensable; they can never be maintained to be just. Pitt's celebrated denunciation of them was none too severe.

No particular reference has hitherto been made to what is on many accounts the most important of all taxes on the indicia of income, that on dwelling-houses, although it is true that under the general property tax houses are assessed; and in England, in addition to the rates, there is an inhabited house duty. Taxes of this kind, however, are so peculiar in their nature, and involve especially so much reference to the law of diffusion, as to make it desirable to consider them separately, and they will accordingly be reserved for treatment by themselves. 


\section{CHAPTER VII}

\section{TAXES ON TRANSFERS OF PROPERTY AT DEATH}

THE taxes imposed on property, the title to which, or the possession or enjoyment of which, is transferred to others at the death of the owner, are known by several names. As property may be transferred in accordance with the will of a testator, a tax then imposed is properly enough described as a legacy tax or duty. When it is transferred from an intestate according to the laws defining the heirs and next of kin of a decedent, the tax may be called an inheritance or succession tax or duty. As the estates of decedents are usually administered under the jurisdiction of what may be generically described as Probate Courts, the taxes imposed may be called probate taxes or duties. All these taxes or duties are sometimes denominated transfer taxes; but loosely, for many other transfers are taxable. As the termination of the life of the owner is the essential fact, a tax then imposed is most accurately named a deathduty, or death-tax; and this name is also preferable because of its brevity. The name " duty" is more commonly employed in England; but in the United States this word is usually understood to mean a tax on imported goods, and it seems better to confine it to that use.

It has been perhaps sufficiently established that neither the proportionate nor the progressive method can be applied unless the tax-gatherer can ascertain the quantity of wealth or income belonging to or enjoyed by every person. Experience seems to prove conclusively that such knowledge 
cannot in practice be obtained, and that the attempt to obtain it inevitably results in the gross violation of admitted principles of justice. The conclusion is strengthened by the obvious fact that immense numbers of married women and children never come within the purview of the tax-gatherer at all; taxes on the goods that they consume not conforming to either of the methods under examination. Yet the very abandoning the attempt to tax proportionately this great number of persons, seems to apply in a way the progressive method. For it may be presumed that infants, and to a considerable extent married women, possess comparatively little wealth, and whatever exemption they enjoy would appear to be in harmony with that principle of justice on which the progressive method is based. Nor does it seem unreasonable to suppose that nearly all persons who do not own the houses in which they dwell, and who support themselves by laboring for wages, are possessed of but a moderate amount of property. If then we can exempt this large class from taxation, and cause it to fall upon those who have great possessions, we have to a certain degree applied the progressive method. Graduated taxation of this kind is often called degressive, as being intended to lighten the burden of those relatively poor.

The problem, it is true, cannot be said to be completely solved by ignoring its most troublesome elements. Even if we may assume it to be practicable to separate the poor from the rich, when we attempt to impose taxes on the latter the difficulty encountered in applying the general property tax reappears. All attempts to levy this tax, and all attempts to levy an income tax, as they require the discovery or disclosure of the wealth of every individual, are irreconcilable with our admitted standards of justice. 


\section{TRANSFERS OF PROPERTY AT DEATH 213}

As between the two great classes of the rich and the poor, we may, after a fashion, apply the progressive principle; but as between the individuals constituting the class of the rich, this seems impossible.

It is therefore on the principle of recognizing the classes of rich men and poor men that death taxes are declared just by the advocates of the progressive method. As no man can carry his possessions with him out of this world, the title to his wealth must somehow be transferred at his death to some living person; and in our country this is usually, and when estates are large, perhaps almost always, accomplished through the Probate Courts. Such proceedings necessarily imply the taking of an inventory and the making of an appraisal of the property of the decedent, and in this way the method of inspection can be very effectively employed. As we have seen, the assessment of property during the life of the owner is very slight evidence of its value; but its appraisal after his death is good evidence, perhaps as good as can possibly be obtained. The temptation to conceal wealth is much less, the difficulty of concealment much greater; and in the case of many of the evidences of indebtedness known in general as securities the form of property that is most commonly concealed while the owner lives - title cannot be transferred without the authority of the court and the attendant publicity. We may conclude, therefore, that the value of all property administered through the court may be quite accurately known, and it would seem to follow that the progressive method could be successfully applied.

But before this conclusion is accepted we need to ascertain more precisely the effect of death taxes, and we shall be aided in this inquiry by examining the arguments em- 
ployed in discussing the subject. Some writers have asserted that such taxes are in the nature of a charge for the services rendered by the government in securing the transfer of the wealth of the dead to such persons as are entitled to it. No doubt moderate probate costs could be justified on this ground, but their amount would be too small to be of importance, and their effect in redressing inequality in the distribution of wealth inappreciable. Furthermore, we find that, in all laws imposing such taxes, transfers of property effected by deeds of trust, which may be carried out without the aid of the Probate Court, are subjected to taxation. It is evident that the legislature considers that otherwise men would dispense with the assistance of government officers, and accomplish such transfers as they desire by other means. In fact, lawyers know very well that a transfer of property to take effect on the death of a certain person requires the aid of the government, unless the legislature interposes, no more than a transfer taking effect on any other future contingency. The claim that death taxes are a charge for services rendered by government seems therefore inadmissible. ${ }^{1}$ It seems to be completely disposed of by the fact that the English statute is retroactive, and treats a gift made within a year of death as an evasion of the tax, unless the giver absolutely divests himself of all beneficial interest in the property.

1 In England property was formerly administered through the Probate Courts to a much smaller extent than in this country. Landed property, especially, did not pass by will; the title to great estates being transmitted through those peeuliar trust deeds known as settlements. But the later returns of the death duties show that comparatively little personalty is settled, and that landed property is, relatively, much diminished in value; although much more of it than of personalty is settled. The law of primogeniture, it may be added, applying only where there is no will or settlement, is very far from having the importance sometimes attached to it by writers in this country. 


\section{TRANSFERS OF PROPERTY AT DEATH 215}

A more subtle suggestion has been made, and almost universally adopted by the courts, to the effect that no right exists in any living person to take the property of a decedent, except such a right as is conferred by statute. This proposition rests substantially on a restricted view of the doctrine of natural rights; it being asserted that no one has a natural right to succeed to the ownership of wealth on the death of its possessor, while he has a natural right to obtain such ownership during the possessor's life. We have already considered the uses of the term "natural," and it is unnecessary to review the discussion. We are concerned not with what the courts declare to be the law, but with what men hold to be just; and, upon reflection, we find that no principles of justice other than those already recognized are applicable in this case. So far as common usage is concerned, it cannot be denied that men speak of the natural right of widows and children to retain the house and goods, title to which was vested in the dead father, but the acquisition of which may have been accomplished through the combined labors of all the members of the family. Historically, as we have seen, family, rather than individual, ownership prevailed in early times, and if we use the term "natural" as meaning what has been customary, it can hardly be denied that the surviving members of a family have a natural right of inheritance. Nor, within certain limits, does the result seem different if the term is used in the sense of what ought justly to be; for it seems impossible to disregard the claims of widows and children.

In order to maintain a position which has not seemed very defensible, legally, to many of the profession, the courts have resorted to an even more subtle distinction. A 
tax on the transfer of property, it is said, is not a tax on the property itself; and in the case of bonds of the United States, which are by their terms exempt from taxation in any form by other authorities, and from the payment of all taxes or duties of the United States, it has been actually held legal for state legislatures to tax banks and similar institutions according to their holdings of such bonds, and they have been declared to be taxable by the United States on the death of their owner. ${ }^{1}$

But, although this distinction is established by law, it seems impossible to maintain it upon ethical grounds, and it finds no support in experience. When one buys something in reliance on the promise of the seller that it shall be exempt from taxation in any form, he unquestionably considers that he has been defrauded when he finds that he cannot transfer the thing without its being subjected to a tax. It admits of no question that when two things otherwise of equal value are offered in the market, one of which can be transferred freely, while the other can be transferred only at some expense, the former will command the higher price. In actual bargaining, the circumstance that

1 "Taxes of this general character are universally deemed to relate, not to property eo nomine, but to its passage by will or by descent in cases of intestacy, as distinguished from taxes imposed on property, real or personal as such, because of its ownership and possession." Knowlton v. Moore, U. S. S. C. Rep. 178. In the course of the opinion it is to be noted that the Court uses words in their usual sense, "The same person," it is remarked, "taking equal legacies from different persons, would pay," etc. So too a legacy tax is spoken of as affecting the "taxation of the property of one person," etc. It may be remarked that this Court has held that a tax on the occupation of an importer is the same as a tax on imports; that a tax on the income of United States bonds is a tax on the bonds; that a tax on a bill of lading is a tax on the goods; that a tax on sales made by auction is a tax on the things sold; that a tax on rents is a tax on real estate; and in general that to tax the use of property is to tax the property whose only value consists in its usefulness. 


\section{TRANSFERS OF PROPERTY AT DEATH 217}

the expense of effecting a transfer is declared not to be a tax on property eo nomine, but upon the transaction, is perfectly immaterial. For all practical purposes, a tax on the transfer of a thing is a tax on the thing; and in fact the law makes the tax on the transfer a lien on the thing. It will scarcely be contended that property subject to lien is so valuable as if it were free; and no one would venture to maintain the proposition that a government bond that may be subjected to taxation to an indefinite amount when it is transferred, could be sold for so much as one that should be really as well as nominally exempt from taxation in every form. Under the general property tax, intangible personal property is in practice so commonly exempt as to make it comparatively immaterial whether a bond is by its terms free from taxation or not; but this is because the ordinary buyer does not expect to pay the tax, and therefore ignores it. Did he believe that he would be obliged to pay it, he would give the preference to non-taxable bonds.

It seems, therefore, that death taxes cannot be justified on the ground that a legal distinction has been made between taxing property and taxing the transfer of property. Value means ordinarily value in exchange; and it is lessened by whatever hinders exchange. It is true that a transfer at death appears to differ from ordinary barter; one party is not in position to receive the consideration for the transfer. But it frequently happens that the consideration has been already received; the decedent has received value in the shape of services, or in substantial goods, for which he pays by means of a legacy. Frequently, also, the property standing in the name of the decedent, is, as we have seen, family property, and the transfer of title at his death amounts to no more than a declaration of the 
values of the several interests. Moreover, no consideration passes when a living person makes a gift to another; the transaction is essentially no more an exchange than in the case of a legacy. Since a valuable consideration frequently exists for a transfer after death, and since it frequently does not exist when the transfer is between living persons, its absence cannot be regarded as constituting the justification of death taxes.

Nor does the fact that the estate possessed at the moment of death is large appear to justify such taxation. For, as we have seen, it is thought just that those who render great services should be liberally compensated; and, in spite of popular clamor, we must hold that the community is often benefited through the acquisition of wealth, even in large amounts. The wealth may have been fairly earned by great services, it may have been employed in enterprises profitable to the community, it may have supported schools and hospitals, and it may be intended for such uses after the death of the possessor. In such cases neither the acquisition nor the expenditure of wealth can be regarded as unfavorable to that equality of opportunity which justice demands, and there is certainly no presumption that if great wealth is seized by the rulers it will be expended by them so as better to promote such equality. Even if legacies for charitable purposes are exempted, we cannot be sure that they will not be diminished if death taxes are levied on other legacies; and we know that in countries where such taxes have long existed the endowment of public institutions by private persons does not prevail as it has hitherto prevailed in this country. It is quite conceivable that the present total of charitable bequests might be decreased by the whole amount of the death taxes; in which 


\section{TRANSFERS OF PROPERTY AT DEATH 219}

case the interests of the community might suffer, unless in the improbable event that all the proceeds of such taxation should be applied to charitable uses. When the possessor of five millions knows that the government will seize onefifth of his estate on his death, he will presumptively not make the same disposition of his property as he would in the absence of such taxation. If he had proposed to apply a million to charity, he may reason that as the government has taken that sum from him, he is relieved from whatever obligation he had felt to the community.

These illustrations are from cases where great wealth has been well acquired and well administered; but many men get rich by iniquitous methods and there seems to be a confused feeling that they are somehow punished and that justice is thereby attained when a part of their wealth is confiscated after they can no longer enjoy it. No doubt it is true that the anticipation of such a result is painful; the pleasure of the possession of great wealth must be diminished by the knowledge that it cannot be disposed of according to the will of the possessor. But it is extremely doubtful if punishment of this kind is efficacious as a deterrent. Unscrupulous men are not apt to be prevented from taking unfair advantage of their neighbors by the reflection that after they are dead their estates will be heavily taxed; they do not hesitate to face much greater risks than this. And perhaps we might fairly reason from historical example that such men are peculiarly apt to compound for their sinful practices in this life by liberal gifts to charitable purposes after they die, and that they may feel that absolution will be sufficiently secured through payment of death taxes. Our knowledge of the motives that will become operative in such circumstances is really 
so imperfect as to make our conclusions very uncertain; still we know that it is customary in England to effect insurance against the damage to estates caused by the death duties, just as it is customary to insure buildings against damage caused by fire, and we may safely infer that their effect cannot usually be to arouse in those who pay them an inclination to confer benefits on the society that exacts them. It seems on the whole probable that when such taxes prevail, the quantity of wealth left by decedents to charitable uses may be considerably decreased, and that to a certain extent the intended removal of inequality may therefore not be attained.

We have hitherto regarded chiefly the effect of these taxes on those who leave property; but it seems rather that the real sufferers are those who take the property diminished by taxation. The decedent may have been aggrieved that his will should be thwarted; but the survivors are actually deprived of wealth that they would otherwise have enjoyed. Our proper inquiry, therefore, is concerning the justice of such deprivation. Now when the estate left by the head of a family is small, it is ordinarily a cruel injustice to diminish the amounts that would naturally go to the widow and children. In most cases the father was presumptively supporting the family, and his death must seriously decrease their income; while the cost of an illness, perhaps prolonged for months or years, and the funeral expenses, often constitute a crushing burden. For the government to increase this burden seems wholly irreconcilable with any admitted principle of justice, and notoriously arouses the bitterest indignation on the part of the sufferers. In the case of small estates, therefore, taxes imposed on widows and lineal descendants may be 


\section{TRANSFERS OF PROPERTY AT DEATH 221}

condemned without qualification; and in such case it must frequently be unjust to tax legacies. ${ }^{1}$

The progressive method, however, should exempt small estates from taxation; and, if consistently applied, it would seem properly to exempt small legacies, whether derived from small or large estates. For its principle is that the possession of a great amount of wealth by one who has done nothing to earn it is unjust. It may often be the case that the recipient of a moderate bequest has done something to earn it, and to avoid injustice it seems necessary to exempt all such recipients. It can perhaps seldom be the case that the recipient of a very large bequest has rendered any equivalent service, and the taxation of such bequests is, theoretically at least, justifiable. Mill, indeed, proposed to limit the amount that any person should acquire in this way; but in our federal state such a restriction would hardly be practicable. It must be added that, in the case of very large estates, to tax moderately the shares of widows and children can cause them no great distress. They may be compelled to live more modestly, but they will usually be deprived of nothing essential to their welfare. Death taxes, therefore, restricted in the manner above indicated, seem adapted to the application of the progressive method; and, if we regard the community as consisting of two classes of persons, the rich and the poor, they appear to satisfy the requirements of justice as between these classes.

1 "The death of a father, to such of his children as live in the same house with him, is seldom attended with any increase, and frequently with a considerable diminution of revenue; by the loss of his industry, of his office, or of some life-rent estate, of which he may have been in possession. The tax would be cruel and oppressive which aggravated their loss by taking from them any part of his succession." A. SMITH, Wealth of Nations, Book V, Chap. II, Art. II, Appendix. 
As between the individuals forming the class of the rich, this is less true. The circumstances of two persons, each of whom receives a legacy of the same amount, can never be quite the same, and must often be extremely different. But the tax-gatherer cannot inquire whether the legatee is young or old, male or female, feeble or vigorous, competent or incompetent, or even comparatively rich or poor. Some distinction may be recognized between relatives and strangers in blood; but the sole important differentia is the magnitude of the legacy. And it is to be considered that, in the case of large estates, it is often practicable for the owner to accomplish during his lifetime those private benefactions which men are perhaps usually prone to neglect until death forbids longer postponement.

Such beneficence during life might, it is true, sometimes diminish the accumulation of wealth; and it has been maintained that the English death duties have this effect. This objection, however, is properly one to the amount of the tax rather than to its nature. The very high English death duties have been only recently imposed, and we must wait a generation before we can form a conclusion as to the various effects which they will produce. For the same reason we are at present unable to judge how far such taxes may operate to discourage prudent and sagacious men from venturing on undertakings which may promise to be highly advantageous to the community as well as to themselves, but which require much time for their completion. The possibility of death is in itself a deterrent that we know to be frequently operative, and the certainty that death will involve a serious diminution of property cannot be without effect. Sometimes, too, the disposition to spend during life may be intensified by the knowledge that 


\section{TRANSFERS OF PROPERTY AT DEATH 223}

much of what is not spent will be appropriated by the officers of government.

As has often been remarked, taxes of this kind are "unthrifty" taxes; they must ordinarily be paid out of the capital of a country, rather than out of its income. It may sometimes happen that the legatee is already rich, and may be able to pay the tax out of the income from property already owned; but this would not usually be true. On the other hand, the legatee may be disposed to repair the damage to his estate by reducing his expenditure for some years, and applying his savings to the increase of his principal. But such savings may be offset by a succession of deaths that cause the tax to be repeated a number of times within a few years, with the effect, possibly, of confiscating half the value of the estate. ${ }^{1}$ Very great inequality of sacrifice may thus be occasioned, and the English statute makes some allowance for the distress produced by this injustice; but, as we have pointed out, there is little pretence that death taxes are levied so as to cause equality of sacrifice among those who pay them. Their avowed purpose is to impose exceptionally heavy burdens on the rich, in order to exempt the poor; and, in a community where the majority rules, such a policy may seem so imperatively demanded by justice, as to cause the injustice of taxing rich people unequally to be regarded with comparative indifference.

1 In the debate on the budget of 1853 , Sir J. Trollope mentioned a case where there had been only one succession to an estate since 1756 . On the other hand, he said, he knew of a family where there had been seven successions within sixty-six years, and in four cases these successions took place within one year of each other. In a recent instance, within four days after a very heavy tax had become due, another of nearly equal size followed. Another eminent conveyancer stated that he had found in his practice that the average interval between successions was about twenty years. The average age of successors seems to be about forty-four years. 
Still, recognized principles of justice cannot be ignored, and if they are grossly violated by death taxes, we must inquire whether that supreme end of equalizing opportunity cannot be otherwise attained. The purpose is not merely to take their wealth from the rich; it is to take such wealth so as to diminish the burdens of the poor. As a matter of fact, in very few cases has the imposition of progressive death taxes been followed by any remission of the taxes paid by the common people, ${ }^{1}$ the revenue derived having been largely applied to increased military expenditure, or to extravagant and unproductive public works. Yet we cannot assert positively that such results will always prevail when the progressive method is applied; we cannot carry on our investigation unless we assume that the revenue obtained by the government is mainly expended for the benefit of the community. It seems clear that if progressive death taxes really reduce the capital of a country, they tend to impair the condition of the common people by decreasing the fund which supports them. But this objection, as has been pointed out, applies to the injudicious extension of the progressive principle, and not to the progressive principle itself; nor would it be easy to prove that in practice the capital of any country has in modern times been seriously reduced by such taxation, whatever may have been true in the past. $^{2}$

1 It should be said that in his budgets Mr. Gladstone consistently labored to attain this result.

2 Prof. Sidgwick, testifying before the Commission on Local Taxation in 1899, said that it could hardly be doubted that if the death duties, then some $£ 14,000,000$, had not been exacted from beneficiaries, by far the larger part would have been treated as capital. His conclusion was "that a diminution in the capital annually saved does tend to result from these duties; and that in consequence a slight tendency to raise the rate of interest and thereby compensate for a portion of the 


\section{TRANSFERS OF PROPERTY AT DEATH 225}

Some reference has been made above to the practice of insuring against the damage to estates caused by the death taxes, and it is plain that if this practice became general, the real burden of these duties might fall elsewhere than as stated. Doubtless it is impracticable to obtain the information necessary to determine the extent of this practice; and perhaps the cost of insurance cannot as yet be accurately known. It is evident, however, that the effect of the practice is to exempt the shares of beneficiaries of decedent's estates from the diminution presumptively to be caused by the taxes. Whatever the amount of the tax levied by the government, that amount is repaid by the insurance company to the beneficiary. The premiums on such policies of insurance, however, have been paid by the decedent during his life. They have constituted a diminution of his income, precisely as the income tax constitutes such a diminution. Apparently, then, the burden of the death taxes may really be borne, not by the beneficiaries, but by the owners of the estates

burden laid by the duties on the owners of capital may reasonably be assumed." Prof. A. Marshall expressed similar views. The considerable rise of the rate of interest since 1899 may be regarded as a confirmation of these propositions; and they may be extended so as to apply to laborers, whose compensation may be lessened by the greater cost of obtaining capital. Prof. Sidgwick's opinion is confirmed by some investigations made by the Statist, covering the three years 1890 , 1891, and 1892. About 140 estates valued at over $£ 100,000$ were subjected to death taxes in each of those years. It is to be observed in the first place that the size of these estates is largely due to the great age of those who acquired them. Thus among the 138 persons dying in 1891 possessed of estates of this size, 40 were between 76 and 95 years old; their average age being 83 , and 33 of them being over 80 . In the second place, the Statist declares, it is the judgment of men conversant with business that hardly one of these estates was the result of financial speculation. Property thus accumulated must to a great extent belong to the capital fund of a country, and to tax it heavily must tend to diminish that capital. 
taxed, who have deprived themselves, perhaps for many years, of a part of their income. But even so much as this cannot be positively asserted. The sum necessary to meet these premiums may have been taken by the decedent out of that part of his income that he had devoted to the maintenance of his family. His personal expense may or may not have been altered. He may deny himself some comforts or luxuries; or he may cease to provide for his wife and children some of the luxuries and comforts to which they have been used. In the latter event, as the wife and children are presumptively the future owners of the estate, they will have paid the tax on the succession in advance, out of the results of their previous abstinence. ${ }^{1}$

These considerations tend to support the view that death taxes may eventually become elements in the cost of production calculable in the same manner as damage from fire and flood and burglary. It may not become customary

${ }^{1}$ Sir H. Primrose, Chairman of the Board of Inland Revenue, calculates that the estate duty amounts to an income tax of $6 d$. in the pound on estates yielding an income from $£ 40$ to $£ 400$ a year, 1 s. on estates from $£ 4,000$ to $£ 6,000$, and 1 s. $3 \frac{1}{2} d$. on $£ 40,000$ a year and upwards. If the calculation is based on what the beneficiary or successor receives, the figures would be respectively $9 d ., 1 s .6 d$. and $2 s$. in the pound. But this calculation omits the legacy and succession duties, which come to nearly $£ 4,000,000$. Were these included the computed income tax would be greater by perhaps twenty-five or thirty per cent.

Since this calculation was made, the death duties have been increased on estates of $£ 150,000$ and over. From $£ 150,000$ to $£ 250,000$ the tax has been raised from $6 \frac{1}{2}$ to 7 per cent; from $£ 250,000$ to $£ 500,000$, from 7 to 8 per cent; from $£ 500,000$ to $£ 750,000$, from $7 \frac{1}{2}$ to 9 per cent; and when the estate is over $£ 1,000,000$, it is taxed at 10 per cent on the first million, and at advancing rates on the excess over a million, so that an estate of $£ 3,000,000$ and over would pay a tax of 15 per cent on this excess. A legacy duty of 10 per cent might be added to this; and as the estate might have to pay taxes in more than one jurisdiction, to say nothing of legal expenses, the supposed evil of great fortunes would seem in a way to be soon eradicated. 


\section{TRANSFERS OF PROPER'TY AT DEATH 227}

in this country to insure against them specifically as is done in England, where one can insure against almost any conceivable occurrence; but the practice of life insurance accomplishes the same purpose. A man insures his life that his family may not be left without resources on his death, and it matters not whether their resources shall be diminished by the exactions of rulers, or by some other cause. We can safely infer from the vast extent of life insurance that the desire to provide for the family after death is extremely powerful, and it is legitimate to reason that the payment of death taxes will before long become an element in the calculations of prudent men. Some of them will arrange to dispense with the interference of the officers of government in disposing of their estates; some will make allowance for the probable loss from this cause in effecting insurance on their lives, and reduce their expenses by the amount necessary for the increased premiums; : some, differently situated, will spend while living that which they would have bequeathed, buying life annuities or consuming their principal directly; some will try to increase their wealth so as to make up for the anticipated loss; some will think it not worth while to save money for the benefit of tax-gatherers and placeholders, and will prefer easier relations and fewer responsibilities than attend marriage and the rearing of children.

The objection that these taxes necessarily result in great inequality of sacrifice on the part of those who pay them is a very serious one. It is impossible for the legislature to ascertain the circumstances of the individual legatee; no practical scheme of such a kind has ever been brought forward. There has been, we have remarked, some attempt in England to alleviate the sacrifices that may be 
caused when several deaths occur in a family within a few years; the statute attempts to avert the ruin that might thus be brought upon an estate. Possibly this particular injustice may admit of a partial remedy; but its victims will naturally entertain very bitter feelings toward a community that, as they look on the matter, has robbed them. It is of no consequence that the community maintains that such feeling is improper and disloyal. The feeling will exist so long as the cause for it exists, and it is certainly a serious evil when any considerable number of citizens feels that it has been oppressed and plundered. Yet this evil also may be mitigated, if not removed, by exempting legacies even of considerable size from taxation, and by applying the progressive method to large legacies with moderation.

A very grave objection to these taxes appears when wo consider the expense of collecting them. This expense is commonly measured by the amount of the fees and salaries paid to the tax-gatherers; a mode of computation that is grossly inadequate. The government is put to additional expense for the rent of offices, etc.; but the chief expense falls on those entitled to the estate of the decedent. When the property is small, and simple in character, and when it passes directly by bequest or devise or inheritance into absolute ownership, it may be practicable to administer the estate without legal aid. But it is only necessary to read the statutes on this subject in order to see that problems must arise in most cases that are quite insoluble by the ordinary layman, and that frequently demand judicial settlement. ${ }^{1}$ In fact, it may be doubted whether the or-

1 Both in England and in this country the statutes provide that where the difficulty of determining the amount of the tax becomes very 


\section{TRANSFERS OF PROPERTY AT DEATH 229}

dinary "business man" could comprehend these statutes at all, especially since it often happens that those of several jurisdictions must be consulted. When the property is of many varieties, and especially when estates not in fee simple are created, expert appraisers and counsel must be employed, not only to advise but also to carry on the proceedings; and in such cases the cost to the estate of preparing to pay the tax may often equal or exceed the amount of the tax itself, and is perhaps, as a rule, more than the cost to the government of collecting it. The expense is sometimes increased by the practice of rewarding the tax-gatherers by fees, which have, in the case of some large estates, been enormous. When the collection of a tax involves so much expense as this, it can be defended as just, if at all, only by clear proof that by no other means can the desired equality of opportunity be attained. An objection, of which it is difficult to estimate the force, relates to the possibility of avoiding the tax. ${ }^{1}$ It is

great, the tax collectors are empowered to fix it at such a figure as they think proper. When governments are steeped in corruption it is easy to see that abuses may result from lodging such arbitrary power in the hands of tax-gatherers.

${ }^{1}$ Prior to 1853 the death duties in England were comparatively light, but were nevertheless to a great extent avoided. Gladstone remarked of this (although the conveyancers contradicted him), "With respect to personal property we know that the astuteness of lawyers and the vigilant care for personal interests continually are at work to defeat and escape the operation of the law - to invent new modes of escaping the legacy duty - and this with such extraordinary success that although there has been an immense increase in the personal property of the country, such increase is scarcely traceable in the tables of your legacy duty; and we know this, that arrangements are made for that end which may be called all but fraudulent." He expected to get $£ 2,000,000$ from his increased taxes, but got only $£ 800,000$, and Sir W. Harcourt remarked in 1894 that even then, after nearly forty years, these taxes produced only three-fourths of the amount anticipated. 
urged that by gifts during life, and by certain expedients with which lawyers are familiar, men may effect the distribution of their estates without subjecting them to taxation. Premature death, however, may interrupt such arrangements, and in such event there will be discrimination against the unfortunate. But, on the theory that beneficiaries are the real sufferers, it is evident that unless they have been taken into the confidence of the decedent, they can do little or nothing to avoid the tax. They may foresee it, and understand how it can be avoided; but they are helpless. It seems altogether impossible at present even to conjecture to what extent men plan to avoid these taxes, which have been applied but a few years, and which are not yet fully understood. Hitherto, it may perhaps be thought, the indications are that most rich men have allowed their estates to be taxed; and if the burden is not very heavy, they may choose to bear it, rather than undergo the trouble of evading it. Aged men, especially, who are often weary of the cares of life, and desirous chiefly of passing the remainder of their days in peace, sometimes appear indifferent to what happens after they are gone. They have learned how difficult it is to anticipate the course of events, and how often the arrangements that men make for the future prove disappointing; they have perhaps seen that great legacies prove occasionally a curse rather than a blessing to those that receive them. Hence the prospect that the government will seize a large part of their property, after they have ceased to enjoy it, may not appal them; they may even regard it with indifference, or be willing to relieve themselves of the care of selecting desirable objects of beneficence by leaving the task to the legislature. Nor may we ignore 


\section{TRANSFERS OF PROPERTY AT DEATH 231}

the desperate tenacity with which the aged often cling to that dominion of which they know that death alone can deprive them. But of these matters experience as yet tells us little; we have never before in this country had legislation directed against the wealthy as a class, and no one can tell what its ultimate results may be. But at least it may be said that the death tax does not occasion the outrageous injustice of the general property tax, and that if it could be substituted for the latter, and graduated as the theory on which it rests requires, justice would be much more nearly attained than at present.

It is to be remarked, however, that the death taxes imposed by our legislatures make no pretence, as a rule, of complying with any principle of justice whatever. They are usually cruel, because levied on small estates, and because they reduce the shares not only of strangers and collateral relatives, but also those of widows and orphans. They seem to be, with few exceptions, imposed on the estate of the decedent and graduated accordingly, rather than regulated by the size of legacies; although the latter principle was adopted in the United States statute of 1898 , and is partially recognized in the laws of some states, as of Massachusetts. What is peculiarly indefensible, and calculated to arouse the most bitter animosity toward the government on the part of the sufferers, is the fact that the laws of the different states often cause the tax to be levied several times on the same estate. A resident of Connecticut, for instance, may own stock in a foreign corporation, and keep the certificates that declare his interest in a vault in the city of New York. His legatees may find themselves mulcted not in one state but in three. For this injustice the legislature of New 
York is primarily responsible; and in order to exact an impost for which no justification exists, it has resorted to the infamous practice - in which it has been imitated by some other states - of offering rewards to informers who succeed in discovering within its jurisdiction property, or the evidences of or claims to property, belonging to the estates of non-resident decedents. It seems clear that a certificate of stock, or a parchment declaring an indebtedness, has no value except for evidential purposes; the stock may be without the jurisdiction, and so may be both the debtor and creditor, and it is where the value exists that the tax for protecting it should be imposed. ${ }^{1}$ There is possibly some hope that interstate comity may in time correct these scandalous abuses.

No doubt the death taxes now generally adopted in this country constitute a serious innovation. With very few exceptions, our governments until recently exacted no fine from those who succeeded to property, and recognized no such principle of taxation as that of the progressive method. That principle, however, has now been accepted by the legislatures, and probably by the mass of the people. If it has been permanently established, there must be some modification of the rights of property, and of the principles of justice affecting those rights. The process of readjustment cannot be watched without anxiety; but we do not here examine its political and social consequences. ${ }^{2}$

1 It is difficult to take seriously the claim of one of the judges of the New York Court of Appeals, that as some decedents might very likely have evaded personal property taxes when living, all personal property should be made to pay death taxes. This theory of justice seems to be that adopted by Herod in ordering the slaughter of the innocents; but it is perhaps to be explained by the confusion of thought due to attributing moral delinquency to such an entity as personal property.

${ }^{2}$ It is somewhat remarkable that Mr. Gladstone stood in fear of the 


\section{TRANSFERS OF PROPERTY AT DEATH 233}

No amount of discouragement, or even persecution, to judge from experience, has availed to extinguish the benevolence of mankind. Yet it is conceivable that very drastic measures of taxation may go far to accomplish this result, and that if rich men feel that they are singled out for plunder, they may relieve themselves of responsibilities hitherto voluntarily assumed. In fact it is contended by some persons that what is now done by charitable men should be done by the officers of government; that what the poor have received as alms shall now be turned over to them as a debt owed by the society whose institutions, it is said, have caused their poverty.

The social consequences, however, of excluding the benevolent emotions from their usual field may be very disastrous; the result in France, it might almost be said, has been to replace charity with hatred. No society is sound when its government is hated by a considerable portion of its better educated citizens; nor, perhaps, will it prove to be sounder when the mass of its poorer citizens have been taught that the easiest way to obtain wealth is to take it from the rich by means of taxation. The benevolent emotions must still have some play; when we

spirit that he had done so much to evoke. He dreaded the results of suggesting to the common people the idea that they might throw the whole burden of taxation upon the rich. When in opposition, in 1876, he declared that those with whom he acted should oppose, not as Liberals, but "as men of honor and prudent men," the policy of abating the tax on small incomes; "a measure the obvious purpose of which is to relieve the larger and more numerous classes of society at the expense of the more limited and wealthier." This is a proposal, he added, "by which I will not say you bribe the majority, but by which you induce the majority of the actual taxpayers to acquiesce in the increase of a tax by making that increase positively and absolutely beneficial to them. You encourage them to run in upon the minority." 
consider the thousand ways, public and private, in which the well-to-do people of this country, as a class, are, in season and - sometimes - out of season, endeavoring to make the lives of their less fortunate neighbors happier and better, we cannot imagine that these emotions will cease to exist. But we can imagine that they will be restricted, and that with the diminution of the means for exercising them, the importance of the self-regarding emotions will be increased. On the other hand, gratitude for benefactions will cease when they are taken as rights; but it may be found that it was gratitude by which envy was held in leash. The meanest of passions may be treated with contempt when exhibited by an individual. When it animates a democracy its power becomes too formidable to be despised. ${ }^{1}$

'In 1907 an "arrangement" was entered into by the governments of France and England (without the authority of either parliament), which may justly be characterized as disgraceful to the English people. The Inland Revenue Board is to furnish to the direction générale de l'enregistrement such information as it acquires concerning the estates of deceased persons whose domicile was in France, and reciprocally. Of this arrangement M. Paul Leroy Beaulieu observes that neither government relinquishes its claims to tax the estate of a foreigner; hence the only purpose of the arrangement is to impose double taxation. "Cela étant, on a le droit de dire que c'est la 'un arrangement" tout à fait illégitime et manifestement immoral; car, en équité, cette succession ne doit pas deux droits; elle n'en doit qu'un." He calculates that only in rare cases would the cumulated tax on direct successions be less than 6 or 7 per cent, and on others less than 15 to 18 per cent; to which must be added several per cent for legal expenses. The French government further proposes to penalize those who succeed to estates which Frenchmen have invested abroad, when they have not been subjected to taxation in France during the life of the owner, to the extent of one-quarter of such investments. We are not here considering the policy or the practice of the French government in taxation; but the comments of this distinguished economist on the character of this agreement deserve the attention of the English-speaking peoples. "Comment les moralistes peuvent-ils juger cet 'arrangement' entre le Gouvernement anglais et le Gouvernement français, qui a pour 


\section{TRANSFERS OF PROPERTY AT DEATH 235}

objet de faire payer deux droits, le droit anglais et le droit français, à la même succession? N'y a-t-il pas là un exemple des plus fâcheux, et quand les Gouvernements violent aussi manifestement les principes de l'équité, sont-ils bien venus à se plaindre que les contribuables cherchent à échapper à leur excessive et inique fiscalité?" 


\section{CHAPTER VIII}

\section{THE DIFFUSION OF TAXES}

THE method adopted in prosecuting this inquiry has been rather historical than logical. This course has been followed because the result of an examination of the diffusion of taxes, which should logically precede historical investigations, might have been to make such investigations seem unnecessary. If taxes are not in fact a burden on those on whom the legislature intends them to fall, it might be thought a waste of time to consider methods and measures of taxation which, so far as relates to equalizing sacrifice, must fail of their purpose. But it is not probable that this cutting the ground from under all existing systems of taxation would have been found satisfactory. The presumption in favor of what is established, simply because it exists, is with most people sufficient to overcome the weight of the most perfect logical demonstration. Hence it has seemed best to examine the practical operation of established methods, on the assumption that, if they were consistently applied, the burdens of taxation would rest where the legislature intended. It has from time to time appeared that this assumption is not altogether tenable; but the inquiry would have been gravely complicated by pausing to examine its validity. We have now, however, reached a stage where this examination can no longer be postponed.

The collection of taxes by government is by definition the same thing as the subtraction of a part of the wealth of its subjects. Some of these subjects, or all of them, 
take money from their pockets and pay it to the taxgatherer. But it is notorious that in all countries many of the subjects never pay any money to their governments; they may never even see a tax-gatherer. The government of the United States takes enormous sums of money from its subjects, but the persons who pay this money probably do not number two per eent of the population, if we leave out of view the money paid for postage, which is not usually reckoned as a tax. The City of New York, or more precisely the Borough of Manhattan, collects a vast revenue, but not one in twenty-five of its inhabitants pays any part of it. The inhabitants number 2,200,000, but the number of parcels of real estate assessed is but 100,000, and the number of individual residents paying taxes on their own personal property is only 13,000. Common sense, however, revolts at the proposition that the wealth of the comparatively few persons who pay these prodigious: sums is depleted to a corresponding extent; that the duties paid by an importer in New York, or the taxes paid by a distiller in Illinois, diminish his property and that of nobody else. ${ }^{1}$ It seems, therefore, that the sacrifice involved in taxation may not be made by the individual who pays the money to the government, but by other persons, and this transference of sacrifice is usually denominated the shifting or diffusion of taxation. It follows also that the intent of the legislature that particular persons shall pay the tax imposed by a general law constitutes no presumption that such persons will really carry the burden of the

${ }^{1}$ This is not clear to the minds of all our statesmen. A representative of Illinois once maintained in Congress that the people of that state paid the taxes on the spirits distilled there, and a representative of New York made a like assertion concerning the duties on imports collected at the port of New York. 
tax. That this is true in many cases, and to a great extent, is disputed by nobody; but in what cases, and to what extent, even if discoverable by experts, is not generally understood.

As was explained at the outset, the scope of this inquiry cannot extend to the complete analysis of the effects immediately produced when a particular tax is first imposed. It is evident that a sudden and unforeseen demand for money made on an individual must be wholly different in its effects on his circumstances from a continuous and anticipated demand. The latter is taken into account in all those calculations concerning the expenses and profits of his occupation which every man must make; the former cannot be. While economists have carefully investigated the results of these unforeseen variations in the conditions of industry, and while their conclusions are of practical value when it is proposed to introduce changes in the system of taxation, the nature of our subject compels us to take but incidental notice of these investigations and conclusions. All that we can here attempt is to ascertain the distribution of burdens under an established system of taxation; a system, that is, where the laws imposing taxes are duly enacted by the legislature, and are changed only gradually, and with such warning as is implied in the obvious tendency of public opinion. The imposition of a new tax usually has many unexpected results, and it is idle to attempt the precise solution of a problem the elements of which are altered while the investigation is taking place. In other words, taxes are to be regarded as known and calculable elements in the cost of the production and exchange of goods, in the sale of services, and in the distribution of expenditure. 
Some confusion of thought may perhaps be avoided if we distinguish, once for all, the unproductive expenditure of government from what has been called its remunerative expenditure. If a citizen pay to a private contractor the same sum for removing ashes from his house that he pays as a tax for the same service to the city government, the expenditure may be called remunerative. Similar reasoning applies in the case of water rates. Charges of this description are not usually classified as taxes; and the charges for the post are by many writers also excluded. But much the greater part of the expenditure of government, however necessary it may be, is not remunerative. It would be absolutely impossible to apportion the benefits resulting from this expenditure amongst individual subjects, and the expenditure is unproductive in the sense of not replacing the capital expended. It may be worth while for a nation at peace to spend $\$ 200,000,000$ a year in preparation for war, but if 200,000 farmers were to spend that amount in increasing the products of their land, the results to the wealth of the society would be very different. Every prudent man distinguishes his income from his outgo, and his productive from his unproductive expenditure. He regards his taxes as an element of cost; he deducts them from what he calls his profits, and never thinks of adding them to his revenue. Whatever criticism may be made of this system of classification, we are obliged to employ it because it is established and understood. To substitute another, even if it be theoretically more scientific, would be for most persons to render the whole subject of economics, as well as taxation, unintelligible. The only taxes here treated, therefore, are taxes that are, in the sense above explained, unremunerative. 
The system of taxation, it should be observed, is a constant factor only in the sense that other economic factors are constant, i.e. to the extent that inferences may be drawn from them with reasonable certainty. The return of the seasons is a factor of this kind; but no two summers are precisely similar. They are, however, so nearly similar that the farmer makes his plans on the assumption of their constancy. There may be more rain or less rain than he expected, but on the whole the quantity is sufficiently constant to form a basis for calculation; and so much constancy as this is to be assumed in the case of taxation. The rate is perhaps never quite the same in any two years, but the changes are not very great; and, taking one year with another, they may be disregarded. It is to be added, however, that in reasoning on this subject we are obliged to ascertain the effect of any tax by supposing it to be, on the one hand, newly imposed or increased; or, on the other hand, to be reduced or abolished. But this, it is apparent, is really an inquiry into the effect on men's calculations of changes in the conditions of the industrial problems which they are continually engaged in solving. It is the fact that men calculate, that they are beings looking before and after, that causes the diffusion of taxes.

For in a modern industrial society most men are animated with the desire to improve their condition and that of their families; even, it may be paradoxically said, before their families exist. This means that if men have services to sell, they will try to sell them for as high a price as possible; that if they have goods to sell, they will get as much for them as they can; that if they have money to lend, they will obtain the highest interest available. On the other hand those who buy services will try to get them 


\section{THE DIFFUSION OF TAXES}

cheap; and so with goods, and so with money. It is hardly necessary to say that these propositions have no reference to prices actually received or paid. They do not mean that a laborer will prefer to get larger wages in a dangerous employment under a brutal master than in wholesome work under pleasant conditions; or that an employer will not pay higher wages to a competent and faithful laborer than to one who is drunken and dishonest. They do not mean that a merchant will try to sell bad things for as much as good ones, or will pay the same price for materials without regard to their quality. Nor do they mean that men entrust their money to the highest bidder, no matter who he may be. They mean simply that men exist in a competitive society, based on barter, and making use of borrowed capital. If then a man pays high interest for his capital and high wages to his laborers, he cannot offer his products for sale at so low a price as his competitor, whose expenses of production are less; if he demands a higher price nobody will pay it, and if he takes a lower price he cannot pay his debts and must go into bankruptcy, a result that takes place in hundreds of thousands of cases every year.

Whoever underestimates the amount that he will pay in taxes suffers in the same way that he suffers from underestimating any other of the expenses of production. Before he engages in business he must calculate this amount, just as he calculates his disbursements for materials or machinery. And in modern times he does not make his calculations without assistance. As Bagehot so lucidly explained, business has to be done now with borrowed money; the men that borrow money can undersell those who have only their own capital. The lenders of money, however, constitute the most alert and astute body of men in exist- 
ence. Their business consists in letting other people have possession of their money, or, what is even more critical, of money which they themselves have borrowed. If they cannot get their money back they will be ruined, and their creditors with them. Hence they must exercise the greatest watchfulness over their debtors; they will not lend in the first place until they are satisfied that the loan is safe, that the debtor can and will repay it, and they will not continue or increase the loan without evidence that the business of the debtor is prospering. They listen to his representations and to his calculations; and if they find them unsatisfactory they cease to give him credit. They are partners in all the business of the country, and they display in estimating the prospects of its several departments an industry and an ability that are truly stupendous.

The celerity with which men act on these calculations is, however, no modern phenomenon. It excited the admiration of Ricardo nearly a century ago, and his comments on it are so judicious as to deserve to be recalled. Speaking of temporary variations of price he remarks:

"It is only in consequence of such variations that capital is apportioned precisely, in the requisite abundance and no more, to the production of the different commodities which happen to be in demand. With the rise or fall of price, profits are elevated above, or depressed below, their general level, and capital is either encouraged to enter into, or is warned to depart from, the particular employment in which the variation has taken place.

"Whilst every man is free to employ his capital where he pleases, he will naturally seek for it that employment which is most advantageous. . . . This restless desire on the part of all the employers of stock, to quit a less profitable for a more advantageous business, has a strong tendency to equalize the rate of profits of all, or to fix them in such proportions as 


\section{THE DIFFUSION OF TAXES}

may in the estimation of the parties compensate for any advantage which one may have, or appear to have, over the other. It is perhaps very difficult to trace the steps by which this change is effected: it is probably effected by a manufacturer not absolutely changing his employment, but only lessening the quantity of capital he has in that employment. In all rich countries there is a number of men forming what is called the monied class; these men are engaged in no trade, but live on the interest of their money, which is employed in discounting bills, or in loans to the more industrious part of the community. The bankers too employ a large capital on the same objects. The capital so employed forms a circulating capital of a large amount, and is employed, in larger or smaller proportions, by all the different trades of a country. There is perhaps no manufacturer, however rich, who limits his business to the extent that his own funds alone will allow; he has always some portion of this floating capital, increasing or diminishing according to the demand for his commodities. When the demand for silks increases, and that for cloth diminishes, the clothier does not remove with his capital to the silk trade, but he dismisses some of his workmen, he discontinues his demand for the loan from bankers and monied men; while the case of the silk manufacturer is the reverse: he wishes to employ more workmen, and thus his motive for borrowing is increased: he borrows more, and thus capital is transferred from one employment to another, without the necessity of a manufacturer discontinuing his usual occupation. When we look at the markets of a large town, and observe how regularly they are supplied both with home and foreign commodities, in the quantity in which they are required, under all the circumstances of varying demand, arising from the caprice of taste, or a change in the amount of population, without often producing the effects of a glut from a too abundant supply, or an enormously high price from the supply being unequal to the demand, we must confess that the principle which apportions capital to each trade in the precise amount that it is required, is more active than is generally supposed." Pol. Ec., Chap. IV. 
Other conditions beside those suggested by Ricardo may operate with similar results. Every year a certain number of those engaged in any trade retire or die; and every year a certain number of young men attain a position which enables them to select the trade in which they will engage. Every year a certain number of factories are burned, and the money received from insurance may be employed in constructing factories for that trade or for any other that is preferred. Every year a certain quantity of machinery is worn out or becomes obsolete; it may or may not be replaced, as the owner chooses. Every year, in our country, population increases and therewith the demand for goods; this increased demand may be more for one kind of goods than another, and capital will be employed accordingly. Every year many manufacturers fail; their factories may thereafter be used to produce the same kind of goods as before, or a different kind. This wonderful elasticity in capital makes the withdrawal from an industry in which the cost of production has increased a comparatively simple and expeditious matter. And the fact that the increase in the cost of production is due to the imposition of a tax rather than to any other expense is immaterial.

It seems, therefore, that a tax on a particular employment will not entail a peculiar sacrifice on the persons following that employment. If it were unexpectedly imposed it would indeed at first do so; but we are assuming it to be an established impost. Hence the saying "An old tax is no tax"; an old tax, as defined by Professor Sidgwick, being a tax "that has lasted long enough for the cessation of the effects of its first imposition, so far as industrial competition tends to do away with those effects." It fol- 
lows then that licenses to pursue particular employments do not constitute a peculiar burden on the persons engaging in those employments. They are indeed an item of expense; but this item, like the other expenses of the employments, is taken into consideration by those who contemplate engaging in them. Nor is it material, so far as sacrifice is concerned, whether the license fee is graduated or not. If it is not graduated, but is the same in amount no matter how large the capital employed may be, it is of course a relatively heavier burden for the man with a small capital than for him that has a large one, and small capitals may seek other employment, thereby freeing the large capitals from their competition. If it is graduated, - although no system of licenses perhaps has ever been graduated with any near approach to proportionality, both large and small capitals may be discouraged from engaging in the employment, thus freeing capitals already employed from the competition that they would suffer were no license fee exacted.

In their reasoning on this subject some writers have fallen into a certain inaccuracy; an inaccuracy from which Adam Smith was not altogether free. He observes: "Taxes upon the profits of stock in particular employments can never affect the interest of money. Nobody will lend his money for less interest to those who exercise the taxed, than to those who exercise the untaxed employments." On their face these propositions may appear selfevident, and the second of them is indisputable; but it is not true that the interest of money can never be affected by a tax on a particular employment. Nobody, it may be presumed, will engage in a taxed employment unless he can make as much profit therein as in an untaxed employ- 
ment, and if that cannot be done, the amount of capital used in the taxed employment will diminish. In order to equalize profits after a tax has been imposed, the product of the taxed employment must be sold at a price sufficient to compensate the producer for the tax. If the quantity sold at a higher price is the same as at the lower price, the buyers of the taxed product cannot buy so much as they did of untaxed products; they have spent more in one way and must spend less in others. In that event those engaged in the untaxed employments must produce a less quantity, if they are to sell it at the same price; or, if they produce the same quantity, they must sell it at a lower price. In either case, if they are to make the same profit, they must reduce their expenses; which means that they must borrow money at a lower rate of interest. If the rates of interest were not lowered, some of them would engage in the taxed employment, but some would go out of business altogether. Therefore, as the demand for money would fall, the rate of interest would also fall.

If, however, the quantity of the product of the employment is reduced, and it is sold at a higher price after the tax is imposed, the quantity of money needed in that employment will be less, and the money no longer lent to those engaged therein must be lent to those exercising the untaxed employments. But it is not needed in those employments, for the buyers of such products have no more money to spend for them than they had before. The competition of lenders will therefore reduce the rate of interest, and those engaged in the untaxed employments will for a time make higher profits; but some of those engaged in the taxed employment will be attracted by these profits and endeavor to participate in them, while some will go out of business 
altogether. Thus, it seems, a tax on a particular employment, like any other event that increases the expense of production, may be felt throughout the whole industrial world; it may decrease the profits of employers, the interest of money lenders, the wages of laborers, and these effects may reappear in a loss to all these persons as members of the general body of consumers, who suffer because the total product of industry is less than it was before. The whole community is poorer; but to ascertain the relative losses of these different individuals in any concrete instance, or in any imaginable case, is a problem the solution of which is entirely beyond human powers.

It is true that Adam Smith speaks of "taxes on the profits of stock in particular employments," but, as his second proposition shows, he means taxes on the employments. In fact, there is no such thing as a tax on the profits of a particular employment, if by that is meant the respective profits of the individuals engaged therein. There are taxes on employments, and taxes on stock; but neither of them have any determinate relation to the actual profit of the individual trader, although they may affect it. The only specific tax on profits is the income tax; but that is meant to be a tax on the net profits from all the employments and investments in which the individual is interested, some of which may be prosperous, and others not. He may, it is true, pay the whole tax out of the gains made in a particular employment; but his neighbor who is also engaged in it may be losing money, and paying his tax from some other source of revenue. In every concrete instance of an income tax, it must be observed, salaries, dividends, and interest are taxed, as well as what are called profits. The taxes on the sale of strong 
drink are enormous; they may amount to as much as all the profits made by those engaged in that sale, and in a sense they may be said to be paid out of those profits. But there is no reason to suppose that such persons are content with any less rate of profit than persons in other occupations, and it can therefore be only misleading to speak of the tax on the sales that they make as a tax on their profits.

In this connection an inordinately litigated matter, the taxation of loans secured by mortgages, may be considered. Like the two knights of tradition, the defenders and the opponents of this tax, each seeing only one side of the shield, have necessarily fought $\grave{a}$ outrance. It admits of no question that to tax a mortgage as well as the property which is pledged for the payment of the mortgage, is in some sense double taxation. Debts form no part of the wealth of a community. Were all the indebtedness of our country consolidated into an issue of government bonds, to an amount equal to all the tangible wealth of the inhabitants, the country would be no richer than if no one of its inhabitants owed a penny. The wealth of an individual is ascertained by subtracting his liabilities from his assets. If he mortgages his land to secure a loan, his creditor becomes the true owner of the land, subject to what is known at law as the equity of redemption retained by the borrower. In fact a mortgage is still in form a deed, with a defeasance. The mortgagor remains in possession of the land, but only if he pays the interest on what he has borrowed, failing which the mortgagee takes possession. Of course there is some economic gain in the proceeding; men borrow money because they can make more than the lenders by using it. 
But this has no bearing on the matter; the value of the land is practically the same, whether mortgaged or not. A, who owns a farm, sells it to $B$, who has no money, for a consideration of $\$ 5,000$, taking B's bond, secured by a purchase-money mortgage of the farm, for the payment of that sum. Until recently, in nearly all our states, A would then be assessed on $\$ 5,000$, the value of the bond and mortgage, and $\mathrm{B}$ would be assessed on $\$ 5,000$, the value of the farm. No value has been created; there is only the farm, but the assessment has been doubled, and double taxation results.

There is, however, a certain ambiguity in the expression "double taxation." For let us suppose that all the wealth in the country belonged to one half of its inhabitants, and that they sold it to the other half, taking back mortgages for its full value. The assessment roll of the country would then be doubled, but the taxes would be the same in amount. They were in the first place all paid by the owners of the wealth; but they are now divided, half being paid by the former owners, as mortgagees, half by the mortgagors, the present owners. There would, it is true, be double assessment; but the rate of taxation would be only one-half what it was before. The defenders of the tax on mortgages would maintain that an equitable distribution of burdens is thus provided. The taxes paid by the owners of the property mortgaged would be lessened, and those paid by the mortgagees would be correspondingly increased. And it must be said that this is perfectly consistent with the theory of the general property tax. If all property is taxed, including choses in action, or claims in general, then by whatever amount is collected from the holders of claims, the amount collected 
from the owners of the property affected by these claims will be reduced. If the general property tax is a proper measure of taxation, the taxation of mortgages is not only a proper but an essential element in this measure.

But here the principle of the diffusion of taxes may be invoked. Disregarding the existence of usury laws they are almost universally evaded where they do exist - the lenders of money may decline to make loans if they are to be taxed on them; or, what is the same thing, they may consent to make them only if the borrower will pay the tax, or pay a proportionately higher rate of interest. That there is some truth in this contention appears from the fact that many legislatures have passed laws forbidding lenders to make contracts obligating the borrowers to pay such taxes. It also appears from the fact that where such laws exist the rate of interest on mortgage loans may be considerably higher than that on others. ${ }^{1}$ The result of the legislative attempt to tax the lender would thus seem to be to throw the tax backward upon the borrower. As the borrower is already taxed on his land, he may well deplore the well-meant but misdirected attempts of the legislature to compel his creditors to share his burdens. To this it may be replied that this result takes place because the general property tax is not enforced; under this tax all other loans, and not those secured by mortgages alone, are taxable. Lenders, therefore, could not discriminate against mortgages. All their loans would be taxable at the same rate, no matter how secured, even if not secured at all. The lenders, it is

1 Prof. C. Plehn has shown from the records of savings banks in San Francisco that for many years the rate of interest on mortgages exceeded that on most other loans by more than the average amount of the tax. 
true, might decline to lend, preferring to use their capital themselves. But if this took place it could be only to a limited extent, and while it might tend to raise slightly the rate of interest, the rise would not be equal to the tax that the lenders would be obliged to pay.

To this the reply - and the conclusive reply - is that the general property tax is not and cannot be enforced. It never has been, it is not now, and the evidence already presented overwhelmingly proves that there is no prospect that it ever will be. Assuming the tax to be enforced so far as it applies to mortgages, the result is to bring the process of lending and borrowing on the security of land into the category of taxed employments, while much of other lending and borrowing belongs in the category of untaxed employments. The principle stated by Adam Smith therefore applies; nobody will lend his money for less interest in one case than in the other. And the corollaries of that principle also apply, so that the ultimate result of this tax would be to distribute the burden throughout the society. We have seen, however, that the assumption that the tax is enforced in the case of mortgages is untenable; only a portion, and a small portion, of such loans is actually taxed. As this portion consists largely of loans made by trustees under legal compulsion, the tax upon it cannot be shifted, and must be borne by those helpless and unfortunate persons whose property is managed under the guardianship of the legislature. The effect on the rate of interest of such conditions would probably be too small to be traceable; and it is also probable that no one maintains that these conditions conform to any standard of justice whatever.

What is true of the general property tax is true, in the 
main, of the income tax. As Mr. E. Cannan has observed, the effect of a universal ad valorem tax on all kinds of property would not be very different from that of a universal income tax. In one case as well as the other, when the tax is imposed the taxpayers must either reduce the amount that they have been used to spend for goods and services by the amount paid to the government, thus lessening demand; or curtail their savings, thus lessening the quantity of capital available for production and the payment of laborers. It is true that the income tax is, to a greater extent than the property tax, degressive; small incomes are, in whole or in part, exempted. To a certain extent, therefore, trade carried on on a small scale is favored, and were it not for the part taken by corporations, the income tax might be raised to such a height as to drive large traders out of business. It is possible that the increase in the number of corporations may be in part due to influences of this nature. . The gain of the small traders, however, may be rather fictitious than real; the economic loss to the whole society of preventing the most productive employment of capital might lessen the real gains of the small trader by more than the amount of his apparent gains from the remission of his taxes. However this may be, sufficient evidence has perhaps been presented to show that the income tax is subject to the same objections as the property tax, and that the inequality of sacrifice that it causes is an irremediable injustice.

This evidence is equally conclusive if the income tax is made progressive, although in this case it is not so clear that the tax can be shifted from those on whom it is imposed. Were eminent physicians and lawyers compelled 
to pay large taxes on the incomes that they derive from high fees, it seems probable that they would be able to obtain still higher fees; for it is to be remembered that the increase of their taxes is intended, and may be presumed, to lessen the taxes of the rest of the community. The community could therefore without inconvenience pay higher fees than before, and such fees would probably to some extent be exacted. Professional charges, however, are regulated by competition much less than the prices of goods, and it is impossible to state any very definite conclusions on such a matter. To some extent, no doubt, the charges of distinguished practitioners are moderated by the competition of less known members of their profession; but when the issue is life or death, or the title to a great property, men are not disposed to haggle over the price of the service, or to spend time in trying to ascertain where they can procure it most cheaply. Much the same is true when the management of a great enterprise is in question; a manager who has the ability to make it succeed may be worth a much higher salary than he demands.

But when the income is derived from investments, it does not appear how a progressive tax can be shifted. In such case no service is rendered for which an increased charge can be made, and this is practically the only way in which taxation is diffused. Most men of great wealth, however, by no means content themselves with the income derived from their investments; they are constantly engaging in new enterprises that promise to increase their possessions. The power of concentrated wealth is often beyond the control of competition; it may fix its own rate of profit. Were these masterful men compelled to 


\section{4}

THE METHODS OF TAXATION

pay very high income taxes, they might in many cases exact them from the community; they might in some cases prefer to abandon enterprises which it is for the advantage of the community to have succeed, but which will not be undertaken except with the inducement of great prospective gains. But we need not pursue this subject further, for as proportionate taxation dependent on selfassessment is notoriously evaded, progressive taxation would probably be evaded even more, and justice be even less attained.

Taxes ad valorem on commodities, or goods, differ from taxes on property only in being collected at irregular intervals, and therefore at no determinate rates. Such taxes may be assessed and collected in several different ways. Fees may be charged by the government for license or permission to produce certain kinds of goods, or to sell them when produced. Licenses to sell certain kinds of services, such as those rendered by physicians or lawyers, are of the same nature as licenses to deal in goods; and the same is true of requirements that compel men proposing to engage in such occupations to prepare themselves by studying for a term of years, and to establish their competency by passing an examination. They are all elements in the cost of rendering the services, they must be calculated by those proposing to render them, they require the expenditure of capital, and they are repaid, in part at least, by the price paid for the services by those who buy them. For several reasons, they cannot be calculated with the same accuracy as the elements in the cost of production or transfer of material goods, but the difference is one of degree and not of kind. 
As has been pointed out, licenses to engage in a particular employment, unless ad valorem or graduated according to the quantity or value of the goods dealt in, are a direct discouragement to men of small means. Some attempt is made by the British government to graduate license fees, especially in the case of dealers in alcoholic drinks; but the attempt is imperfectly successful, and seems not to have been imitated in this country. We have here, however, very marked gradations according to locality. License fees vary extremely between different states, and between different towns in the same state. They are often made very high in cities, with the avowed purpose, and with the effect, of driving men of small capital out of the liquor business; it being apparently supposed that the sale of strong drink on a large scale is less prejudicial to morality than on a small one. The effect of such licenses, however, must be, through diminishing the number of competitors, to increase the profits of those who continue in the business; and there is no reason to believe that the different rates imposed in different towns cause any other difference in the profits of those who carry it on. A liquor-seller, like a grocer, will not engage in business in a small town unless he has reason to believe that he can make as much money there as in a large city, and whether his expenditure be for a license or for the rent of his shop, he will sell his goods at such a price as will repay him and give him the ordinary rate of profit beside.

Licenses to produce goods of a certain kind, when the government supervises the production, can be graduated according to the quantity produced, as is done in the case of excise taxes. Such taxes may be regarded as taxes 
on sales, or transfers of title. When the excise was established in England, liquors intended for the consumption of the producer and his family were exempted, or taxed at a lower rate, and some such exemption still exists. But it is impossible to prevent goods so produced from passing into consumption, and the quantity of such goods is very small compared with the quantity produced for sale. Some such exemption takes place in France, as in the case of the production of what is known as cru; and in this country wine and cider are taxed lightly, if at all. In both cases, political considerations are influential. On the whole it seems that no serious error can result if we class taxes on the production of goods with taxes on transfers of title. Such taxes are usually imposed on what are called raw materials, or goods in one of the early stages of manufacture; although, in the case of the excise, they may be repeated at several stages. In this country they are commonly repeated also by the state governments, and every drinking place displays two licenses. By whomsoever they are advanced, it seems to be universally understood that they are finally paid by the consumer. In so far as they compel the use of large capitals, they tend to limit competition and to increase the rate of profit.

These conclusions are confirmed by some remarkable episodes in our fiscal history. During the Civil War, distilled spirits were for the first time for many years subjected to taxation by the general government. The tax first imposed was 20 cents a gallon. It did not apply to spirits already produced, and the owners of these spirits promptly advanced the price, thus securing a very large sum in profits. This experience was so satisfactory that 
those engaged in the trade welcomed and even labored to obtain additional taxes, amounting in March, 1864, to 60 cents a gallon, in July of the same year to $\$ 1.50$ a gallon, and in January, 1865 , to $\$ 2$ a gallon. Evidence taken before the Revenue Commission in 1865-66 showed that there was in January, 1864, a stock of spirits on which the tax had been paid, large enough to supply the country for half a year, and that on this stock profits of from 60 cents to $\$ 1.40$ a gallon were obtained. It seems clear from this instance that the imposition of a tax may be highly advantageous to those engaged in an industry, a result which can follow only if they are able to shift the tax to the consumers of their products.

Another instance mentioned by Mr. D. A. Wells, is even more conclusive on this point, although here those engaged in the taxed employment struggled only to retain the tax, not to increase it. A tax on matches was imposed, in 1864 , at the rate of one cent per package of one hundred or less, yielding at one time a revenue of over $\$ 3,500,000$ a year. This sum the manufacturers were required to advance by purchasing and affixing on every package a stamp before sale was permitted. To manufacturers furnishing their own design for the stamp, a discount of ten per cent was granted on purchases amounting to $\$ 500$, and sixty days' credit was also allowed to those offering government bonds as security for their payments. These conditions were too onerous for manufacturers on a small scale, and the business fell into the hands of a few concerns, which raised the retail price of matches considerably more than the amount of the tax. When it was proposed, in 1883, to abolish the tax, these manufacturers struggled vigorously to prevent it. They did 
not succeed, and the retail price fell from fifteen cents for six packages to six cents. ${ }^{1}$

These premises seem to authorize the conclusion that a tax on the sale of anything is, as a general rule, followed by an increase in the price for which the thing is sold; but whether this increase in price will be equal to, or be greater or less than, the tax, is not so clear. For reasons that have been stated, a tax on all sales would diminish general profits; were the tax adjusted by omniscience, every employment would be equally burdened, and nothing would be gained by changing from one taxed employment to another. No such adjustment, however, is within the capacity of any legislature, and while in a few cases a universal tax on sales has been enacted, it has been enforced - so far as it was enforced at all with most disastrous results. The Alcavala of Spain was a tax of this kind, being levied on the sale of every sort of property, and repeated every time the property was sold; and the decline of that country has been, it is supposed, largely due to the ruinous effects of this tax. When taxes are imposed on the sale of certain things consumed in large quantities, the investment of capital in the production of those things tends to be checked, and its overflow into other channels would tend to decrease the returns from those channels, and thus cause a general distribution of the burden. To a certain extent, therefore, the producers of the taxed articles might be prevented from raising the price for which they are sold by the whole amount of the tax.

1 The repeated increases of the beer duty in England have been followed by very marked decreases in the number of brewers. Their number is scarcely one-half what it was a few years since. 
On this subject Adam Smith and other writers of his time made some statements that seem to have been regarded by most subsequent writers as axiomatic, and that are constantly repeated at the present day. They are, nevertheless, not free from error, and should be considered in the light of the criticism of Ricardo. It was asserted by Adam Smith that taxes on wages, or on the necessaries of life consumed by laborers, would cause wages to rise, and that the increase of wages would be recovered by the employer, "who would be entitled and obliged to charge it with a profit upon the price of his goods." Upon this Ricardo observes that as according to Adam Smith's supposition corn would not be raised in price, while manufactured goods would be, manufacturers would be benefited and not injured by such a tax. $\mathrm{He}$ demonstrated that the tax would fall on the profits of stock, for manufacturers could not increase the price of their goods. This is in harmony with his general doctrine that "profits are the leavings of wages"; and he expressed the opinion that except in the immediate effects it made little difference whether the profits of stock or the wages of labor were taxed. $\mathrm{He}$ applied the same criticism to the assertion that such taxes were repeated and accumulated four or five times. According to Adam Smith:

"In the price of leather . . . you must pay, not only for the tax upon the leather of your own shoes, but for a part of that upon those of the shoemaker and the tanner. You must pay, too, for the tax upon the salt, upon the soap, and upon the candles, which those workmen consume while employed in your service, and for the tax upon the leather which the saltmaker, the soap-maker, and the candle-maker consume, while engaged in their service." 
To this Ricardo replies that as neither of these persons will be benefited by the tax on leather, etc., and as the government will receive no more than the tax imposed, it is impossible to conceive that more can be paid by the public upon whomsoever the tax may fall. He further illustrates his position by his comment on M. Say's assertion that as when Turgot reduced the market dues on fish sold in Paris by one-half without reducing the revenue from those dues, the consumption of fish must have doubled, and the profits of fishermen and those engaged in the trade must have doubled, thereby increasing the income of the country by the whole amount of these increased profits. Of this Ricardo says, these profits could have doubled only as the result of withdrawing capital and labor from other trades, where they were already profitably employed. The real gain to accumulation was measured "by the difference between the profits obtained in the business in which the capital was newly engaged, and those obtained in that from which it was withdrawn."

An error of more importance is that of some modern writers who have maintained that when a tax was imposed on raw materials, the tax was increased to a very great extent by the repeated profits made on it by dealers. It is no doubt true, as M. Say stated, and as Ricardo admitted, that the dealers and manfacturers through whose hands the material may successively pass, must employ greater funds in having to advance the tax, which may often be difficult for a person of very limited capital and credit. But Ricardo did not admit that the profits on the tax advanced must also be charged to the consumer, and that this additional tax is one from which the treasury derives no advantage. The error arises from disregarding 
the fact that when we speak of a rate of interest we mean the interest for a year, whereas profits are calculated on the capital employed in a transaction, even if it is completed in a month or a day. It is impossible to explain the matter more briefly or more lucidly than Ricardo has done in the following passage:

“M. Simonde, in his excellent work, De La Richesse Commerciale, following the same line of argument as M. Say, has calculated that a tax of 4,000 francs, paid originally by a manufacturer, whose profits were at the moderate rate of 10 per cent, would, if the commodity manufactured only passed through the hands of five different persons, be raised to the consumer to the sum of 6,734 francs. This calculation proceeds on the supposition, that he who first advanced the tax would receive from the next manufacturer 4,400 francs, and he again from the next, 4,840 francs; so that at each step 10 per cent on its value would be added to it. This is to suppose that the value of the tax would be accumulating at compound interest; not at the rate of 10 per cent per annum, but at an absolute rate of 10 per cent at every step of its progress. This opinion of M. Simonde would be correct, if five years elapsed between the first advance of the tax and the sale of the taxed commodity to the consumer; but if one year only elapsed, a remuneration of 400 francs, instead of 2,734 , would give a profit at the rate of 10 per cent per annum to all who had contributed to the advance of the tax, whether the commodity had passed through the hands of five manufacturers or fifty:"

Most things, perhaps, are consumed within a year from the time when they began to be prepared for consumption; but many substances become instruments of production, and may last a long time before they are worn out. Certain things are not fit to be used until ripened by time; some must undergo many processes before they. 
reach the final stage. In such cases some governments endeavor to confine their taxation to this final stage, and the permission to store goods in warehouses under governmental control which is now usually extended, is in furtherance of this purpose. Spirits intended to be drunk should lie for four years before use, during which time there is great loss from evaporation. To exact the duty on them as soon as they were produced, would not only burden the consumer with the accumulated interest on the tax on what he consumed but would tax him on what had never reached him. The cost of producing a gallon of whiskey is perhaps not over twenty cents, and the tax is more than five times that sum. One-fifth of a gallon, the ordinary contents of a "quart" bottle, may be sold for a dollar or more. When the price of anything is advanced to such an enormous extent, it is certainly reasonable to postpone the collection of the tax until the goods are withdrawn from storage, and to collect it only on the amount actually withdrawn. It seems to be universally admitted that the consumers pay this heavy taxation; but some part of it may be shifted back on the producers of the grain used by distillers, as the demand for their products cannot be so great as it would be were there no tax on spirits.

From the foregoing considerations it would seem that taxes are diffused according to the general law that profits, including under the term all returns to labor and capital, tend to be equalized. This law, however, implies not only freedom of competition but also an unlimited supply of materials at a constant price. It assumes that manufactured goods, for example, can be produced in greater or less quantities with proportionate cost. But this is 
not true of land. Its quantity can only with great difficulty be increased; and, in the great centers of trade it is very sharply limited. What is of especial importance, different pieces of land have very different advantages, whether of fertility or situation; from which arises the phenomenon of rent. Rent is the price paid for the use of land from which more than ordinary profit can be derived. So wise a man as Adam Smith, influenced by the Physiocrats, held that there was no land that did not yield some rent, but Ricardo declared that much land in cultivation produced only enough to give the ordinary return to capital, and that nobody could afford to pay rent for it. Those who wish to cultivate better lands must pay a rent equal to the excess of their product over that of the inferior lands." They can make more by the use of such lands, and they can afford to pay more.

If a tax is levied on ground rent, it seems to be universally admitted, the landlords alone pay it. The tax is not paid by those using the lowest grade of land, as it bears no rent; and if those using the higher qualities paid it, they would be making less profit than those who paid no rent. It is true that the landlords cannot accumulate so much, or spend so much, as before, and to a slight extent the tax may be thus diffused. The extent would be so slight as to be negligible; and on the assumption that landlords are charging all the rent that their land will bear, it seems clear that any additional burden on the land cannot be shifted from them. Of course, where rents are rapidly rising, they may not be positively reduced by taxation, but they will be relatively reduced. They may continue to rise, but not to the height to which they would have risen. It would seem then that rent 


\section{4}

\section{THE METHODS OF TAXATION}

is a peculiarly fit subject for taxation according to the progressive method. As Adam Smith observed, it is "a species of revenue which the owner, in many cases, enjoys without any care or attention of his own. Though a part of this revenue should be taken from him in order to defray the expenses of the State, no discouragement will thereby be given to any sort of industry. The annual produce of the land and labor of the society, the real wealth and revenue of the great body of the people, might be the same after such a tax as before. Ground rents and the ordinary rent of land are, therefore, perhaps, the species of revenue, which can best bear to have a peculiar tax imposed upon them." The obstacles in the way of applying such a tax, however, are very serious. They have been considered at length in a preceding chapter, and it is only necessary to refer to the enormously wide diffusion of the ownership of land, either directly, or by mortgage or other charge; to the impossibility of separating the value of land due to the expenditure of the owners from its value due to other causes; and to the vast extent of the "unearned increment" in other property as well as land.

House rent may be divided into two parts: the ground rent, and the building rent. The latter is regulated by the same principles that regulate the gains made in any employment. If houses cannot be rented for enough to make it profitable to build them, they will not be built. The builder will consider what the taxes will be on the completed house, just as he considers what he will have to pay for materials and labor, and if the whole expense is likely to be so great as to leave him less profit than he can make in some other business, he will not engage in building. Pro- 
vided he can obtain a sufficient rent, it makes no difference to him whether taxes are high or low, or whether materials and labor are high or low. But the ability of the tenant to pay rent is limited, and he may be affected by a tax on rent as he is affected by a tax on any necessary of consumption. If a tax on houses is imposed, that part which falls on the ground rent, it seems to be admitted, will be paid by the landlords; but that part which falls on the building rent might be partly paid by the tenant. Were there no compressibility in human beings, the tenants might indeed pay the whole tax. Men must have shelter, and if all existing shelter is taken, there seems nothing to do but to pay more rent, if more is demanded. In fact, however, population is very compressible, and there are always some vacant tenements. Some men would prefer to live in smaller houses, or in lodgings, rather than pay more rent; and, taken as a whole, the population might be accommodated in cheaper quarters. But rather than have the better class of houses vacant the landlords would lower their rent, and the same might take place down to the lowest class of tenement. In a decaying town, all taxes, it might be said, must fall on the landlords; but in an improving town they may be able to recover them at once out of the increasing value of their land and the greater rents that they are constantly enabled to charge. But the principle is unaffected that whatever discourages building in any place tends to lessen the demand for unused land, and this decrease in the value of land decreases also the discouragement to investment.

As has been observed, the fact that taxes are higher in one town than in another makes no difference with the profits of builders; there will always be some building 
to be done, the most profitable jobs will be taken first, and the least profitable ones must yield the marginal return, which would be substantially the same in both towns. But a difference in the rate of taxation may cause a redistribution of capital that cannot be affected without some loss to the whole society; the differential tax is subtracted from the price of the differential advantage of situation for which the tenant pays, but there may be some loss from friction in the process. Allowing for friction, it would seem to be true that a general tax on real estate would have about the same effect on the distribution of wealth as a tax on all forms of property. The owners of personal property would for a time get some profit from exemption; but if capital were driven out of the building trades the effect would be to diminish the rate of profit in the industries into which it made its way. Were it possible to tax personal property effectively, landlords would have to bear a part of the burden, on the principle that if less can be made by the use of land less will be paid for it; but the nature of personal property is such that no general tax on it can be collected.

In treating of taxes on expense it was observed that taxes on house rent required more particular consideration than could then be advantageously given them. On this subject the sagacious comments of Adam Smith remain unchallenged; they are as true now as when they were made, and there is as little to add to them as to take away from them. They are substantially as follows:

"The rent of houses, though it in some respects resembles the rent of land, is in one respect essentially different from it. The rent of land is paid for the use of a productive subject. The land which pays it produces it. The rent of houses is 
paid for the use of an unproductive subject. Neither the house nor the ground which it stands upon produce anything. The person who pays the rent, therefore, must draw it from some other source of revenue, distinct from and independent of this subject. A tax upon the rent of houses, so far as it falls upon the inhabitants, must be drawn from the same source as the rent itself, and must be paid from the revenue, whether derived from the wages of labor, the profits of stock, or the rent of land. So far as it falls upon the inhabitants, it is one of those taxes which fall, not upon one only, but indifferently upon all the three different sources of revenue; and it is in every respect of the same nature as a tax upon any other sort of consumable commodities. In general there is not, perhaps, any one article of expense or consumption by which the liberality or narrowness of a man's whole expense can be better judged of, than by his house rent. . . . The proportion of the expense of house rent to the whole expense of living is different in the different degrees of fortune. It is perhaps highest in the highest degree, and it diminishes gradually through the inferior degrees, so as in general to be lowest in the lowest degree. The necessaries of life occasion the great expense of the poor. They find it difficult to get food, and the greater part of their little revenue is spent in getting it. The luxuries and vanities of life occasion the principal expense of the rich; and a magnificent house embellishes and sets off to the best advantage all the other luxuries and vanities which they possess. A tax upon house rents, therefore, would in general fall heaviest upon the rich; and in this sort of inequality there would not, perhaps, be anything very unreasonable. It is not very unreasonable that the rich should contribute to the public expense, not only in proportion to their revenue, but something more than in that proportion." Wealth of Nations, Book V, ChaP. XI, Part II, Art. 1. ${ }^{1}$

1 Later writers have concurred in this judgment. John Mill observes: "No part of a person's expenditure is a better criterion of his means, or bears on the whole more nearly the same proportion to them. A house tax is a nearer approach to a fair income tax than a direct assessment on income can easily be! having the great advantage that it makes 
A tax of this description, it would seem, cannot be shifted to any great extent. If the occupants of very costly houses owned them, they would pay the tax on the ground rent as landlords, and on the houses as consumers. When they do not own them, they may perhaps in many cases insist that the landlord should pay a part of the tax, if not all of it; and, rather than have the house vacant, the landlord might yield to the demand. $\mathrm{He}$ is presumed to exact the highest possible rent, and the tenant may decline to bear any additional charge. But as houses of this description are exceptionally costly, the ground rent is often a small part of the gross rent when compared with that of the building. The house is intended to be luxurious, and to impress the world with its magnificence; often, it may be thought, to cause astonishment at its lavish extravagance. A tax on the rent of such a house is in some respects like a tax on any other expensive luxury; it may tend to decrease the demand for the luxury by reducing the number of those who are able or willing to afford it. It would probably do so in times of financial distress; but with the return of prosperity the demand would revive. The case is peculiar in that the motive is ostentation; men wish to display their opulence. They cannot well display it in any other way, for the "luxuries and vanities" that they possess would make them ridiculous if placed in a mean abode. He who lives in such an abode is apt to be

spontaneously all the allowances which it is so difficult to make, and so impracticable to make exactly, in assessing an income tax; for, if what a person pays in house rent is a test of anything, it is a test not of what he possesses, but of what he thinks he can afford to spend." Prof. A. Marshall asserts that those who live in expensive houses are just those who now pay less than their fair share to the expense of the country; they might be made to pay very high rates on their houses. He suggests a progressive rate, rising from $4 s$. in the pound to $10 \mathrm{~s}$. 
thought unable to afford a better one; he cannot expect fashionable people to visit him, and the women of his family will be discontented with their position. If he is known to be rich, he will be despised for being penurious, and he can derive but a miserly enjoyment from his riches. The payment of a high tax upon an expensive house thus becomes an additional sign of great wealth, and the desire to display wealth is too strong to be overcome by the reflection that it will cost much money to display it. ${ }^{1}$

It is no objection to such a tax that, like a tax on any other luxury, it can be evaded by self-denial. Rather than pay it, some men will choose to inhabit cheap houses in unfashionable quarters, and to be looked down upon as either poor or penurious. Persons of this unpopular class, however, are precisely those whom it is not advantageous for the community to tax. Their savings maintain that great fund of capital which is the life-blood of modern industry. What is taken from those whose vanity leads them to build luxurious houses, is taken from a fund which, so far as producing wealth is concerned, would be wasted in extravagant living. What is taken from the parsimonious is taken from a fund which employs productive labor, and adds to the wealth of the community. It is common to condemn ostentatious luxury, and it is equally common to sneer at those who abstain from such luxury when they can afford to indulge in it; but, if it is an evil, to relinquish it is commendable, and whatever revenue from taxes on such luxury the government might lose by abstention, would be more than made up for by the increase of

1 When the income tax was levied in this country, the returns being published, it was said that many persons gave in their incomes as much larger than they really were. They were willing to pay a premium for the distinction of being reputed wealthy. 
that fund from which its chief revenue must be derived, to say nothing of the gain in moral welfare from more modest living.

A universal tax on house rent would conform more nearly, perhaps, to the requirements of the proportionate method than any other tax that can be devised. Like all these taxes, however, it would be unequal because of the unequal needs of different individuals. A physician in good practice, for example, must ordinarily live in a good neighborhood; his patients demand prompt attendance, and he must live where they can easily find him. What with other men is ostentation may be with him a necessity; and as his expense for house rent seems unavoidably greater than that of other men having equal incomes, a tax upon it would be exceptionally onerous. Even in this case the tax might after a time be shifted by means of increased fees; but the proportionate method, as exemplified in practice, ignores the diffusion of taxes. A more serious inequality arises from variations in age, in health, and in the size of families. An unmarried man needs incur no great expense for house rent, and a tax on this expense might cause him no inconvenience. But a man who has given hostages to fortune is in a very different condition, which he could not improve by shifting the tax. Like the English tax on windows, such a tax might thus seriously affect the health of the community, and operate to discourage marriage. Even here, therefore, the proportionate method seems not to conform much better to the demands of justice than in the other instances in which it has been applied.

These difficulties do not occur, or are less serious, if the tax on house rents is made progressive, and it is remark- 
able that the advocates of the progressive method have paid so little attention to this tax. Adam Smith expressed surprise that it had been so seldom applied, and there has been little change since he wrote. The British government, it is true, levies a tax on inhabited houses that is moderately progressive. Houses renting for less than $£ 20$ are exempted, those renting at a higher rate up to $£ 40$ are taxed $2 d$. and $3 d$. in the pound, those from $£ 40$ to $£ 60$ are taxed $4 d$., and all above $£ 60$ are taxed $6 d$. in the pound. Like the income tax, this duty is rather degressive than progressive, and certainly falls with no peculiar weight on the very rich. It is, however, the only tax, the death taxes to a certain degree excepted, by which the progressive method can be applied without evident injustice. It is free from the objections to self-assessment, it involves little vexation or inquisition, it can be graduated so as to cause no suffering to persons of moderate wealth, it can be collected with little cost, and it is paid by those who choose rather to pay it than to diminish their ostentatious expenditure. It has all the advantages in fact which the income tax has only in theory, and avoids most of the injustice which that tax, as actually levied, occasions. Such inequality as it may create can be reduced to a minimum by judicious exemptions; and some inequality, it must be remembered, is inseparable from human life, and from all taxation. With proper graduation, this tax would seem more than any other to afford that equality of opportunity which justice is thought to demand; for, while it furnishes revenue to the government, it obtains much of it from the profusion of the extravagant, and at the same time enables the parsimony of the frugal to accumulate the wealth on which the prosperity of the society depends. 
The taxation of monopolies might properly be considered here, as it must of course be affected by the causes that operate to diffuse taxation. That subject, however, has become much confused in the course of recent discussion; and, before it can be disposed of, some popular opinions will require examination. It is enough here to point out the distinction between monopolists and monopolies. A monopoly may be the property of a great many people, none of whom has any large share of it. In such a case there could be no application of the progressive theory; and without making taxation disproportionate, no additional tax perhaps could be laid on the monopoly. Both the proportional and the progressive methods have reference to the property of individual men; but unless a monopoly is owned by a single man, or by a few men in equal shares, a tax upon it would affect individuals very unequally. For this, and some other reasons, it seems desirable to consider taxation of this sort in connection with the economic method.

A review of the facts and principles above set forth seems to justify the conclusion that taxes, as a rule, are not peculiarly burdensome to those who actually pay them to the government; even when the intent of the legislature is clear that they shall fall on certain persons, they often fall elsewhere. Had it not been demonstrated that the attempts made in this country to apply the proportionate method had completely failed of their design, the principles governing the diffusion of taxes would show that such attempts would in any event fail. The forces operating to bring about the existing distribution of wealth seem too powerful to be overcome by legislation; partly, it is proper to observe, because much of our legislation is of a 
kind to maintain the present distribution, while some of it is even designed to create or increase those inequalities which excite legislative attempts at their removal. To a certain extent this conclusion must be modified in speaking of the progressive method; there are taxes that can be made to reduce the wealth or income of designated individuals. We have had few progressive taxes hitherto in this country, and such experience as we have had with them is of little value. The present English system perhaps carries the method as far as is prudent; two-thirds of the income of the English people is exempted from income tax, and the death duties are chiefly paid by the larger estates. But the equalization of wealth which is aimed at by this system, it can hardly be doubted, is to some extent defeated by the shifting of the taxes. It is even probable that it is defeated to a large extent; for, to the astonishment of some of those most competent to judge of such matters, there are signs that the former rate of increase in the number and in the size of large estates tends still to continue. ${ }^{1}$

In view of the injustice that seems to be inseparable from the existing attempts to apply either the proportionate or the progressive method, as well as of the uncertainty in the results of those attempts due to the diffusion of

1 The products both of Sir W. Harcourt's death duties and of the increased income tax have been greater than was anticipated. In fact, every penny added to the income tax has brought in a proportional increase in revenue. But it is to be noted that during this period of high taxation the increase in the wealth of the world has been very great, general prices have risen perhaps 25 per cent, and the rate of interest has been for a part of the time very high. Measured in money, the income of the country may have increased more rapidly than the tax: and as the tax is paid in money, it is a smaller part of the true wealth of the country than it appears to be. Recent prices of consols have been such as to give a greater net return than when the tax was lower. 
taxes, it seems not unreasonable to conclude that justice cannot be attained through measures depending for their equal application on the ascertainment of the property or income of the individual taxpayer. Such knowledge is in his possession alone, and not always even in his; and to found a system of taxation on the supposition that he will, or can be made to, disclose it, demoralizes society by making fraud and corruption pecuniarily advantageous. It makes dishonesty the best policy. We may, therefore, proceed to inquire whether the requirements of justice will not be better complied with by what we have denominated the economic method. 


\section{CHAPTER IX}

\section{THE ECONOMIC METHOD}

THE proportionate method, as above set forth, aims to adjust the burden of taxation according to the possessions of the individual, and in practice this implies that the amount of the possessions, or revenue, of every individual must be known; an impossible condition. The progressive method escapes this difficulty by dividing all men into two classes, the rich and the poor, and placing the burden on the rich. But to classify is to ignore differences in the condition of the individual members of the class, and since submission to burdens means suffering or sacrifice by individual sentient beings, to ignore the differences in their condition is evidently unjust. Moreover in practice the progressive method to some extent resorts to self-assessment, a process that inevitably leads to injustice of an especially pernicious sort. Some of the measures of the progressive method, it is true, are free from this objection; and by judicious graduation individual sacrifices may be made tolerably equal. But these measures do not produce sufficient revenue, and they are supplemented by taxes that may not only be unjust, but may even neutralize the effect of the progressive taxes. The great aim of the progressive method is not so much to diminish the wealth of the rich as to increase that of the poor; to give the poor more opportunity to become rich. Progressive taxes, it is maintained, will do this. But this is not established by experience, for the limits of the diffusion 
of taxes are not known; and, moreover, it is conceivable that the same end may be attained with other means. As was explained at the outset, the economic method may in practice bring about the results aimed at by the other two.

The predominant aim of the economic method is to procure the revenue of the government with the least possible diminution of the revenue of its subjects. But this does not mean that the recognized principles of justice are to be disregarded; on the contrary, it is itself a principle of justice. Taxes are by nature burdensome, and nobody will deny that it is unjust to make the burden heavier than needs be. Nor are the other principles of justice that we have found to be implicitly or explicitly accepted by men in general less controlling. Nothing can excuse the legislature for resorting to the morally disastrous practice of demanding disclosure by the taxpayer, or for employing spies and informers. No measure, however productive of revenue, conforms to the economic method, if it disappoints the expectations which the government has caused its subjects to form with reference to the future conditions of industry and tenure of property. Nor, whether the progressive method holds up the true ideal of justice or not, can any measure be tolerated that clearly diminishes such opportunity to obtain wealth as is now open to the poor. It is perhaps not easily conceivable that such a measure should be even in theory economically advantageous; but were it so, a prevalent feeling that it was unjust would make it impracticable. This indeed illustrates a general principle. The loss from friction in applying any measure of taxation condemned by public opinion as unjust is apt to make it relatively unproductive of revenue. 
The fact that a particular tax violates no rule of justice and is economically collected does not by itself prove that such a tax should be adopted. For we have to consider taxation as a whole, and particular taxes as parts of that whole. Hence the relations of taxes must be examined; one tax may, as it were, neutralize the effect of another, or enlarge and intensify those effects. We cannot, in a federal state like our own, expect to attain justice when no harmony exists between the system of taxation employed by the general government, and that of the states, especially when the systems of the states differ among themselves. One state might develop a system admirable in its design, and that might be satisfactory in its results were the state isolated, but which, owing to the different policy of its neighbors, might muin some of its own industries or drive them from its borders. What is known as the protective system of customs duties operates in favor of certain manufacturers on a very large scale, and the states where those manufacturers carry on their trades may so adapt their taxes as to add to these favors. An attempt by an adjoining state to diminish these favors by its system of taxes could hardly fail to expel these trades, and concentrate them to an even greater degree. It seems, therefore, that the economic method can be put in practice only on the condition that substantial harmony prevails among the systems of the states and that of the general government; or at least that lack of harmony may seriously impair the results that it is proposed to attain.

Subject to this condition, and to the rules of justice, the economic method seems to prescribe the employment of only such taxes as shall interfere with industry to the least possible extent, and - which is much the same thing 
- be collected with the least possible expense; vexation, as Adam Smith says, being, if not strictly speaking expense, certainly equivalent to the expense at which every man would be willing to redeem himself from it. "The distinguishing feature of the best tax," said J. R. MacCulloch, "is not that it is most nearly proportioned to the means of individuals, but that it is most easily assessed and collected, and is, at the same time, most conducive to the public interests." Nobody pretends that it is possible to apportion equitably the benefits of government, and it seems equally hopeless to distribute its burdens with any approximation to justice. Nothing can be more certain, however, than that justice is not offended by doing away with useless expense and vexation, and the extent to which this can be done may perhaps appear to be so great as to make it highly inequitable not to do it. What Adam Smith said on this subject is too well known to be quoted, and later writers have done little more than repeat his statements. Some recent observations by Prof. A. Marshall, on the futility of legislative attempts to equalize the sacrifices of individual taxpayers, are, however, so judicious as to deserve mention. They are as follows:

"No near approach to equity in taxation is attainable. . . . Even in the interests of equity, canons based on mere considerations of equity are often of but secondary importance in practice. Speaking generally, those systems of finance have caused the least injustice and hardship which have most favored the development of the energies and inventiveness of the people; which have hindered them the least in the selection of those routes for the satisfaction of their wants; which, partly in pursuance of this end, have given a preference to taxes which were productive and elastic in proportion to the army of officials needed to levy them; which have avoided 


\section{THE ECONOMIC METHOD}

vexatious meddling, and which have been most definite and certain, and free from surprises and from opportunities of corruption."

The field of inquiry is thus considerably narrowed; and much of it has been already traversed. The objections to the general property tax may be regarded as conclusive, and it will be dismissed from consideration. The income tax proper - for much of the taxation under this head is miscalled - as it must be assessed by those who pay it, is to be rejected, although something remains to be said of the practice of "taxing income at its source." The death taxes, as they are usually assessed by those who do not pay them, or under conditions that make underassessment difficult, are comparatively free from injustice of the worst kind, and may deserve a place in an economic system of taxation. They have been discussed at length and there is little more to be said of them at present. They are in this country an experiment, and we cannot yet determine their effects. Nor, as the very high rates in other countries are comparatively recent, can we reason from their analogy. Taxes on expense, on transfers of title to goods, stamp taxes, licenses, taxes on occupations and on corporations, all require to be examined with reference to the cost of collection and the obstruction of industry, as well as to the principles of the diffusion of taxation. Particular attention must be given to the taxation of land and other monopolies; and since the amount and value of property to be taxed are not properly fixed by the owners, the office of assessor and the function of assessment acquire an importance much greater than has hitherto been assigned to them, and demand exceptional consideration. 
As a general rule, a tax that produces little revenue, even if otherwise satisfactory, is not expedient. The expense of collecting a tax seldom increases at the same rate as the amount collected. A certain number of officers will in any case be required, and a certain number of offices must be kept open. The amount collected at these offices may not be enough to pay for their rent, yet it might cause those who pay their taxes there much inconvenience were they compelled to go to more distant places. Nor is it easy for the government to close an office once established, or to discharge superfluous employees. There are not a few custom-houses in this country where the duties collected do not pay the cost of collecting them; but, although these conditions are of long standing, the attempts that have been from time to time made to abolish these offices have proved unsuccessful. Even when very few persons are liable to pay a tax, it may cost as much to collect it as when there are a great many, for in order to be sure that the tax is paid by the few who owe it, it may be necessary to examine a great many who do not. Much the same is true of a tax on a commodity that is little used. Special machinery may have to be contrived for its collection, and a vast amount of inspection may be necessary to prevent a small amount of evasion.

Taxes of this kind, as well as others, are usually levied by means of licenses, or of stamps affixed to merchandise or to documents. The number of license taxes in this country is not very great, and many of them may be regarded rather as measures of police than of taxation. There may be sufficient reasons why the exercise of certain professions or occupations should be subject to regulation. Some governmental certificate of competency or 


\section{THE ECONOMIC METHOD}

character may be thought necessary to protect the public against imposition; and, if licenses have that effect, they may be justified, and a fee sufficient to pay the expense of examination and registration may be proper enough. Fees of greater amount are obviously taxes, and as explained above, by increasing the cost of services they tend to fall on the whole society. The English government imposes many licenses of this kind, some of which are graduated and some are not. When not graduated, such taxes are obviously unequal. They are a heavier burden on the practitioner or the dealer in a small way, than on those whose income is larger, and their effect must be to diminish that opportunity to prosper which men of small resources seem justly to demand. Perhaps the only licenses in this country that deserve consideration as taxes are those issued to dealers in alcoholic drinks and tobacco. In England such taxes are graduated with a good deal of care, either according to the rent of the premises where these drinks are sold; or, in the case of tobacco, according to the quantity dealt in. In this country, although the rates vary greatly in different places, there is for the most part little attempt at graduation. In general it seems to be thought just to drive small dealers out of the trade, and to confine it to those who have large capitals. But the sudden imposition of high rates has in not a few cases ruined the proprietors of small but decent eating-houses, whose guests have abandoned them because they were unable to bear the expense of furnishing customary beverages; a result difficult to reconcile with any known principle of justice.

If it be thought just, as it appears to be by a great many people, to prevent men of little wealth from engaging in 
the liquor traffic, it may still seem reasonable that the license taxes paid by those who do engage in the traffic should be graduated, even if only by the rude standard of the rent of the premises occupied. It cannot be denied that in England, especially when compensation is granted for the refusal of the government to renew a license, very great difficulties are encountered in estimating this rent, the premises (called "Tied" houses), being often owned by brewers who supply the liquor sold, and who can mingle the elements of price and rent inextricably. Some approximation to the truth is after a fashion attained, and perhaps no more accurate measure of the profits of a dealer can be employed than the rent that he pays. To carry on a larger traffic he must have more space and a better situation, and the landlord may on the whole be trusted to see that when very great profits can be made by the use of his property, very high rent shall be paid for it. A license tax of this kind, therefore, might be only in part paid by the consumer, but would fall also on rent, and on rent which it may be thought peculiarly just to tax at an exceptional rate. In what are called the residential parts of a town, the proximity of a place where drink is sold frequently depreciates house rent, and it seems reasonable that those who obtain high rents by means of a traffic that impairs the rents of their neighbors should pay correspondingly higher taxes. It does not necessarily follow, however, that this tax should be levied by means of a license fee; it could obviously be paid as a tax on rent, or on land, as in the case of other premises having a high rental value.

So far as these license taxes are required of retail dealers, they do not seem to increase the cost of what is 
sold by much more than the amount of the tax. This is because the tax, to the extent that it is collected from the consumer, is collected with little delay, the commodity taxed passing at once into consumption. When the license is required of wholesale dealers and' of producers this is no longer true, and there seems no reason either on fiscal grounds or as a police regulation why such taxes should be repeated a number of times. When the tax on retail dealers is made very high, the expense of collection becomes much greater. The temptation to illicit sale becomes very strong, and a large force of inspectors must be maintained not only to secure revenue but also to protect legitimate dealers against ruinous competition. The expense is of course still further increased when there is also a heavy tax on production, a point which has already been illustrated in considering taxes on luxuries. These remarks apply in the main to taxes on tobacco as well as on alcoholic drinks. They are all objectionable on the principles of the economic method; but they are supported by a public opinion that cannot be disregarded. When the traffic in liquor is in question, the principles of justice ordinarily accepted by men cease to be binding, and nobody who engages in this traffic needs expect that his protests against unjust legislation will receive much attention. Whether it is on the whole for the welfare of the society that this traffic should be forced into the hands of men who are treated as social outcasts, if not as outlaws, seems to be a question that arouses little public interest.

What are known as stamp taxes, with which most other countries are cursed, are fortunately not here prevalent. The name is misleading, or at least not descriptive, for it tells nothing of the nature of the tax, but merely refers 
to a particular evidence of payment. In a few cases, the stamp indicates the payment of a tax by the producer. The beer tax, for example, is paid in the purchase of stamps, one of which is affixed to every barrel of beer by the brewer, in such a manner that the beer cannot be drawn without cancelling the stamp, This tax, whatever may be thought of it as a sumptuary impost, is on the whole very economically collected. Owing to the bulky character of the commodity it is not easy to produce it illicitly, and owing to the fact that it enters into consumption almost immediately after the payment of the tax, the enhanced cost to the consumer is very slight. The tax, too, is very moderate, and is perhaps fiscally the most productive and advantageous of all sumptuary taxes. Breweries are not very numerous, and a small force of inspectors can supervise them. Beer, unlike spirits, is produced solely to be drunk, and a tax upon its production seems hardly burdensome to any other industry. The national government still levies an absurd and unproductive tax on playing-cards, but with that exception, and that of the stamps on packages of tobacco, oleomargarine, etc., it has no other stamp taxes of importance. The State of New York is perhaps the only one that has adopted the pernicious policy of taxing sales, or transfers of property, by means of stamps, as will be presently explained.

The fallacy that is likely to arise from making such a class as that of stamp taxes, is due to the fact that some things are of a relatively permanent and indestructible nature, while others are immediately consumed and entirely disappear. A tax on beer and a tax on the transfer of title to real estate may both be collected by means of stamps, but they are very different in their effects. 
The tax on beer may be regarded as a tax on the sale of beer; but it is collected only once. The tax on the sale of real estate is collected whenever a sale takes place. It may be collected several times in a single year, and several dozen times in the course of a number of years. Real estate, however, is something that is transferred comparatively seldom, while the title to a share of stock in a corporation is now-a-days transferred perhaps several times in a single day. It seems best, therefore, to ignore the accident of affixing a stamp, and to confine the attention to the essential element of the burden of the tax. With the exceptions noted above, we may safely treat stamp taxes as taxes on sales, or transfers of title. Some of them might be classified as taxes on acts; such are the English taxes on agreements, on many legal formalities, and on receipts for the payment of sums over ten pounds. These acts, however, almost always relate to the transfer of property, In the case of receipts it is to be presumed that some thing or some service has been paid for; and in the other cases property is usually involved, the value of which must be reduced by whatever increases the expense of transferring it. Such taxes are all hindrances to that freedom of barter or exchange which is the vital principle of our modern industrial system. It is to be added that by far the largest part of the revenue from the English stamp taxes comes from conveyances and mortgages of real property and from sales of shares of stock. Nobody can doubt that such taxes, even when graduated according to the value of the property, are altogether arbitrary and unequal, owing to the uncertain number of the sales of any particular piece of property, and they evidently. lessen the value of the property affected. 
Bearing in mind the foregoing cautions, we may safely treat the great body of taxation as consisting (1) of taxes levied according to the capitalized or rental value of tangible property; and (2) of taxes levied either on the physical transfers of such property or on the transfers of title to it. The second class of taxes, as has been already suggested, tends to affect the value of what is subjected to taxation of the first class. Taxes on the physical transfer of things - and we may with some important qualifications include persons - are levied chiefly on railroad or water transportation, and on imported goods. We might, it is true, regard imported goods as sold by a foreign producer or merchant to a resident of this country, and customs duties could then be treated as taxes on sales. It would make little difference if this classification were adopted; but it may often be the case that the goods are produced or bought by a resident of this country, and are not sold by him until after he has paid the duty on them. For this reason, and because the physical act of importation is visible and notorious, it seems proper to make a class of the taxes specifically declared by statute to be due when that act takes place. The foreign origin of the goods may be in the view of the scientific economist nothing but an accident; but it is an accident so conspicuous and so familiar to every one that it might cause confusion to ignore it. In principle, however, a tax on imported goods does not differ from a tax on the production of spirits or beer. The essential fact is that both must be paid before the commodity can enter into trade or consumption.

Owing to the prevalence of some grave misunderstandings, it seems desirable to consider separately taxes on 
incorporations, and on what are commonly called monopolies. A corporation, from the industrial point of view, is nothing but a number of persons who contribute some of their wealth for the prosecution of an enterprise which is managed by trustees or agents chosen for that purpose. Apart from statutory restrictions, there is no reason why the enterprises carried on by means of corporations should not be carried on by means of firms or by individuals, except their occasional magnitude. Some of these enterprises are perhaps necessarily on such a colossal scale that no individual could command the capital required. Nor could any firm or partnership carry them on, because the common law makes every member of a partnership liable for its debts to the extent of his whole private estate, and prudent men will incur this risk only when they know the responsibility of those with whom they are associated - a condition which cannot be complied with when their number is large. It has therefore been the policy of the legislature in modern times to limit the liability of those who incorporate an enterprise to the amount of the capital, usually, which they contribute.

The economic gain from this limitation has been beyond question enormous. A vast amount of wealth which could not be productively employed with safety by those who have saved it, is rendered available to industry. Enterprises which could not otherwise have been undertaken at all become practicable; enterprises which could be carried on to little advantage on a small scale become profitable. By this means a very great number of people who were formerly obliged to employ their capital in a single form of industry under their own supervision, or who had great difficulty in safely employing it at all, are enabled 
to participate in the profits of nearly all the industries of the country. They are also enabled by the exercise of their own judgment, or that of competent advisers, to distribute their investments in so many ways that the failure of one enterprise will be balanced by the success of the others. In spite of the very great losses that have been incurred through the mismanagement of corporations, the evidence appears to be conclusive that, before this form of investment was available, the losses not only from inability to invest but also from the mismanagement of such enterprises as were open to investors, were relatively much greater. Nor do the figures of modern trade show that the losses of creditors are any greater from the failure of companies of limited liability than from the failure of firms or individuals; it would perhaps not be very diffcult to prove that quite the contrary is true.

From these premises two important conclusions follow. In the first place it is obvious that when an enterprise can be made profitable only by the use of a vast capital, its existence cannot be said to limit the opportunity of a man of little capital to engage in it. He could not do it, no matter whether his competitor were a corporation or an individual. No man having little capital could build and manage an ocean steamship; and if corporations were not tolerated, it is doubtful if they could be built to any great extent, if at all. It is of course true that if there were no enterprises on a large scale, there would be, in a sense, more opportunity for small capitals. If there were no large vessels, there might be more small ones; just as if there were no mowing machines or harvesters there would be more scythes and sickles. Experience, however, does not support this view. Every great enterprise begets a 
number of little ones. It creates a demand for new things and enlarges the demand for old ones. ${ }^{1}$ If justice consists in increasing opportunities for the employment of small capitals, it will not be furthered by diminishing the opportunities for the employment of large ones. To lay exceptionally heavy taxes on such employment may therefore tend to hinder rather than to promote the attainment of justice; and even if large concerns prevent the growth of small ones, it would still be true that they afford, by the division of their stock into shares, an almost limitless increase in the opportunities of the small investor.

The second conclusion is that when an enterprise can be carried on by a corporation with a small capital, no diminution of the opportunities for individuals results. Any individual can incorporate his business if he chooses. By doing so he can perhaps obtain more capital and operate with less risk; but so can his competitor. He can obtain more capital, however, only by sharing the profits of the business with those who furnish the capital, which is the same thing as offering them an opportunity for investment. There is no economic reason why a corporation should have better credit than a firm or an individual of equal resources; indeed, because of its limited liability, it should have less credit. No doubt many of the managers of corporations have been dishonest; they have cheated their shareholders and their creditors. It is equally true that many partners in firms, and many individual traders have been dishonest; the records of the bankruptcy courts afford ample evidence. Dishonesty in the management of cor-

1 On this point some figures presented by the late Edward Atkinson are instructive. The number of small industries existing in the City of Boston he found to be surprisingly large, and to show a marked tendency to increase. 
porations may be on a larger scale, because their operations are on a larger scale; but it is on the whole more difficult and more liable to exposure. And, as there is an economic gain in the increased opportunity for investors afforded by incorporated enterprises; so there is a diminution of loss, owing to the wider diffusion of the effects of failure.

No principle of justice, therefore, seems to forbid carrying on business, on either a large or a small scale, under the corporate form; on the contrary, justice seems to demand that it should not only be permitted but even encouraged. Hence the practice of laying heavier taxes on capital employed in this form than on that employed by individuals may seem unjust. It is like laying a tax on any improved method of production or exchange; it increases the price at which the society would obtain better service or cheaper goods. There may be economic reasons why such taxation should sometimes be adopted; and many of the taxes on corporations are of such a nature as to be collected with little expense and with much certainty. It may be very proper to collect a fee for issuing a license to a corporation, and perhaps a fee for registering its certificates of stock; but when these fees are made to produce revenue they become taxes, and have the same effect as taxes on individuals engaged in business. They are similar to the French patentes, and like them tend to result in increased burdens on the consumer. So long as they are not very heavy this result may be imperceptible; but in that event they may not produce revenue enough to pay the officers employed to collect them. If they were made very heavy they might not produce very much more, for the economic gain from incorporation might be neutralized. But owing to the exposure of scandalous abuses in certain concerns, a tor- 
rent of denunciation has been recently directed against corporations in general, and they are not likely to be soon relieved of discriminative taxation, even though it fall eventually, in some degree, on those who indulge in denunciation of this kind.

As a condition of limiting the liability of shareholders to pay the debts of their company, the legislature imposes many restraints which do not apply to individuals. The charter may be issued only for a term of years, and it is subject to alteration or repeal. The amount of the profits distributed as dividends may be limited, and burdens of many kinds may be imposed, including special rates of taxation. In defense of these restraints it may be said that shareholders do not exercise proper control over their agents; the managers of corporations do as they please, and may use their powers to oppress weak competitors. No manager of a corporation, however, can be quite so arbitrary as an individual, or a firm, of very great wealth. He may do a great many arrogant and oppressive things; but he does them at the risk of being made chargeable as a trustee. He is in fact usually the representative of a few men of great wealth, who can prescribe his conduct and displace him if it does not please them. These men would be powerful in any event, and the restraints that the legislature can impose on corporations, cannot be imposed on them, except by general laws which would restrain the activities and reduce the opportunities of poor men much more than those of the rich. It is undoubtedly a very dangerous course for the legislature to empower corporations to do certain acts which it forbids individuals to do ; the disgraceful history of many, if not of most, of the banks chartered by the states before the Civil War shows 
this plainly enough. When the legislature adopts this policy, it is of course necessary to prescribe the terms on which these special powers may be exercised. It does not follow even then that corporations exercising these powers should be taxed at an exceptionally high rate. When an act is unjust, whether done by an officer of a corporation or by an individual, it is not to be punished or prevented by laying taxes on the business in which that corporation or that individual is engaged; still less when such taxes must be laid on all corporations engaged in such business, whether their officers are guilty of such acts or not. Such taxes are apt to fall in the end with accumulated weight not only on shareholders, who may be ignorant or innocent, but also on consumers, who are both. They may be regarded as belonging to the class of taxes on the capitalized value of tangible property, even when they are called franchise taxes.

It has seemed necessary to consider this subject at some length and with some repetition, because the tendency to personify abstractions, inveterate in mankind, seems to influence much of the discussion and even of the legislation concerning corporations. They are constantly spoken of as if they were persons, having all the vices, although perhaps not all the virtues, of sentient beings. They are accused of ambition, of oppression, of corruption, of greed, of dishonesty, of robbery. Such charges evidently cannot be sustained against metaphysical entities; they imply personality. A corporation, however, is a person only by a figure of speech. It is a legal term signifying that a number of persons may agree to combine for the purpose of using their wealth in carrying on a certain business according to the terms of a charter or franchise granted 
by the legislature, in which case they may sue and be sued collectively under their corporate name. These persons, the shareholders or stockholders, being too numerous to transact business, must employ trustees and managers; they are pecuniarily responsible for the acts of such agents, but the conditions are such that they can have little moral responsibility. It is really the managers who are responsible, whose acts have moral quality, who may be blameworthy, who may be guilty of all the iniquities attributed to corporations.

It seems clear that if any law is broken it must be by these persons, and that they are the persons to be punished as individual malefactors are punished. The directors or trustees who appoint them may sometimes instruct them to disregard the law, and may thus participate in their guilt, and deserve to share their punishment. But to "punish a corporation," when its managers have been guilty of crime, by depriving the shareholders of some of their property, is certainly a very primitive way of administering justice. With the wonderfully extensive ramifications of our modern credit system, it may be, by depreciating the value of the securities of the corporation, to punish millions of depositors in savings banks and holders of lifeinsurance policies, some of whom may never even have heard of its existence, and none of whom have any knowledge of the acts of its managers. It seems still more unreasonable to propose to "curb" or " chastise" corporations in general, because the managers of some of them have violated the law. The zeal with which such violations are frequently denounced seems little more discriminating than that of the leader of the Catholics in the massacre at Béziers, with his cry: "Tuez toujours; Dieu reconnaîtra 
les siens!" To levy taxes on corporations under the influence of such zeal seems not likely to have consequences either morally or economically desirable.

No one who considers the outcries against monopolies can fail to be struck with the confusion of thought which these outcries imply. Attention has already been called to the distinction between a monopolist and a monopoly; between an individual exercising a certain right of property, and a right of property which may be exercised by a large number of persons, as in the case of shareholders in a corporation. We may say broadly that a monopoly exists whenever a right of property is of such a nature as enables its owner, or owners, to obtain from its exercise more than what is called, to use Adam Smith's language, fair, ordinary, reasonable profit. This definition may not seem scientifically accurate, for the exclusion of competition which is usually associated with the term monopoly may not enable its owner to obtain more than ordinary profit. A substance might conceivably be found only in a single mine, and yet the price at which it could be sold might be only enough to pay the cost of production. So a railroad might be the only means of transportation between two places, while the cost of operating it might be so great as to leave little profit for its owners; and there are in fact many such cases. Where competition would not take place, there can be no injustice in its exclusion. It is evident, therefore, that to constitute a monopoly in the ordinary sense, there must be such a right of property as actually enables its owner, by the employment of a certain amount of capital, to obtain more than the usual rate of profit thereon.

Now there are monopolies deliberately and intentionally created by the legislature. Such are patent rights, 


\section{THE ECONOMIC METHOD}

which are a species of property of very long standing, and of scarcely questioned justice. The legislature explicitly grants to one who invents a new process the right to make use of it, to the exclusion of all other persons. Many of these rights, no doubt, prove to have little or no value, and can produce no profit. But it is reasonable to presume that as a class such rights have a value; in many instances these values have proved to be almost fabulous. This result is obviously contemplated by the legislature; it is too notorious to be ignored. The policy is to stimulate inventors with the hope of exceptional profits. Were they to spend years of thought and toil in developing processes which any one might freely use, they would obtain no reward for their labors. Their monopoly is their reward, and to impose special taxes on such monopolies is plainly inconsistent with the general policy. It would be to take away with one hand what was bestowed with the other, and would destroy the whole system of granting patent rights for the purpose of encouraging invention. So long as the system prevails, the monopolies that it creates must be free from exceptional taxation. This principle is the foundation on which numbers of great industries have been built, and to repudiate it would be such a disappointment of reasonable expectations as justice could not tolerate. With due notice it may be modified and even abandoned in the future, but vested rights must be respected.

Another class of monopolies created by the legislature, although not with such explicit declaration of purpose, is that promoted by the policy of laying on imported goods duties from which similar goods produced in the country are exempt. So far as there is free competition in the production of such goods, this policy may not create monop- 
olies. The manufacture of cotton cloth, for example, seems to be a business in which any one with sufficient capital may engage with as much opportunity for making a profit as his competitors. When the duty on cotton cloth was first imposed, to be sure, those engaged in the manufacture may have for a time made exceptional gains; but competition would tend to make them temporary. But there are many concerns that, as we say, produce their own raw materials; they have two sources of profit. The great companies manufacturing iron and steel own mines of coal and iron ore, and it seems clear that the exclusion of foreign coal and iron ore tends, by limiting competition, to increase the price of the domestic products, and the value of the mines from which they are obtained. This result is too obvious to have been unforeseen by the legislature; the avowed purpose of what are called protective duties is to increase the gains of domestic producers, and it would be absurd to maintain that when it laid a tax on imported coal the legislature did not intend to benefit the owners of coal mines in this country. So far as such owners possess a monopoly, it must be regarded as to a certain extent created deliberately by the legislature, and it would be inconsistent with the whole theory of protective duties to lay exceptional taxes on things to which these duties are meant to give an exceptional value. If the protective policy is just, such taxes, being inconsistent with that policy, would be unjust.

Still another class of monopolies purposely created by the legislature is that of companies formed for building and operating railways, and for the supply of water, light, etc., to towns. The status of persons owning rights of property so created is somewhat peculiar; they are authorized, 
on paying compensation, to take the property of other persons for the uses prescribed by the legislature. In other words, they exercise the right of eminent domain, a right usually regarded as a sovereign prerogative. For the sovereign to delegate this right was a proceeding which, at the beginning of the railroad era, aroused a good deal of question; the debates which took place in the courts and elsewhere may still be read with interest. The economic gain from the construction of railways was, however, perceived to be so great as to make it imperative to secure it, and the franchises of these corporations were soon established on a legal basis. So urgent was the demand that the general government presented vast tracts of land to such persons as would risk their capital in these comparatively untried enterprises, and pledged its credit as security for their loans, while states, counties, and towns vied with one another in offering like inducements. It needs no argument to prove that these land grants and other bounties were intended to bring exceptional profits to the recipients; that was their avowed purpose and their obvious result. Monopolistic gains of this kind may be classed with those of the grantees of patent rights ; both are held out as inducements to employ money and labor in particular ways, and it seems as unreasonable in one case as in the other to defeat this policy by exceptionally heavy taxation. Many of those who invested their money in railroads lost it all, as many inventors have lost their time and trouble, and the exceptional gains of some investors and some inventors must be regarded as meant by the legislature to persuade men to take the risk of such losses.

For the legislature to attempt to deprive men of the gains thus deliberately promised them seems unjust, as 
being a disappointment of reasonable expectations. The doctrine of estoppel, which is imbedded in the national constitution in the form of a prohibition of laws impairing the obligation of contracts, is a necessary condition of industrial progress, and even of civilized life. To keep promises is elementary morality, and promises made by an authorized agent are as binding as if made by the principal. Rulers chosen by the people are the people's agents, and so long as they act within their authority, the people cannot justly repudiate their contracts. Nor can they in fact successfully repudiate them if they would, for the courts must enforce the constitution. No doubt, in many cases, the legislature has exceeded its authority; it has made contracts that it was not empowered to make. Such contracts may be justly repudiated; the expectations that men form concerning their results may not be reasonable. He who deals with an agent, whether an individual or a legislature, must assure himself of the agent's powers, if he proposes to hold the principal. The courts seem to have held the balance fairly even. They have enforced valid and abrogated invalid contracts.

The foregoing statements need to be qualified in some important respects. As the excitement aroused by the advent of railroads subsided, cooled frequently by the failure of many of them to earn the interest on their bonded debts, the charters granted became less liberal. The term of existence was usually limited, bounties ceased to be given, power to amend charters was reserved, and in various ways investors were warned not to be too sanguine in their expectations. And there was always a warning in the very character of the business carried on by railroads. At the common law a carrier who plies his trade on the 
highway is subject to regulation. He makes use of the highway not as an incident to his other business, but as an essential part of his business. Since the highway is maintained at the expense of the public, such exceptional use of it justifies the legislature in exacting some equivalent for the public benefit. This may be done by requiring the carrier to maintain the highway, or to pay part of the expense of maintaining it; or the carrier may be required to serve the public at reasonable rates.

When our first railroads were built, it seems to have been supposed that they were enterprises of the same kind as the old "turnpike" companies. These companies were empowered to lay out or improve highways, and to reimburse themselves by taking toll from those who made use of their improvements. A railroad, it was thought, would construct its line, and any one could load his own car and haul it over the line, as a farmer drives his cart over a turnpike. This theory which, grotesque as it may sound, has been seriously propounded by some modern writers as the true one, was very soon abandoned, and the railroad companies not only constructed their lines but also conducted all the traffic thereon. But as their lines could be constructed only by the exercise of the right of eminent domain; they retained some of the legal qualities of highways, and the companies were allowed exclusive rights only on the ground that they were common carriers. As common carriers their charges have always been subject to regulation by the state, and have often been reduced when they were unreasonably high, and perhaps sometimes when they were not. The exceptional inducements held out to investors in railroads, therefore, must always have been viewed in the light of this possibility of governmental regulation, 
and the proper exercise of this power constitutes no disappointment of reasonable expectations. Nor has its proper exercise, perhaps, been regarded as unjust by the owners of railroad property. They have complained not that the legislature has forbidden them to exact rates that were unreasonably high, but that it has compelled them to accept rates that were unreasonably low. The question has always been, and is, one rather of fact than of principle.

The owners of railroads, like the owners of other property, have as a matter of course been subjected to taxation on their property; and often, too, on their debts. Whether they should be subjected to a higher rate of taxation depends partly, as we have seen, on the rights granted them by their charters, and partly on the relation that such taxes bear to the cost of furnishing transportation. It must be admitted that when reasonable rates have prevailed, to increase the cost of furnishing transportation, whether by taxes or by other means, may make it necessary to increase the rates. That is to say, a tax levied on the railroad may be really paid by those who travel on it, or whose goods are carried by it, and be thus ultimately diffused throughout the whole society. Such a tax may or may not be advantageous; it falls into the class of taxes on the transfers of goods, which are yet to be considered. So far as the owners of a railroad obtain more than the ordinary rate of profit under the guarantee of their charter, it would seem that they may properly charge such rates as will give them this profit, and that such rates cannot justly be reduced either by specific ordinance or by special taxation. So far as monopolistic profit is not secured by contract with the legislature, it may be reduced by lowering rates so as to extinguish it, or by imposing taxes without permit- 
ting an advance in rates. When such a reduction takes place, the owner of railroad property is deprived of an " unearned increment" of value. Whether he can be justly so deprived depends on the answer to the question whether all unearned increments should be specially taxed, or only those owned through certain kinds of corporations. Some reasons were given at the outset for believing that the conviction that it would be unjust to deprive individual owners of all such increment in the value of their land was too deeply rooted to be overthrown. It remains to consider whether the circumstance that the individual owns land in partnership with others, by means of a railroad corporation, seems properly to modify this conviction.

Reference has been made to the grants of land made to the builders of railroads, especially by the general government. But similar graints have been and are now made to individuals. Many millions of acres have been bestowed in this way, freely, or for a nominal consideration. Many of these millions have increased enormously in value; lands bought for a dollar or two an acre are now worth a hundred times their cost to the first occupant. A certain part of this increment is due to the expenditure of labor on the lands. A large part of it, however, is due to the growth of population and to the construction of railroads, without which the products of these lands could not have been marketed. This cause is even now in constant operation; new lines of railroads, operated by electricity as well as steam, are every year adding to the value of the lands through which they are constructed. The most impressive illustration of this process is afforded by the extension of the local railroads in the City of New York, to which allusion has been already made. When the elevated railway 
common law and in our constitutions. The title of the railroad owner is of modern origin, it is statutory, and limited to a special use. It has the support of law, but not the support of sentiment, which has always justified the retention by the freeholder of all the increase in the value of his land, be it earned or unearned. The freehold has the sacredness of a home; its associations make it much more than a mere embodiment of pecuniary value. The owner spends his own labor on it. He makes his living from it, and he has an intimate, personal interest in its products. As a landlord he may obtain from consumers prices that have an element of monopoly, but as he does not directly deal with consumers they do not realize this. The public grumbles at the high prices of food, but it never blames the farmer for them.

There is nothing sentimental about the ownership of a share in a railroad. The owner can pretend no attachment to the land in which he has a share. He cannot plead his affection for a roadbed, which he may never have seen, which he cannot use as a home, which he has spent no labor on, which he can utilize only as a money making machine, and by means of agents who have hardly more personal interest in it. For the services rendered by this machine the public pays directly in fares and charges, and it is incessantly watchful over their amount. It admits; rather grudgingly perhaps, that the owners of this machine deserve a reasonable compensation, but it is reluctant to concede that this compensation should include the element of unearned value. The law may recognize this claim, contracts may assert it, courts may enforce it; but it lacks the moral support and prestige that ancient custom and precedent and sentiment have thrown about the absolute 
right of the individual freeholder. Whatever may be true of corporate rights acquired in the past, it is evident that in the future, unearned increments in the value of the property of public corporations are not likely to be held sacred, and may after due notice be subjected to special taxation. As has been observed, there may be a monopoly without monopolists. All the shares in a railroad may be held by persons who have paid prices based on the entire value of the property, earned or unearned, and who may receive no more than the ordinary return on their investments. It would be unjust to confiscate their property; but henceforth prudent investors will hesitate to pay for prospective values, which public opinion may justify the legislature in annihilating as soon as they come into existence.

In the foregoing statement railroad companies have been taken to illustrate principles that apply generally to companies acquiring rights in trust for the public. Water companies, and telegraph and telephone companies, cannot operate without exercising the right of eminent domain, and are as subject to regulation as railroads. Street railways and companies furnishing light may occupy a slightly different position. Such companies must make use of highways, and where the public ownership is limited to the surface, it would seem that abutting owners might claim compensation for their expropriation from the soil beneath and the air above. Where the fee of the land on which the highway is laid out belongs to the public, there may be no occasion to condemn private property. But the difference is not very material. In every case certain persons are allowed to make use of property which they have not acquired by grant in the usual form, and which they can use only for a purpose and on terms prescribed by a public 
common law and in our constitutions. The title of the railroad owner is of modern origin, it is statutory, and limited to a special use. It has the support of law, but not the support of sentiment, which has always justified the retention by the freeholder of all the increase in the value of his land, be it earned or unearned. The freehold has the sacredness of a home; its associations make it much more than a mere embodiment of pecuniary value. The owner spends his own labor on it. He makes his living from it, and he has an intimate, personal interest in its products. As a landlord he may obtain from consumers prices that have an element of monopoly, but as he does not directly deal with consumers they do not realize this. The public grumbles at the high prices of food, but it never blames the farmer for them.

There is nothing sentimental about the ownership of a share in a railroad. The owner can pretend no attachment to the land in which he has a share. He cannot plead his affection for a roadbed, which he may never have seen, which he cannot use as a home, which he has spent no labor on, which he can utilize only as a money making machine, and by means of agents who have hardly more personal interest in it. For the services rendered by this machine the public pays directly in fares and charges, and it is incessantly watchful over their amount. It admits, rather grudgingly perhaps, that the owners of this machine deserve a reasonable compensation, but it is reluctant to concede that this compensation should include the element of unearned value. The law may recognize this claim, contracts may assert it, courts may enforce it; but it lacks the moral support and prestige that ancient custom and precedent and sentiment have thrown about the absolute 


\section{THE ECONOMIC METHOD}

right of the individual freeholder. Whatever may be true of corporate rights acquired in the past, it is evident that in the future, unearned increments in the value of the property of public corporations are not likely to be held sacred, and may after due notice be subjected to special taxation. As has been observed, there may be a monopoly without monopolists. All the shares in a railroad may be held by persons who have paid prices based on the entire value of the property, earned or unearned, and who may receive no more than the ordinary return on their investments. It would be unjust to confiscate their property; but henceforth prudent investors will hesitate to pay for prospective values, which public opinion may justify the legislature in annihilating as soon as they come into existence.

In the foregoing statement railroad companies have been taken to illustrate principles that apply generally to companies acquiring rights in trust for the public. Water companies, and telegraph and telephone companies, cannot operate without exercising the right of eminent domain, and are as subject to regulation as railroads. Street railways and companies furnishing light may occupy a slightly different position. Such companies must make use of highways, and where the public ownership is limited to the surface, it would seem that abutting owners might claim compensation for their expropriation from the soil beneath and the air above. Where the fee of the land on which the highway is laid out belongs to the public, there may be no occasion to condemn private property. But the difference is not very material. In every case certain persons are allowed to make use of property which they have not acquired by grant in the usual form, and which they can use only for a purpose and on terms prescribed by a public 
authority. When property so acquired advances in value through other causes than the expenditure of the grantee's capital thereon, the principles already stated in the case of railroads seem to apply. The right to the enhanced value may be secured to the owners of the property by contract; or, if not, this value may be subjected to special taxation by means of franchise taxes or higher assessments, or it may be extinguished by lowering the charges for the services rendered to the public so as to produce only the ordinary return on the capital invested. Both processes may conform to the progressive method; whether they conform to the economic method is a question more difficult to answer.

According to the established doctrine of economics, the owner of a monopoly fixes the price charged for his commodity at such a rate as to bring him the greatest possible profit. As has been pointed out, this may be only the ordinary or reasonable profit, which cannot properly be subjected to exceptional taxation. When the profit is greater, the gross receipts of the monopoly may be taxed; but the result might be to make it for the advantage of the monopolist to furnish less of his commodity at a higher price. His gross receipts and his net receipts might both be diminished, but the latter to a less degree than the former. A tax on net receipts, or a tax on the monopoly as a unit, cannot be thus avoided. As it seems impossible to devise any satisfactory method of taxing monopolies as units, the tax on net receipts is properly adopted. It may be levied directly; but the same result might be attained by taxing the property of the monopoly, if its value could be precisely determined. This is what is attempted in taxing what are called franchises, as is now done in the State of 
New York. The courts held that the rights in the highways enjoyed by various companies were not taxable as real estate. The value of these rights had become very great, and they would seem to be properly easements, but as the law stood they were not so classified. The amended law in effect made them taxable under the name of special franchises. Had they been assessed as personal property, the debts of the companies might have been deducted, thus leaving nothing subject to the tax. A franchise in this sense may be defined as a right to operate, but as this right must be exercised by means of the easements in the streets, the value of the franchise and the value of the easement are practically the same.

The important point is that this value must be measured by the profits of the company. If it does not earn anything its franchise is worth nothing. We are thus brought back to the taxation of net receipts as the only practicable method. The problem is really one of assessment. If we would tax property we must assign it a value, and we must be guided by the rent or profit that the property will produce. When we have to deal with the property of a company of this kind, we find it impossible to assign values to the several parcels of which it is composed. The fact that a parcel might have a certain value if used for another purpose is immaterial; it is essentially a part of a complex whole. We cannot say of a locomotive engine that this wheel has a certain value and that cylinder another; even if we could ascertain the cost of producing the separate parts we should not know the earning power of the machine, and it is that which fixes its value. The attempt to tax a railroad piecemeal leads to inequalities in assessment that may without exaggeration be described 
as frightful. Local assessors are under a constant pressure to assess the owners of such property, who have no votes, at the highest possible figure, as this enables them to reduce the taxes of their neighbors, by whose votes they hold office. But when a railroad constructs a costly bridge the increased value seems properly assessable as belonging to the railroad as a whole, and not to that part of it situated in a particular taxing district.

A recent investigation by a parliamentary commission in England has disclosed many striking instances of such inequality. In addition to the stamp taxes, the passenger tax, and the income tax, railway property is assessed to the rates or local taxes, usually at very high figures. In one parish the land of the Great Western Railway is rated at $£ 284$ an acre, other lands at $£ 36 s$. The Midland Railway pays in 180 parishes from 16 per cent to 83 per cent of the rates, while its acreage never exceeds five per cent and does not average two per cent. In 60 parishes the rates paid by the railway are more than half the total assessment. In 166 parishes the land of the railway is rated at from $£ 23$ to $£ 345$ an acre, the rest of the land being rated from $9 s$. $6 d$. to $£ 88 s$. an acre. The controversies over the ratings in the larger towns are often very expensive and inconclusive. Professional valuers have in some cases bargained with the authorities for a commission on whatever increase in the assessment they may establish, an arrangement that obviously impairs the weight of their evidence. The whole matter seems to be in as deplorable a state of confusion in England as in this country, and it should obviously be regulated by a central authority, having power to assess net earnings and to apportion the proceeds of the tax thereon among the localities according to a 
fixed principle; or having power at least to equalize assessments.

We cannot here examine the details of the methods adopted in the different states in dealing with this diffculty, but attention should be directed to an ingenious compromise which is practicable when the property of a monopoly lies within a single taxing district. The South Metropolitan Gas Company of London has for a long time operated under such a system, its charges for gas and its dividends being inversely proportioned. Whenever the company reduces the price of gas one penny per thousand feet, its standard dividend may be raised one farthing, or five shillings per cent. The shares of the consumers and of the stockholders are stated to be about as thirty-five to six. Hence if the assessment of the company is increased too much, the consumers pay six-sevenths of the excess. Probably no better system of dealing with public service companies operating within the limits of municipalities can be devised, and where it has been introduced in this country the results seem to have been satisfactory. The plan has the advantage of calling the attention of the consumer to the fact that special taxation imposed on the company may enhance the price of the commodity furnished. So far as the company is concerned, it makes little difference whether it pays a higher tax and charges more for its product, or pays a lower tax and charges a smaller price. To the individual consumer the difference may be material. He may consume little gas, but pay a large tax on his property, and he is thus interested rather in having taxes lower than gas cheaper. Hence it may seem more equitable, within certain limits, to increase the tax as the dividend increases, rather than to lower the price of gas. 
Such a tax is collected with very little expense, and when first imposed might conform to the progressive as well as to the economic method.

This illustration brings us face to face with the great question whether it is desirable to tax transportation, or the physical transfer of persons and things. Strong arguments can be advanced in support of the proposition that no such taxation should be imposed. All the property of railroad companies might be exempted from taxation, while the rates charged might be fixed so as to bring the owners only a reasonable return on their investment. To the objection that this would be to confer a favor on those whose goods are transported, the answer is that whatever saving in freight might be thus caused would be substantially a reduction in the cost of producing goods, and would thus benefit the whole body of consumers. But this answer is not so conclusive in the case of passengers. Much travel is to be classed as luxurious expenditure, and to diminish its cost to the persons who indulge in it, at the expense of the public, would be unjust. It is true that many foreign municipalities carry on transportation and other functions on this principle; they own their own roads or plants, and serve the public at lower rates than would be necessary if they paid taxes. But what the passengers save must be made up in some way; either the passengers must pay higher taxes, or other people must, and it seems reasonable, since the passengers must pay a part of the cost of their transportation, that they should pay the whole of it. In this country, where municipalities have not to any great extent engaged in trade, it is probable that public opinion would condemn a proposal to exempt the business of transportation from taxation by 
exempting property employed in that business. Nor are the fiscal advantages of such a policy so clear as to encourage the belief that public opinion on this point could be changed.

We may therefore assume that railroad property is to be taxed; and, if it is earning only a reasonable profit, its taxes cannot be increased without an increase in the charges for its service. Otherwise new capital could not be obtained for extensions and improvements needed in the business of the country. Now the fiscal advantages of a tax on transportation are very great, and the advantages of a surtax are even greater, because the cost to the treasury of collecting a large sum is no more than that of collecting a small one. So far as passengers are concerned, the tax is collected at the very moment of consumption, so to speak; the passenger pays as he goes, and it costs the railroad company no more to collect a high fare than a low one. The tax, too, may be progressive. The English government, as has been noted, taxes the receipts from passengers paying the higher fares; but the tax being on gross receipts, third class travel has been much favored, somewhat to the loss of the treasury. Were it not for the complication introduced through the reduction of fares to such passengers as ride for short distances daily, taxation of this kind would have few disadvantages. Two conditions are extremely favorable; fares are as a rule proportioned to distance traveled, and human beings are not classified, except to an insignificant extent. In our practice, the rates charged for luxurious travel are relatively low; they might be raised by taxation without increasing the number of classes of passengers. Were the several states to agree upon uniform laws, a large revenue 


\section{THE METHODS OF TAXATION}

might be derived from this traffic at a very small expense, and without serious injustice.

Part of the cost of carrying passengers may be paid now in some cases out of receipts from carrying freight, and vice versa; but such inequalities must in practice be disregarded. Merchandise and men are totally different commodities. Their transportation involves different principles and requires different methods. Passenger fares are on the whole to be classified as expense, like other disbursements for direct personal consumption. Freight charges are more properly treated as elements in cost of production. Passengers we scarcely need to classify at all ; of freight the number of classes is infinite, and necessarily so. Charges for carrying freight are not, and cannot be, proportioned to distance; there are a hundred other elements in the problem. Things differ in value, in bulk; in weight, in fragility, in durability, in composition, in a hundred respects; who can measure the difference in the cost of transporting a carload of dynamite and a carload of butter? It is altogether beyond human power to apportion the expense of terminal facilities, for example, among hundreds of different commodities, carried different distances, many of which may never reach a terminal at all. The course of traffic is often such that many cars after being unloaded must be sent back empty unless they are filled with goods carried at extremely low rates. It costs little more to haul loaded than empty cars; if they are hauled empty, the cost must be made up by higher charges on the freight that is carried. As a rule it costs less to transport goods by water than by land. When a railroad extends between two points between which water transportation takes place, the railroad must carry 


\section{THE ECONOMIC METHOD}

at as low rates as the vessel, or not at all. It may be able to carry the freight at these low rates if it charges high rates to places between the competing points; and if it does not obtain those high rates, it may be impossible for it to operate. The very small profit from the competitive freight must be made up for by larger profit from the non-competitive freight; but this small profit may make all the difference between prosperity and ruin. Complaints, often violent complaints, will be heard from the interior towns; superficially they seem to be discriminated against unjustly. But the fact may be that without such apparent discrimination these towns could have no railroad service at all. Their location, not the policy of the railroad, discriminates against them.

The system of charges for carrying freight has been developed with enormous labor. It has taxed the ingenuity of the ablest men, and it is perhaps surprising that they have been able to attain success at all. The mechanism is so prodigiously complicated as to make it almost impossible to calculate what will be the result of changing a single rate. No general principles can be applied, no theories are found to work. The existing body of rules is a growth, the product of innumerable forces, the result perhaps as much of chance as of design. Chaotic and irrational as it may seem, to reconstruct it would revolutionize trade. It would destroy the prosperity of many towns, it would ruin many enterprises, and it cannot be said that any other system has been devised that promises much improvement. Not only must the interests of individuals be regarded, but the rivalries of cities, the jealousies of states, the intricacies of foreign trade and foreign commercial policies. Were the commerce of the coun- 
try wholly under the control of the general government, it is perhaps conceivable that some plan for its equitable taxation might be conceived. As it is, there seems to be little reason to think that the governments of the several states could be induced to agree upon uniform laws, even if they were capable of framing them. The conclusion appears unavoidable that any attempt to tax the transportation of goods is likely to cause so much injustice as to outweigh its obvious fiscal advantages. The taxes now imposed on railroad property are, it must be admitted, taxes on transportation, but they have perhaps become a recognized element in cost of production, and with a rational system of assessment they might be made to meet the requirements of the fiscal method.

The main conclusions on this subject may be briefly restated. Assuming that more than ordinary profits are obtained by an individual or a company exercising a monopoly unprotected by legislative contract, these profits may be reduced in two ways. The thing or service furnished by the monopoly may be of such a kind that its price can be lowered by law to a reasonable figure. Or, both in such a case, and when prices cannot be fixed by statute, the property owned by the monopoly may be assessed at a rate corresponding with its value as indicated by the profit that can be made from it. In both cases, what may be regarded as an unearned value is taken from the owners of the monopoly and distributed, in the former instance, among the consumers of the product affected; in the latter, among the whole body of taxpayers. The latter course seems more equitable, as involving no discrimination in favor of a particular class of consumers; yet the power to fix charges must be held in reserve by. 
the government, even if not actually exercised. If the latter course is adopted, the monopoly may be taxed either on its net receipts, a process that implies some valuation of its investment of capital; or on this investment, in assessing which the net receipts above operating expenses should be taken into account. Owing to the imperfect manner in which the accounts of companies rendering public service have been frequently kept in the past, it is impossible to determine the amount of their investments, and justice seems on the whole more likely to be attained by adopting some principle of assessment based on the experience of many companies and communities in their struggles to assign a definite meaning to the term net receipts.

It must be added that all reasonings and conclusions concerning monopoly are so speculative as to have little practical value. This is because monopoly value is found everywhere and in every degree. It implies some differential advantages, and such advantages are not only numberless but also extremely variable and sensitive to changed conditions. Property in land is not intrinsically of the nature of monopoly, for much land produces no rent. But property in a certain piece of land may have a monopoly value, and we should, strictly speaking, treat every one of the millions of pieces of land owned by our citizens and bearing rent as a distinct monopoly. In a broad sense they are all in competition with one another, and their value is constantly fluctuating. The same is true of other monopolies. They cannot be classified; every one must be considered by itself. There is no such thing as a complete monopoly. The general government assumes to monopolize the transportation of letters; it prosecutes 
those who would compete with it. But even this monopoly is very imperfect. The express companies, the telegraph and telephone companies, limit it. A patent right is apparently as complete a monopoly as can exist; but many things may be substituted for a thing that is patented. Electricity competes with gas, and oil with both. Cisterns, springs, and artesian wells compete with water companies. Carriages drawn by horses or propelled by electricity compete with tramways, and all compete with railways, and so do sailing vessels and steamships, which compete also with each other. The monopoly supposed to be enjoyed by one railway may be far less complete than that of another. The New York Central railway has many competitors among railways, and it has besides a formidable competitor in the Erie canal, for the maintenance of which it is itself heavily taxed. This competition between enterprises carrying on the same business, together with the competition of enterprises offering substituted services, makes the situation of every monopoly different from that of every other. To institute a comparison between two great railroad systems, if the result is to have any scientific value, necessitates investigation of the most laborious character, and requires so much time that when the later stages of the inquiry have been reached the earlier ones have already become obsolete. The attempt to tax monopolies, therefore, must produce a great deal of inequality, and it involves so much expense for investigation as to make it a very questionable expedient from the point of view of the fiscal method.

We have so far confined our attention to companies owning chiefly real estate and tangible personalty of a durable nature. But many companies and individuals 
own little real estate, their wealth consisting almost entirely of personal property, either tangible or intangible, while a large class owns intangible property almost exclusively. Merchants often carry on business in rented stores, and as a rule perhaps their holdings of real property are relatively small. They are, under modern conditions, both debtors and creditors on a large scale. A mercantile concern may have a shop piled full of goods in which its ownership is very limited. They may not even have been bought, but are to be sold on commission; and even if they have been bought they may not have been paid for, and will not be, until they are sold. Even then payment is not made in money but in promises, and the banks are called on to cash these promises. But they cash them for the most part by the use of other promises, either their own or those of the government; either by credits or by currency. Hence it is a matter of no little diffculty for a mercantile company to know just how much it is worth. To determine this accurately, it would have to know just how much numerous other concerns are worth, all of whom would labor under similar difficulties.

Under these circumstances it is evident that the assessor can form little idea of the amount of property owned by a trader. $\mathrm{He}$ is obliged to be governed largely by indications that are liable to be deceptive, and that are often intentionally made so. He must fall back on the method of disclosure, of the evils of which enough has been said. Many merchants would not dare to make a true statement of their condition to the tax-gatherer; it would sometimes put it in his power to ruin them. Many do not choose to make such statements, because they know that their enemies in trade will not make them, and they are 
not inclined to pay their enemies' taxes by increasing their own. In considering the general property tax we have already remarked the evanescent nature of merchandise. Much of it is produced and consumed before it can be assessed, and it is in constant motion, accelerated often by the approach of the period of assessment. Such property can be taxed only by guessing at its average amount, year by year, with such aid as the owner chooses to afford. It is obvious that all manner of injustice may be perpetrated when such taxation is imposed, and as most of the monopolies in trade are maintained by the policy of the government, to tax them seems unreasonable. Such other monopolies as exist may be presumed to owe their success to the ability of their managers, and to burden them is not likely to benefit the community. In view of these facts, and of the expense and annoyance involved in the process, the taxation of personal property employed in trade seems not compatible with the fiscal method, and in some comparatively enlightened communities it is not attempted. Were it carried out, the burden would not remain on the owners of such property, but would be diffused throughout the community; and it seems impracticable to confine the burden to unearned values, their amount being quite indeterminate.

The case of persons and companies owning and dealing in intangible property as a business has been extremely complicated by legislation. In a primitive state, barter is facilitated by the use of the precious metals. Promises to pay would not have been acceptable, because the judicial machinery for enforcing such promises had not been developed. But it was discovered long ago that a very great saving could be made, if promises to pay could be sub- 
stituted for actual payment in coin, and the governments of the world, after innumerable more or less successful attempts to defraud their subjects, have now established tolerably stable and honest systems of credit currency. Modern barter, however, is conducted on such a colossal scale as to require far greater facilities than these systems provide, and the development of our credit system has brought into existence a great number of institutions whose office it is to trade in claims or evidences of indebtedness of every description. Such institutions may be called generically banks, and that term may be conveniently applied to individuals as well as corporations dealing in what is called money, but which would perhaps better be called credit.

It is true that all the countless millions of promises to pay outstanding at any moment are ultimately solvable in the precious metals; but, paradoxically enough, men do not desire such payment unless they fear that they cannot get it. The possibility of this demand, however, makes it necessary for the banks to keep such a quantity of coin on hand as experience has shown to be necessary to meet it, and to that extent bankers are owners of tangible property. . But this is an incident of their business which needs not here be considered; the property of a bank consists essentially in its ownership of credits or claims for the payment of money, and its profits are made by acquiring such claims and transferring and issuing them. Owing to a misunderstanding of this fact, which has even at the present day not been dispelled, legislatures have imposed many conditions that have operated injuriously. To the unreflecting mind, wealth means money, and the ordinary legislator is prone to regard an issue of promises to pay 
as a creation of capital. It seems obvious enough now, although it required a long and bitter experience on the part of the colonies, to say nothing of that of the general government, to disclose it, that a promise to pay has little value unless the promisor has the means of performance. Yet even after the states were prohibited by the constitution from issuing bills of credit, they persisted up to the time of the Civil War in granting charters practically authorizing this practice, and these charters were frequently issued to very irresponsible parties.

There seems no particular reason why anybody should not sell his promise to pay coin if he can find a customer for it, and there is little doubt that if the government had not interfered, the bankers of the country would have developed a sound and scientific currency system. But this was prevented by the action of government in monopolizing this right, or in granting it as a privilege to those whom it favored. And owing to the misunderstanding above referred to, the supervision of the issue of notes or bills of credit, rendered necessary by the policy of the government, was extended to banks of discount, or the banking business proper. If the business of issuing notes payable to bearer as a substitute for coin was to be monopolized, it may have been proper enough for the government to provide that those exercising the monopoly should furnish security for the payment of their notes. In the numberless transactions of daily life, there is no time to investigate the solvency of those whose paper is employed as currency, and the conditions that prevailed before the national system was established were such as to make that system appear like a transition from barbarism to civilization. But there was no reason for extending the 
monopoly to the banking business proper. The solvency of a bank concerns only its depositors and stockholders, and had it not been for governmental interference, exercised by legislators frequently dishonest and almost always ignorant, the bankers of the country would have established rules that would have protected the community against unscrupulous speculators. The ablest and most successful men in a community usually direct its banks, and by their achievements in maintaining our vast structure of credit in times of panic they have repeatedly proved their capacity. The severity of these crises is aggravated by the conditions created by the banking laws; but by combinations unrecognized by law the bankers have overcome many of these obstacles.

These observations are, however, rather beside the mark. We have to deal with the taxation of banks, and must assume that they will continue to be conducted under the existing laws. The general government grants the privilege of issuing notes to corporations that will deposit its bonds as security, and imposes a tax on the exercise of the privilege. Such a tax cannot be peculiarly burdensome to these corporations. Unless the men who organized them were satisfied that the investment would be profitable they would not engage in it. They make allowance for taxation, as they make allowance for rent and for clerk hire. The tax therefore falls on the use of that peculiar contrivance, the substitution of paper for coin. Whatever saving is thus attained would enure to the community, were the use of the contrivance free. Its restriction gives it a monopoly value, which it is certainly proper for the government to appropriate. Were there an unlimited supply of government bonds, the restriction 
would be less severe, but it would still exist, and the value created by it is a value to which the whole community is entitled. Owing to the exact form in which the accounts of national banks are necessarily kept, a tax on their notes is collected with little expense and with no opportunity for evasion. Such a tax might be made to conform in every respect to the requirements of the fiscal method.

The taxation of the banks of discount, which are to a great extent corporations organized under state laws, presents more difficult problems. Their property, as represented by their authorized capital stock and surplus, is usually subject to assessment at the place where their business is carried on, and there is thus no uniformity in the rate of taxation. Where it is made uniform, it may bear little relation to the earning power of the bank, and it is not always practicable to ascertain the market value of the stock. Dealings in such stock are comparatively infrequent, and the quotations of its price are not conclusive evidence of its value. But whatever method of taxation is adopted, it cannot be maintained that it will constitute a peculiar burden on those who invest their money in the business. Trade cannot be carried on without borrowing, and the rate of interest is controlled by the relation between the supply of capital and the demand for it. Whatever makes it more difficult to furnish the supply tends to raise the rate of interest. This in turn tends to check demand and thus to restrict trade. A tax on banking is a tax on borrowing, and as trade is now carried on by means of credit, such a tax must be diffused throughout the industrial world. Were there no such tax, doubtless many banks would be organized in 
places where they do not now exist, to the great advantage of the trade of those places. It would also be to the advantage of the whole country, for the lack of banking facilities compels the use of great quantities of currency, to supply which sometimes causes a good deal of embarrassment. Were all taxes taken off the business of banking, all other business would be benefited; and after a short time, competition would bring down the profits of bankers to a normal level.

Apart from legislative restraints, banking is not the subject of monopoly, and even chartered banks must feel the competition of other money lenders. When there is but one bank in a town, it may be able to obtain somewhat higher rates for its loans than it would if there were several, but this advantage is not very great. If very high rates were obtained, competitors would soon learn it, and endeavor to share the abnormal gain, and borrowers would go away to get their paper discounted. It is true that an old bank with much capital enjoys a kind of monopoly. Its prestige, or good will, may be an asset of very great value. But it seems inequitable to lay a special tax on a monopoly of this kind, which is the result of ability of a high order applied to the promotion of trade. The successful management, which gives the prestige, means that thousands, perhaps millions, of loans have been prudently made, and that as many depositors have been honorably repaid. The enhanced value which a property so managed acquires cannot be said to be unearned; even if the men who created the value have passed away, it seems for the public interest that others should be encouraged to follow their policy. So far as the good will of a bank appears in the valuation of its 
stock, it is taxed when the stock is taxed, and it would be difficult to devise any other way of reaching an asset of such a fleeting and perishable nature.

Were a scientific system of taxing banks established, it might recommend itself as a fiscal measure. It would not require self assessment, and while it would be a burden on trade, it would be very generally diffused, and might perhaps violate no principle of justice. No such system now exists, and the methods and rates of assessment vary greatly in different states and localities. As is shown in the appendix, the most outrageous inequality has prevailed in assessing the banks of Chicago, and similar inequality is everywhere to be found. Nor is it easy to avoid. The assets of a bank are constantly changing, and it is difficult to assign them a precise value. Nor does this value measure the profits of the bank. The simplest plan would be to tax the dividends that it made, and attempt no other taxation of stockholders. There is, unfortunately, little probability that such a tax would commend itself to our legislatures. In spite of the obvious usefulness of banks, they are a favorite object of denunciation by demagogues, and much ignorance and prejudice have been displayed in the legislative regulation of their functions.

Savings banks are often forbidden to engage in banking, and where this restriction prevails, they are simply investing agencies. As they are not carried on for the profit of stockholders, any taxes levied on them fall directly on their depositors. To some extent the banks may shift the tax upon borrowers, by demanding higher rates of interest; and they may be enabled to buy securities at lower prices. In this way the tax would be generally diffused; but, owing to the character of the depositors in these banks, they would 
probably pay a large part of it. This is because their opportunities for investment are limited; many of them would not know what to do with their money if they could not put it in the savings bank, and they might bear a heavy tax rather than withdraw it. It seems oppressive to exact such a tax from persons in this situation, and it is the policy of some of our states to encourage thrift among the poor by exempting their savings. Complaint is heard that rich people take advantage of this exemption. But were it abolished they would find other ways of investing their money so as to escape double taxation. As with taxes on other corporations, the cost of collection is small; and the burden is equally distributed. It is not on fiscal grounds that the tax is objectionable.

Life insurance companies resemble savings banks in many respects. They are properly investing companies, organized for the benefit of those who wish to provide for their families; although when they have a capital stock, it sometimes becomes very valuable, and the mutual ownership plan seems more consistent with the purpose of such institutions. As the holders of their policies are not of the poorer class, these companies are usually taxed, and sometimes at very high rates. In the State of New York the tax amounts to one-fourth of the payments to beneficiaries. Such a tax is evidently paid by the policy holders, and it tends to be diffused, as in the case of the tax on savings banks. It is easily collected, but of questionable wisdom. Fire insurance companies are more commonly organized for the profit of their stockholders; but, as already explained, the burden of the tax upon them falls on the policy holders, and thus raises the cost of fire insurance. As the practice of insuring against loss by fire 
is universal, the policy of making it more expensive is open to question. Some attempt has been made to limit the amount of business done by life insurance companies, on the ground that the great funds controlled by some of them constitute a kind of monopoly; and they are forbidden to invest in certain securities. How far regulations of this nature are for the benefit of the community is a matter on which opinions differ.

Allusion has been made to two taxes recently imposed in the State of New York, one a tax on transfers of title to shares of stock in corporations, the other a tax on mortgages. The former tax violates every principle of justice. It is levied on the face value of stock, and is therefore grossly unequal. Two stocks may have the same face value, but one of them may sell at 20 , the other at 200 . To transfer one of them will involve the payment of a tax ten times as heavy as when the other is transferred. Whenever the stock is sold, the tax is repeated, and it may be levied a hundred times in a year on the same property. The tax requires self-assessment, ' and it is a misdemeanor to evade it. Nevertheless it can often be, and it often is, evaded. The legislature has endeavored to prevent evasion by requiring dealers to open their accounts for inspection by the tax-gatherers, but the courts have declared this proceeding unconstitutional. Such a tax puts a premium on dishonesty, and is to be condemned on every ground. It no doubt brings in a large revenue, and it is defended as a tax on gambling. But to tax all transfers of title because some transfers are made by speculators is a travesty of justice. It is a reversion to barbarism.

The tax on mortgages stands on a somewhat different footing. For a long time mortgages were nominally taxed 


\section{THE ECONOMIC METHOD}

at their face value, but the exemptions were numberless and evasion was universal. Finally, as a compromise, the tax was reduced to a low figure, and made payable when the mortgage is recorded. The tax is equal in so far as it is proportioned to the amount of the mortgage, but unequal in that it is not proportioned to the time for which the mortgage runs. It is unequal, too, because it falls on those who have occasion to borrow on the security of their land, and not on those having no such need. It is obviously a tax on land, because it renders trading in land more expensive; and on this ground the mortgages taken by companies formed for the acquisition of homes by coöperation are exempted. But the rate is so moderate as to have no perceptible effect on land values, and the expense of collection ought to be extremely small. If it is thought desirable to tax transfers of title to land at all, the present tax is perhaps as satisfactory as any that could be devised, and as such transfers are relatively infrequent the occasional inequality may be disregarded. Under our system of title by public record, little inequality through evasion of the tax can arise.

This review indicates the limitations of the fiscal method. On the one hand justice forbids the resort to selfassessment, and on this account both the general property tax and the income tax must be rejected. License taxes are objectionable because they are unequal. They fall heaviest on men of small capital, and few of them produce revenue enough to compensate for the vexation which they cause. The great taxes on the production of spirits, beer, and tobacco, seem to have become part of the natural order of things, although many persons now living remember when they did not exist. So long as public opinion regards 
them as sumptuary taxes, they will probably be retained. They are certainly very productive of revenue, and while they offend against some of the principles of the fiscal method, it seems hopeless at present to try to dispense with them. Some of the progressive taxes can be collected with moderate expense; if the progressive principle is admitted to be just, not much objection can be raised on fiscal grounds to high taxes on large legacies, and a graduated tax on house rents has very exceptional recommendations. With these exceptions, the fiscal method rejects all attempts to ascertain the wealth, or the ability to bear taxation, of the individual. What are known as stamp taxes are usually taxes on transfers of title, and are almost necessarily unequal. They may have fiscal advantages, but such advantages are not sufficient to overcome this objection. Taxes on corporations as such are taxes on the machinery of trade; they diminish the economic gain which the corporation is created to secure, and seem to be therefore irrational as well as burdensome. Taxes on monopolies are in most cases repugnant to the governmental policy which creates and favors monopolies, and are in other cases of uncertain fiscal merit. Public opinion certainly does not demand that the monopoly value of lands held by individual owners should be confiscated by the legislature through special taxation. Whether it is fiscally desirable, if practicable, to expropriate the owners of this value when represented in public service corporations, and in what manner, are questions concerning which public opinion is still unformed. In general, companies engaged in trade, in banking, in insurance, etc., are subject to so much competition as to make it vain to attempt to tax them as monopolies; and, while there are apparently fiscal advantages in taxing 


\section{THE ECONOMIC METHOD}

them, the burdens of the community may be thereby eventually increased to an extent that will neutralize the fiscal gain.

It thus appears that a number of taxes may comply with the chief requirement of the fiscal method, inexpensiveness of collection; but there is danger of a fallacy of composition. Taken by itself every one of these taxes may be satisfactory, but taken together they may require a multiplication of taxing officers, and a needless amount of bookkeeping by taxpayers. If it should appear practicable to obtain the required revenue by means of a few of these taxes, or even by a single tax, the gross expense of collection might be materially reduced. In order to ascertain this, we need to consider with care what elements make, up the cost of collection; and as this cost is of peculiar importance in the case of that large class of taxes known as customs duties, it will be convenient to examine them at the same time. 


\section{CHAPTER $\mathrm{X}$}

\section{THE COST OF COLLECTING TAXES}

THE amount of a tax is properly the amount finally deducted from the wealth of the community, including not only the money actually paid over to the tax-gatherer, but also all the disbursements of the taxpayer, whether they be in the shape of the payment of money, or loss of time, or trouble or vexation of any kind. This part of the cost of collecting taxes never appears in the reports or statistical tables of the public treasury, nor has it received very much attention from economists. Adam Smith, with his usual comprehensiveness of treatment, showed its importance; and many other writers have pointed out that certain taxes may take out of the pockets of the people much more than they bring in to the treasury. How this comes to pass has been partly explained under the head of the diffusion of taxes, the general principle being that a tax falling on what are called raw materials tends to increase by more than its amount the cost of finished goods. This element of cost is so striking as perhaps to have caused the others to be disregarded; and their nature is such as to make it very difficult to estimate their amount accurately. This difficulty, however, should not be allowed to preclude all attempts at such an estimate.

To avoid circumlocution, we shall speak of the disbursements of the government in obtaining revenue as the cost of collecting, and the disbursements and expenses of the taxpayers as the cost of paying taxes; the sum of these 


\section{THE COST OF COLLECTING TAXES 331}

costs expressing the total cost of the taxing process. The cost of collection may be first examined. As has been said, the government reports throw no light on the cost of paying taxes, and unfortunately, they are of little value in ascertaining the cost of collecting them. They do not state the cost that they profess to state, but only a portion of it. As a part of its machinery of collection, the general government has spent enormous sums in constructing public buildings, post offices, custom houses, etc., all of which are exempt from taxation. Under a proper system of bookkeeping, these disbursements should appear in a capital account, and the cost of maintenance, including a proper allowance for local taxes, should appear as an operating expense. No such accounts are exhibited when the government reports the cost of collecting its revenue. To judge from these reports, the costly structures where customs are collected have no existence, and of course cost nothing to maintain.

When the government rents a building for a post office, the rent appears as a disbursement, and out of the rent the owner pays the local taxes. When it builds its own office, always at a great, and usually at an unnecessary expense, the charge for rent disappears. Apparently the government is carrying on its business more economically than before; really the expenses have increased and sometimes very greatly increased. The city where the building is located is poorer through the loss of the tax formerly paid, ${ }^{1}$ and the whole community is poorer through the sinking of a part of its capital on which no interest is charged, and through an increase in the cost of maintaining the public

${ }_{1}$ Although the buildings occupied by the British government are not rated, the government assumes some of the expense of the district where the buildings are situated, by contributing to the rates. 
service. The post office always reports a large deficiency. If its accounts were kept as those of every sound corporation should be kept, this deficiency would be very greatly increased.

The reports of the cost of collecting customs duties are equally incorrect. They include the salaries and wages of employees and little else. They do not include expenditures for consulships, for revenue cutters, for fuel, lights, water, furniture, janitors, etc., for buildings owned by the government, ${ }^{1}$ nor any interest charge, nor the cost of new buildings. They include no disbursements at Washington, although the expenses of the treasury there are admitted to be some four millions, and would be twice that, if account were kept of capital there expended. According to the statement of the government, its cost of collection is from three to five per cent of the duties received; the expense of collection not increasing in proportion to the volume of imports. It is perhaps not unreasonable to suppose that the true cost is double what is stated. To determine it accurately would require an examination of a large part of the accounts of the government for many years past; but the size of the annual appropriations for public buildings is notorious, and it is easy to calculate that the interest charge for such investments would reach an enormous figure. Similar criticisms apply to the statement of the cost of collecting the internal revenue. This statement includes almost nothing except disbursements for salaries and wages. The expenses of this department are much less than in that of the customs; but they are much larger than they are admitted to be.

1 The appropriations for wages and salaries for this account run up to nearly $\$ 2,000,000$. 
The cost of paying taxes is illustrated in the process of meeting the requirements of the government when goods are imported from foreign lands. The importer is put to some expense before the transportation of his goods begins, as the preparation of invoices and the determination of market values is not a simple matter. When the goods arrive, only experts can comply with the necessary formalities, and a large number of customs brokers are constantly engaged in assisting importers in clearing their goods, a service which is by no means gratuitous. ${ }^{1}$ It might be supposed that when a tariff has been in force for a dozen years it must be thoroughly understood. As a matter of fact the disputes over duties seem to be endless, and they occupy the time not only of the customs officers, but of the lawyers and experts paid by the importers. During the fiscal year of 1907 the Board of Appraisers settled protests in 87,631 cases. It would probably be a gross underestimate to suppose the cost of each case to average only ten dollars; but even then the total cost would be nearly a million, and at a hundred dollars a case it would be nearly as much as what the government declares to be the cost of the customs service. In every case, samples must be taken, packages opened, fees paid, errors atoned for. Duties paid by mistake on a larger quantity of goods than is actually imported cannot be recovered. There is no appeal to the collector, for such appeals lie only in the case of imported goods, and the goods in question were not

1 Every railway car entering this country requires a certain paper manifest, the cost of which is incalculably small. But the collectors of customs sell these forms to the railways at ten cents a piece. In some districts the collectors are supposed to pocket as much as $\$ 30,000$ a year in this way. This is not a cost of collecting taxes; it is a cost of paying them. 
imported. Nor is anything gained by appealing to the Department, for when the money has been covered into the treasury it will not be refunded. And a very little delay in protesting or applying for re-appraisement is fatal to the proceeding.

In view of the hundreds and even thousands of classes of goods recognized by the tariff and the commentaries upon it, it might seem that no doubt could exist as to the proper classification of any article of merchandise. There could be no greater mistake. The disputes over classification seem rather to increase than diminish, and there is no prospect of their terminating. This is partly because new things are constantly invented, and new combinations of old things made. In order to meet the demands of the protective system, all sorts of materials must be taxed not only in their most simple forms, but also in their composite forms. There must be a tax on jute, on cotton, on wool, on silk, on mohair, etc. But a fabric may be woven of all these substances, and of varying proportions of them, and how shall it be taxed? In fact the number of new fabrics is constantly increasing, and novelties appear in every department of manufacture.

Sugar may seem a simple substance; but there are many different kinds of sirups and sugars, having different qualities and values, and they are subjected to many different processes. To determine how imported sugar should be taxed, not long since caused such violent disputes in Congress as nearly wrecked a tariff bill, and came near wrecking an administration. To lay a tax on sugar is to disturb a hundred industries, situated all over the world. It may seem surprising that we eat jam made in Dundee, where neither fruit nor sugar are indigenous. We do so because 


\section{THE COST OF COLLECTING TAXES}

the governments of Europe adopted a policy of taxing their subjects which had the result of supplying sugar to the Scottish manufacturers at less than cost. We may perhaps cease to eat this jam, for now the government of England has adopted the policy of taxing its subjects on the sugar that they import, in order to benefit the West Indian planters. ${ }^{1}$ Nothing is more misleading than to apply a class name to a number of things that have important differences. Beet sugar differs from cane sugar, and the sugar of Java differs much from that of Cuba. The sugar at the top of a hogshead differs in quality from that at the bottom, and under most tariffs would be dutiable at a different rate. The government is now suing the American Sugar Refining Company on the ground that for many years it has not paid the proper duties on its imports. When every bag and hogshead of sugar has to be weighed, and should be scientifically sampled, it would not be surprising if in testing so many millions of packages there should be a vast number of errors:

The difficulty of determining the cost of paying taxes on sugar is increased by the policy of protection. A number of years ago the planters of Hawaii succeeded in having their product exempted from duty, and this product now amounts to over 700 million pounds. The planters of Porto Rico more recently obtained this favor, and their product has risen from an insignificant quantity to over 400 million pounds. The planters of the Philippines have been less favored, paying three-fourths of the full duty, while those of Cuba pay four-fifths of it. The planters of Louisiana and the domestic producers of beet sugar of

1 The customs officers even claim that certain leathers shall pay a duty on the sugar that is used in treating them. 
course pay no duty. Out of a total consumption of about 6,400 million pounds, some 1,130 million pounds pay the full duty, and about 2,850 million pounds pay a part of it. The duties amount to some $\$ 52,000,000$, and the bounties in the shape of exemption and reduction are probably not much less. The duties themselves vary from less than a cent a pound on inferior sugars to nearly two cents on the highest grades. The greater part of the imported sugars are supposed to pay a duty of about one cent and two-thirds a pound. Probably the tropical countries could produce all the sugar consumed here for two cents a pound. The cost of refining is a notoriously litigated subject. It may be one-eighth, or one-fourth, or possibly one-half a cent a pound. Consumers, however, pay some six cents a pound for their sugar; which, on a moderate estimate, is perhaps nearly twice what they would pay were all duties abolished, and is certainly one-half more. They pay, to the planters and the government together perhaps $\$ 100,000,000$; but what part of this is due to protection and what part to taxation proper it is impossible to determine. In this discussion we have assumed the policy of protection to be established; but granting all that is claimed for it, it can hardly be doubted that the cost of paying taxes on sugar is more than the amount of the taxes themselves. The cost of collecting these taxes therefore must be far less than the cost of paying them.

Most people would perhaps regard wheat as a simple substance. In fact there are many species of wheat, and many grades of the same species. There are spring wheats and winter wheats, and the latter are grown in many widely separated regions, under different conditions, and the same grade may vary much in quality according as it is shipped 


\section{THE COST OF COLLECTING TAXES}

from Galveston or from New York. If there are such differences in the case of grain, they must obviously be much greater in the case of manufactured goods. It is impossible to lay specific duties upon them without the grossest inequality. To do so would often be to prohibit the importation of the cheaper grades of a commodity. Hence it is necessary to resort to ad valorem duties, under which all the evils of self-assessment arise. In order to check undervaluation the government employs spies abroad, and rewards inspectors with a part of the moneys which their zeal, so stimulated, may justly or unjustly obtain as penalties. The whole system reeks with inequality and fraud. It has all the evils of the taxes on intangible personalty, and produces the same results on the morals of merchants. The methods of undervaluation, to say nothing of actual smuggling, are infinite in number, and it is notorious that reputable importers in certain lines of trade have been driven out of business by unscrupulous competitors. ${ }^{1}$

Moreover, in spite of the constitutional provision for uniform duties, the cost of paying taxes varies much at different ports of entry. At Boston, the importer must claim his goods and pay the duties within two days of the vessel's discharge, failing which the goods are sent to a

1 Cobden, speaking in Parliament in 1853, said he remembered being in the Chamber of Commerce in Manchester when a deputation from the dealers in tobacco and snuff came in to complain of adulteration caused by high taxes. "The gentlemen who were the largest dealers and manufacturers said to us most frankly, after exposing all the different articles with which tobacco was colored and adulterated, such as the beard from malt, peat moss, and things of that kind, "There is not a man in this neighborhood who carries on the tobacco and snuff trade without illegal adulteration except Mr. Read,' a gentleman who was then present, but who has since left the trade and who although not less than forty years of age, went to Cambridge and is now in holy orders." 
bonded warehouse, at a cost of fifty cents a package for the first month, and twenty-five cents thereafter. The charge is the same for a keg of fish worth five dollars, or an automobile worth five thousand. Under this general order system at Boston, goods that would be stored elsewhere for five cents a month pay ten times that amount to the government, or to a favored contractor, while in New York, where the charge is now by weight, the burden is much lighter. The truth is that it is impossible to tax merchandise with any approach to justice, either by local assessment or by customs duties. Specific duties necessarily discriminate against the cheaper grades of any commodity; ad valorem duties necessarily encourage dishonesty. The customs were established in barbarous times, and are a relic of barbarism. Unfortunately, they are intimately connected with the excise. Spirits and tobacco cannot be taxed for inland revenue unless taxed when imported; and if a single import is taxed, all the other imports, and even travelers' baggage, must be inspected to prevent smuggling. The English duties are the most scientific of any, but owing to the high rates imposed on spirits and tobacco, these articles are often concealed among other goods, and the cost of collecting a few duties may thus be not much less than if there were many; although the cost of paying duties is much diminished.

On such a subject as this, conclusions must be largely conjectural; but the evidence seems sufficient to prove that the cost of collecting duties may be as much as ten per cent of the amount collected. The cost of paying them, exclusive of the enhanced price to consumers, may be as much more. We can form some idea of the extent to which price may be enhanced from the figures concerning sugar; 
we know that it can be bought abroad, raw, for a little more than two cents a pound, and that our people pay about six cents for it when refined. We know, too, that this tax is relatively much more burdensome to the poor than to the rich, and it must require great faith in the doctrine of protection to make such a tax seem desirable. But such faith unquestionably prevails, and on this account it is not worth while to quote the elaborate computations of such writers as David A. Wells, Thomas G. Shearman, and Edward Atkinson. As estimated by them, the enhanced prices caused by our customs duties amount to far more than the duties themselves; but the subject is too controversial to be here considered. Nevertheless the most zealous believer in protective duties cannot deny that they enhance prices; for that is their avowed purpose. And, whether imposed for protection or for revenue, when they fall on materials that are subjected to many processes after importation, or that are instruments of production, they must often greatly increase the price paid by the final consumer. Some sugar is used in certain processes of manufacture, and as an instrument of production; but the great bulk of it, when refined, passes directly into consumption. We know how greatly the price of sugar is nevertheless enhanced, and we may properly infer that the prices of goods manufactured from imported materials, especially when imported machinery is used, must be enhanced in a greater degree.

This examination proves that the cost of paying and collecting taxes, although commonly neglected, is a factor of transcendent importance in the problem of taxation. The aggregate injustice caused by making the process needlessly expensive is enormous. Many taxes must be con- 
demned because they offend against justice in other ways; but more are to be rejected because they offend in this way. We are thus brought face to face with the question whether there is any tax, or any system of taxes, that offends in neither way. Such taxation must not depend on self-assessment, and it must fall only on property that is visible and tangible. It must not be laid on movable or evanescent property, but only on what is durable and open to the inspection of the public as well as of the assessor. The value of the property too, should be notorious, or easily ascertainable, not only that few assessors may be paid, but also that their judgments may be open to correction. While it is desirable that the property taxed should be in universal use, in order that the tax may seem proportionate, it will also be advantageous if it has some monopoly value, in order not to offend against the progressive principle. And, finally, the payment of the tax should be so simple a matter as not to compel the taxpayer to employ expert assistance, or to waste time in complying with vexatious formalities.

A tax on real property, proportioned to the rental value of every separate parcel, seems to comply very perfectly with all these requirements. Land is permanent and immovable. It cannot be concealed, and its value can be ascertained by inspection. The owner needs not be compelled to disclose it, for others can estimate it nearly as well as he. Every one owns or hires some land. He uses it for the extraction of materials, for the production of food, for making and storing goods, or for his own shelter. If the ore or the grain obtained from a piece of ground is valuable, that value is reflected in the price of the land. If the goods kept on the land are of great value, the value of the 
land is enhanced. If its possession enables the occupant to carry on a very profitable business, this profit will compel him to pay a high rent. The poor man must content himself with cheap shelter, erected on cheap land. The rich man will indulge in costly shelter, and his rent will correspond with his circumstances. The expense of collecting the tax on real property is very small; it is caused chiefly by the labor of assessment. The expense of paying the tax, provided the assessment has been properly made, is insignificant; it may amount to no more than the cost of a few postage stamps, expended once a year.

Many tracts of land produce no rent, and if any taxes are laid on such land, they must be merely nominal. Most parcels of land have a value due either to the labor of the owner and of those from whom he derives title, or to the growth of population, the existence of valuable minerals or properties of soil, the construction of roads, etc. This latter value is distinguished as unearned, or public value. In theory, it would be most just to confine taxation to this value. Practically, as has been explained above, this would not be true, because it would involve a revolutionary change in the constitution of the industrial world, and because it would be a task of enormous difficulty to distinguish earned from unearned value. No doubt this attempt is made under some of our systems of assessment. The assessors assign a certain value to the land, and a certain value to the improvements thereon. ${ }^{1}$ It often happens that men buy land on which buildings are standing, intending to destroy and replace them. In such cases,

1 Of course, it is easy enough to do this. As has been said in England, a professional valuator will put a value on anything, if he is paid for it. The scientific value of these valuations is questionable. 
perhaps, a definite value can be assigned to the land; but this is because the value of the existing improvements has become relatively so small as to be negligible. The same thing takes place when agricultural land becomes available for building sites. The labor expended in fertilizing the soil is disregarded, being swallowed up in the new value. Nevertheless, we cannot ignore the fact that this labor has been expended, and has become embodied in the land; the new value would be greater did it not involve the destruction of the old. On the whole, it seems that justice will be better attained by continuing the existing system of taxing every parcel of real estate as a unit, basing the assessment on its rental value.

This conclusion is strengthened when we reflect that such a tax falls progressively on the unearned, or public value. As a rule, costly buildings are erected only on costly land. In some parts of New York City it would perhaps be impracticable to construct a building that should have the value of its site. Hence a tax on the land and building together falls in great part on the public value of the land; it is levied more on the monopoly value than on the earned value. It is admitted that a tax on rent proper cannot be shifted; it must be paid by the landlord. To a certain extent, therefore, the existing tax on real estate falls on landlords as a class, and the obstacles in the way of going further in this direction are very great. It would not be easy to overcome them in the cities. In the country it might be impossible.

In so far as this tax falls on improvements, as we have seen, it tends to be diffused; but it is diffused throughout the community. If buildings are heavily taxed, building will be expensive; but it will be proportioned to the de- 


\section{THE COST OF COLLECTING TAXES 343}

mand. Men must have shops and houses, and they must therefore pay such a price for them as will cause them to be built. And, as has been observed, where buildings cost more, any diminution in the demand for them tends to diminish the value of land. In some degree, therefore, a tax on buildings falls on rent proper. To attempt to throw the whole burden on rent would certainly increase very much the cost of collecting the tax. Rent represents a differential advantage, and to assess such advantages with accuracy would require a very high order of ability and integrity in the officers charged with that duty. Their task is already very difficult, and their assessments are to a considerable extent conjectural. The inequalities now prevailing cause many protests; were they increased, the injustice might become serious.

Not many persons, perhaps, are aware how small is the cost of collecting this tax. The assessor of the City of Glasgow reports the cost of valuing real property in that city at only $£ 2,000$ a year. All premises are surveyed annually, from door to door, the names of owners and occupants taken, and the rent paid, when the premises are let. At the same time schedules are issued to all owners, requiring them to give the names of their tenants and the rents paid. These schedules are compared with and corrected by the results of the survey. The rental value of premises occupied by the owner is usually ascertained by comparison with similar rented premises. After the valuation roll has been made up, every owner or occupier is served with a notice of his assessment, the number being about 180,000. Appeal lies to the surveyor, and from him to the town council, and finally to two judges of the Court of Session. In the year for which this report was made, there 
were no appeals to this Court; those to the town council are usually from 80 to 100 . This valuation roll is always accepted without question by the Board of Inland Revenue in levying the income tax. The permanent staff of the assessors' office is only 34 , but at times the number rises to 100. The small cost of valuation is partly explained by the fact that this staff performs many other duties, the cost of which is not a part of the expense of assessment.

The cost of valuation in London and the Metropolitan district is, partly because rates are levied by both County and Parochial authorities, materially larger, being estimated at from $£ 25,000$ to $£ 40,000$. As the amount of taxes collected in the year when this estimate was made was about $£ 12,000,000$, the cost was moderate enough. It may cause surprise to learn that this cost is quite moderate in the City of New York. The department of taxes and assessments in that city is carried on for a little over $\$ 400,000$. The total valuation of the land in 1907 was $\$ 6,240,000,000$ and the number of parcels assessed was over 483,000 , making the cost per parcel little more than 80 cents. This department assesses personal property also, a process that involves much labor. Were this charge deducted, it would considerably reduce the cost of assessing the land. In the City of Philadelphia the number of parcels assessed is 350,000 , the cost of the Tax Department being about $\$ 187,000$. In Baltimore this cost is reported to be $\$ 33,800$; the number of parcels being 120,000 .

It is true that these figures require to be raised. They apparently include no charge for office rent and several other expenses, and it is probable that they do not include a proper charge for receiving and apportioning the pro- 
ceeds of taxation, or for the expenses of litigation. But even if the figures were doubled, the result would compare very favorably with the cost of collecting customs duties. That cost may well be ten per cent, while the cost of collecting nearly one hundred million dollars from the owners of real estate in the City of New York, especially if we deduct the expense of the tax on personalty, can hardly be so much as one per cent. Nor is the cost of paying this tax at all burdensome. There are comparatively few disputes concerning assessments, and while the expense of litigation is considerable, it is probably much less than in the case of customs duties.

It cannot be denied that the part of the tax on real estate that falls on improvements, such as factories, shops, stations, etc., is a tax on the instruments of production, and thus increases the cost of products to the consumer. This fact constitutes a strong argument for exempting improvements, and confining the tax to rent. The advantage, however, is probably more theoretical than practical. The cost of distinguishing the different elements of value, and that of settling the disputes that the attempt to distinguish them would occasion, would perhaps more than equal the expected gain. In spite of the reasonings of economists, the opinions of experts, the reports of numerous commissions, and the complaints of thousands of outraged citizens, it seems to be almost impossible to induce legislators to abolish taxes on intangible personalty. The popular conviction is very strong that it is unjust to exempt the property of a rich man from taxation, no matter what the nature of his property may be. It would probably be equally strong as to the injustice of exempting the shop of a rich merchant, or the factory of a large 
firm or corporation. The community would no doubt gain through such exemption, as it gains through every decrease in cost of production; but at least it may be said that the loss from taxation of this kind is distributed equitably. What the actual loss may be seems altogether indeterminable. That it is less than might be supposed, may perhaps be inferred from the experience of numerous concerns whose property has been exempted from taxation for a term of years, under the statutes of some of our states. The prosperity of these concerns has perhaps seldom been so great as to prove that this exemption has been very advantageous, and if it has not been of great advantage to them, it cannot have been to the community. And, it may be repeated, if a factory is to be taxed, those who propose to build it cannot pay so much for the rent of a site as they otherwise could, so that a part of the tax may be thrown back on the landlords.

In his classical report on the reform of taxation in the State of New York, rendered in 1871, Mr. Wells proposed to tax personal property employed in trade. $\mathrm{He}$ was well aware of the strength of the prejudice against exempting any form of property from taxation, and his suggestion was in the nature of a compromise. It was based on the principle that the rental value of buildings is a sign of the value of the personal property of the occupants, and was in the form of an alternative. Either the land might be taxed separately at one-half its market value, and the building at its full value as shown by its rent; or the land and building might be taxed jointly at their market value, while the occupant should also be taxed, as the putative owner of personal property to the amount of three times the rental value of the premises. 
At the time of this report, real estate was commonly assessed at not more than half its value, and it was deemed expedient to recognize the practice. The assumption that the occupant of a building owns personalty worth three times the rent that he pays, is arbitrary. It may be true on the average of men engaged in trade, so far as their factories and shops are concerned; but it could be true of the occupants of dwellings only if their incomes were reckoned as property. No doubt, with such a system of taxation, more revenue would have been derived from personal property than under the general property tax, and a great deal of injustice would have been corrected. Nevertheless it is economically unwise to tax capital employed in production, as the consumers of final products may have to pay more than the tax in enhanced prices; and for the reasons about to be stated, the desired end can be obtained through a measure based on a distinction of really fundamental importance.

For dwelling-houses are not to be classed with other buildings. The distinction may seem unreasonable, but it exists, and it would cause great confusion to disregard it. To a great extent it is certainly true that a man thinks of his house as an expense. When he builds a shop or a factory, he calculates what profit he can make out of it. When he builds a house he calculates how much of the income derived from the business carried on in other buildings he can afford to expend in house rent. No doubt house building and house renting are trades. The builders and the owners of tenement houses regard them not as sources of expense, but of profit; but that is not the view of the occupants. No doubt, too, we may treat man as a producing machine, requiring food and shelter, just as 
a steam engine requires fuel and protection against the weather. But that would be to turn economics upside down; it would be as perplexing as adding a fourth dimension to space. It seems proper therefore to treat house rent as belonging with expense and not with income, and to regard a tax on house rent as an income tax.

The real estate tax, therefore, comprises a tax on unearned or public value, a tax on buildings used as instruments of production, and a tax on expense; although these taxes are often inextricably mingled. The last tax, as has been shown, has very great fiscal advantages. It can be collected with the same machinery as the ordinary real estate tax - although this is not done in England - and at no additional expense. It accomplishes the purpose of the income tax, with none of its evils. It can be made progressive, and in that event tends to fall on rent. It can be avoided, but it will be avoided only by those who do not feel able to pay it, or by the parsimonious, whose savings are necessarily poured into the great reservoir of capital from which all business is supplied, and whom it is therefore advantageous to exempt from taxation, just as it is advantageous to exempt any productive agency. For, it must be repeated, the opportunities of the poor are limited, not by the accumulations of the rich, but by their extravagance. The rich man who spends little, necessarily invests his income. He pays laborers and supports industries. He expends a part of his income for food and clothing and house rent; the rest goes to other men who are thereby enabled not only to pay for food and clothing and house rent, but who also create food and clothing and houses of a greater value than what they consume. It can seldom be disadvantageous to the com- 


\section{THE COST OF COLLECTING TAXES}

munity to tax extravagance and waste; it must always be injurious, although it may be unavoidable, to tax prudence and frugality.

We have not in this country the necessary materials for estimating the amount of house rent. It is otherwise in England, and the returns for the inhabited house duty are instructive. This tax is not levied on buildings used in trade, unless they are also used as dwellings; nor does it fall on houses renting for less than $£ 20$ a year. The total number of premises is about $8,300,000$, the number exempt being about $6,500,000$, of an annual value of over $£ 104,000,000$, and the number charged being more than $1,800,000$, of a value of some $£ 90,000,000$. Of the premises charged, those renting from $£ 20$ to $£ 41$ number about $1,230,000$, and those renting from $£ 41$ to $£ 80$ about 390,000 . Between $£ 80$ and $£ 100$, the number is about 60,000 ; between $£ 100$ and $£ 150$, about 70,000 ; between $£ 150$ and $£ 200$ some 27,000; and between $£ 200$ and $£ 300$, about 22,000 . The number of premises renting for more than $£ 300$ falls off rapidly; between $£ 300$ and $£ 400$ it is less than 9,000 ; between $£ 400$ and $£ 500$, a little over 4,000 ; between $£ 500$ and $£ 600$, under 2,300 ; between $£ 600$ and $£ 700$, about 1,500 ; between $£ 700$ and $£ 1,000$, about 1,800 ; and over $£ 1,000$ it was in 1903-04 the same. The rate of duty on premises of an annual value between $£ 20$ and $£ 60$ rises from two pence in the pound to six pence; beyond that the rate is not increased. It may be remarked that the rental of premises in the metropolis is one-third of the total for the country, and that the rental of those worth over $£ 600$ is two-thirds the total for premises of that class.

This duty is to a considerable extent degressive; the 
annual value of exempt premises being more than that of those taxed; and the value of those partly exempt being nearly $£ 50,000,000$. The value of those between $£ 60$ and $£ 100$ is some $£ 11,500,000$; of those over $£ 1,000$ it is about $£ 3,750,000$. What is somewhat surprising, in view of the heavy taxation recently imposed on the rich, the number of premises renting for more than $\$ 500$ continues to increase nearly as rapidly as before. The assessment of this tax should occasion very little expense; all houses are assessed to the rates, and one assessment ought to suffice for all purposes. In view of the enormous cost, both in money and vexation, of the income tax, and of its violation of the principles of justice, the house duty might very well be substituted for it. Much of the so-called income tax is already derived from land, and from taxes on permanent investments, and can be collected without resorting to self-assessment. Its effect has been to depreciate the values of these investments, and little injustice would now be caused by retaining it. The amount of the income tax proper is not so large that it could not be replaced by increasing the house duty. Leaving houses renting for less than $£ 20$ exempt, there would remain nearly $£ 100,000,000$ of rental value, which could very well be taxed at ten per cent. The charge to the community would be no greater than before; and probably it would be greater in the case of only a few individuals, except in so far as the progressive feature was extended. On the other hand, the saving in expense would probably far more than make up for the abatements and repayments that now complicate the system. It would be practicablealthough not fiscally desirable - to extend the duty to premises used for trade, the rental value of which is of 


\section{THE COST OF COLLECTING TAXES 351}

course in such a country as England very great. Such premises are already in effect taxed through the tax on the profits of their occupants; were this tax removed, a corresponding one on rental values would be no additional burden to trade, and the change would remove a prolific source of discontent and dishonesty.

It is evident that for the proper assessment of such a tax, or of any tax on real estate, there must be established principles of valuation, applied by men of experience. In England land is rented more commonly than in this country, and it is probable that information concerning the terms of leases is more easily obtained than here. In the City of New York it is the practice of the assessors to fix the value of the land in a somewhat arbitrary manner, and to estimate the cost of replacing whatever buildings may be standing thereon, due allowance being made for the fitness of the building for its site, and for depreciation. In England the allowance for this account and for repairs may be as much as twenty per cent, but no such rule seems to obtain here. In New York, after the land is valued at a certain rate per front foot - which rate may prevail for a whole block, or may change with every lot, - the number of square feet is calculated, and then the number of square feet of floor surface. Frame dwellings and factories, it is assumed, may be replaced at a cost of from $\$ 1$ to $\$ 3$ per foot of floor surface; ordinary brick dwellings for $\$ 3$ to $\$ 5$; modern office buildings and hotels from $\$ 3.50$ to $\$ 8$; and very costly buildings for as much as $\$ 10$. In making these valuations the assessors are guided by reported sales, by mortgages, by leases, and by whatever knowledge they may be able to procure. They are not elective officers, but hold their positions by a secure 
tenure. They could hardly accomplish their work if their term of office were short and uncertain, as is commonly the case in other communities.

Were this system of valuation supplemented by a properly constituted court for hearing appeals from the judgments of the assessors, as near an approach to justice as is practicable would perhaps be attained. Value is essentially uncertain and indefinite. It means the price which will be paid for a thing by a purchaser; but purchasers differ in their estimates, in their knowledge, in their needs, and in their means. All that an assessor can do is to learn what prices are commonly paid, and to compare similar properties. He may never be quite accurate in his judgment; but if competent, he should never be very far wrong. If his assessment of a particular parcel is too high, the aggrieved taxpayer should have prompt and cheap relief by appeal; if too low, the owners of adjacent property should have similar relief. And, whatever the imperfections of such a system, they seem to be less than in any other that human ingenuity has contrived.

It is probably true that land owners, as a class, would view with alarm any proposal that seemed likely to increase their burdens. Yet if taxes are shifted and diffused, it can scarcely be denied that nearly all the charges levied on personal property and on trade fall eventually on land, and with enormously increased weight. Were these taxes abolished, the value of land would inevitably be increased. The larger profits would impel men to make larger investments, and enable them to pay higher rents. The vast saving in the cost of collecting taxes by the existing methods would constitute a fund that would be divided among all 
the members of the community, the landlords included; and the share of the landlords might well be far more than would compensate them for their increased taxes. It must not be forgotten that the exemption of personal property is no untried experiment. Such exemption, so far as local taxation is concerned, has long prevailed to a great exient in Pennsylvania, and certainly few states have enjoyed greater prosperity. It has practically, though not legally, prevailed in many other communities; in the City of Buffalo, for example, personal property forms only 2.1 per cent of the total assessment.

To increase suddenly the burden on land, if the increase were considerable, would certainly be unjust. The government is estopped by its prolonged recognition of the rights of landlords, and their expectations of secure possession are reasonable. But justice does not seem to demand that speculative and prospective values shall be protected; it is only when the action of government diminishes the present market value of land that it can be called unjust. Furthermore, the negative decrease of value, as it may be called, caused by securing to the public the future increment, can injure no one. It is only the present owners of land that can suffer from a new tax upon it; the claims of heirs and devisees being, so to speak, latent in the present ownership. After the tax is imposed the market value of the land is reduced; a purchaser computes the profit to be made from using the land, reckoning the tax as an expense, and pays a correspondingly lower price. The tax is therefore no burden on him, nor on any subsequent purchaser. They cannot complain of the injustice of a burden which already lay on the property when they bought it, which they assumed 
with full knowledge of its weight, and which was in effect extinguished in the reduction of the purchase price. ${ }^{1}$

The reasons above given make it probable that land owners would in several ways be more than recompensed for the apparent increase of their taxes. But, whether this be true or not, it is certain that not only they, but the whole people might be relieved of a heavy burden by a very simple reform. There are at present three bodies of tax-gatherers, - the collectors employed by the counties, cities, towns and smaller taxing districts; those of the states; and those of the general government. It is perhaps common to assume that, as every governing body requires revenue, it should have its own force of collectors; but this assumption does not bear examination. Provided the necessary amount of revenue can be raised by one system of taxes and one body of officers, the presumption is in favor of its being so raised. In order to understand why this simple system has not prevailed, a brief retrospect is necessary.

Curiously enough, an attempt was made to apply it in part at the time of the separation of the colonies from the mother country. The Articles of Confederation provided that taxes were to be apportioned among the states "in proportion to the value of all land within each state granted to or surveyed for any person, as such land and the buildings and improvements thereon shall be estimated, according to such mode as the United States in Congress assembled shall from time to time direct and appoint," the taxes for paying that proportion to be laid and levied by the state legislatures. The feebleness of the state governments, and their jealousies, rendered this and all other

1 See Appendix C. 


\section{THE COST OF COLLECTING TAXES 355}

measures for obtaining revenue by taxation nugatory, and the Congress was compelled to resort to foreign loans, and to the miserable expedient of issuing paper money to which a forced currency was legally given. When the Constitution was adopted, this principle was abandoned, for reasons which it is unnecessary to detail, and instead it was provided that direct taxes, as well as representatives, should be apportioned among the states according to population.

But as wealth was not then, and has never since been, proportioned to population, direct taxes have been seldom laid by the general government, and when laid have aroused so much opposition as to have been unproductive of revenue. For similar reasons excise taxes were soon given up, and not renewed until the emergency of the civil war. The general government began at once to rely on customs duties, and until that time this was practically its only source of revenue.

For many years the state governments were carried on with very little expense, and the principle stated in the Articles of Confederation was generally recognized, a small surtax for state purposes being added to the taxes levied by the local authorities, and this surtax was collected by the same tax-gatherers. Of late, however, the real or pretended needs of the state governments have enormously increased, and the amount of the surtax has become a very serious matter. The result has been to develop all the evils attendant on the method of self-assessment. As the basis of the state tax, the valuations of property made by the assessors of the minor political divisions were taken. The smaller the assessed valuation of the property in a town, therefore, the smaller the state tax; and in spite 
of drastic provisions commanding assessors to list property at its fair market value, the pressure of local sentiment was too great to be resisted. Such assessors as complied with the law caused heavy penalties to be laid on their districts, in the shape of disproportionately heavy state taxes. Such assessors as disregarded the law, and assessed property below its value, procured exemptions for their localities in the shape of disproportionately light state taxes. Assessors of the former class were unpopular, and were not reëlected. ${ }^{1}$ Inequalities as outrageous as in the case of the taxation of individuals were of common occurrence, and the attempts of the state authorities to equalize assessments were but partly successful. Under these circumstances the inducement to resort to indirect taxation, in order to secure revenue for the state, was too strong to be resisted, and a number of new taxes, and an additional force of tax-gatherers, were created. Such, in a general way, is the explanation of the existence of three practically independent systems of taxation in this country. The tendency in this direction has of course been increased by the natural desire of rulers to conceal from their subjects the extent of their exactions, through the device of indirect taxes.

When the union was formed, it would probably have been impossible for the general government to obtain its revenue by direct taxation. Its powers were not defined by the judicial interpretation of the Constitution, and obedience to its mandate was at first reluctantly yielded. It is now beyond question supreme, and little resistance seems likely to be offered by the state governments to any taxation that it decides to impose. Were the necessary amendment

See Appendix A. 


\section{THE COST OF COLLECTING TAXES}

to the Constitution made, it would be entirely practicable to raise all the revenue of the national government by means of a direct tax, proportioned to the revenue received by the state and local governments, and it would be equally practicable for the state governments to obtain, as they have in some fashion in the past, all their revenue by means of a direct tax, proportioned to the revenue of their constituent political bodies. The change above referred to, by which this reform could be effected, is as simple as it would be revolutionary. It consists merely in applying the principle of the income tax to the case of municipalities.

The chief objection to a tax imposed on the income of the individual is that the individual is called on to disclose his income; this process of self-assessment resulting, as we have seen, in the most demoralizing injustice. But this objection does not arise when we wish to learn the income of a political body. The amount of its revenue, as well as that of its expenditure, is a matter of public record, and it can always be ascertained by inspection. Instead of basing the state tax on the assessed valuation of the property owned in any municipality, the legislature should have based it on the municipal income; or, what is nearly the same thing, the municipal expenditure. To have done so would have extinguished all the evils whose existence led to the imposition of the present state taxes. It would have removed all inducement to assess property at less than it was worth; whether it was listed at its full value or at a nominal figure would have been a matter of purely local concern.

Only in exceptional cases does the revenue of a municipality fail to indicate the wealth of its inhabitants. A 
town where there is little wealth can spend little on its government, and its share of the state tax would be of trifling amount. A rich city maintains an expensive government, and can afford to pay a large tax to the state. There is perhaps no more accurate measure of the ability of the inhabitants of a community to contribute to the support of the government of the state, than their ability to contribute to the support of the government of their community; and this ability is measured by the amount contributed. As a matter of fact, the indirect taxes now collected at so much expense by the state are probably distributed among its communities in very nearly this proportion. Furthermore, taxation in the manner described would tend to check extravagance in both state and local governments; the amount of the state tax would be brought to the attention of all taxpayers, and the legislators would, as experience has. shown, dread to increase it. On the other hand, the local authorities, knowing that if they increased taxes, the state tax would increase, might be more prudent in their disbursements.

The total amount of what may be called the public income in every state being thus accurately known, to levy a proportional surtax on this income for national purposes would require the employment of but a few scores, or at most a few hundreds, of clerks. The expense of collecting the national revenue in this manner would perhaps not be a thousandth part of what it is now; nor would the cost of paying taxes be diminished in a less degree. So great a relief from unnecessary burdens seems to be clearly just; and the general conclusion seems reasonable that taxation according to the economic method best conforms to the commonly accepted rules of justice. 
There is, of course, no present possibility of establishing such a system of taxation as is here suggested; those interested in maintaining existing abuses are too thoroughly entrenched to be dislodged. Indeed, the tendency is now, and seems likely to be for some time to come, to multiply taxes, and to increase the numbers and the emoluments of those who derive their subsistence, directly or indirectly, from this source. Should this tendency be reversed, it would be easy to present an overwhelming body of proof in support of the claims of the economic method. But it is not the aim of this treatise to elaborate, or even to advocate, particular measures of taxation. Its aim will be attained if it shall direct attention to the deplorable inconsistency between our practices in taxation and the rules of justice that are universally recognized.

The air is filled with outcries against the unprincipled conduct of many of those who carry on the great industries of the country. It seems strange that it does not occur to the authors of these complaints to ask if the unprincipled conduct of our rulers does not make it hard for upright men to carry on business at all. The evidence here presented shows that such men must enter the race with a grievous handicap; they must pay charges that their unscrupulous rivals do not pay. The calumnies of a licentious press, the malicious attacks of a despotic executive, may be met by upright men with a high front; but how can they meet competitors whom the laws enable to use the weapons of evasion and deception, even of bribery and perjury?

It is notorious that many charters for public service corporations have been corruptly obtained. It is equally true that without bribery they would not have been granted. 
There was no dearth of men of wealth and probity who would have been glad to secure these franchises, could they have done so without soiling their hands; they did not care to submit proposals, that would have been laughed at by rulers accustomed to get gain by trafficking in the rights of the community. Our legislators know the requirements of justice. Commission after commission has reported the iniquities of the present laws; men in every department of industry have pleaded not to be forced to be dishonest, but they have pleaded in vain. Under present conditions scrupulous men often cannot succeed; they must give up their scruples or give up their business. Nevertheless affairs must be carried on; if not by honest men, then by others. As a result, the whole tone of the industrial world has been lowered; that chastity of honor, that sensibility of principle, which will not stain itself by deception, is gone. Nothing would do more to elevate business morality than to remove the temptations to palter with conscience that are now confessedly overpowering. Nothing would be more advantageous, and nothing more just, than to encourage men of the highest character to engage in the activities from which they are excluded by our present systems of taxation. 
APPENDICES 



\section{APPENDIX A}

\section{Extract from “Taxation of Personal Property"}

\section{By Lawson Purdy}

THE labor and skill required to make a reasonably fair assessment of personal property is simply appalling; the mere enumeration of some of the items of personal property which might be owned by any prosperous citizen is a sufficient demonstration of this. The assessor might start at the taxpayer's residence, where he must value all the furniture, pictures, works of art, bric-a-brac, plate, linen, wearing apparel, books, jewelry, including, of course, the jewelry and wearing apparel actually being worn by members of the family. In order to make a fair valuation, the assessor must be an expert in valuing paintings, antique furniture, jewelry, carpets, and practically have expert knowledge of every class of articles in the house. An ordinary man could do little more than value paintings by the square foot; and one picture a foot square might be worth $\$ 5,000$, while another five feet square might be worth $\$ 5$. One antique rug would readily sell at auction for $\$ 1,000$ and a much larger one might be worth less than $\$ 100$. Unless the assessor were an expert in valuing precious stones, he would be thousands of dollars out of the way in setting a value on the jewelry of hundreds of New York families.

From the residence of the taxpayer the assessor might then go to his stable, and there he would have to be an expert in valuing horses, harness, and carriages, for it would not be difficult to make an error of several thousand dollars in valuing three or four horses.

Let us suppose that our taxpayer is a merchant, and carries a large stock of goods, then the assessor's next duty would be to value that stock of goods. Every one knows that it would take the merchant's own clerks several weeks to make a correct inventory of his stock, and they would know the actual prices paid for the goods, while the assessor must estimate their value by mere inspection. 
It is perfectly clear that the most skillful man could not possibly make a fair appraisal of even one small department store in a week's time.

\section{The System in Cities of New York}

The actual working of the system in New York is very much simpler than the method outlined, and the work in the old City of New York was all done by two or three men. As described by Mr. Feitner, ${ }^{1}$ Commissioner of Taxes, the names of persons who are likely to be possessed of taxable personal

1 Testimony of Hon. Thos. L. Feitner, President Department of Taxes and Assessments, before Mazet Committee, as reported in New York Sun, June 2, 1899:

"Q. - How is the roll made up? A. - The City Directory is taken for the names. Inquiry is made as to location, business, etc., and any further information that is attainable is taken. Then the man is put on the books if he is taxable. It is a sort of sifting process. If a man swears off taxes one year he is n't put on for a year or two.

"Q. - Do you generally accept a man's affidavit? A. - Not necessarily. If we know he's all right or if his circumstances are obviously poor we do.

"Q. - Now, does n't the tax system as at present constituted I'm not holding you responsible for it or intimating that you are in any way to blame - does n't it result in a lot of people who have saved up a couple of thousand dollars getting on the tax list while a lot of rich persons go unnoticed? A. - Yes, it does. It's a very defective system and works great injustice. It's been compared to a trap that lets the big fish through while the little ones are caught. The great majority of persons who pay personal taxes are worth under $\$ 10,000$, and there are few who pay on more than $\$ 100,000 . "$

Mr. Harkness, former tax assessor of Brooklyn, said before the Manufacturers' Association of New York, December 19, 1898:

"I made inquiry in regard to the way and manner they had been assessing heretofore, and they told me that they simply guessed at it. If a man in the manufacturing business was prosperous looking, he had a pretty good assessment levied upon him. If he lived in a brownstone house, he was assessed $\$ 10,000$; if he lived in a brick house, he was assessed a little less; and if he lived in a frame house he got off for \$2,000. Some amusing episodes came up in my experience every once in a while. We had a servant in a gentleman's house, a coachman, who was assessed for $\$ 5,000$, simply because his residence was with his master. The whole system of personal assessments in Brooklyn - and I do not know that it is any different in New York - is simply absurd." 
property are taken from directories, and they are assessed for a sum which is thought to be in keeping with their manner of living. Many men are placed on the rolls who have no property in excess of their debts, and many thousands, who have taxable property, escape altogether.

The difficulty of assessing all personal property in a large city is proportionately much greater than in small towns. ${ }^{1}$ In 1903 the number of individuals, corporations, and estates who were assessed in the City of New York was 78,339; of these 37,687 appeared before the tax commissioners and swore that they had no taxable property in excess of their debts, and the whole number taxed was 40,652 . This is a very small proportion of the total population, a smaller proportion than the same effort would have obtained in small towns. In thirtytwo cities of Massachusetts, with an average population of less

${ }^{1}$ Comparison between some large cities and small towns of New York, showing the percentage of personal property to the total assessed raluation:

\begin{tabular}{|c|c|c|c|c|}
\hline City or Town. & County. & $\begin{array}{c}\text { Assessed Value } \\
\text { of Personal } \\
\text { Property. } \\
1901 .\end{array}$ & $\begin{array}{l}\text { Total Assessed } \\
\text { Value of Real } \\
\text { and Personal } \\
\text { Property. } \\
1901 .\end{array}$ & $\begin{array}{l}\text { Per Cent } \\
\text { of Per- } \\
\text { gonal to } \\
\text { Total. }\end{array}$ \\
\hline Large Citres. & & & & \\
\hline $\begin{array}{l}\text { Albany : : } \\
\text { Buffalo : } \\
\text { Rochester : : } \\
\text { Syracuse : : } \\
\text { Smay . : } \\
\text { Smowns. }\end{array}$ & $\begin{array}{l}\text { Albany : : : } \\
\text { Erie : : : } \\
\text { Monroe : : : } \\
\text { Onondaga : : } \\
\text { Rensselaer : : }\end{array}$ & $\begin{array}{r}\$ 3,712,875 \\
7,522,000 \\
9,145,662 \\
6,058,243 \\
3,406,137\end{array}$ & $\begin{array}{r}\$ 65,073,275 \\
242,262,073 \\
116,448,973 \\
87,143,653 \\
53,802,814\end{array}$ & $\begin{array}{l}5.7 \\
3.1 \\
7.9 \\
7.2 \\
6.3\end{array}$ \\
\hline 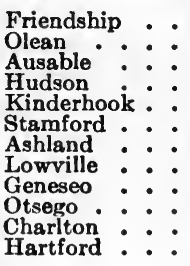 & $\begin{array}{l}\text { Allegany } \\
\text { Cattaraugus: } \\
\text { Clinton } \\
\text { Columbia : : } \\
\text { Columbia : } \\
\text { Delaware : } \\
\text { Greene }: \\
\text { Lewis : } \\
\text { Livingston : } \\
\text { Otsego : } \\
\text { Saratoga : } \\
\text { Washington: }\end{array}$ & $\begin{array}{r}223,168 \\
1,020,267 \\
98,800 \\
1,389,860 \\
529,645 \\
331,145 \\
55,500 \\
618,600 \\
975,050 \\
508,550 \\
127,350 \\
171,980\end{array}$ & $\begin{array}{r}1,037,848 \\
4,170,157 \\
555,370 \\
\mathbf{5 , 4 8 5 , 1 6 0} \\
\mathbf{2 , 1 6 0 , 4 3 5} \\
\mathbf{1 , 0 8 0 , 4 2 5} \\
\mathbf{2 1 4 , 7 2 0} \\
\mathbf{2 , 5 2 5 , 9 3 0} \\
\mathbf{3 , 4 1 2 , 1 6 5} \\
\mathbf{2 , 5 4 5 , 5 2 5} \\
\mathbf{6 2 2 , 9 9 9} \\
\mathbf{7 2 6 , 5 4 9}\end{array}$ & $\begin{array}{l}21.5 \\
24.3 \\
17.7 \\
25.9 \\
24.5 \\
30.6 \\
25.8 \\
24.8 \\
27.4 \\
20.0 \\
20.0 \\
23.6\end{array}$ \\
\hline
\end{tabular}


than 50,000 persons, the number taxed on personal property was 82,211 . If the same proportion had been taxed in the City of New York, the number would have exceeded 180,000. The persons taxed in Massachusetts were put upon the assessment rolls by the same methods as those in use in New York, only five per cent having made sworn returns as required by law. These results can only be attributed to the greater ease of assessment in smaller places.

When the City of New York was smaller, personal property paid a larger share of the tax. In 1865, personal property paid 35 per cent, in 1870,29 per cent, in $1898,21.5$ per cent, and in 1903, 12.5 per cent of the total. Other cities of the state show a similar decrease in the assessment of personal property. ${ }^{1}$

\section{a Tax on Honesty and Intelligence}

The result of this haphazard, impracticable method of raising revenue has been serious injustice to those cities where tax assessors are intelligent, honest, and efficient, and enormous injustice to individuals, more ignorant or more honest than their neighbors. Those cities have prospered most where the assessors have been negligent or incapable. Tax officials

1 A comparison between the assessed valuation of real and personal property in 1870 and 1901, for four counties of New York, which contain large cities;

\begin{tabular}{|c|c|c|c|c|c|c|}
\hline \multirow[b]{2}{*}{ County. } & \multicolumn{3}{|c|}{1901.} & \multicolumn{3}{|c|}{1870.} \\
\hline & Real. & Personal. & $\begin{array}{l}\text { Per cent } \\
\text { of Per- } \\
\text { sonal to } \\
\text { Total. }\end{array}$ & Real. & Personal. & $\begin{array}{c}\text { Per } \\
\text { cent of } \\
\text { Per- } \\
\text { sonal } \\
\text { to } \\
\text { Total. }\end{array}$ \\
\hline $\begin{array}{l}\text { Albany : } \\
\text { Erie. : : } \\
\text { Monroe : } \\
\text { Rensselaer }\end{array}$ & $\begin{array}{r}\$ 93,297,880 \\
277,307,745 \\
142,745,862 \\
72,357,516\end{array}$ & $\begin{array}{r}\$ 5,581,950 \\
9,981,128 \\
10,929,842 \\
5,051,068\end{array}$ & $\begin{array}{l}05.6 \\
03.4 \\
07.1 \\
06.5\end{array}$ & $\begin{array}{r}\$ 35,345,497 \\
41,462,863 \\
23,066,624 \\
21,720,013\end{array}$ & $\begin{array}{r}\$ 7,669,879 \\
11,431,680 \\
2,739,692 \\
7,796,515\end{array}$ & $\begin{array}{l}17.0 \\
22.0 \\
10.0 \\
27.0\end{array}$ \\
\hline Total & $\$ 585,709,003$ & $\$ 31,543,988$ & 05.1 & $\$ 121,594,997$ & $\$ 29,637,766$ & 19.1 \\
\hline
\end{tabular}


in this state have complained of the injustice of our tax system in almost every report. ${ }^{1}$

1 Some quotations from the reports on taxation of officers of the State of New York:

Official documents tell us that, "instead of being a tax upon perscnal property, it has in effect become a tax upon ignorance and honesty. That is to say, its imposition is restricted to those who are not informed of the means of evasion, or, knowing the means, are restricted by a nice sense of honor from resorting to them" (Report of Com. of Taxes and Assessments, City of N. Y., 1872, p. 9).

The defects of our system are too glaring and operate too oppressively to be longer tolerated (Comptroller's Report, 1859).

A more unequal, unjust, and partial system for taxation could not well be devised (First Annual Report State Assessors, 1860, p. 12).

The burdens are so heavy and the inequalities so gross as almost to paralyze and dishearten the people (Assessors' R., 1873, p. 3).

The hope of obtaining satisfactory results from the present broken, shattered, leaky laws is vain (Report of Com. of Taxes and Assessments, 1876, p. 52).

The absolute inefficiency of the old and rickety statutes passed in a by-gone generation is patent to all (Assessors' Report, 1877, p. 5).

The system is a farce, sham, humbug (Assessors' Report, 1879, p. 23).

[The general property tax is] a reproach to the state, an outrage upon the people, a disgrace to the civilization of the nineteenth century, and worthy only of an age of mental and moral darkness and degradation, when the "only equal rights were those of the equal robber" (Assessors" Report, 1879, p. 7).

The present result is a travesty upon our taxing system, which aims to be equal and just (Comptroller's Report, 1879, p. 34).

I am still firmly of the opinion that the attempt to reach personal property in a general property tax should be abandoned. This has long since been done in practically every civilized community in the world, except the United States. . . . Upon no class in the community does the tax on personal property, as now administered, bear more inequitably than upon the farmer. . . . The tax upon personalty is therefore unjust as between individuals; unjust as between communities, and, as experience has shown the world over, it is impossible of even approximately just administration. Then why should it be continued? (The Report for 1898 of Comptroller James A. Roberts.)

Political economists are all but unanimous in insisting that an enlightened system of taxation must exempt all personalty, and the tendency seems to be to embody that theory in law, as it has already come to obtain largely in practice (The Report for 1898 of Superintendent of Banks Frederick D. Kilburn). 


\section{Massachusetes Towns}

Those who are inexperienced and rely blindly upon the mistaken theory that to secure equality of taxation all kinds of property must be equally taxed, frequently claim that the fault is not in the law but in its administration. It is generally conceded that the state of Massachusetts has unusually able and competent assessors, and that their work is performed, on the whole, better than in any other state of the Union, yet the proportion which the assessment of personal property bears to the assessed value of real estate varies greatly throughout the state. ${ }^{1}$ In some towns the proportion of personalty assessed is very small, being less than five per cent, in 1895, of the total valuation in Revere, Winthrop, Hull, and Mashpee. In a few towns it is less than ten per cent, and in a considerable number less than fifteen per cent of the total. These figures in comparison with some other Massachusetts towns are remarkable, for there are eight towns in which the assessed value of personal property exceeds the assessed value of realty. In Falmouth the personalty is sixty-

${ }^{1}$ Assessed value of real and personal property in eighteen Massachusetts cities and towns.

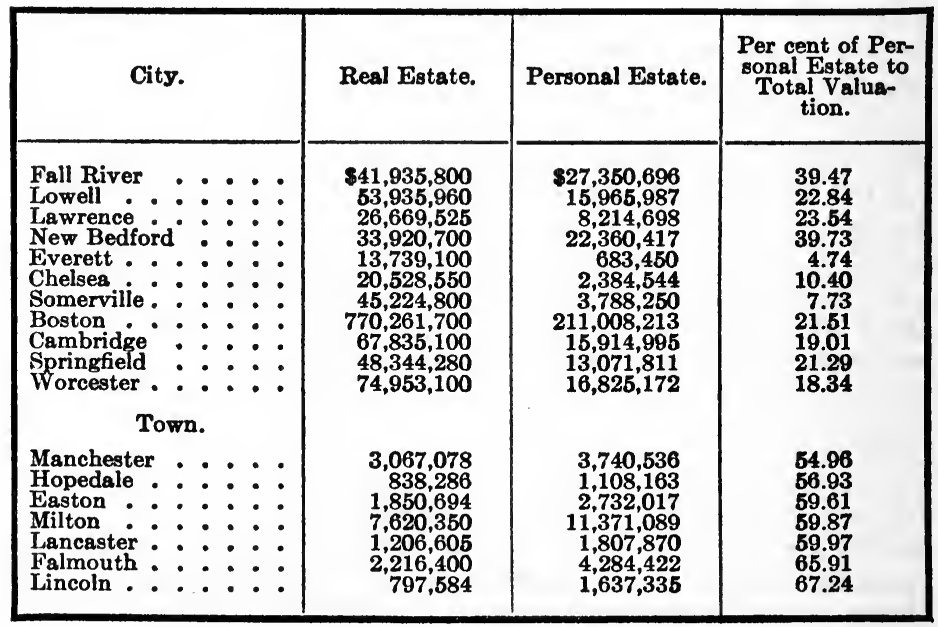


five per cent of the total, and in Lincoln sixty-seven per cent. A commission appointed to inquire into the expediency of revising the tax laws of the state, in their report issued in October, 1897, says: "The taxation of personal property in the form of securities and investments is thus a failure. It is incomplete, uncertain, not proportional to means as between individuals, grossly unequal in its effects in different parts of the state. The experience of Massachusetts in this regard is the same as that of the other states in the Union. Everywhere, without exception, the testimony is that this part of the system of the general property tax is unequal, unsuccessful, often demoralizing to tax officers, always irritating to taxpayers.

"The experience of Massachusetts is the more striking because here the difficulty does not lie mainly in the administration of the tax laws. The assessors are usually honest, competent, zealous. We have heard much of grave abuses, of almost corrupt laxity, in other states, but in this Commonwealth, notwithstanding occasional defections (some of which we have just referred to) the standard of public duty continues to be high, and the cause of failure is not to be found mainly in official dereliction. It lies in the system itself."

\section{Illinois Listing System}

In the state of Illinois the statutes require personal property to be listed yearly according to the quantity owned on the first of May. Persons listing are required to make statement under oath and to deliver to the assessor an itemized schedule of the number, amounts, quantity, and quality of all taxable personal property in their possession or under their control.

Recently all attempt to obey the letter of the law was abandoned in Chicago, and for the tax upon personal property there has been substituted what is practically a gross revenue tax upon business. Professor Commons has described this extra-legal system in the Review of Reviews, February, 1903:

"Lists are made out for each line of business, and are sent to all the taxpayers appearing on the list. In addition, the Board of Review selects a committee of citizens from each 'line,' and submits the list to them for revision. This committee, being familiar with all the business houses, rates them all according to the amount of business and regard- 
less of the itemized schedules returned by each. At the present time there are more than 200 of these separate committees of citizens cooperating in the assessment machinery. The Board of Review accepts their ratings, but at the last assessment added 10 per cent all around, in order to relieve real estate that much. This method of citizen assessment has resulted in raising the valuation of personal property in Chicago from $\$ 21,000,000$ to $\$ 88,000,000$. . . Naturally, in each line, the stock of goods is proportionate to the amount of business, but it is assessed as a unit and no longer by items. The law is indeed conformed to by publishing the items as returned in the schedules, but the additions made by the Board are entered under the item 'all other property,' and this item is now two-thirds of the personal property assessment. One notable feature of this practice is the entire elimination of mortgages from the lists, and the almost complete elimination of credits. While other parts of the state and other states pay attention to these items, the Chicago assessors lump them all together under their 'unit rule' of assessment."

\begin{tabular}{|c|c|c|c|c|c|c|c|c|c|}
\hline Name. & \multicolumn{2}{|c|}{$\begin{array}{l}\text { Farm } \\
\text { Lands. }\end{array}$} & \multicolumn{2}{|c|}{$\begin{array}{l}\text { Town and } \\
\text { City Lots. }\end{array}$} & \multicolumn{2}{|c|}{$\begin{array}{l}\text { Total Real } \\
\text { Estate. }\end{array}$} & \multicolumn{2}{|c|}{ Personal. } & 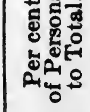 \\
\hline $\begin{array}{l}\text { Cook County } \\
\text { Remainder of State }\end{array}$ & \multicolumn{2}{|c|}{$\begin{array}{l}\$ 14,915,853 \\
300,002,192\end{array}$} & \multicolumn{2}{|c|}{$\begin{array}{l}\$ 282,834,401 \\
113,089,736\end{array}$} & \multicolumn{2}{|c|}{$\begin{array}{l}\$ 297,750,254 \\
413,091,928\end{array}$} & \multicolumn{2}{|c|}{$\begin{array}{l}\$ 88,109,999 \\
118,983,855\end{array}$} & $\begin{array}{l}22.8 \\
22.3\end{array}$ \\
\hline \multicolumn{2}{|l|}{ Name. } & \multicolumn{2}{|c|}{$\begin{array}{l}\text { Watches } \\
\text { and } \\
\text { Clocks. }\end{array}$} & \multicolumn{2}{|c|}{$\begin{array}{l}\text { Carriages } \\
\text { and } \\
\text { Wagons. }\end{array}$} & \multicolumn{2}{|c|}{ Money. } & \multicolumn{2}{|c|}{ Credits. } \\
\hline \multicolumn{2}{|c|}{$\begin{array}{l}\text { Cook County } \\
\text { Remainder of State } \\
\text { Proportion in Cook County }\end{array}$} & \multicolumn{2}{|c|}{$\begin{array}{l}\$ 62,202 \\
428,021 \\
1 / 8\end{array}$} & \multicolumn{2}{|c|}{$\begin{array}{l}\$ 236,249 \\
2,411,653 \\
1 / 10\end{array}$} & \multicolumn{2}{|c|}{$\begin{array}{l}\$ 2,253,282 \\
18,875,452 \\
1 / 9\end{array}$} & \multicolumn{2}{|c|}{$\begin{array}{c}\$ 5,026,746 \\
21,345,914 \\
1 / 5\end{array}$} \\
\hline
\end{tabular}

Cook County has more than $1 / 3$ of the total real estate value of the state.

\section{APPENDIX B}

\section{Taxation in Chicago}

Is Chicago, in 1897, the Taxpayers' Defense League was organized by Mr. Z. Swift Holbrook, in order to cause the assessors to reduce such assessments as were higher than the 
average, and to raise those that were lower. The circumstances in Chicago are peculiar in that it is necessary to assess property at about one-tenth of its value in order to keep the state tax within proper limits. The cause of this condition has been explained by Mr. D. A. Wells. The constitution requires a certain percentage of the assessed value of property to be applied to the payment of an old railroad debt, and unless this value was kept down at a very low figure, more money would be collected than could be applied to the designated purpose. But to obtain the revenue needed for local purposes the rate of taxation had to be raised, from time to time, until it came to stand at nearly ten per cent of the assessed valuation in the business quarters of Chicago.

It is therefore of the utmost importance to a property owner that his assessment should be low; otherwise his tax might exceed his income. Many assessors, it seems, have agreed with taxpayers that their assessments should be very small, or nothing; and they have also levied blackmail by raising, or threatening to raise, assessment to confiscatory figures. A few of the cases examined by the Taxpayers' League may be cited: A jewelry firm rated by Bradstreets at over $\$ 500,000$ was assessed at $\$ 12,500$. A corporation rated at over a million was not assessed on personal property at all; and one of the greatest of corporations was assessed at $\$ 60,000$. A man rated at over half a million, who has a library worth $\$ 40,000$, to say nothing of a yacht, and horses, carriages, and furniture to correspond, was rated at $\$ 200$; while a poor woman complained that, though hardly able to afford a carpet, her assessment had been raised from $\$ 200$ to $\$ 1,000$. A large manufacturer, with a capital of $\$ 1,500,000$, beside a surplus, was assessed at $\$ 3,000$ on property at the store, and $\$ 2,500$ on that at the factory. A great corporation was recently capitalized in a combination at $\$ 6,500,000$, but was assessed the year following at $\$ 80,000$. One of the largest wheat-brokers in the country, rated at several millions, was assessed at $\$ 2,500$. One of the largest packing-houses in the world was not assessed at all; one of the great harvester companies at $\$ 47,100$. A great firm in the grocery business was assessed at $\$ 50,000$, while another of similar size was assessed $\$ 750,000$. Agents from the assessors' office offered to have this assessment reduced to about $\$ 50,000$ for a bribe of $\$ 5,000$. Another dealer in the same line, rated at over $\$ 1,000,000$, was assessed 
at $\$ 10,000$; a rich banker, who has spent $\$ 13,000$ for a rare Bible, and large sums for art, was assessed at $\$ 400$. One of the largest department stores, carrying probably $\$ 2,000,000$ worth of stock, and making a profit of $\$ 1,000,000$, was assessed at $\$ 45,000$; another, as large, was assessed at $\$ 48,-$ 000 ; and a third, rated at $\$ 500,000$, was assessed at $\$ 25,000$. The largest house in its line of business, rated at $\$ 1,000,000$, was assessed at $\$ 500$. A brewery, rated at over $\$ 500,000$, was assessed at $\$ 1,500$. A prominent concern, being informed that its personal property was not assessed at all, at first denied, and then defended, the omission; but rather than submit to investigation consented to be assessed at $\$ 25,000$. The list might be extended indefinitely, and many persons known to be rich are not assessed at all. The estate of one of the richest and most prominent merchants in Chicago was recently settled, and the city has claimed several millions from the estate as taxes on property which was not assessed while its owner was alive. Four prominent banks appealed to the Taxpayers' League on finding that their assessment was over fourteen per cent of their combined capital, surplus, and undivided profits, while many other large banks were assessed below seven per cent, four below four per cent, and two not at all.

From 1873 to 1893 the assessment of personal property in the state fell from $\$ 287,000,000$ to $\$ 140,000,000$, while that of real estate fell from $\$ 900,000,000$ to $\$ 614,000,000$. In Cook County, which includes Chicago, the assessment of real estate dropped from $\$ 228,400,000$ to $\$ 210,000,000$; that of personalty from $\$ 55,000,000$ to $\$ 39,880,000$. The assessment of railroad property, however, has increased enormously.

The report of the tax commissioners of Ohio, for 1908, commenting upon the inequalities in the assessment of real estate, says :

"In Adams county, of 931 pieces of real estate transferred the average tax value is 43.4 per cent. of the sale value, while 191 pieces are on tax duplicate at 11.3 per cent. and 121 at 120.7 per cent. of the real value. In Brown county 706 pieces of real estate are on the tax duplicate at an average of 53.3 per cent. of their sale value, such average ranging from 12.3 per cent. to 116.6 per cent. In Monroe county, 709 pieces are on the tax duplicate at an average of 36.7 per cent. of their sale value and this average ranges from 10.8 per cent. to 107.3 per cent. In Montgomery county 4,000 pieces are on the tax duplicate at 37.1 per cent. of their value and this average ranges from 12.2 per cent. to 106.9 per cent." 


\section{'APPENDIX C}

\section{Taxation of Land}

"ON principle, and as a scientific economist views it, the ownership of land is a monopoly given by the state for the purpose of cultivation, just as the concession of a railway is a monopoly given for the purpose of locomotion. In both cases a privileged opportunity is given by the state which one person enjoys and other persons do not - which is the source of profit and enjoyment to the possessor, a profit and an enjoyment from which all others are excluded. As a principle of political philosophy, no monopoly ought ever to be conceded by the state, except upon the condition for services to be performed, and with a right of supervision reserved. Mankind in general have not been philosophers, but they have in most cases rudely recognized the most obvious truths of philosophy. They have done so here. Almost everywhere in the world the monopoly of land ownership has been burdened with some conditions; hardly anywhere, if anywhere, is there a separate ownership of land such as we now naturally think of it (though historically the very idea is recent and of yesterday) to be found, except subject to certain duties, charged with certain responsibilities. In England least of all has it ever been so. In the middle ages, when the beginnings of our real property law were laid, the land was subject to very formidable burdens; it was the basis and foundation of our entire military system. It paid the "army estimates," as we should now speak. Gradually this condition of the privilege was evaded by the possessors of the privilege. The land now pays no more for our army than the funds; a long history has taken it from them. But the same history has brought other duties. For nearly three centuries the land has been liable for the relief of the poor. The owners of land have been burdened with that duty to the nation, and all land has been inherited and bought subject to it and with notice of it. It has also, in forms more or less modified, been subject to what we have called the mixed charges, which are partly for the benefit of the locality and partly for the benefit of the nation, and, naturally, it was always subject to improve- 
ment charges, which were spent on its improvement, and which increased its rent. The owners of the land must not therefore complain of bearing national burdens; they have always borne national burdens, and the predecessors under whom they claim took the land on the condition of bearing them." W. BAGEHOT, in Economist, 8 April, $18 \% 1$.

\section{The Taxation of Real Estate}

To understand the effect of a tax upon real estate it is necessary first to explain the incidence of a tax upon land and of a tax upon houses and other improvements upon land, for the operation of an ad valorem land tax is entirely different from an ad valorem tax upon improvements.

To discover the effect of any tax the rule already given must be applied, that price depends upon demand and supply. If demand increases without any increase in supply, price rises. If supply increases without any increase in demand, price falls. If there is a perfect monopoly of an article and a price is arbitrarily fixed, a certain quantity of the article can be sold. If price is raised, a less quantity can be sold, and if price is reduced a larger quantity can be sold with the same expenditure of effort.

The only way to affect price is through an increase or decrease of the demand or the supply.

If the element of speculation in land is entirely disregarded a tax upon land in proportion to its value has no effect upon the demand for land or upon the supply of land, and, consequently, such a tax has no effect upon the price of land expressed in rent. Disregarding speculation, so long as the tax is not more than the entire sum which can be obtained for the use of land, it makes no difference in rent whether the tax is high or low. As such a tax cannot affect demand or supply, and therefore does not affect rent, it falls wholly upon the owner. If the owner is not the user, the tax gives him no power to increase the payment demanded for the use of the land, for the tax has no effect whatever upon the number of persons who desire to use it, and no effect upon the supply of land competing with his own.

If the owner of land is also the user, a tax upon it, whether high or low, provided it is not higher than its entire value, gives no power to the owner to increase the price of his 
product. The price of products is limited by the cost of production upon the least desirable site, and as the least desirable site has no value, there would be no tax upon it, and the cost of the most expensive increment would not be affected by the tax. This statement is merely another form of saying that the rent of land does not affect prices, which is so obvious a fact as not to require proof. Every one knows that where the value of land is greatest goods are cheapest, cheaper in New York, for instance, than in a country village.

The usual illustration to explain this law is taken from agriculture, but it is equally true of all industries.

So far the discussion has been based upon the supposition that there is no speculation in land. As a matter of fact, there is speculation, and consequently a tax upon land affects the market supply of land and therefore affects the price of land. In the absence of any tax, valuable land is held out of use at prices higher than it is worth for present use. When the supply is thus restricted the price of all land for rent or sale is increased. A tax upon land in proportion to its value, as it is high or low, more or less forces into use valuable land previously held idle in expectation of a rise in value. When the market supply of land is thus increased, the price of all land is thereby decreased.

An important feature of ad valorem land taxation is that, when the rate is uniform, the tax falls wholly upon those who own the land at the time of the imposition of the tax. The selling price of land depends upon the net revenue which can be obtained from it, and if the net revenue is reduced by the imposition of a tax, the selling price falls proportionately. For example, the gross revenue which can be obtained from a certain lot or farm is $\$ 1,000$. If there is no tax upon it, the selling price, calculated on a basis of five per cent would be $\$ 20,000$. If there is a tax of $\$ 200$ a year, the net revenue would be only $\$ 800$, and the selling price would be $\$ 16,000$. The owner at the time the tax is imposed would suffer a loss of income of $\$ 200$ a year, and if he sold could only obtain a price based on the reduced revenue. The subsequent purchaser would only buy a revenue of $\$ 800$ a year, and upon him the tax would be no burden. 


\section{SUMMARY}

When there is no speculation in land an ad valorem tax upon land is paid entirely by the owners, and neither increases the rent nor the price of land.

When valuable land is held idle or put to an inferior use, being held for speculation, an ad valorem tax upon it forces some such land into use, the market supply is increased, the tax is paid entirely by the owners, and rent and price of land decrease.

When an ad valorem tax upon land is imposed at a uniform rate it falls wholly upon present owners, and subsequent purchasers pay a price reduced by the amount of the tax capitalized at the current rate of interest.

\section{The Taxation of Improvements on Land}

In considering the effect of a tax upon improvements on land, the principle already explained must be constantly borne in mind, namely, that price depends upon demand and supply.

In order to ascertain the effect of the tax, we must discover how it will operate upon demand or supply, for in no other way can it have any effect at all upon the price which can be obtained for the use of the improvements.

Capitalists are always on the watch for investments which will yield a safe and large return; the result is that the returns to capital tend to be equal in all businesses in which risk is the same. The imposition of any charge upon a business which reduces the possible profit will soon restrict the investment of capital in that business, then the profit will tend to rise to the rate which can be obtained in other forms of investment of equal safety and convenience. If any existing charge is removed from any business, or if, for any cause, the customary returns to capital invested in that business are increased, new capital tends to seek investment in that business until the profit is again reduced to the average level.

If a tax is imposed upon buildings and other improvements upon land, the investment of capital in land improvements is checked until the supply of such improvements is reduced in proportion to demand to such an extent as to raise the price sufficiently to yield the average return to capital. If a tax heretofore imposed upon buildings and other improvements is 
removed, capital at once seeks this investment until the supply is so increased that the return to capital falls to the average again.

This is a statement of the general rule applicable to the taxation of improvements upon land, but there is another factor to be taken into account. We have so far considered only the increase and decrease of supply, but the increase and decrease of demand exerts an equal influence upon price and an increase or decrease of population directly affects the demand for the use of land improvements. We have, therefore, three cases to consider: (a) The effect of a tax upon improvements when population is stationary; (b) the effect of a tax upon improvements when population is decreasing; (c) the effect of a tax upon improvements when population is increasing.

(a) When population is stationary. If the conditions of population remain the same, the demand for the use of land improvements will be steady, and the price which can be obtained for their use can be affected only by an increase or decrease of supply. If a tax ts imposed the return to capital will be decreased, but demand and supply being for the time constant, price will not be affected. Houses in time wear out and other improvements decay, so that slowly, but surely, the supply of improvements will diminish unless new ones are made, but as return to capital is decreased new improvements will not be made so long as the return to capital in this investment is below the average. When, in the course of time, the supply has fallen to a point sufficiently low so that more than the usual return to capital can be derived, capital will again seek this investment.

We see that when population is stationary and a tax is imposed upon land improvements, the tax will be paid, in the first instance, by the owners of the improvements, then as improvements wear out the tax will gradually be shifted to those who hire the improvements until they are obliged to pay the entire amount of the tax.

(b) When population is declining. If the decline in population is so rapid as to keep pace with the decrease in the supply of the improvements due to decay, there will be no shifting of the tax from the owners to those who hire the improvements. As, proportionately to the demand, the supply will be constantly increasing, there can be no increase of price.

(c) When population is increasing. With an increase in 
population there is a constant increase in the demand for land improvements. The tax checks the flow of capital to this investment until the demand increases to that point at which the price rises so as to include the average return to capital, plus the tax. In this case the tax may fall for a very short time upon the owners of the improvements, but it is certain to be rapidly shifted to those who hire them and continues to rest upon the tenants.

In the United States, increasing population is the rule, and a stationary or declining population is the exception, so that in general taxes upon land improvements are shifted from the owners to those who hire them.

When those who hire houses use them as residences the tax falls upon them and can be shifted no further.

When the tax falls upon improvements used for production, it adds to the cost of production and is shifted to the final consumers of the goods produced. Thus a tax upon all factory buildings falls upon all those who manufacture goods, and must ultimately be recovered from the purchasers of the goods in the same manner as any other expense of the business.

\section{The Real Estate Tax}

The effect of a tax upon real estate is the result of two opposing forces. We have seen that a tax upon the value of land not only does not increase its selling or rental value, but also tends to diminish the selling and rental value by inducing the owners of some unimproved land to improve or sell, thereby increasing the market supply of land. We have seen that the tax upon buildings is generally paid by the user of the buildings, as such a tax tends to check the erection of new. buildings until the supply of buildings is decreased in proportion to the demand sufficiently to enable building owners to obtain the average rate of interest upon their investment.

When real estate is taxed the tax falls partly upon land and partly upon improvements. So far as it falls upon land, the tendency, as we have seen, is to decrease the price which can be obtained for the use of land, and so far as it falls upon buildings the tendency is to increase the price which can be obtained for the use of buildings. It is impossible to determine precisely what will be the net result of a real estate tax in any particular place, but certain general rules may be 
laid down which will be found to be substantially correct. An increase in the tax rate is wholly paid by the owners of the real estate, for the effect of the increased rate put upon unimproved land is to induce the owners to improve or sell, and this effect counteracts the tendency of the increased tax upon buildings to check their erection, and more than counteracts it. We have seen this result in the boroughs of Manhattan and the Bronx, in the City of New York during the year of 1899. The tax rate increased about 20 per cent, and the number of new buildings was more than double that of the previous year; and a number of land owners gave as their reason for building the fact that the increased tax upon their vacant land rendered it unprofitable to hold it longer unimproved. It is alleged that there was an exception to this general tendency toward reduced rentals in some crowded sections of the city, inhabited by laborers, who found it extremely important to be near their work. It is said that rents were raised in these quarters, and that landlords asserted that they were obliged to raise the rentals because of the increased tax. While this may be true, it is perfectly obvious that the landlord could have raised the rent to the same extent if there had been no increase in the tax rate at all, so that in reality this apparent exception is not an exception.

During the year 1898, in the borough of Brooklyn, there was a considerable decrease in taxation, but there is no evidence of any decrease in rentals. In fact, the evidence shows an increase rather than a decrease.

There is no evidence that rentals are higher in cities where the tax rate is uniformly high than in cities where the tax rate is uniformly low, other conditions being the same.

Where population is stationary or declining it is certain that a tax upon real estate is paid entirely by the owner of the real estate and does not at all increase rentals. When population is increasing the effect of a tax upon land appears to at least counteract the effect of a tax upon improvements, so that an increase in the tax rate does not increase rentals.

One effect of the tax upon real estate is generally almost lost sight of, and it is one of the most important. So long as the tax rate remains at about the same point the tax upon the owners, who bought while that rate prevailed, is in reality no tax at all. The reason is that the buyer of a parcel of real estate pays a sum determined by the probable net return, and 
if the tax is low, and the net return high, the price will be high; if the tax is high, the net return will be correspondingly lower and the price proportionately affected.

If the tax rate increases after the purchase of a parcel of real estate, the increase falls wholly upon the owner at the time the increase takes place. If the rate of taxation continues at the increased rate and other conditions remain the same the owner will be obliged to accept a smaller price from a buyer, and the buyer, so long as the rate does not again increase, will practically pay no tax at all, as his purchase price will be as much less as the capitalized value of the increased annual tax.

\section{Conclusion}

The general conclusion of the whole matter is that taxes upon things capable of reproduction are paid by the consumers of the things taxed, and that taxes upon things not capable of reproduction, but of fixed quantity, are paid by the owners and only by those who are the owners at the time the tax is imposed. - From The Burdens of Local Taxation and Who Bears Them, by Lawson Purdy. 

THIS BOOK IS DUE ON THE LAST DATE STAMPED BELOW

AN INITIAL FINE OF 25 CENTS WILL BE ASSESSED FOR FAILURE TO RETURN THIS BOOK ON THE DATE DUE. THE PENALTY WILL INCREASE TO 50 CENTS ON THE FOURTH DAY AND TO \$1.00 ON THE SEVENTH DAY OVERDUE.

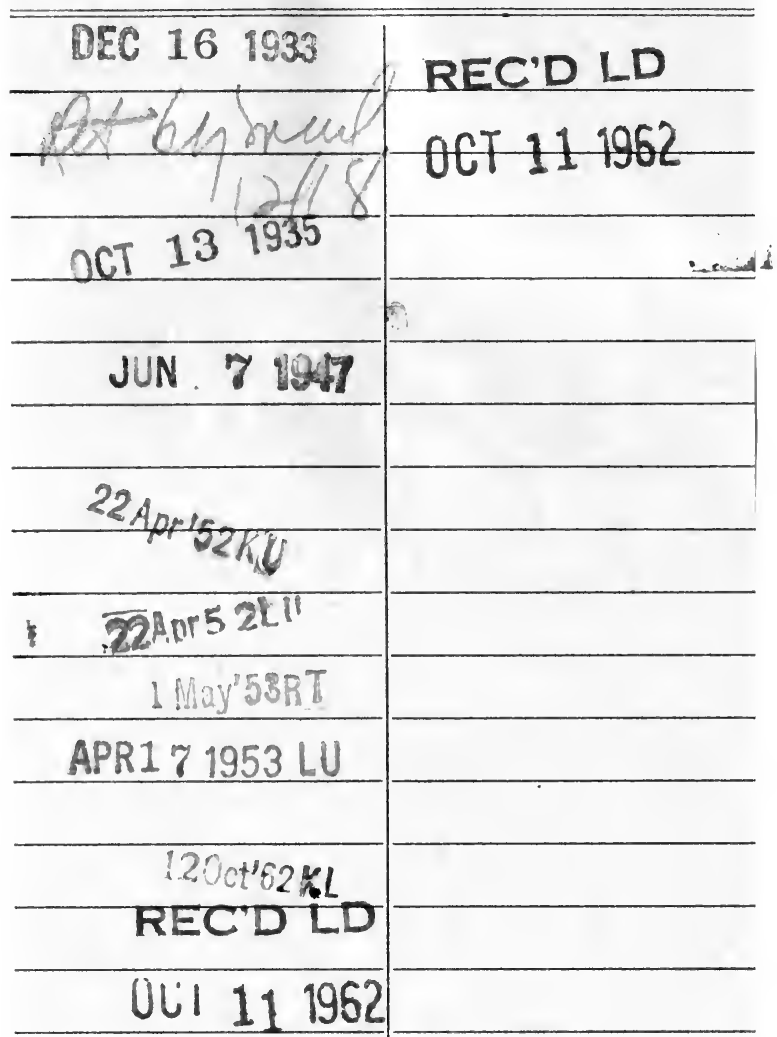

LD 21-100m-7,'33 
trute a YC 23351 $\overline{\gamma \varepsilon}$ m

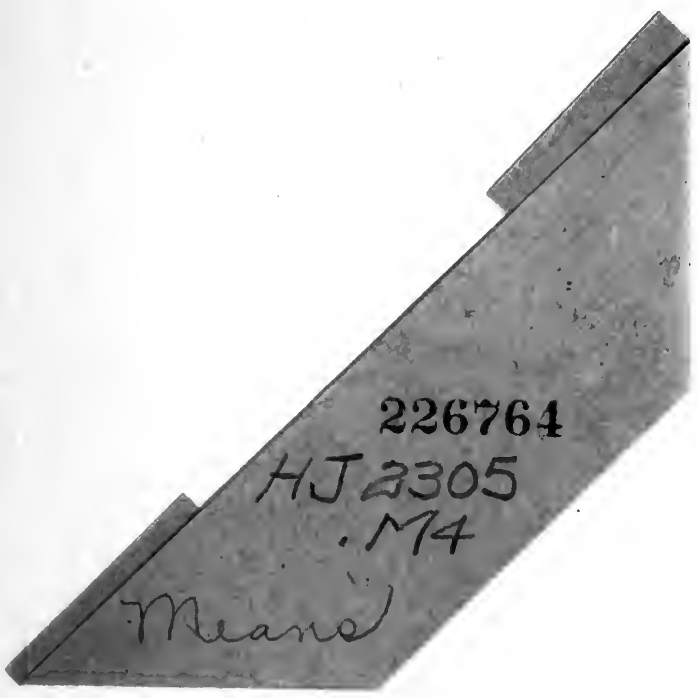


